\title{
AN-102 SIMULANT SR/TRU PRECIPITATION AND ULTRAFILTRATION (U)
}

February 10, 2003

\author{
Savannah River Technology Center \\ Waste Treatment Technology \\ Waste Processing Technology Section \\ Immobilization Technology Section
}

Westinghouse Savannah River Company

Savannah River Site

Aiken, SC 29808 
This document was prepared in conjunction with work accomplished under Contract No. DE-AC09-96SR18500 with the U. S. Department of Energy.

\section{DISCLAIMER}

This report was prepared as an account of work sponsored by an agency of the United States Government. Neither the United States Government nor any agency thereof, nor any of their employees, makes any warranty, express or implied, or assumes any legal liability or responsibility for the accuracy, completeness, or usefulness of any information, apparatus, product or process disclosed, or represents that its use would not infringe privately owned rights. Reference herein to any specific commercial product, process or service by trade name, trademark, manufacturer, or otherwise does not necessarily constitute or imply its endorsement, recommendation, or favoring by the United States Government or any agency thereof. The views and opinions of authors expressed herein do not necessarily state or reflect those of the United States Government or any agency thereof.

This report has been reproduced directly from the best available copy.

Available for sale to the public, in paper, from: U.S. Department of Commerce, National Technical Information Service, 5285 Port Royal Road, Springfield, VA 22161, phone: (800) 553-6847, fax: (703) 605-6900

email: orders@ntis.fedworld.gov

online ordering: http://www.ntis.gov/help/index.asp

Available electronically at http://www.osti.gov/bridge

Available for a processing fee to U.S. Department of Energy and its contractors, in paper, from: U.S. Department of Energy, Office of Scientific and Technical Information, P.O. Box 62, Oak Ridge, TN 37831-0062,

phone: (865)576-8401,

fax: (865)576-5728

email: $\underline{\text { reports@ adonis.osti.gov }}$ 
Key Words:

Envelope C

Cells Unit Filter

Slurry Rheology

Permeate Flux

Retention: Permanent

Key WTP R\&T References:

24590-WTP-TSP-RT-01-019, Rev. 0

SRT-RPP-2002-00007, Rev. 0

Test Scoping Statement S-43

\title{
AN-102 SIMULANT SR/TRU PRECIPITATION AND ULTRAFILTRATION (U)
}

\author{
John R. Zamecnik \\ Mark A. Baich \\ Erich K. Hansen \\ Michael R. Poirier
}

February 10, 2003

Westinghouse Savannah River Company

Savannah River Site

Aiken, SC 29808

Prepared for the U.S. Department of Energy Under Contract Number DE-AC09-96SR18500

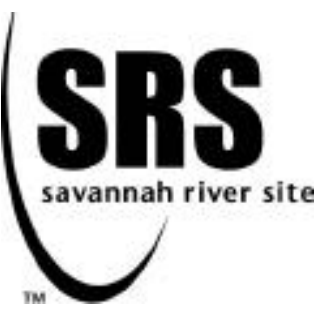




\section{TABLE OF CONTENTS}

LIST OF TABLES ....................................................................................................... vii

LIST OF ACRONYMS ............................................................................................ viii

TERMS AND DEFINITIONS .................................................................................................. ix

1.0 SUMMARY OF TESTING .......................................................................................... 1

1.1 OBJECTIVES …........................................................................................................... 1

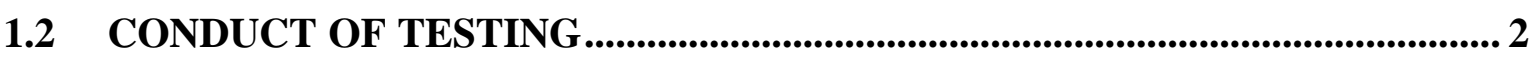

1.2.1 Tests with First Remediation (R1) Simulant ........................................................... 2

1.2.2 Tests with Second Remediation (R2) Simulant ....................................................... 3

1.3 RESULTS AND PERFORMANCE AGAINST OBJECTIVES ........................... 5

1.3.1 Remediation 1 Baseline Conditions ......................................................................5 5

1.3.2 Remediation 2 with Newly Optimized Conditions and Baseline Conditions. 6

1.4 QUALITY REQUIREMENTS ..................................................................................... 7

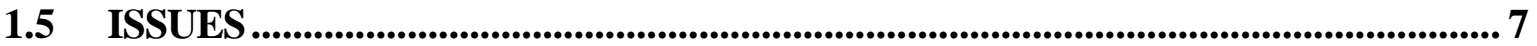

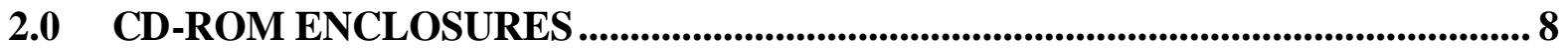

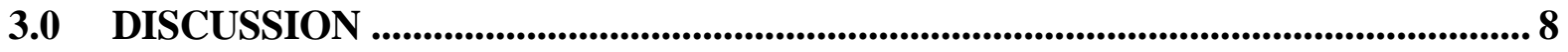

3.1 EXPERIMENTAL DETAIL ......................................................................................... 8

3.1.1 Simulant Remediation 1 Precipitation at Baseline Conditions ....................... 11

3.1.2 Simulant Remediation 2 and Newly Optimized Conditions Precipitations. 13

3.1.3 Simulant Remediation 2 and Baseline Conditions ............................................ 14

3.2 RESULTS ........................................................................................................................ 15

3.2.1 Simulant Formulations ................................................................................................. 15

3.2.1.1 Simulant Remediation 1 ..................................................................... 15

3.2.1.2 Simulant Remediation 2 ................................................................................. 16

3.2.1.3 Precipitations .................................................................................................... 18

3.2.2 Concentration of Precipitated Simulants - Composition and Properties.... 21

3.2.2.1 Remediation 1 - Baseline Conditions ...........................................................21

3.2.2.2 Remediation 2 - Newly Optimized Conditions Run 2 (R2NOC2) ...... 24

3.2.2.3 Remediation 2 - Baseline Conditions ......................................................26

3.2.3 R1BC Washing and Re-Concentration........................................................... 28

3.2.4 Rheological Measurements......................................................................28

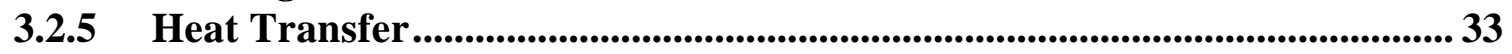

3.2.6 Particle Size Distributions ..................................................................................... 34

3.2.7 Feed Decontamination - R1BC and R2NOC2 Data ....................................... 42

3.2.8 Filtration - Remediation 1 Baseline Conditions ................................................... 49

3.2.8.1 Clean Water and Strontium Carbonate Fluxes......................................... 49

3.2.8.2 Factorial Design Tests - R1BC........................................................................ 52

3.2.8.3 Flux versus Insoluble Solids Concentration................................................ 57

3.2.9 Filtration - Remediation 2 Runs .................................................................... 62

4.0 FUTURE WORK ............................................................................................................... 65

5.0 REFERENCES ............................................................................................................... 66

APPENDIX A1. GRAPHICAL FLUX DATA …….................................................................... 68

APPENDIX A2. RAW FLUX DATA .................................................................................... 77

APPENDIX A3. ANALYTICAL DATA................................................................................. 81

APPENDIX A4. RHEOLOGICAL DATA ...................................................................... 88 
WSRC-TR-2003-00056, REV. 0

SRT-RPP-2002-00231, REV. 0

APPENDIX A5. JMP CURVE FITTING DATA ......................................................... 101

APPENDIX A6. SIMULANT RECIPES ............................................................................. 108

APPENDIX A7. PARTICLE SIZE DISTRIBUTION DATA ......................................... 113

APPENDIX A8. EMAIL FROM TOWNSON TO ZAMECNIK ................................. 123 


\section{LIST OF FIGURES}

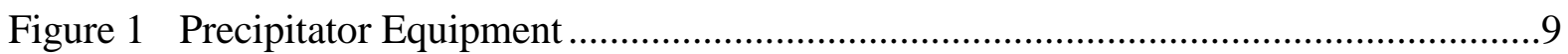

Figure 2 Cold Cells Unit Filter (Cold CUF) System .........................................................10

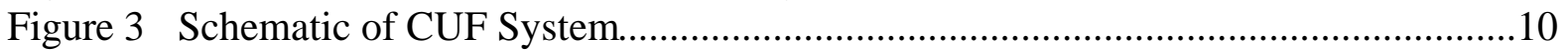

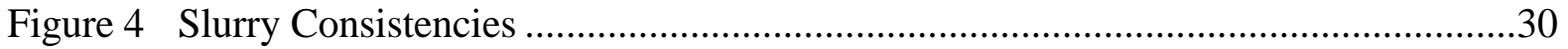

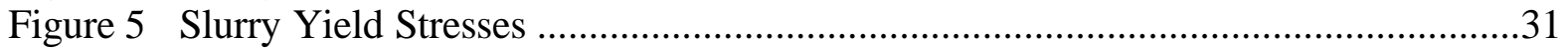

Figure 6 Feed Tank Sketch Showing Possible Stagnation......................................................32

Figure 7 CUF Feed Slurry Mixing at Approximately 15-17 wt\% Insoluble Solids ...............32

Figure 8 Reynolds Number in Filter Tube versus Insoluble Solids Content ..........................33

Figure 9 Heat Transfer During Concentration of R2NOC2 Slurry........................................34

Figure 10 Particle Size Volume Distribution for R1BC Slurry .................................................36

Figure 11 Particle Size Volume Distribution for R2NOC Pilot Scale Slurry ............................37

Figure 12 Particle Size Volume Distribution for R2NOC2 Slurry............................................38

Figure 13 Particle Size Volume Distribution for R2BCL Slurry............................................39

Figure 14 Volume Distributions of Concentrated Slurries by the X100 Absorptive

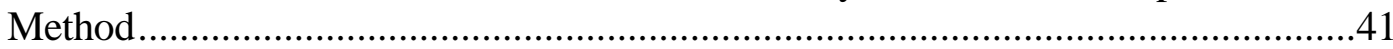

Figure 15 Volume Distributions of Concentrated Slurries by the SRA150 Reflective Method

Figure 16 Volume Distributions of Initial Precipitates by the X100 Absorptive Method.

Figure 17 SEM Photo of Filtered R1BC \& R2NOC1 Slurries .................................................43

Figure 18 Definitions for Percent Retained and Decontamination Factor................................45

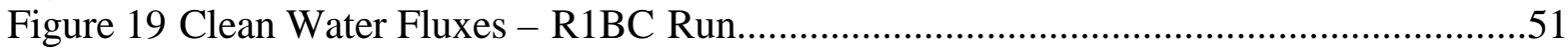

Figure 20 Clean Water and $\mathrm{SrCO}_{3}$ Fluxes - R1BC Run .................................................52

Figure 21 Factorial Design Arrangement: Low and High Solids Concentrations ....................53

Figure 22 Low Solids Factorial: Flux versus Time at 11 fps Velocity. ...................................53

Figure 23 Low Solids Factorial: Flux versus Time at 30 psi TMP........................................54

Figure 24 Low Solids Factorial: Flux versus Time at 11 fps Velocity, 40 psi TMP................54

Figure 25 Comparison of Fluxes for this Work, AN-102 Small C, and AN-107 Pilot

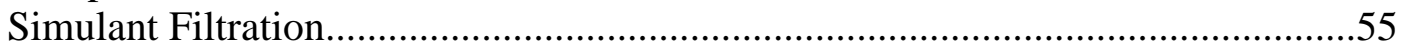

Figure 26 Predicted Flux versus Time for Concentration of Unwashed Slurry ……...............57

Figure 27 Flux During Concentration Showing Flux Decline ..............................................58

Figure 28 Comparison of Fluxes During R1BC Concentration..............................................58

Figure 29 Fluxes for R1BC Concentration and Re-Concentration of Washed Slurry..............59

Figure 30 Predicted Flux versus Insoluble Solids Content .....................................................60

Figure 31 Predicted Flux versus Time for Concentration of Unwashed \& Washed

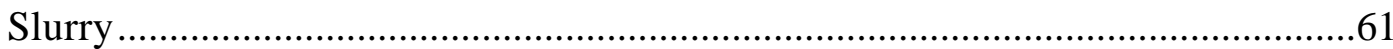

Figure 32 Flux Corrected for Time \& Viscosity...............................................................62

Figure 33 R2NOC Filtration Fluxes versus Insoluble Solids .................................................63

Figure 34 Baseline Conditions Fluxes versus Insoluble Solids ..............................................64

Figure 35 Flux Comparison of CUF Concentrations with Large C.........................................64 


\section{LIST OF TABLES}

Table 1 Summary of Conditions for Precipitation Runs .................................................5

Table 2 Approved Solids Simulant Formulation...........................................................16

Table 3 Calculated and Measured Composition of R1BC Precipitate Slurry Feed

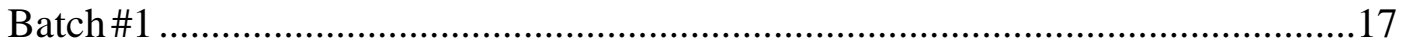

Table 4 Composition of Batches 3B and 3C Simulant .................................................. 18

Table 5 Summary of Reagents for R1BC (per 5L of Simulant) ...................................... 19

Table 6 Precipitation Reagent Quantities for R1BC ..................................................20

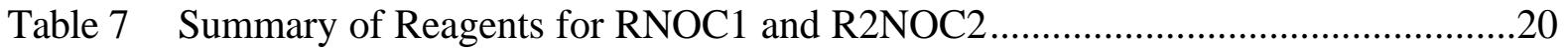

Table 8 Summary of Reagents for R2BCL ..............................................................21

Table 9 Solids Content of R1BC Precipitate Batches and Concentrated Slurry.................21

Table 10 R1BC Measured and Calculated Solids Content and Volume ...............................22

Table 11 R1BC Permeate Compositions During Concentration........................................23

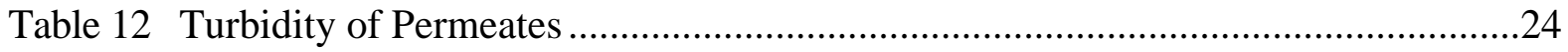

Table 13 Summary of R2NOC2 Solids Contents ..............................................................24

Table 14 R2NOC Slurry and Permeate Compositions ...................................................25

Table 15 Summary of R2BCL Solids Contents ...............................................................26

Table 16 Composition of R2BCL Precipitate and Concentrated Slurry ..............................27

Table 17 R1BC Composition of Unwashed and Washed Slurry and Permeate ....................29

Table 18 Rheological Properties of Initial Precipitates, Concentrated Slurries, and

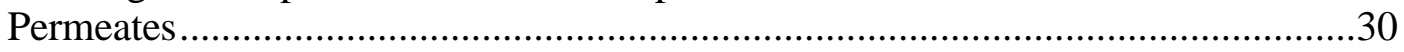

Table 19 Microtrac Particle Size Analyzer Methods ...........................................................35

Table 20 Comparison of Permeate and Precipitate Compositions ......................................44

Table 21 Decontamination Factors and Fraction Retained .............................................47

Table 22 Measured and Calculated Concentrated Washed Slurry Concentrations ................48

Table 23 Permeate and Concentrate Decontamination Factors ............................................49

Table 24 Factorial Design Test Conditions for R1BC ….............................................50 


\section{LIST OF ACRONYMS}

$\begin{array}{ll}\mu m & \text { micrometer } \\ \text { AA } & \text { atomic absorption } \\ \text { ADS } & \text { Analytical Development Section (SRTC) } \\ \text { cp } & \text { centipoise } \\ \text { CUF } & \text { Cells Unit Filter } \\ \text { DF } & \text { decontamination factor } \\ \text { EDL } & \text { Engineering Development Laboratory (SRTC) } \\ \text { fps } & \text { feet per second } \\ \text { gpm } & \text { gallons per minute } \\ \text { HLW } & \text { high level waste } \\ \text { IS } & \text { insoluble solids } \\ \text { L } & \text { liter } \\ \text { LAW } & \text { low activity waste } \\ \text { M } & \text { molar } \\ \text { NA or na } & \text { not applicable or not available } \\ \text { NC } & \text { not calculated } \\ \text { NIST } & \text { National Institute of Standards and Testing } \\ \text { NM } & \text { not measured } \\ \text { NQA } & \text { Nuclear Quality Assurance } \\ \text { NTU } & \text { nephelometric turbidity unit } \\ \text { psi } & \text { pounds per square inch } \\ \text { QA } & \text { quality assurance } \\ \text { R \& T } & \text { Research \& Technology } \\ \text { RPP } & \text { River Protection Project } \\ \text { SRTC } & \text { Savannah River Technology Center } \\ \text { TMP } & \text { transmembrane pressure } \\ \text { TRU } & \text { transuranic } \\ \text { TS } & \text { total solids } \\ \text { WSRC } & \text { Westinghouse Savannah River Company } \\ \text { wt\% } & \text { Weight percent } \\ \text { WTP } & \end{array}$


WSRC-TR-2003-00056, REV. 0

SRT-RPP-2002-00231, REV. 0

\section{TERMS AND DEFINITIONS}

\begin{tabular}{|c|c|}
\hline $\begin{array}{l}\text { suspended solids } \\
\text { or } \\
\text { insoluble solids }\end{array}$ & $\begin{array}{l}\text { Solids that are not dissolved in solution; these solids would be } \\
\text { filterable; often called undissolved solids }\end{array}$ \\
\hline $\mathrm{R} 1$ & First remediation of Optima simulant \\
\hline $\mathrm{R} 2$ & Second remediation of Optima simulant; has more carbonate \\
\hline $\mathrm{R} 1 \mathrm{BC}$ & $\begin{array}{l}\text { First remediation simulant, large batch, precipitated at the baseline } \\
\text { conditions: } 0.9 \mathrm{M} \text { added hydroxide, } 0.075 \mathrm{M} \mathrm{Sr}, 0.05 \mathrm{M} \mathrm{Mn}, 50^{\circ} \mathrm{C}\end{array}$ \\
\hline R2NOC1 & $\begin{array}{l}\text { Second remediation simulant, first large batch }(115 \mathrm{~L}) \text {, precipitated at } \\
\text { the "newly optimized conditions" (NOC): no added hydroxide, } \\
0.03 \mathrm{M} \mathrm{Sr}, 0.03 \mathrm{M} \mathrm{Mn}, 25^{\circ} \mathrm{C}\end{array}$ \\
\hline R2NOC small & $\begin{array}{l}\text { Second remediation simulant, small batch, precipitated at the "newly } \\
\text { optimized conditions" (NOC): no added hydroxide, } 0.03 \mathrm{M} \mathrm{Sr}, 0.03 \mathrm{M} \\
\mathrm{Mn}, 25^{\circ} \mathrm{C}\end{array}$ \\
\hline R2NOC2 & $\begin{array}{l}\text { Second remediation simulant, second large batch, precipitated at the } \\
\text { "newly optimized conditions" (NOC): no added hydroxide, } 0.03 \mathrm{M} \\
\mathrm{Sr}, 0.03 \mathrm{M} \mathrm{Mn}, 25^{\circ} \mathrm{C}\end{array}$ \\
\hline $\mathrm{R} 2 \mathrm{BC}$ & $\begin{array}{l}\text { Second remediation simulant, small batch, precipitated at the baseline } \\
\text { conditions: } 0.9 \mathrm{M} \text { added hydroxide, } 0.075 \mathrm{M} \mathrm{Sr}, 0.05 \mathrm{M} \mathrm{Mn}, 50^{\circ} \mathrm{C}\end{array}$ \\
\hline R2BCL & $\begin{array}{l}\text { Second remediation simulant, small batch, precipitated at the baseline } \\
\text { conditions (slightly modified): } 0.8 \mathrm{M} \text { added hydroxide (to give } 1.0 \mathrm{M} \\
\text { hydroxide total), } 0.075 \mathrm{M} \mathrm{Sr}, 0.05 \mathrm{M} \mathrm{Mn}, 50^{\circ} \mathrm{C}\end{array}$ \\
\hline
\end{tabular}




\subsection{SUMMARY OF TESTING}

\subsection{OBJECTIVES}

The objectives of these tests were specified in R\&T Test Scoping Statement S-43, Test Specification 24590-WTP-TSP-RT-01-019, Rev. $0^{1}$, and SRTC Task Technical \& Quality Assurance Plan SRT-RPP-2002-00007, Rev. 0. ${ }^{2}$ The test included gathering data on performance of the single-tube crossflow ultrafilter unit to de-water the simulant precipitate derived from a project approved tank 241-AN-102 simulant.

The initial task objectives and requirements are as follows:

1. Perform a de-watering test (details described later) to estimate the removal efficiency for soluble species.

2. Using a filtration test matrix, measure indicative data on equipment performance (permeate flux, back pulse efficiency) with the initial precipitate and also at approximately $15 \mathrm{wt} \%$ insoluble solids.

3. Compare filtration flux data with the work done using active waste ${ }^{3}$ to validate the simulant. Validation of the simulant was verbally agreed upon to mean that if the fluxes determined during concentration of the precipitate were within $\pm 25 \%$ of the Large $\mathrm{C}$ radioactive demonstration fluxes, the simulant would be validated. Validation of the simulant will then allow work to be conducted at a larger scale on the (multi-tube) filtration pilot plant. (This pilot scale work was covered under separate Test Specifications. ${ }^{4,5}$ )

4. Show that the mean flux throughout the complete de-watering cycle is greater than 0.02 $\mathrm{gpm} / \mathrm{ft}^{2}$.

5. After completion of filtration, chemically clean the filter system and measure the clean water fluxes to establish that the fluxes can be returned to pre-operation (clean) levels.

6. Determine if a final insoluble solids concentration of $15 \mathrm{wt} \%$ can be improved.

A general requirement that applied to all of this work was that no solids must pass into the ultrafiltration permeate. The work listed above was done with a remediation of a purchased simulant; this remediation was called "R1".

Upon completion of the above objectives with the approved R1 simulant, the simulant specification was changed and additional work at modified precipitation conditions was requested. The revised simulant formulation was called "R2". The additional requirements were:

7. With "newly optimized" precipitation conditions and the $\mathrm{R} 2$ simulant recipe, perform a de-watering test and show that the time-averaged flux is above $0.02 \mathrm{gpm} / \mathrm{ft}^{2}$.

8. Perform a precipitation with the original baseline conditions and the new simulant recipe and show that the time-averaged flux is above $0.02 \mathrm{gpm} / \mathrm{ft}^{2}$. 


\subsection{CONDUCT OF TESTING}

For the tests described below, the following equipment and sequence of work was performed for each set of tests. Crossflow filtration testing of the feed samples was then conducted on a Cells Unit Filter (CUF, shown later in Figure 2). The CUF consisted of a single Mott industrial grade $0.1 \mu \mathrm{m}$ tube filter module 24 " long, with a $3 / 8$ " inside diameter tube. The concentrate slurry and permeate flows, concentrate temperature, tube inlet, outlet, and permeate pressure, volumes collected, and time were measured with calibrated devices.

Before filtering the simulant slurry, the CUF was cleaned with $2 \mathrm{M} \mathrm{HNO}_{3}$, and then rinsed with inhibited water $(0.01 \mathrm{M} \mathrm{NaOH})$. Clean water flux measurements at 10,20 , and $30 \mathrm{psi}$ transmembrane pressure (TMP) and a velocity of $11 \mathrm{feet} / \mathrm{sec}$ (fps) were then performed. These same conditions were duplicated with a $5.0 \mathrm{wt} \%$ slurry of granular strontium carbonate. The unit was rinsed with inhibited water, then briefly with $2 \mathrm{M} \mathrm{HNO}_{3}$ to dissolve residual carbonate, then rinsed again with inhibited water. The clean water fluxes were then measured again.

The permeate fluxes were expressed in terms of flux corrected to $25^{\circ} \mathrm{C}$ by the use of a temperature correction factor specified by WTP. ${ }^{1}$ Samples of the slurry and permeate were taken throughout this task as specified by WTP. These analyses included particle size distribution, rheology, total solids, insoluble solids, specific gravity, elemental analysis by ICPES, ion chromatography, and turbidity.

Following completion of the tests, the CUF was cleaned with inhibited water to establish the cleaning efficiency for water alone prior to chemical cleaning with $2 \mathrm{M}$ nitric acid. The system was then flushed with inhibited water, followed by repeating the inhibited water, strontium carbonate, and second inhibited water flux tests.

\subsubsection{Tests with First Remediation (R1) Simulant}

The Envelope C AN-102 simulant solution developed by SRTC (WTP level IV activity ID 2BPR1SC202) was specified to be used for this work. This simulant recipe included both a supernate simulant recipe and a solids simulant recipe. The amount of solids simulant added to the supernate simulant was $0.1 \mathrm{wt} \%{ }^{6}$ This simulant recipe has been designated "AN102R1" or just "R1" for remediation 1 since it was the result of remediating a purchased simulant prepared by Optima Chemicals. The remediation was required because the simulant recipe was changed after purchase of the simulant. This simulant recipe and a second remediation recipe are shown in the Appendix.

The Test Specification gave the Sr/TRU precipitation recipe to be used for this work. ${ }^{5}$ This recipe specified first diluting the simulant with water to achieve $6.0 \mathrm{M}$ sodium, addition of $\mathrm{NaOH}$ so that the total (not specified as added hydroxide) hydroxide was $1.0 \mathrm{M}$, addition of $\mathrm{Sr}\left(\mathrm{NO}_{3}\right)_{2}$ at $50^{\circ} \mathrm{C}$ to give a final $\mathrm{Sr}$ concentration of $0.075 \mathrm{M}$, and addition of $\mathrm{NaMnO}_{4}$ at $50^{\circ} \mathrm{C}$ to give an added permanganate concentration of $0.05 \mathrm{M}$. The recipe subsequently published by SRTC specified that the added hydroxide should be $1.0 \mathrm{M}$. However, in a follow-up email from Townson ${ }^{8}$ regarding an error in the Test Specification recipe, the added 
hydroxide was specified as $0.9 \mathrm{M}$ rather than $1.0 \mathrm{M}$; this value was subsequently used for the $\mathrm{R} 1 \mathrm{BC}$ precipitation. (See Section 3.2.1.3 for additional discussion.)

The specific amounts of reagents called for in the recipe were adjusted for the actual reagent concentrations to give the same number of moles. Nine batches of simulant precipitate, each starting from 5 liters of simulant, were made; the final volume of each batch of precipitate was about 6.5 liters. This set of experiments has been designated "AN102R1BC" or "R1BC", which means the first remediation simulant precipitated at the baseline conditions.

The precipitate generated from the steps above resulted in a slurry with approximately $1.45-$ $1.60 \mathrm{wt} \%$ insoluble solids. The flux was then measured for a 17-point modified factorial matrix of TMPs and axial velocities to determine the optimum set of conditions and compare to the results of the active waste tests. Each set of conditions was run for one hour, with multiple backpulses of permeate between each set of conditions. The slurry temperature in all tests was maintained at $25 \pm 5^{\circ} \mathrm{C}$.

Eight additional batches of precipitate were then made over the course of several days and each was fed into the CUF system. The dewatering test was conducted at 50 psi TMP and 12 fps velocity. These are the same conditions used during most of the first dewatering in the active waste run. ${ }^{3}$ Once all precipitate batches were added, the final concentration step was performed, reducing the total volume below the initial 6.5 liters. The slurry was concentrated to about 4.5 liters volume, or about $19.3 \mathrm{wt} \%$ insoluble solids. Permeate was added back into the slurry and reduced the insoluble solids concentration to approximately $17.2 \mathrm{wt} \%$ versus the target of $15 \mathrm{wt} \%$. Samples of slurry and permeate were taken at approximately $13.3 \mathrm{wt} \%$ and at $17.2 \mathrm{wt} \%$ insoluble solids in the slurry.

The approximately $17.2 \mathrm{wt} \%$ insoluble solids slurry was subjected to the same set of factorial experiments described above for the dilute slurry. The total volume of permeate collected during concentration was about 54 liters. The final concentrated slurry volume was about 4.5 liters.

After concentrating to approximately $17.2 \mathrm{wt} \%$ insoluble solids, and performing the factorial experiments, the solids were washed with a single equal volume of inhibited water. The slurry was then re-concentrated to approximately $20.6 \mathrm{wt} \%$ insoluble solids.

\subsubsection{Tests with Second Remediation (R2) Simulant}

After completion of the tests with the R1 formulation and baseline conditions, the customer determined that the carbonate concentration in the simulant specification should have been higher. This revised simulant recipe is designated "AN102R2" or "R2". In addition, the $\mathrm{Sr}$ TRU precipitation recipe was also changed. Washing and re-concentration of the slurry was not performed for any of the runs with the R2 simulant. 


\section{WSRC-TR-2003-00056, REV. 0}

SRT-RPP-2002-00231, REV. 0

The "newly optimized conditions" (NOC) targets for precipitation were specified by WTP as:

1. No added caustic

2. $0.03 \mathrm{M} \mathrm{Sr}$ final concentration added as $\mathrm{Sr}\left(\mathrm{NO}_{3}\right)_{2}$

3. $0.03 \mathrm{M} \mathrm{Mn}$ final concentration added as $\mathrm{NaMnO}_{4}$

4. Precipitation temperature of $25^{\circ} \mathrm{C}$

The first precipitation with R2 simulant was conducted with a single large batch of 115L of R2 simulant; this material is designated "AN102R2NOC1" or "R2NOC1". The insoluble solids content of this batch as about 0.74-1.19 wt\%. Immediately upon starting the filtration, the flux decreased below $0.02 \mathrm{gpm} / \mathrm{ft}^{2}$, so this test was stopped.

Per project direction, this precipitation was repeated with 5L of R2 simulant (R2NOC small) and filtered. The initial fluxes measured were significantly higher that found during R2NOC1, so another $115 \mathrm{~L}$ batch (R2NOC2) was prepared at the same precipitation conditions. The initial fluxes were again higher $\left(0.119 \mathrm{gpm} / \mathrm{ft}^{2}\right)$, so this material was concentrated to $18.5 \mathrm{wt} \%$ insoluble solids. The initial precipitate insoluble solids was 1.32 $\mathrm{wt} \%$ before concentration. Although the initial fluxes were acceptable, the flux dropped below the minimum $0.02 \mathrm{gpm} / \mathrm{ft}^{2}$ at about $8 \mathrm{wt} \%$ insoluble solids. The time-averaged flux was $0.013 \mathrm{gpm} / \mathrm{ft}^{2}$.

After extensive discussions with Project personnel, the path forward was changed to go back to the baseline conditions for precipitation. A small batch of R2 simulant was precipitated at the baseline conditions (R2BC small) and filtered. The initial filtration fluxes were much higher than those found for the NOC recipe. A large batch was then planned with the following conditions:

1. Add caustic to give $1.0 \mathrm{M}$ hydroxide (rather than added caustic equal to $1.0 \mathrm{M}$ )

2. $0.075 \mathrm{M} \mathrm{Sr}$ added as $\mathrm{Sr}\left(\mathrm{NO}_{3}\right)_{2}$

3. $0.05 \mathrm{M} \mathrm{Mn}$ added as $\mathrm{NaMnO}_{4}$

4. Precipitation temperature of $50^{\circ} \mathrm{C}$

Note that this modification of the baseline conditions with a smaller hydroxide additional is still referred to herein as "baseline conditions" since it is much closer to the true baseline conditions than the NOC conditions.

This precipitation was performed on a large batch (approx. 880L) in the Engineering Development Laboratory, with a small quantity then sent for use in the CUF. The initial insoluble solids content was $1.60 \mathrm{wt} \%$. Filtration of this batch gave acceptable flux results and it was concentrated to $18.8 \mathrm{wt} \%$ insoluble solids. The time-averaged flux was $0.060 \mathrm{gpm} / \mathrm{ft}^{2}$.

The tests at the various conditions are summarized in Table 1. The hydroxide was added at no particular rate or temperature, while the $\mathrm{Sr}\left(\mathrm{NO}_{3}\right)_{2}$ and $\mathrm{NaMnO}_{4}$ reagents were each added over approximately 20 minutes at the specified temperature, with a 30 minute waiting period both before the $\mathrm{Sr}\left(\mathrm{NO}_{3}\right)_{2}$ addition and the $\mathrm{NaMnO}_{4}$ addition. The hold time at temperature 
after completion of the $\mathrm{NaMnO}_{4}$ addition was four hours (or a wait time before filtration of four hours for those runs at $25^{\circ} \mathrm{C}$ ).

Table 1 Summary of Conditions for Precipitation Runs

\begin{tabular}{|clcccccc|} 
Experiment & \multicolumn{1}{c}{ Batch Source* } & Remediation & $\begin{array}{c}\text { OH- } \\
\text { Added }(\mathrm{M})\end{array}$ & $\begin{array}{c}\mathrm{Sr} \\
(\mathrm{M})\end{array}$ & $\begin{array}{c}\mathrm{Mn} \\
(\mathrm{M})\end{array}$ & $\begin{array}{c}\text { Temp. } \\
\left({ }^{\circ} \mathrm{C}\right)\end{array}$ & $\begin{array}{c}\text { Batch Volume } \\
(\mathrm{L})\end{array}$ \\
\hline R1BC & $\begin{array}{l}\text { Small remediation of } \\
\text { Optima simulant }\end{array}$ & $\mathrm{R} 1$ & 0.9 & 0.075 & 0.05 & 50 & 115 \\
\hline R2NOC1 & $\begin{array}{l}\text { Optima remediation } \\
\text { batch 3C by EDL }\end{array}$ & $\mathrm{R} 2$ & 0 & 0.03 & 0.03 & 25 & 115 \\
\hline $\begin{array}{c}\text { R2NOC } \\
\text { small }\end{array}$ & $\begin{array}{l}\text { Optima remediation } \\
\text { batch 3C by EDL }\end{array}$ & $\mathrm{R} 2$ & 0 & 0.03 & 0.03 & 25 & 5 \\
\hline R2BC & $\begin{array}{l}\text { Optima remediation } \\
\text { batch 3C by EDL }\end{array}$ & $\mathrm{R} 2$ & 0.9 & 0.075 & 0.05 & 50 & 5 \\
\hline R2NOC2 & $\begin{array}{l}\text { Optima remediation } \\
\text { batch 3C by EDL }\end{array}$ & $\mathrm{R} 2$ & 0 & 0.03 & 0.03 & 25 & 115 \\
\hline R2BCL & $\begin{array}{l}\text { Optima remediation } \\
\text { batch 3B by EDL }\end{array}$ & $\mathrm{R} 2$ & $\begin{array}{c}0.8 \text { (to } 1.0 \\
\text { total) }\end{array}$ & 0.075 & 0.05 & 50 & $\begin{array}{c}880 \text { (approx. } \\
60 \text { to CUF) }\end{array}$ \\
\hline
\end{tabular}

\subsection{RESULTS AND PERFORMANCE AGAINST OBJECTIVES}

Prior to and after all filtration work, the clean water and $\mathrm{SrCO}_{3}$ fluxes were measured. The before and after fluxes were found to be essentially identical for both water and $\mathrm{SrCO}_{3}$, indicating that no irreversible changes in the filter occurred. The $\mathrm{SrCO}_{3}$ fluxes were about $30 \%$ lower than the clean water fluxes. These results complete Objective 5: After completion of filtration, chemically clean the filter system and measure the clean water fluxes to establish that the fluxes can be returned to pre-operation (clean) levels.

\subsubsection{Remediation 1 Baseline Conditions}

Nine 5L batches of simulant were prepared and precipitated using the $\mathrm{Sr} / \mathrm{TRU}$ precipitation recipe that was the latest baseline formulation at the time of the test (as specified by the Test Specification).

The optimum dewatering conditions for the initial (approximately 1.45-1.60 wt\% insoluble solids) slurry were determined by performing the specified factorial experimental design. The experimental design data was analyzed and fit to a mathematical model.

Maximum flux is predicted to occur at the maximum velocity and TMP. Of the conditions actually tested, the optimum was a velocity of $15 \mathrm{fps}$ and a TMP of $40 \mathrm{psi}$. The permeate flux was found to decrease with time at the same process conditions, which may indicate pore plugging or reduced efficiency due to decreasing particle size versus time.

The slurry was successfully dewatered to greater than $15 \mathrm{wt} \%$ insoluble solids. The highest concentration achieved was $19.3 \mathrm{wt} \%$ insoluble solids. This slurry was diluted with permeate to $17.2 \mathrm{wt} \%$ and a factorial design matrix was performed. The optimum conditions were the 
highest velocity; pressure had no significant effect. The permeate flux was again found to decrease with time at the same process conditions. These results complete Objective 2: Using a filtration test matrix, measure indicative data on equipment performance with the initial precipitate and also at approximately $15 \mathrm{wt} \%$ insoluble solids.

Concentration of the slurry from the initial solids loading to $19.3 \mathrm{wt} \%$ was conducted at the specified conditions. The fluxes achieved were shown to be linearly dependent on the insoluble solids content when the effect of time was included. The mean permeate flux during dewatering was $0.036 \mathrm{gpm} / \mathrm{ft}^{2}$ compared to the average design flux of $0.02 \mathrm{gpm} / \mathrm{ft}^{2}$. This completes Objectives 4: Show that the mean flux throughout the complete de-watering cycle is greater than $0.02 \mathrm{gpm} / \mathrm{ft}^{2}$.

For the fluxes measured, $73 \%$ were within $\pm 25 \%$ and the remaining fluxes were within $32 \%$ of the fluxes determined during the initial concentration step of the Large $\mathrm{C}$ active waste filtration work. ${ }^{3}$ Although not meeting Objective 3 exactly, the results are sufficiently close that we consider the simulant to be validated. (Objective 3: Compare filtration flux data with the work done using active waste to validate the simulant. Validation meant that the fluxes determined during concentration were within $\pm 25 \%$ of the Large C fluxes.)

The concentrated slurry was subjected to a 1:1 volumetric water wash and then re-concentrated to $20.6 \mathrm{wt} \%$ insoluble solids. The flux during re-concentration was predicted well by the previously determined model, with the addition of a term for the permeate viscosity. Concentration of both the unwashed and washed slurry meets Objective 6: Determine if a final insoluble solids concentration of $15 \mathrm{wt} \%$ can be improved.

The decontamination factors for removal of soluble components from the concentrated slurry ranged form 1.61 to 28.4 for soluble or partially soluble species. Greater than $95 \%$ of the Al and $\mathrm{Na}$ were removed from the slurry. These results complete Objective 1: Perform a dewatering test (details described later) to estimate the removal efficiency for soluble species.

Permeate samples analyzed all had turbidities of less than 5 NTU, which indicates that no breakthrough of solids, due to a crack or similar failure, occurred during filtration After standing for several days, all permeates had formed a brown coating on all container surfaces, indicating post precipitation. However, the liquid was still transparent, as indicated by the turbidity results.

\subsubsection{Remediation 2 with Newly Optimized Conditions and Baseline Conditions}

For the succeeding experiments, the full factorial matrices were not requested for either the dilute initial precipitate or the concentrated slurry. A few selected factorial points were run for several of the experiments. The objectives for each run were determined both before and during the run, depending on the results found.

The filtration for both runs with the R2 remediation and the NOC conditions showed that the desired fluxes could not be maintained. This result shows that the NOC conditions result in unacceptable performance. These runs also neither validate nor invalidate the R2 simulant 
since the precipitation conditions were also changed. The NOC2 run flux, above an insoluble solids concentration of about $4 \mathrm{wt} \%$, ranged from about $50-65 \%$ of the Large $\mathrm{C}$ active waste fluxes. The pilot filtration fluxes from the EDL for this same case were even lower. These results showed that Objective 7 could not be met. (Objective 7: With "newly optimized" precipitation conditions and the new simulant recipe, perform a de-watering test and show that the time-averaged flux is above $0.02 \mathrm{gpm} / \mathrm{ft}^{2}$.)

The $\mathrm{R} 2$ run with the baseline conditions resulted in an time-averaged flux of $0.060 \mathrm{gpm} / \mathrm{ft}^{2}$, which was about two times greater than those measured for the R1BC run and the Large C active waste run. This result completes Objective 8: Perform a precipitation with the original baseline conditions and the new simulant recipe and show that the time-averaged flux is above $0.02 \mathrm{gpm} / \mathrm{ft}^{2}$.

\subsection{QUALITY REQUIREMENTS}

This work was conducted in accordance with the RPP-WTP QA requirements specified for work conducted by SRTC as identified in DOE IWO MOSRLE60. Researchers followed the WSRC Quality Assurance Program, which has been approved by WTP, and the WSRC Quality Assurance Management Plan (WSRC-RP-92-225). SRTC has provided matrices to WTP demonstrating compliance of the SRTC QA program with the requirements specified by WTP. Specific information egarding the compliance of the SRTC QA program with NQA-1 1989, Part 1, Basic and Supplementary Requirements and NQA-2a 1990, Subpart 2.7 is contained in these matrices. This program will apply the appropriate quality assurance requirements for this task, as indicated by the QA Plan Checklist in Section VIII.

Analytical sample labeling and tracking complied with established procedures (WSRC Manual L1, Procedure 7.15). The SRTC Analytical Development Section (ADS) conducted all analyses using the routine level QA program. Calibrated measuring and test equipment were utilized for all flow rate, pressure, and temperature measurements on the CUF unit.

The Task Technical \& Quality Assurance Plan provided the quality requirements for this work. ${ }^{2}$ NQA-1 1989, Part 1, Basic and Supplementary Requirements and NQA-2a 1990, Subpart 2.7 were applied as appropriate.

Calibrated balances were checked with calibrated weights that were traceable to NIST before use. The accuracy was $\pm 1 \%$. Pressures were measured with calibrated pressure gauges that had an accuracy of \pm 2 psi. The flow meters were calibrated and verified to have an accuracy of $\pm 10 \%$. The thermocouples used to measure temperature were checked against calibrated thermometers and had an accuracy of $\pm 1{ }^{\circ} \mathrm{C}$. Calibrated stopwatches were used to measure the filtrate flow rate and had an accuracy of $\pm 1 \%$.

\subsection{ISSUES}

The slurries for all three runs that were concentrated to higher than $15 \mathrm{wt} \%$ insoluble solids were very difficult to mix in the slurry feed tank. The small agitator used provided little

agitation; a larger agitator used in the later runs was somewhat more effective. This problem 
became even worse with the washed concentrated $(20.6 \mathrm{wt} \%)$ slurry. The slurry samples above $13 \mathrm{wt} \%$ insoluble solids were all found to be non-Newtonian, with the specific behavior being close to a Bingham plastic. The measured consistencies and yield stresses of these slurries put these slurries in the laminar flow region for both tank agitation and pipe flow. These results indicate that the best equipment for mixing would be laminar mixers, and for pumping, would be positive displacement pumps, possibly with screw suction.

In addition to affecting fluid transport, the high consistencies and non-Newtonian behavior increased the heat load on the heat exchanger. Significantly more energy was input into the fluid by the pump when the slurry was more concentrated. At the highest concentrations, there was insufficient heat transfer area to maintain the slurry temperature within the required range. The overall heat transfer coefficients decreased only about $20 \%$, so the main factor in heat removal appears to be assuring sufficient heat exchange area.

The "newly optimized" precipitation conditions did not result in a filterable precipitate. Future optimization of the precipitation reactions should be coupled with crossflow filter tests to assure that the precipitate will be filterable. These tests should take the precipitate to at least $10 \mathrm{wt} \%$ insoluble solids, and preferably beyond.

During the precipitations, it was noted that ammonia gas was formed. Ammonia evolution may be a flammability, emissions, or ammonium nitrate formation concern for the WTP.

\subsection{CD-ROM ENCLOSURES}

The enclosed CD-ROM contains two movies:

1. Resuspension of a settled precipitate batch: "Slurry-Resuspension.mpg"

2. Mixing of concentrated slurry in feed tank: "Feed-Mixing.mpg"

These movies can be viewed using the Windows Media Player or other multimedia software.

An electronic copy of this report is also included on the CD-ROM. Adobe Acrobat Reader is required to view this document.

\subsection{DISCUSSION}

\subsection{EXPERIMENTAL DETAIL}

The experimental work will be discussed in chronological order. The precipitator equipment used for the $5 \mathrm{~L}$ precipitations is shown in Figure 1. 


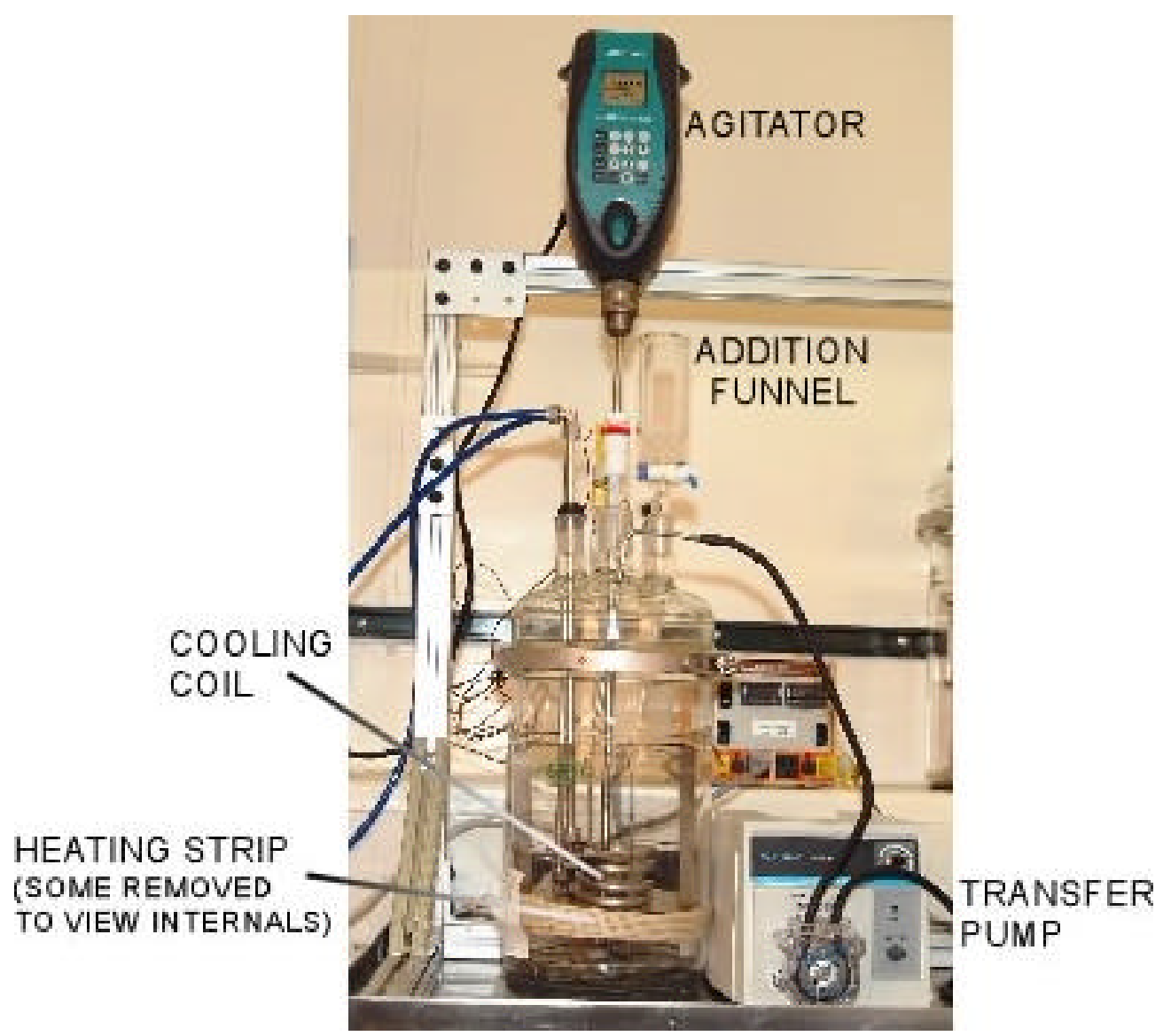

Figure 1 Precipitator Equipment

Crossflow filtration testing of the feed samples was then conducted on a Cells Unit Filter (CUF). The CUF consisted of a single Mott industrial grade $0.1 \mu \mathrm{m}$ tube filter module 24" long, with a 3/8" inside diameter tube. A photo of the CUF is shown in Figure 2 and a piping diagram in Figure 3. The concentrate flow and temperature, and tube inlet, outlet, and permeate pressure were all measured with calibrated measurement devices. The flowrate of permeate was measured by determining the amount of time to collect a specific amount of permeate, which was $40 \mathrm{ml}$ during tests where the permeate was recycled, 250 or $500 \mathrm{ml}$ during concentration, and $250 \mathrm{ml}$ during clean water flux tests. Calibrated stopwatches and graduated cylinders were used. 
WSRC-TR-2003-00056, REV. 0

SRT-RPP-2002-00231, REV. 0

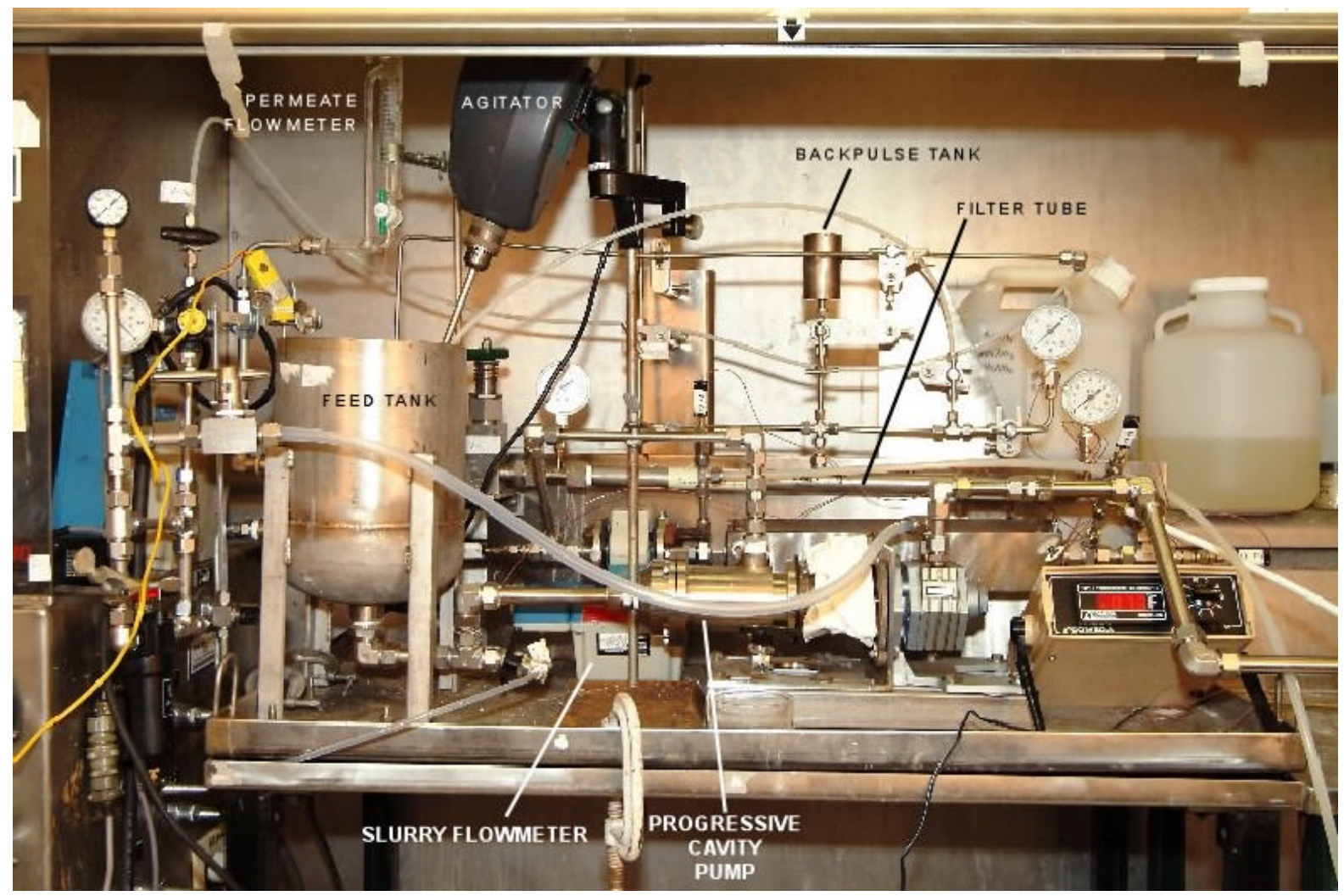

Figure 2 Cold Cells Unit Filter (Cold CUF) System

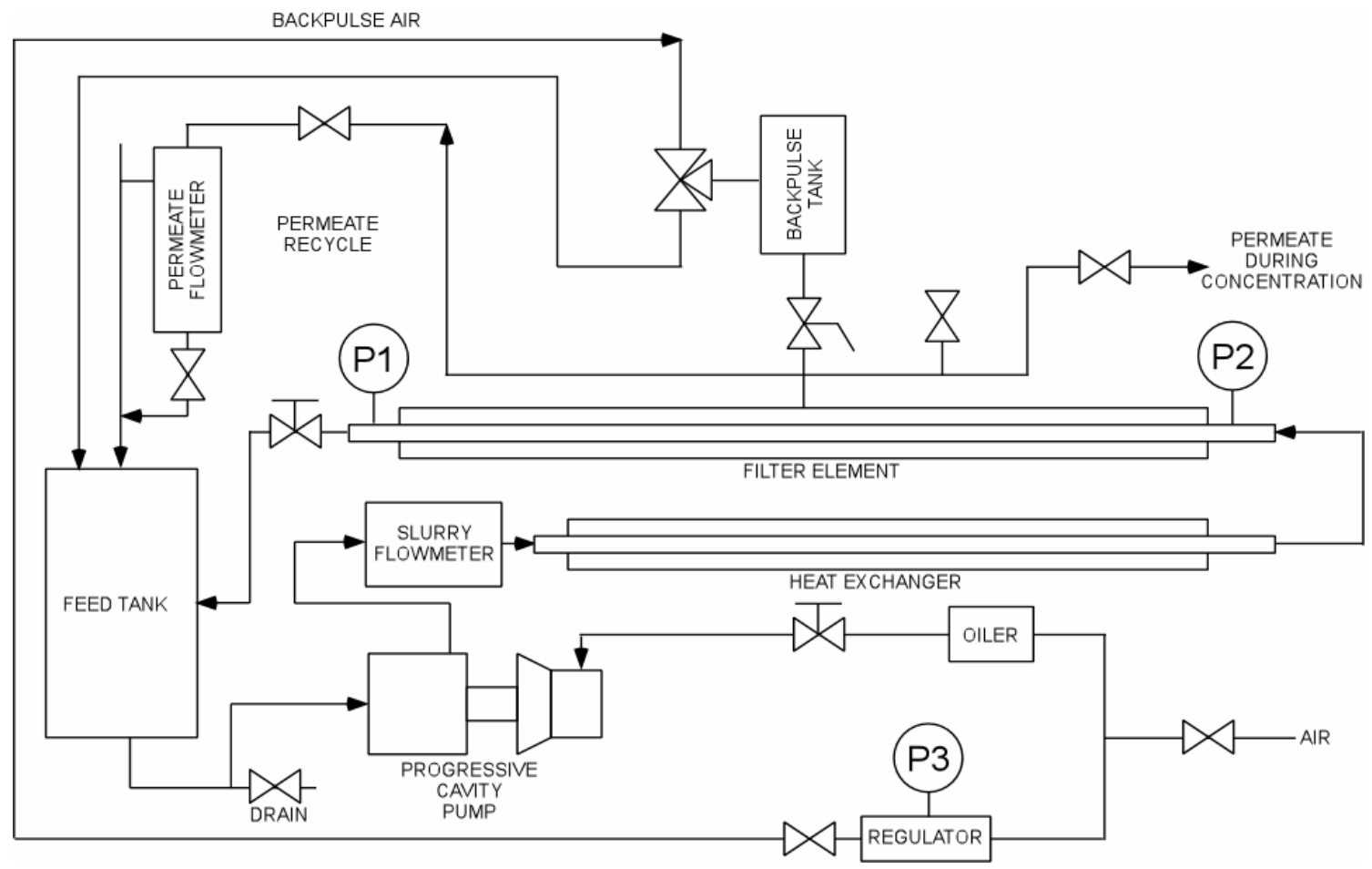

Figure 3 Schematic of CUF System 
Before filtering the simulant slurry, the CUF was cleaned with $2 \mathrm{M} \mathrm{HNO}_{3}$, then rinsed with inhibited water $(0.01 \mathrm{M} \mathrm{NaOH})$. "Clean water flux" measurements at 10,20 , and 30 psi transmembrane pressure (TMP) and a velocity of $11 \mathrm{feet} / \mathrm{sec}$ (fps) were then performed. Note that "clean water flux" actually uses inhibited water. After measuring these fluxes, the same conditions were duplicated with a $5.0 \mathrm{wt} \%$ solution of granular strontium carbonate. This strontium carbonate was purchased as nominal $1 \mu \mathrm{m}$ material; particle size distribution analysis showed a relatively Gaussian distribution centered on $4 \mu \mathrm{m}$. After the strontium carbonate fluxes were measured, the unit was rinsed with inhibited water, then briefly with $2 \mathrm{M} \mathrm{HNO}_{3}$ to dissolve residual carbonate, then rinsed again with inhibited water. The clean water fluxes were then measured again.

\subsubsection{Simulant Remediation 1 Precipitation at Baseline Conditions}

The Envelope C AN-102 simulant solution developed by SRTC (WTP level IV activity ID 2BPR1SC202) was specified to be used for this work. ${ }^{6}$ This simulant recipe included both a supernate simulant recipe and a solids simulant recipe. Both of these recipes were received via email from the SRTC researcher after verbal approval by Project personnel (Townson). The amount of solids simulant to use in the supernate simulant was also verbally communicated; this value was $0.1 \mathrm{wt} \%$. The supernate simulant for this portion of the task was made by remediating simulant prepared for SRTC by Optima Chemicals. This remediation, called "R1", was performed to give 50L of remediated simulant. The target and measured compositions of the simulant, as well as other samples, are shown and discussed more fully in Section 3.2.1.

The Test Specification gave the Sr/TRU precipitation recipe to be used for this work. ${ }^{5}$ This recipe specified first diluting the simulant with water to achieve $6.0 \mathrm{M}$ sodium, addition of $\mathrm{NaOH}$ so that the total (not specified as added hydroxide) hydroxide was $1.0 \mathrm{M}$, addition of $\mathrm{Sr}\left(\mathrm{NO}_{3}\right)_{2}$ at $50^{\circ} \mathrm{C}$ to give a final $\mathrm{Sr}$ concentration of $0.075 \mathrm{M}$, and addition of $\mathrm{NaMnO}_{4}$ at $50^{\circ} \mathrm{C}$ to give an added permanganate concentration of $0.05 \mathrm{M}$. However, in a follow-up email from Townson ${ }^{8}$ (see Appendix) regarding an error in the Test Specification recipe, the added hydroxide was specified as $0.9 \mathrm{M}$ rather than $1.0 \mathrm{M}$; this value was subsequently, and erroneously, used for the R1BC precipitation. (See Section 3.2.1.3 for additional discussion.)

The specific amounts of reagents called for in the recipe were adjusted for the actual reagent concentrations to give the same number of moles. Per 1-liter, the amounts of each reagent were specified to be added within specific tolerances. The actual initial concentration of $\mathrm{Na}$, the concentration of the $\mathrm{NaOH}$ reagent, and the concentration of the $\mathrm{NaMnO}_{4}$ reagent differed from those specified (which was acceptable), so the actual amounts added were adjusted to give the same number of moles. The "per liter of simulant" tolerances specified were maintained. All water used during the course of this task for reagent preparation was deionized and filtered with a $0.1 \mu \mathrm{m}$ filter. Nine batches of simulant precipitate, each starting from 5 liters of simulant, were made; the final volume of each batch of precipitate was about 6.5 liters.

The first and fifth precipitate batches were analyzed; the first was analyzed after the filtration factorial experiments (described below), while the fifth batch was analyzed directly from the 


\section{WSRC-TR-2003-00056, REV. 0}

SRT-RPP-2002-00231, REV. 0

precipitator. The first batch analysis should show if there are any effects of the pumping operation on the particle size distribution.

The precipitate generated from the steps above resulted in a slurry with $1.45-1.60$ wt\% insoluble solids. The flux was then measured for a 17-point modified factorial matrix of TMPs (20-70 psi) and velocities (7-15 fps) to determine the optimum set of conditions and compare to the results of the active waste tests. Each set of conditions was run for one hour, with multiple backpulses of permeate between each set of conditions. The approximate steady state flux for each set of conditions was determined by first visually examining the graph of flux versus time and then taking the average of 1 to 3 of the last points $(40,50,60$ min), per the researchers judgment. During the time interval of 60 minutes for each set of conditions, the flux did not reach as steady state value in most cases, but continued to drop slightly. The slurry temperature in all tests was maintained at $25 \pm 5^{\circ} \mathrm{C}$.

Eight additional batches of precipitate were then made over the course of several days and each was fed into the CUF system. The level in the CUF feed tank was maintained approximately constant by adding precipitate at the same rate that permeate was drawn off, thus concentrating the slurry. Each test was conducted at the conditions of 50 psi TMP and 12 fps velocity used during the active waste run. ${ }^{3}$ Each added batch increased the insoluble solids concentration of the slurry by about $1.45-1.60 \mathrm{wt} \%$. Slight variations from this value occurred due to the removal of slurry samples.

Once all precipitate batches were added, the final concentration step was performed, thus reducing the total volume of slurry below the initial 6.5 liters. Backpulses performed between each batch required successively longer time to perform because the decreased flux increased the amount of time necessary to fill the backpulse tank. The amount of time between a backpulse and the resumption of permeate collection also increased; the backpulses introduced air into the permeate side of the filter element which then had to be displaced before the flow measurement could resume. Note that it is the measurement of permeate flow that is delayed and not the actual resumption of permeate flow. For these reasons, the first flux reading after backpulsing is actually lower than the true initial flux.

The total volume of permeate collected during concentration was about 54 liters. The final concentrated slurry volume was 4 liters, or about $19.3 \mathrm{wt} \%$ insoluble solids. The amount of permeate to be removed was calculated to be larger than necessary due to assuming the precipitate batches were $1.0 \mathrm{wt} \%$ insoluble solids rather than $1.45-1.60 \mathrm{wt} \%$. When filtration became very difficult, a slurry sample was taken and analyzed for total solids. The total solids analysis indicated the insoluble solids were approximately 16-18 wt\% rather than 15 wt $\%$, so a calculated amount of permeate was added back into the slurry. At this point, the insoluble solids content was not measured; later analyses showed that the slurry had actually been concentrated to about $19.3 \mathrm{wt} \%$ insoluble solids and then diluted to about $17.2 \mathrm{wt} \%$. Samples of slurry and permeate were taken at approximately $13.3 \mathrm{wt} \%$ and at $17.2 \mathrm{wt} \%$ insoluble solids in the slurry.

The approximately $17.2 \mathrm{wt} \%$ insoluble solids slurry was subjected to the same set of factorial experiments described above for the dilute slurry. The amount of time required for the 
permeate to start flowing in the flowmeter, due to the air in the permeate side of the filter, resulted in the first permeate flow (flux) measurements actually occurring at about 20 minutes after backpulsing rather than only several seconds to at most a minute for the low solids factorials. For this reason, most of the flux versus time curves for approximately 17.2 $\mathrm{wt} \%$ insoluble solids do not show the initial flux decline after backpulsing. The typically seen flux decline is in general due to buildup of the solids on the filter membrane.

The permeate fluxes were expressed in terms of flux corrected to $25^{\circ} \mathrm{C}$ by the use of a temperature correction factor specified by WTP: $\exp \left(2500\left(\frac{1}{273+\mathrm{T}}-\frac{1}{298}\right)\right)$, where $\mathrm{T}$ is in ${ }^{\circ} \mathrm{C}$. This temperature correction factor corrects flux back to an equivalent flux at $25^{\circ} \mathrm{C}$ and accounts for changes in fluid viscosity and surface tension. The equation shown above was reported by WTP to have been derived at Oak Ridge National Laboratory, but no reference for this equation was supplied.

After concentration to approximately $17.2 \mathrm{wt} \%$ insoluble solids, and performing the factorial experiments, the solids were washed with a single equal volume of inhibited water. The slurry was then re-concentrated back to approximately $20.6 \mathrm{wt} \%$ insoluble solids.

Following completion of these tests, the CUF was cleaned with only inhibited water to establish the cleaning efficiency for water alone prior to performing chemical cleaning with $2 \mathrm{M}$ nitric acid. After chemical cleaning, the system was then flushed with inhibited water, followed by repeating the inhibited water, strontium carbonate, and second inhibited water flux tests.

Samples of the slurry and permeate were taken throughout this task as specified by WTP. A complete listing of these samples and results are given later.

\subsubsection{Simulant Remediation 2 and Newly Optimized Conditions Precipitations}

After completion of the R1BC run, Project personnel determined that the composition of the supernate simulant was incorrect. The carbonate concentration should have been higher than what was used. A new remediation recipe was devised (R2). At the same time, optimization work on the precipitation process indicated that lower reagent additions could accomplish the required decontamination, ${ }^{9}$ so an additional run at these conditions was requested.

Approximately $115 \mathrm{~L}$ of R2 remediated simulant was precipitated with no added hydroxide and final $\mathrm{Sr}$ and $\mathrm{Mn}$ concentrations of $0.03 \mathrm{M}$ each. The temperature was room temperature, which ranged from $19^{\circ} \mathrm{C}$ to $23^{\circ} \mathrm{C}$, compared to the nominal $25^{\circ} \mathrm{C}$ requested. Heating of the drum used for the precipitation was not possible. The agitation during the precipitation was moderate. An 8" diameter marine propeller was used without baffles. The agitator speed had to be limited due to splashing and significant vortex formation. Stringy globs of the reacting reagents could be seen in the liquid for up to 30-60 seconds as the reagents were being added onto the surface of the liquid. Eventually, these strings mixed into the bulk liquid. 
The $\mathrm{Sr}\left(\mathrm{NO}_{3}\right)_{2}$ and $\mathrm{NaMnO}_{4}$ additions were each done in about 17 minutes. A 30-minute waiting period between the $\mathrm{Sr}$ and $\mathrm{Mn}$ additions was observed. After adding the $\mathrm{NaMnO}_{4}$, the solution was mixed for four hours.

The precipitated simulant was transported to the CUF location and filtration was begun five days after completion of the precipitation. Within two hours, the flux had dropped from an initial 0.033 to $0.015 \mathrm{gpm} / \mathrm{ft}^{2}$, which was below the plant minimum average flux. The CUF unit was then emptied, cleaned, and the clean water and $\mathrm{SrCO}_{3}$ fluxes were determined. These fluxes were acceptable. The R2NOC1 precipitate was added back into the CUF feed tank and filtered again. The flux again dropped quickly, from an initial 0.047 to 0.019 $\mathrm{gpm} / \mathrm{ft}^{2}$ after only 30 minutes.

At this time, SRTC and Project personnel discussed possible paths forward. Two potential causes for the low flux results were proposed: 1) the delay in beginning filtration (aging); 2) the less than "vigorous" agitation. Therefore, a small (5L) batch precipitation (R2NOC small) was performed with vigorous mixing and no time delay between the end of the precipitation and the filtration. The flux measured ranged from 0.046 to $0.067 \mathrm{gpm} / \mathrm{ft}^{2}$ at TMPs of 40 and $50 \mathrm{psi}$ and a velocity of $12 \mathrm{fps}$. Based on these encouraging results, a large batch precipitation was planned.

The next precipitation (R2NOC2) was a repeat of R2NOC1. Vigorous agitation was maintained by adding baffles and operating the propeller agitator at a higher speed $(220 \mathrm{rpm}$ versus the previous approximately160 rpm or less). The quantities of reagents added were the same as for R2NOC1, with adjustments for the reagent concentrations. Immediately upon completion of the precipitation four hour hold time, filtration was begun. The initial flux was $0.119 \mathrm{gpm} / \mathrm{ft}^{2}$, which was acceptable. However, the flux dropped very quickly to less than $0.03 \mathrm{gpm} / \mathrm{ft}^{2}$, and was less than $0.02 \mathrm{gpm} / \mathrm{ft}^{2}$ at 23 hours of processing. This batch was concentrated to a final insoluble solids concentration of $18.5 \mathrm{wt} \%$. The time-averaged flux was $0.013 \mathrm{gpm} / \mathrm{ft}^{2}$. A parallel precipitation and filtration was conducted in the pilot unit. The results from this run were even worse than the CUF results; within several hours, the flux had dropped below the minimum.

\subsubsection{Simulant Remediation 2 and Baseline Conditions}

The poor results for R2NOC2 prompted Project personnel to go back and try the baseline conditions with the R2 remediation. An 880L precipitation was performed at the EDL with the following conditions:

1. Caustic added to give 1.0M free hydroxide before $\mathrm{Sr}$ and $\mathrm{Mn}$ additions ( $0.8 \mathrm{M}$ added).

2. Sr added to $0.075 \mathrm{M}$

3. Mn added to $0.050 \mathrm{M}$

4. Temperature of $50^{\circ} \mathrm{C}$

About 41L of precipitate was then processed in the CUF. The initial average flux measured over the collection of the first 3L of permeate was $0.192 \mathrm{gpm} / \mathrm{ft}^{2}$. Extrapolation of the flux measurements back to the starting time gives an estimated initial flux of $0.25 \mathrm{gpm} / \mathrm{ft}^{2}$. This 
material was concentrated to about $18.8 \mathrm{wt} \%$ in about 14 hours. The final flux was 0.018 $\mathrm{gpm} / \mathrm{ft}^{2}$ and the time-averaged flux was $0.060 \mathrm{gpm} / \mathrm{ft}^{2}$.

\subsection{RESULTS}

\subsubsection{Simulant Formulations}

The initial experiments for this work used the WTP verbally approved simulant for the supernate and solids. Subsequent work on the supernate simulant formulation resulted in changes to the formulation. Optimization work on the Sr/TRU precipitation led the WTP to request additional filtration work be done with the updated supernate simulant and the "newly optimized conditions" Sr/TRU precipitation.

\subsubsection{Simulant Remediation 1}

The simulant formulations used for this work are summarized in Table 2 and Table $3{ }^{6}$ The simulant recipe on a per liter basis is shown in the Appendix. The supernate simulant used was a remediation of simulant purchased from Optima Chemicals. The remediation calculations were based on the recipe for the purchased simulant rather than on analytical measurements. Table 3 shows the predicted composition of a precipitated simulant batch and the measured composition of the first batch. This prediction is based on the simulant recipes, the amounts of precipitating reagents used, and assumed precipitation reactions. The elemental compositions were determined from a sodium peroxide fusion/ $\mathrm{HCl}$ uptake and aqua regia dissolution.

The raw analytical data was generally about $10 \%$ lower than the expected values for the elemental, IC, and carbon analyses, which suggests that the sample may have been more dilute than expected. However, the solids analyses matched well. To compare on a relative basis, the measured values were normalized so that the measured $\mathrm{Na}$ concentration equaled the calculated value. Good agreement was then found for $\mathrm{Al}, \mathrm{Ca}, \mathrm{Ni}, \mathrm{Cd}, \mathrm{Cr}, \mathrm{NO}_{3}^{-}, \mathrm{NO}_{2}^{-}$, $\mathrm{Cl}^{-}, \mathrm{SO}_{4}^{-2}$, and formate. Both $\mathrm{Mn}$ and $\mathrm{Sr}$ were 15-20\% lower than expected based on the reagent additions. Phosphorus and phosphate were low by about 33 and $24 \%$, which indicates that the phosphate was precipitated from the simulant prior to the precipitation. These concentrations could be low due to formation of insoluble sodium fluorophosphate $\left(\mathrm{Na} 7 \mathrm{~F}\left(\mathrm{PO}_{4}\right)_{2}\right)$ that was identified as a precipitate during simulant development. ${ }^{6}$ The fluoride concentration was high by about $33 \%$, but this value is inconsistent with the calculated value, values from later simulant remediations (see Table 4), and permeate compositions (see Table 11). The fluoride concentrations measured in the permeates tend to indicate that the fluoride content of the simulant may have actually been less than the calculated value, which would be consistent with the formation of the fluorophosphate. If phosphate and fluoride precipitated from the simulant and were not quantitatively transferred with the bulk of the liquid, low values would result.

Iron was about six times higher than expected. Potassium measurements on dissolved samples by ICPES were unreliable, so the measured value should be discarded. The test specification called for potassium analysis by ICPES, but SRTC would recommend for future work that it be measured by atomic absorption (AA). The higher than expected barium 
concentration is probably due to a contamination problem in the preparation of the samples for analysis; higher than expected values have been seen in other samples in other programs. The high value for oxalate is probably the result of the permanganate oxidation of the organic materials; oxalate is a likely product of these reactions. Duplicate analyses for total and insoluble solids were performed. The calculated insoluble solids (IS) in the table was based on the assumption that all added $\mathrm{Sr}$ formed $\mathrm{SrCO}_{3}$ and all $\mathrm{NaMnO}_{4}$ formed $\mathrm{MnO}_{2}$. This assumption should give an approximate upper bound for the amount of anhydrous solids formed during the precipitation; hydration of the precipitated material and also the initial insoluble solids may account for the measured values $(1.60,1.88 \mathrm{wt} \%)$ being higher than the calculated value $(1.45 \mathrm{wt} \%)$. The formation of heavier $\mathrm{Sr}$ compounds such as $\mathrm{SrHPO}_{4}$, $\mathrm{SrFPO}_{4}$, or $\mathrm{SrSO}_{4}$ would be consistent with the higher measured solids values. However, no measurements were made to determine if these compounds actually were formed.

The solids simulant composition is shown in Table 2. The solids simulant was added to the supernate simulant to give $0.1 \mathrm{wt} \%$ of solids simulant. Some of the solids were purchased material and most of the oxalates and the $\mathrm{FeOOH}$ were made in the laboratory from reagent grade chemicals. This solids simulant formulation was used for all of the runs.

Table 2 Approved Solids Simulant Formulation

\begin{tabular}{|c|c|c|}
\hline Solid & $\begin{array}{c}\mathrm{g} / 100 \mathrm{~g} \\
\text { solids }\end{array}$ & Source \\
\hline $\mathrm{Al}_{2} \mathrm{O}_{3}$ & 15.12 & Reagent \\
\hline $\mathrm{BaSO}_{4}$ & 0.02 & $\mathrm{Ba}\left(\mathrm{NO}_{3}\right)_{2}+\mathrm{Na}_{2} \mathrm{SO}_{4}$ \\
\hline $\mathrm{CaC}_{2} \mathrm{O}_{4} \cdot \mathrm{H}_{2} \mathrm{O}$ & 0.13 & $\mathrm{Ca}\left(\mathrm{NO}_{3}\right)_{2}+\mathrm{Na}_{2} \mathrm{C}_{2} \mathrm{O}_{4}$ \\
\hline $\mathrm{CaWO}_{4}$ & 0.11 & Reagent \\
\hline $\mathrm{Na}_{2} \mathrm{CO}_{3} \cdot \mathrm{H}_{2} \mathrm{O}$ & 42.71 & Reagent \\
\hline $\mathrm{Ce}_{2}\left(\mathrm{C}_{2} \mathrm{O}_{4}\right)_{3} \cdot 9 \mathrm{H}_{2} \mathrm{O}$ & 0.02 & $\mathrm{Ce}\left(\mathrm{NO}_{3}\right)_{4}+\mathrm{Na}_{2} \mathrm{C}_{2} \mathrm{O}_{4}$ \\
\hline $\mathrm{Cr}_{2} \mathrm{O}_{3}$ & 0.93 & Reagent \\
\hline $\mathrm{NaF}$ & 3.15 & Reagent \\
\hline $\mathrm{FeOOH}$ & 0.68 & $\mathrm{Fe}\left(\mathrm{NO}_{3}\right)_{3}+\mathrm{NaOH}$ \\
\hline $\mathrm{La}_{2}\left(\mathrm{C}_{2} \mathrm{O}_{4}\right)_{3} .9 \mathrm{H}_{2} \mathrm{O}$ & 0.02 & $\mathrm{La}\left(\mathrm{NO}_{3}\right)_{3}+\mathrm{Na}_{2} \mathrm{C}_{2} \mathrm{O}_{4}$ \\
\hline $\mathrm{PbSO}_{4}$ & 0.08 & Reagent \\
\hline $\mathrm{MnO}_{2}$ & 0.15 & Reagent \\
\hline $\mathrm{Nd}_{2}\left(\mathrm{C}_{2} \mathrm{O}_{4}\right)_{3} \cdot 10 \mathrm{H}_{2} \mathrm{O}$ & 0.04 & $\mathrm{Nd}\left(\mathrm{NO}_{3}\right)_{3}+\mathrm{Na}_{2} \mathrm{C}_{2} \mathrm{O}_{4}$ \\
\hline $\mathrm{NiO}$ & 0.01 & Reagent \\
\hline $\mathrm{Na}_{2} \mathrm{C}_{2} \mathrm{O}_{4}$ & 16.1 & Reagent \\
\hline $\mathrm{Na}_{3} \mathrm{PO}_{4} \cdot 12 \mathrm{H}_{2} \mathrm{O}$ & 12.28 & Reagent \\
\hline $\mathrm{SiO}_{2}$ & 0.05 & Reagent \\
\hline $\mathrm{Na}_{2} \mathrm{SO}_{4}$ & 8.35 & Reagent \\
\hline $\mathrm{ZnC}_{2} \mathrm{O}_{4} \cdot 2 \mathrm{H}_{2} \mathrm{O}$ & 0.02 & Reagent \\
\hline $\mathrm{ZrO}_{2}$ & 0.02 & Reagent \\
\hline \multicolumn{3}{|c|}{99.99} \\
\hline
\end{tabular}

\subsubsection{Simulant Remediation 2}

The R2 remediation formulation is given in the Appendix. Several measurements of the composition of this remediated material were made by the EDL and are shown in Table 4. Remediation batch "3C" from the EDL was used for the R2NOC CUF runs (and also R2BC small). Batch "3B" was used for the R2BCL CUF run. 
WSRC-TR-2003-00056, REV. 0

SRT-RPP-2002-00231, REV. 0

Table 3 Calculated and Measured Composition of R1BC Precipitate Slurry Feed Batch \#1

\begin{tabular}{|c|c|c|c|}
\hline & $\begin{array}{c}\text { Calculated } \\
\text { from Batching }\end{array}$ & Measured & $\begin{array}{l}\text { Measured / } \\
\text { Calculated }\end{array}$ \\
\hline \multirow[t]{32}{*}{ ICPES (mg/L) } & 7670 & 7540 & 0.98 \\
\hline & 22.9 & $<92$ & $<4.02$ \\
\hline & 0.1 & 189 & 1630 \\
\hline & 306 & 306 & 1.00 \\
\hline & 37.9 & 36.1 & 0.95 \\
\hline & 2.1 & $<35$ & $<16.8$ \\
\hline & 160 & 162 & 1.02 \\
\hline & 15.1 & $<35$ & $<2.32$ \\
\hline & 30.2 & 196 & 6.50 \\
\hline & 0 & $<47$ & $<47.0$ \\
\hline & 0 & $<41$ & NA \\
\hline & 2770 & 2320 & 0.84 \\
\hline & 28.1 & $<69$ & $<2.46$ \\
\hline & 135000 & 135000 & 1.00 \\
\hline & 260 & 270 & 1.04 \\
\hline & 1140 & 768 & 0.67 \\
\hline & 116 & $<302$ & $<2.61$ \\
\hline & 6.5 & $<69$ & $<10.7$ \\
\hline & 0 & $<163$ & NA \\
\hline & 6570 & 5360 & 0.81 \\
\hline & 0 & $<69$ & NA \\
\hline & 0 & $<69$ & NA \\
\hline & 3.2 & $<163$ & $<50.9$ \\
\hline & 8.5 & $<23$ & $<2.72$ \\
\hline & 9.9 & $<324$ & $<32.6$ \\
\hline & 1270 & 293 & 0.23 \\
\hline & 2640 & NM & NA \\
\hline & 19.9 & $<232$ & $<11.7$ \\
\hline & 0.1 & NM & NA \\
\hline & 9.9 & NM & NA \\
\hline & 5.2 & NM & NA \\
\hline & 105 & NM & NA \\
\hline \multirow{8}{*}{$\begin{array}{r}\mathrm{NO}_{3}^{-} \\
\mathrm{Cl}- \\
\mathrm{F}- \\
\mathrm{PO}_{4}^{-3} \\
\mathrm{SO}_{4}^{-2} \\
\text { formate } \\
\text { oxalate }\end{array}$} & 48100 & 50900 & 1.06 \\
\hline & 137000 & 134000 & 0.98 \\
\hline & 2980 & 3030 & 1.02 \\
\hline & 1080 & 1440 & 1.33 \\
\hline & 3500 & 2680 & 0.76 \\
\hline & 7910 & 7590 & 0.96 \\
\hline & 5240 & 5770 & 1.10 \\
\hline & 397 & 1960 & 4.94 \\
\hline \multirow{3}{*}{$\begin{array}{r}\text { Carbon }(\mathrm{mg} / \mathrm{L}) \text { Total Organic Carbon } \\
\text { Total Inorganic Carbon } \\
\text { Total Carbon } \\
\end{array}$} & $\mathrm{NC}$ & 6220 & NA \\
\hline & $\mathrm{NC}$ & 4950 & NA \\
\hline & $\mathrm{NC}$ & 11100 & NA \\
\hline Total Solids (wt $\%)$ & $34.1-34.5$ & $33.1,33.6$ & $0.96-0.99$ \\
\hline Insoluble Solids (wt $\%)$ & 1.45 & $1.60,1.88$ & $0.77-0.91$ \\
\hline $\begin{array}{l}\text { NM: not measured NA: not available } \\
\leq: \text { measurement below detection limit }\end{array}$ & NC: not c & lated & \\
\hline
\end{tabular}


Table 4 Composition of Batches 3B and 3C Simulant

\begin{tabular}{|c|c|c|}
\hline & Batch 3C & Batch 3B \\
\hline ICPES (mg/L) & 9110 & 9880 \\
\hline B & 39.1 & 37.5 \\
\hline $\mathrm{Ba}$ & $<0.01$ & 0.45 \\
\hline $\mathrm{Ca}$ & 395 & 418 \\
\hline $\mathrm{Cd}$ & 38.5 & 33.8 \\
\hline $\mathrm{Ce}$ & 28.7 & 28.9 \\
\hline Co & 1.11 & 1.76 \\
\hline $\mathrm{Cr}$ & 154 & 158 \\
\hline $\mathrm{Cu}$ & 7.3 & 7.1 \\
\hline $\mathrm{Fe}$ & 33.4 & 27.8 \\
\hline $\mathrm{K}$ & 2530 & 3180 \\
\hline $\mathrm{La}$ & 26.7 & 21.9 \\
\hline $\mathrm{Mg}$ & 0.53 & 1.48 \\
\hline $\mathrm{Mn}$ & 18.6 & 14.6 \\
\hline Mo & 31.6 & 29.8 \\
\hline $\mathrm{Na}$ & 134000 & 140000 \\
\hline $\mathrm{Nd}$ & 33.4 & 47.1 \\
\hline $\mathrm{Ni}$ & 258 & 272 \\
\hline $\mathrm{P}$ & 748 & 643 \\
\hline $\mathrm{Pb}$ & 68.3 & 58.4 \\
\hline $\mathrm{S}$ & 3200 & 3550 \\
\hline $\mathrm{Sr}$ & 0.52 & 5.35 \\
\hline $\mathrm{Si}$ & 42.6 & 37.7 \\
\hline W & 131 & 142 \\
\hline $\mathrm{Zn}$ & 4.9 & 4.0 \\
\hline $\mathrm{Zr}$ & 9.2 & 7.0 \\
\hline Ion Chrom. (mg/L) $\mathrm{NO}_{2}^{-}$ & 54500 & 54500 \\
\hline $\mathrm{NO}_{3}^{-}$ & 137000 & 137000 \\
\hline $\mathrm{Cl}-$ & 3700 & 3690 \\
\hline F- & 921 & 920 \\
\hline $\mathrm{PO}_{4}^{-3}$ & 1970 & 1970 \\
\hline $\mathrm{SO}_{4}^{-2}$ & 10400 & 10300 \\
\hline formate & 7350 & 7340 \\
\hline oxalate & 343 & $<1000$ \\
\hline Free $\mathrm{OH}-(\mathrm{M})$ & 0.228 & 0.203 \\
\hline Total Base (M) & 1.61 & 1.70 \\
\hline Specific Gravity & 1.32 & 1.32 \\
\hline
\end{tabular}

\subsubsection{Precipitations}

The batching calculations for the precipitation reactions are summarized in Table 5. A total of nine precipitation batches were prepared. The initial volume of a precipitation batch was 5.0L. As discussed in Section 1.2.1, the added hydroxide concentration target used was 0.9M rather than 1.0M. In addition, an error in batching the $\mathrm{NaOH}$ was made. The added $\mathrm{NaOH}$ 
was based on increasing the hydroxide concentration from zero $\mathrm{M}$ to $0.9 \mathrm{M}$, but more accurately should have been based on inc reasing it from $0.3 \mathrm{M}$ to $1.2 \mathrm{M}(0.9 \mathrm{M}$ added $)$. The initial free hydroxide concentration was assumed to be about $0.3 \mathrm{M}$, based on the formulation. Free hydroxide concentration in the simulant was not measured, so the final free hydroxide concentration is only an estimate. Table 6 shows a comparison of the actual and target reagent use. These errors introduced by the calculations should be smaller than the uncertainty in the initial hydroxide concentration. The final calculated free hydroxide concentration was $1.13 \mathrm{M}$ versus the target of $1.20 \mathrm{M}$; the correct final value would be $1.3 \mathrm{M}$ based on $1 \mathrm{M}$ added hydroxide. The concentrations of $\mathrm{Sr}, \mathrm{Mn}$, and $\mathrm{Na}$ were correct to two decimal places. The final volume of the precipitate was about 6.5 liters.

Table 5 Summary of Reagents for R1BC (per 5L of Simulant)

\begin{tabular}{|c|c|c|c|}
\hline Initial Volume (L) & 5.0 & Final $\mathrm{Na}(\mathrm{M})$ & 5.93 \\
\hline Initial $\mathrm{Na}(\mathrm{M})$ & 6.53 & Final $\mathrm{OH}(\mathrm{M})$ & $1.13 * *$ \\
\hline Estimated Initial OH- (M) & 0.300 & Final Sr (M) & 0.075 \\
\hline $\operatorname{Sr}\left(\mathrm{NO}_{3}\right)_{2}$ reagent $(\mathrm{M})$ & 1.00 & Final NaMnO4 (M) & 0.050 \\
\hline $\mathrm{NaMnO}_{4}$ reagent $(\mathrm{M})$ & 1.128 & & \\
\hline \multirow[t]{2}{*}{$\mathrm{NaOH}$ reagent $(\mathrm{M})$} & 19.17 & Water added $(\mathrm{mL})$ & 439.2 \\
\hline & & $\mathrm{NaOH}$ added $(\mathrm{mL})$ & 306.4 \\
\hline Target $\mathrm{Na}$ after water addition (M) & 6.00 & $\mathrm{Sr}\left(\mathrm{NO}_{3}\right)_{2}$ added $(\mathrm{mL})$ & 489.3 \\
\hline Target final OH- $(\mathrm{M})$ & 1.20 & $\mathrm{NaMnO}_{4}$ added $(\mathrm{mL})$ & 289.2 \\
\hline Target final $\mathrm{Sr}(\mathrm{M})$ & 0.075 & Total volume added $(\mathrm{mL})$ & 1524.1 \\
\hline \multirow[t]{2}{*}{ Target final $\mathrm{NaMnO} 4(\mathrm{M})$} & 0.050 & & \\
\hline & & Final volume (L) & 6.55 \\
\hline \multirow[t]{3}{*}{ Actual $\mathrm{Na}$ after water addition (M) } & 6.00 & & \\
\hline & & Estimated density $(\mathrm{kg} / \mathrm{L})$ & 1.268 \\
\hline & & Estimated Total Solids (wt\%) & 34.07 \\
\hline
\end{tabular}

** Target was 1.20; value low due to calculation error.

One precipitate batch was allowed to settle overnight. The volume of the settled solids was about $30 \%$ of the total volume. The liquid above the solids was very clear. If the liquid above the settled slurry solids was decanted, an immediate concentration of the slurry from about $1.5 \mathrm{wt} \%$ insoluble solids to about $4.5 \mathrm{wt} \%$ could have been achieved. The decanted liquid should filter essentially like clear permeate would. A movie of the re-suspension of the settled batch is contained in the report CD-ROM ("Slurry-Resuspension.mpg").

During several of the precipitations, evolution of ammonia gas was noted by its odor. Later work on precipitation of a $115 \mathrm{~L}$ batch confirmed that ammonia was formed. Ammonia is likely formed from the oxidation by the permanganate of the disodium ethylenediamine tetraacetate (NaEDTA), n-(2-hydroxyethyl)ethylenediaminetriacetic acid (HEDTA), and ammonium acetate. The odor was quite strong, but it only takes about $10 \mathrm{ppm}$ of ammonia to be detected by its odor. Since the amount of ammonia generated was not determined, the WTP may want to consider quantifying the amount formed or determining an upper bound for its formation. Ammonia is flammable, with a lower flammable limit of about $15 \%$ and an upper flammable limit of about $25 \%$. By itself, ammonia is rarely flammable due to its high auto-ignition temperature of about $650^{\circ} \mathrm{C}$. However, in the presence of hydrogen from 
radiolysis, it may be a concern. Alternatively, the evolution of ammonia into the WTP vent system may need to be accounted for to meet environmental release limits or for permitting.

\section{Table 6 Precipitation Reagent Quantities for R1BC}

\begin{tabular}{|c|c|c|c|}
\hline & $\begin{array}{l}\text { Correct } \\
\text { Batching }\end{array}$ & $\begin{array}{c}\text { Batching } \\
\text { Calculation } \\
\text { Used }\end{array}$ & $\begin{array}{c}\text { Actual } \\
\text { Batching } \\
\text { Used }\end{array}$ \\
\hline \multirow{4}{*}{$\begin{array}{r}\text { Final } \mathrm{Na}(\mathrm{M}) \\
\text { Final } \mathrm{OH}(\mathrm{M}) \\
\text { Final Sr }(\mathrm{M}) \\
\text { inal } \mathrm{NaMnO} 4(\mathrm{M})\end{array}$} & 6.00 & 5.95 & 5.95 \\
\hline & 1.20 & 0.900 & 1.13 \\
\hline & & 0.0750 & 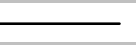 \\
\hline & & 0.0500 & 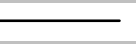 \\
\hline Water added $(\mathrm{mL})$ & 439.2 & 439.2 & 439.2 \\
\hline $\mathrm{NaOH}$ added $(\mathrm{mL})$ & 332.0 & 306.4 & 306.4 \\
\hline $\mathrm{Sr}\left(\mathrm{NO}_{3}\right)_{2}$ added $(\mathrm{mL})$ & 491.5 & 489.3 & 489.3 \\
\hline $\mathrm{NaMnO}_{4}$ added $(\mathrm{mL})$ & 290.5 & 289.2 & 289.2 \\
\hline Final volume, estimated (L) & 6.55 & 6.52 & 6.52 \\
\hline
\end{tabular}

The R2NOC runs all used the same precipitation recipe, as shown in Table 7. The Batch 3C simulant for from the EDL contained about $0.23 \mathrm{M}$ hydroxide before dilution and entrained solids addition.

Table 7 Summary of Reagents for RNOC1 and R2NOC2

\begin{tabular}{|c|c|c|c|}
\hline Initial Volume (L) & 115 & Final $\mathrm{Na}(\mathrm{M})$ & 5.65 \\
\hline Initial $\mathrm{Na}(\mathrm{M})$ & 6.53 & Final OH (M) & 0.258 \\
\hline Estimated Initial OH- (M) & 0.300 & Final Sr (M) & 0.030 \\
\hline $\mathrm{Sr}\left(\mathrm{NO}_{3}\right)_{2}$ reagent $(\mathrm{M})$ & 1.00 & Final NaMnO4 (M) & 0.030 \\
\hline $\mathrm{NaMnO}_{4}$ reagent $(\mathrm{M})$ & 0.976 & & \\
\hline \multirow[t]{2}{*}{$\mathrm{NaOH}$ reagent $(\mathrm{M})$} & 19.17 & Water added (L) & 10.10 \\
\hline & & $\mathrm{NaOH}$ added (L) & 0 \\
\hline Target $\mathrm{Na}$ after water addition $(\mathrm{M})$ & 6.00 & $\mathrm{Sr}\left(\mathrm{NO}_{3}\right)_{2}$ added $(\mathrm{L})$ & 4.01 \\
\hline Target final $\mathrm{OH}-(\mathrm{M})$ & NA & $\mathrm{NaMnO}_{4}$ added (L) & 4.11 \\
\hline Target final Sr (M) & 0.030 & Total volume added (L) & 18.21 \\
\hline \multirow[t]{2}{*}{ Target final NaMnO4 (M) } & 0.030 & & \\
\hline & & Final volume (L) & 133.6 \\
\hline \multirow[t]{3}{*}{ Actual $\mathrm{Na}$ after water addition (M) } & 6.00 & & \\
\hline & & Estimated density (kg/L) & 1.270 \\
\hline & & Estimated Total Solids (wt\%) & 34.26 \\
\hline
\end{tabular}

The R2BCL run precipitation was performed by the EDL on approximately $880 \mathrm{~L}$ of Batch 3B simulant. The precipitation recipe is shown in Table 8. 
Table 8 Summary of Reagents for R2BCL

\begin{tabular}{|rc|rc|}
\hline Initial Volume (L) & 880 & Final Na (M) & 5.94 \\
Initial Na (M) & 6.0 & Final OH (M) & 0.866 \\
\hline Estimated Initial OH- (M) & 0.20 & Final Sr (M) & 0.030 \\
\hline $\mathrm{Sr}_{\left(\mathrm{NO}_{3}\right)_{2} \text { reagent (M) }}$ & 1.00 & Final NaMnO4 (M) & 0.030 \\
\hline $\mathrm{NaMnO}_{4}$ reagent (M) & 1.00 & Water added (L) & 0 \\
\hline $\mathrm{NaOH}$ added as solid & $\mathrm{NA}$ & $\mathrm{NaOH}$ added (kg) & 28200 \\
\hline & & $\mathrm{Sr}\left(\mathrm{NO}_{3}\right)_{2}$ added (L) & 75.43 \\
\hline $\begin{array}{r}\text { Target final OH- (M) } \\
\text { (prior to Sr \& Mn additions) }\end{array}$ & 1.00 & $\mathrm{NaMnO}_{4}$ added (L) & 49.06 \\
\hline Target final Sr (M) & 0.075 & & \\
\hline Target final NaMnO4 (M) & 0.050 & Final volume (L) & 1006 \\
\hline & & & \\
\hline & & Estimated density $(\mathrm{kg} / \mathrm{L})$ & 1.30 \\
\hline
\end{tabular}

\subsubsection{Concentration of Precipitated Simulants - Composition and Properties}

\subsubsection{Remediation 1-Baseline Conditions}

The Sr/TRU precipitates from precipitation batches \#1 and \#5 were analyzed for rheology, total solids, suspended solids, and particle size distribution. Batch \#1 was also analyzed for elements, anions, and carbon as previously described. The major difference between batch \#1 and batch \#5 is that batch \#1 had been subjected to the entire factorial matrix of filtration tests, whereas batch \#5 was fresh material from the precipitator. A comparison of the solids concentrations is shown in Table 9.

Table 9 Solids Content of R1BC Precipitate Batches and Concentrated Slurry

\begin{tabular}{|c|c|c|c|c|c|}
\hline & $\begin{array}{c}\text { Total } \\
\text { Solids } \\
\text { (wt } \%)\end{array}$ & \multicolumn{4}{|c|}{ Insoluble Solids (wt\%) } \\
\hline Simulant (Supernate + Solids) & not meas. & $\begin{array}{c}0.10 \\
\text { from } \\
\text { batching }\end{array}$ & $\begin{array}{c}0.31 \\
\text { measured }\end{array}$ & $\begin{array}{l}0.49 \\
\text { calc. }\end{array}$ & $\begin{array}{l}0.85 \\
\text { calc. }\end{array}$ \\
\hline Calculated Precipitate Batch & 34.5 & 1.29 & 1.45 & & \\
\hline Measured Precipitate Batch \#5 (fresh precipitate) & 33.6 & & & 1.60 & \\
\hline Measured Precipitate Batch \#1 (subjected to filtration) & 33.1 & & & & 1.88 \\
\hline Measured Concentrated Slurry & 42.1 & 13.33 & & & \\
\hline Measured Concentrated Slurry & 45.0 & 17.17 & & & \\
\hline Measured Washed Concentrated Slurry & 35.1 & 20.63 & & & \\
\hline
\end{tabular}

The estimated and measured total solids concentrations agree well. There are four columns for insoluble solids. The first shows that the expected insoluble solids in the precipitate batch was $1.29 \mathrm{wt} \%$ which $\dot{\mathrm{s}}$ based on the addition of $0.1 \mathrm{wt} \%$ sludge solids to the supernate simulant. However, the supernate simulant actually contained some insoluble solids; the measured value was $0.31 \mathrm{wt} \%$, which results in a calculated insoluble solids after precipitation of $1.45 \mathrm{wt} \%$. The measured insoluble solids in the precipitate $(1.60,1.88 \mathrm{wt} \%)$ 
were used to back-calculate the incoming insoluble solids concentrations, which were 0.49 and $0.85 \mathrm{wt} \%$. Based on these data, a reasonable estimate of the insoluble solids concentration in the simulant is $0.31-0.49 \mathrm{wt} \%$ and in the precipitate it is $1.45-1.60 \mathrm{wt} \%$.

To determine if the measured total and insoluble solids contents of the concentrated slurries were consistent, they were checked using the starting total and insoluble solids concentrations in the precipitate batches and calculating the increase in solids as these precipitate feed batches were added and concentrated. Based on a precipitate insoluble solids content of $1.60 \mathrm{wt} \%$, the volume and total solids content of the concentrated slurry was calculated for insoluble solids concentrations of 13.33 and $17.17 \mathrm{wt} \%$. This same calculation was also performed for the washing and re-concentration step. The results of these calculations are shown in Table 10. The total solids concentrations and concentrated slurry volumes calculated match the measured values very well, so the data is consistent.

Note that the initial goal for the dewatering step was $15 \mathrm{wt} \%$ insoluble solids, but the actual value reached initially was about $19.3 \mathrm{wt} \%$. The overshoot occurred because of the assumption that the precipitate feed batches would be approximately $1 \mathrm{wt} \%$ rather than $1.45-$ $1.60 \mathrm{wt} \%$. After it was apparent that the solids concentration was higher than expected, the slurry was diluted with permeate back to $17.2 \mathrm{wt} \%$ (the goal here was again $15 \mathrm{wt} \%$, but the actual wt $\%$ insoluble solids was not known, so the dilution was based on an estimate).

Table 10 R1BC Measured and Calculated Solids Content and Volume

\begin{tabular}{|c|c|c|c|c|c|c|c|c|}
\hline & \multirow{2}{*}{$\begin{array}{c}\text { Typical } \\
\text { Batch ** }\end{array}$} & \multicolumn{2}{|c|}{$\begin{array}{l}\text { Nine Batches } \\
\text { Concentrated to } \\
13.3 \mathrm{wt} \% \text { IS }\end{array}$} & \multicolumn{2}{|c|}{$\begin{array}{l}\text { Concentrated to } \\
17.2 \mathrm{wt} \% \text { IS }\end{array}$} & \multirow{2}{*}{$\begin{array}{l}\text { Wash } \\
\text { Water } \\
\text { Added }\end{array}$} & \multicolumn{2}{|c|}{$\begin{array}{l}\text { Concentrated to } \\
20.63 \mathrm{wt} \% \text { IS }\end{array}$} \\
\hline & & Calculated & Measured & Calculated & Measured & & Calculated & Measured \\
\hline Volume $\quad \mathrm{L}$ & 6.55 & 6.44 & approx. 6.5 & 4.69 & $\begin{array}{l}\text { approx. } \\
4.6\end{array}$ & 9.19 & 4.26 & $\begin{array}{l}\text { approx. } \\
4.2\end{array}$ \\
\hline Estimated Density kg/L & 1.27 & 1.36 & & 1.40 & & 1.19 & 1.28 & \\
\hline Insoluble Solids $\mathrm{g}$ & 130 & 1169 & $* *$ & 1124 & & 1124 & 1124 & \\
\hline Total Solids & 2778 & 3677 & & 2912 & & 2912 & 1903 & \\
\hline Total Mass $\mathrm{g}$ & 8153 & 8770 & & 6544 & & 11044 & 5446 & \\
\hline Insoluble Solids wt $\%$ & 1.60 & 13.33 & 13.33 & 17.17 & 17.17 & 10.17 & 20.63 & 20.63 \\
\hline Total Solids wt $\%$ & 34.07 & 41.93 & 42.14 & 44.50 & 44.98 & 26.37 & 34.94 & 35.06 \\
\hline
\end{tabular}

** 0.125 to $0.250 \mathrm{~L}$ samples removed from each batch

Permeate samples were taken during the initial factorial experiments (at 1.45-1.60 wt\% insoluble solids), during concentration at approximately 13.3 and $17.2 \mathrm{wt} \%$ insoluble solids, and during concentration of the washed slurry. The compositions of the permeate samples (except the washed slurry) should be essentially identical and the soluble components should be similar to the precipitate composition. The permeate concentrations are summarized in Table 11. To within the accuracy of the measurements, the permeate composition in R1BC did not change as the slurry was concentrated. 
Table 11 R1BC Permeate Compositions During Concentration

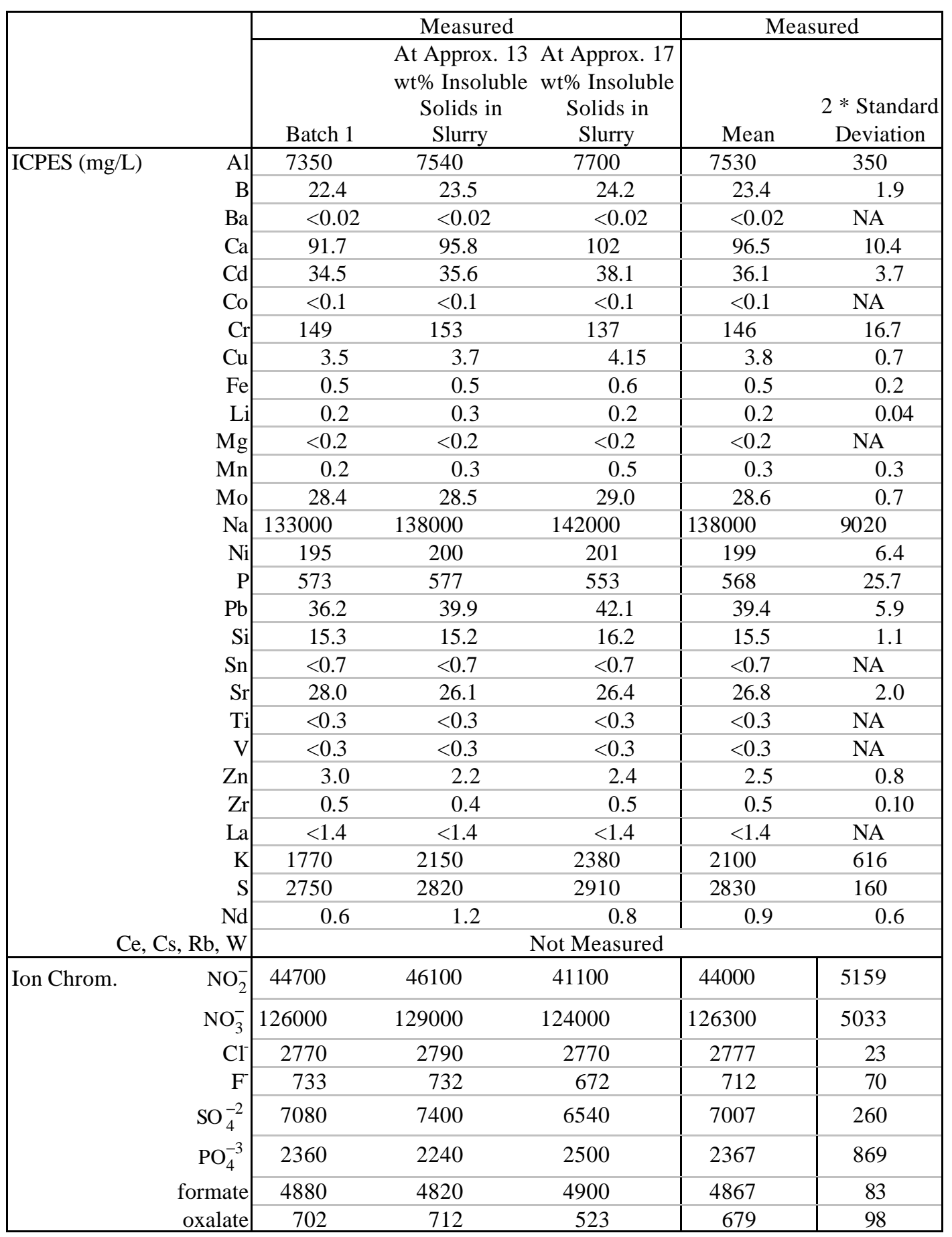

The permeate samples from the concentration of the unwashed R1BC slurry were all initially yellowish in color, with no discernable orange or red tint. The permeates produced from the R2NOC precipitates all were much more orange-red in tint and were much darker. The R2BC permeates were yellowish like R1, but a with little bit of an orange tint. 
After about 2-4 days, the color of the R1BC permeate changed to a greenish tint. The other permeates also showed similar color changes, but the greenish color was not as intense. For all samples, within about one week, a dark brown precipitate coated the bottle surfaces, but the permeate liquid remained transparent. Table 12 shows the turbidity measured for several permeate samples. The samples were not shaken before measurements were made because the initial permeates were transparent and shaking would have released the post-precipitated solids from the bottle surfaces. Measurement of the turbidity immediately after filtration would have been ideal, but was not possible. All permeate samples had turbidities of less than 4 NTU, even after standing. At SRS, turbidities of less than 5 NTU are considered to indicate that no breakthrough of particles has occurred in the filter.

\section{Table 12 Turbidity of Permeates}

\begin{tabular}{|crc|}
\hline Run & Permeate from Batch \#1 & $\begin{array}{c}\text { Turbidity } \\
\text { (NTU) }\end{array}$ \\
\hline R1BC & $<1$ \\
\hline & Permeate at 13.3 wt\% IS & 1.34 \\
\hline & Permeate at 17.2 wt\% IS & 3.80 \\
\hline R2NOC1 & Permeate from Washed Slurry & 1.80 \\
\hline R2NOC2 & Initial Permeate & 0.09 \\
\hline & Intermedial Permeate & 0.40 \\
\hline & Intermediate Permeate & 0.86 \\
\hline R2BCL & Permeate at 18.4 wt\% IS & 1.00 \\
\hline & Initial Permeate & 0.35 \\
\hline & Permeate at 14.5 wt\% IS & 0.30 \\
\hline & Permeate at 18.8 wt\% IS & 0.36 \\
\hline
\end{tabular}

\subsubsection{Remediation 2 - Newly Optimized Conditions Run 2 (R2NOC2)}

The R2NOC2 precipitate was concentrated from an initial $1.32 \mathrm{wt} \%$ insoluble solids to a final $18.48 \mathrm{wt} \%$. Table 13 summarizes the measured and calculated solids concentrations and specific gravities.

Table 13 Summary of R2NOC2 Solids Contents

\begin{tabular}{|rcccc|}
\hline \multicolumn{1}{|c|}{$\begin{array}{c}\text { Total } \\
\text { Solids } \\
\text { (wt\%) }\end{array}$} & $\begin{array}{c}\text { Insoluble } \\
\text { Solids } \\
\text { (wt\%) }\end{array}$ & $\begin{array}{c}\text { Specific } \\
\text { Gravity }\end{array}$ & $\begin{array}{c}\text { Volume } \\
\text { in Feed } \\
\text { Tank (L) }\end{array}$ \\
\hline Simulant: Measured & 35.87 & $0.2-0.62$ & NM & \\
\hline Simulant: Calculated & 36.98 & 0.86 & 1.30 & \\
\hline Precipitate: Measured & 33.60 & 1.32 & 1.26 & \\
\hline Precipitate: Calculated * & 33.6 & 1.32 & 1.26 & \\
\hline Concentrated Slurry: Measured & 42.50 & 12.30 & 1.37 & approx. 6 \\
\hline Concentrated Slurry: Calculated & 40.99 & $12.30 *$ & 1.35 & 6.00 \\
\hline Concentrated Slurry: Measured & 47.36 & 18.48 & NM & approx. 4 \\
\hline Concentrated Slurry: Calculated & 45.15 & $18.48 *$ & 1.41 & 3.84 \\
\hline
\end{tabular}

* Calculated set equal to measured. $\mathrm{NM}=$ not measured. 
In the calculations, the initial measured precipitate solids contents were used to predict the concentrated slurry. The calculated total solids for the concentrated slurries were 1-2 wt $\%$ low when the calculated insoluble solids concentrations were set to equal the measured values. The volume calculated for the final slurry (3.84L) matches the observed approximately $4 \mathrm{~L}$ value.

The measured compositions of the precipitate slurry and permeate generated are given in Table 14. The precipitate from $\mathrm{R} 2 \mathrm{NOC} 1$ is also shown. Elemental analysis measurements from the peroxide fusion $\left(\mathrm{Na}_{2} \mathrm{O}_{2}\right)$ and aqua regia dissolutions agree well.

Table 14 R2NOC Slurry and Permeate Compositions

\begin{tabular}{|c|c|c|c|c|c|}
\hline & \multicolumn{4}{|c|}{ Slurries } & \multirow{2}{*}{$\begin{array}{l}\text { Permeate } \\
\text { R2NOC2 } \\
\end{array}$} \\
\hline & \multicolumn{2}{|c|}{ R2NOC1 } & \multicolumn{2}{|c|}{ R2NOC2 } & \\
\hline Dissolution: & $\mathrm{Na}_{2} \mathrm{O}_{2}$ & Aqua Regia & $\overline{\mathrm{Na}_{2} \mathrm{O}_{2}}$ & $\begin{array}{l}\text { Aqua Regia } \\
\end{array}$ & \\
\hline ICPES (mg/L) Al & 8880 & 8810 & 8850 & 86010 & 8980 \\
\hline $\mathrm{B}$ & 66.7 & 74.2 & $<93$ & $<38$ & 28 \\
\hline $\mathrm{Ba}$ & $<6$ & $<6$ & 40.3 & 19.9 & $<0.02$ \\
\hline $\mathrm{Ca}$ & 508 & 376 & 1110 & 296 & 89 \\
\hline $\mathrm{Cd}$ & 42.4 & 43.4 & 46.6 & 44.4 & 41 \\
\hline $\mathrm{Co}$ & $<13$ & $<13$ & $<21$ & $<13$ & $<0.2$ \\
\hline $\mathrm{Cr}$ & 308 & 186 & 195 & 152 & 146 \\
\hline $\mathrm{Cu}$ & 22.2 & 21.0 & $<21$ & 16.2 & 7 \\
\hline $\mathrm{Fe}$ & 531 & 49.7 & 202 & 77.7 & 3 \\
\hline $\mathrm{Li}$ & $<26$ & $<26$ & $<42$ & $<25$ & $<0.2$ \\
\hline $\mathrm{Mg}$ & 18.0 & 19.9 & $<36$ & 19.8 & $<0.2$ \\
\hline $\mathrm{Mn}$ & 1680 & 1730 & 1930 & 1800 & 12 \\
\hline $\mathrm{Mo}$ & 42.6 & 29.2 & 41.2 & 34.6 & 35 \\
\hline $\mathrm{Na}$ & NA & 134000 & NA & 129000 & 136000 \\
\hline $\mathrm{Ni}$ & 391 & 305 & 341 & 307 & 275 \\
\hline $\mathrm{P}$ & 2790 & 2250 & 1390 & 1040 & 775 \\
\hline $\mathrm{Pb}$ & $<195$ & $<195$ & $<296$ & $<252$ & 47 \\
\hline $\mathrm{Si}$ & 48.9 & $<26$ & 149 & 27.0 & 27 \\
\hline $\mathrm{Sn}$ & $<65$ & $<65$ & $<127$ & $<63$ & 1 \\
\hline $\mathrm{Sr}$ & 2290 & 2730 & 3750 & 2670 & 23 \\
\hline $\mathrm{Ti}$ & $<26$ & $<26$ & $<42$ & $<25$ & $<0.3$ \\
\hline $\mathrm{V}$ & $<26$ & $<26$ & 78.7 & $<25$ & $<0.3$ \\
\hline $\mathrm{Zn}$ & $<65$ & $<65$ & $<106$ & $<63$ & 2 \\
\hline $\mathrm{Zr}$ & NA & $<130$ & NA & $<10$ & 3 \\
\hline $\mathrm{La}$ & $<130$ & $<130$ & $<296$ & $<126$ & 3 \\
\hline $\mathrm{K}$ & NM & 1640 & 1540 & 1370 & 1840 \\
\hline $\mathrm{S}$ & NM & $\mathrm{NM}$ & $\mathrm{NM}$ & $\mathrm{NM}$ & 3180 \\
\hline $\mathrm{Nd}$ & $<65$ & $<65$ & 137 & 81.8 & 6 \\
\hline NM: not measured & ot availa & $<: \mathrm{me}$ & rement b & W detection & imit \\
\hline
\end{tabular}


Table 14 R2NOC Slurry and Permeate Compositions (continued)

\begin{tabular}{|c|c|c|c|c|}
\hline & $\begin{array}{r}\text { R2NO } \\
\text { Duplica } \\
\end{array}$ & $\begin{array}{l}\text { Slurry } \\
\text { Samples }\end{array}$ & R2NOC2 Slurry & $\begin{array}{l}\text { Permeate } \\
\text { R2NOC2 }\end{array}$ \\
\hline Ion Chrom (mg/L) $\mathrm{NO}_{2-}$ & 54400 & 63300 & 48500 & 50500 \\
\hline $\mathrm{NO}_{3}^{-}$ & 138000 & 160000 & 116000 & 124000 \\
\hline $\mathrm{Cl}^{-}$ & 3550 & 4340 & 3140 & 3150 \\
\hline $\mathrm{F}$ & 1180 & 784 & 1220 & 1180 \\
\hline $\mathrm{PO}_{4}^{-3}$ & 4160 & 4890 & 3650 & 3310 \\
\hline $\mathrm{SO}_{4}^{-2}$ & 8560 & 11400 & 8300 & 8460 \\
\hline formate & 6290 & 6130 & 5680 & 5860 \\
\hline oxalate & 1600 & 1830 & 1590 & 1020 \\
\hline Carbon $(\mathrm{mg} / \mathrm{L})$ TOC & 10500 & 10100 & NM & NM \\
\hline TIC & 7370 & 9610 & NM & NM \\
\hline $\mathrm{TC}$ & 17900 & 19700 & NM & $\mathrm{NM}$ \\
\hline Carbonate (M) & 0.55 & & NM & NM \\
\hline Carbonate $(\mathrm{mg} / \mathrm{L})$ & 33000 & & NM & NM \\
\hline Free $\mathrm{OH}^{-}(\mathrm{M})$ & 0.15 & & NM & NM \\
\hline Total Base (M) & 1.50 & & NM & NM \\
\hline Total Solids (wt\%) & 33.6 & & 33.2 & 35.43 \\
\hline Insoluble Solids (wt\%) & 1.32 & & $0.74-1.33$ & 0 \\
\hline Specific Gravity & 1.26 & & 1.27 & $\mathrm{NM}$ \\
\hline
\end{tabular}

NM: not measured

\subsubsection{Remediation 2-Baseline Conditions}

The solids contents and specific gravities for the R2BCL run are shown in Table 15. The agreement between the values calculated by material balance match the measured values reasonably well, except for the total solids concentrations. The calculated values are substantially higher than the measured values. These calculated values were determined by a material balance on the volumes of precipitate added and permeate removed. Note that for this type of calculation, the cumulative errors build up since the permeate collected was measured incrementally. The composition of the R2BCL precipitate slurry is shown in Table 16. The permeate composition was not measured.

Table 15 Summary of R2BCL Solids Contents

\begin{tabular}{|r|cccc|}
\hline & $\begin{array}{c}\text { Total } \\
\text { Solids } \\
\text { (wt\%) }\end{array}$ & $\begin{array}{c}\text { Insoluble } \\
\text { Solids } \\
\text { (wt\%) }\end{array}$ & $\begin{array}{c}\text { Specific } \\
\text { Gravity }\end{array}$ & $\begin{array}{c}\text { Volume } \\
\text { in Feed } \\
\text { Tank (L) }\end{array}$ \\
\hline Simulant: Measured & NM & NM & 1.32 & \\
\hline Simulant: Calculated & 0.30 & 37.0 & 1.31 & \\
\hline Precipitate: Measured & $32.6-33.7$ & $1.3-1.6$ & $1.26-1.28$ & \\
\hline Precipitate: Calculated & 33.8 & $1.60^{*}$ & 1.265 & \\
\hline Concentrated Slurry: Measured & 42.93 & 14.85 & 1.38 & approx. 4 \\
\hline Concentrated Slurry: Calculated & 46.71 & 14.51 & 1.43 & 3.92 \\
\hline Concentrated Slurry: Measured & 45.43 & 18.83 & NA & approx. 3 \\
\hline Concentrated Slurry: Calculated & 51.36 & 19.15 & 1.49 & 2.92 \\
\hline
\end{tabular}

* Calculated set equal to measured. $\mathrm{NM}=$ not measured 
Table 16 Composition of R2BCL Precipitate and Concentrated Slurry

\begin{tabular}{|c|c|c|c|}
\hline & Initial Precipitate & \multicolumn{2}{|c|}{ Concentrated Slurry } \\
\hline Dissolution: & Aqua Regia & $\mathrm{Na}_{2} \mathrm{O}_{2}$ & Aqua Regia \\
\hline \multirow{2}{*}{ ICPES (mg/L) } & 7870 & 9220 & 8340 \\
\hline & 27.2 & $<169$ & 24.0 \\
\hline $\mathrm{Ba}$ & 34.5 & 616 & 567 \\
\hline $\mathrm{Ca}$ & 483 & 4267 & 3490 \\
\hline $\mathrm{Cd}$ & 22.1 & 68.7 & 71.5 \\
\hline $\mathrm{Co}$ & $<1.0$ & $<35$ & 30.9 \\
\hline $\mathrm{Cr}$ & 122 & 275 & 214 \\
\hline $\mathrm{Cu}$ & 17.4 & 190 & 186 \\
\hline $\mathrm{Fe}$ & 32.8 & 781 & 630 \\
\hline $\mathrm{Li}$ & NM & $<70$ & $<4$ \\
\hline $\mathrm{Mg}$ & $<0.1$ & 187 & 204 \\
\hline $\mathrm{Mn}$ & 2420 & 36800 & 34800 \\
\hline $\mathrm{Mo}$ & $\mathrm{NM}$ & $<70$ & 30.9 \\
\hline $\mathrm{Na}$ & 138000 & $\mathrm{NM}$ & 154000 \\
\hline $\mathrm{Na}($ by $\mathrm{AA})$ & $\mathrm{NM}$ & NM & 148000 \\
\hline $\mathrm{Ni}$ & 214 & 875 & 800 \\
\hline $\mathrm{P}$ & 874 & 5060 & 6230 \\
\hline $\mathrm{Pb}$ & 92.6 & 1440 & 1240 \\
\hline $\mathrm{Si}$ & 33.7 & 236 & 1630 \\
\hline $\mathrm{Sn}$ & NM & $<197$ & $<10$ \\
\hline $\mathrm{Sr}$ & 7090 & 74600 & 80300 \\
\hline \multirow{2}{*}{$\frac{T}{V}$} & $\mathrm{NM}$ & $<99$ & 6.24 \\
\hline & NM & $<99$ & $<5$ \\
\hline $\mathrm{Zn}$ & $<0.1$ & $<282$ & 28.6 \\
\hline $\mathrm{Zr}$ & 2.8 & NA & 101 \\
\hline $\mathrm{La}$ & 24.6 & $<493$ & 318 \\
\hline $\mathrm{K}$ & 2730 & 1580 & 1380 \\
\hline $\mathrm{K}$ (by AA) & $\mathrm{NM}$ & NA & 1260 \\
\hline$S$ & 2460 & 3160 & 2900 \\
\hline $\mathrm{Nd}$ & 42.4 & 614 & 600 \\
\hline Ion Chrom (mg/L) $\quad \mathrm{NO}_{2}^{-}$ & 38200 & & 500 \\
\hline $\mathrm{NO}_{3}^{-}$ & 105000 & & 300 \\
\hline $\mathrm{Cl}^{-1}$ & 2650 & & 800 \\
\hline $\mathrm{F}^{-}$ & 1020 & & 210 \\
\hline $\mathrm{PO}_{4}^{-3}$ & 2800 & & 200 \\
\hline $\mathrm{SO}_{4}^{-2}$ & 7570 & & 270 \\
\hline formate & 5340 & & 320 \\
\hline oxalate & 1400 & & 200 \\
\hline Carbon $(\mathrm{mg} / \mathrm{L}) \quad \mathrm{TOC}$ & NM & 93 & \\
\hline TIC & NM & 120 & \\
\hline $\mathrm{TC}$ & NM & 213 & \\
\hline Total Solids (wt $\%)$ & $32.66-33.65$ & & 5.43 \\
\hline Insoluble Solids (wt\%) & 1.60 & & 8.83 \\
\hline Specific Gravity & 1.28 & 1.41( & timated) \\
\hline
\end{tabular}

NM: not measured NA: not available <: measurement below detection limit 


\subsubsection{R1BC Washing and Re-Concentration}

The slurry at $17.2 \mathrm{wt} \%$ insoluble solids was washed with an equal volume (not mass) of inhibited water and then re-concentrated to the original volume. By material balance, the estimated and measured total solids content and the slurry volume agreed very well when calculated assuming the measured insoluble solids content, as shown in Table 10. Table 17 shows comparisons of the compositions of the unwashed and washed slurries and permeates. The soluble components $\mathrm{Al}, \mathrm{Na}, \mathrm{NO}_{2}^{-}, \mathrm{NO}_{3}^{-}, \mathrm{Cl}, \mathrm{F}-, \mathrm{PO}_{4}^{-3}, \mathrm{SO}_{4}^{-2}$, and formate in the washed slurry were approximately one-half the unwashed slurry as expected; the same ratio is found for the permeate. Note that the insoluble solids content of the washed slurry is greater than before washing. This occurred since the wash was on a volumetric basis, whereas the insoluble solids content is on a mass basis.

\subsubsection{Rheological Measurements}

All rheological measurements shown in Table 18 were taken at $25^{\circ} \mathrm{C}$ and the flow curves were not corrected for non-Newtonian behavior (slip, geometry, etc.), if applicable, and are consistent with how data is interpreted for RPP-WTP related reports. For the slurry samples, the mean results of the up curve would typically be used for startup of pipe flow or agitator startup and the mean results of the down curve would be used for typical steady pipe flow calculations. The shear rate range for the Newtonian samples was $0-500$ or $0-550 \mathrm{~s}^{-1}$ and for the non-Newtonian samples it was $50-1000 \mathrm{~s}^{-1}$.

These results show that the initial precipitate slurries and permeates were Newtonian, while the concentrated slurries were all non-Newtonian. Figure 4 shows the slurry consistencies plotted versus the insoluble solids content. The data for the baseline conditions slurry fall roughly along a line, but the NOC2 slurry has a higher consistency at about $12 \mathrm{wt} \%$ and a much higher value at approximately $18 \mathrm{wt} \%$. The washed R1BC slurry consistency is similar to the unwashed slurry. The yield stresses of the slurries are plotted in Figure 5. The yield stresses are relatively linear with insoluble solids concentration up to about $16-18 \mathrm{wt} \%$, but then increase dramatically above $18 \mathrm{wt} \%$. The NOC2 slurry also had a much higher yield stress at approximately $18 \mathrm{wt} \%$ than the baseline condition slurries did. 
WSRC-TR-2003-00056, REV. 0

SRT-RPP-2002-00231, REV. 0

Table 17 R1BC Composition of Unwashed and Washed Slurry and Permeate

\begin{tabular}{|c|c|c|c|c|c|c|}
\hline & & $\begin{array}{c}\text { Feed Slurry } \\
\text { @ 1.45-1.60 } \\
\text { wt } \% \\
\text { Insoluble } \\
\text { Solids } \\
\text { (Measured) }\end{array}$ & $\begin{array}{l}\text { Unwashed } \\
\text { Slurry } \\
\text { @ } 17.2 \text { wt\% } \\
\text { Insoluble } \\
\text { Solids } \\
\text { (Calculated) }\end{array}$ & $\begin{array}{c}\text { Washed } \\
\text { Slurry } \\
\text { @ 20.63 wt\% } \\
\text { Insoluble } \\
\text { Solids } \\
\text { (Measured) }\end{array}$ & $\begin{array}{c}\text { Average } \\
\text { Permeate } \\
\text { from } \\
\text { Unwashed } \\
\text { Slurry } \\
\text { (Measured) }\end{array}$ & $\begin{array}{c}\text { Permeate } \\
\text { from Washed } \\
\text { Slurry } \\
\text { (Measured) }\end{array}$ \\
\hline \multirow[t]{28}{*}{ ICPES (mg/L) } & $\mathrm{Al}$ & 7540 & 7790 & 4730 & 7530 & 3510 \\
\hline & $\mathrm{B}$ & $<92$ & $<100$ & $<90$ & 23.4 & 11.3 \\
\hline & $\mathrm{Ba}$ & 198 & 2440 & 2440 & $<0.024$ & $<0.02$ \\
\hline & $\mathrm{Ca}$ & 306 & 3090 & 3040 & 96.5 & 50.5 \\
\hline & $\mathrm{Cd}$ & 36.1 & 61.6 & 45.3 & 36.1 & 18.8 \\
\hline & $\mathrm{Co}$ & $<35$ & $<34$ & $<34$ & $<0.1$ & $<0.1$ \\
\hline & $\mathrm{Cr}$ & 162 & 311 & 251 & 146 & 69.6 \\
\hline & $\mathrm{Cu}$ & $<35$ & 174 & 174 & 3.8 & 0.4 \\
\hline & $\mathrm{Fe}$ & 196 & 673 & 673 & 0.5 & $<0.1$ \\
\hline & $\mathrm{Li}$ & $<47$ & $<45$ & $<45$ & 0.2 & $<0.2$ \\
\hline & $\mathrm{Mg}$ & $<41$ & 235 & 234 & $<0.2$ & $<0.2$ \\
\hline & $\mathrm{Mn}$ & 2320 & 37300 & 37300 & 0.3 & 0.7 \\
\hline & Mo & $<69$ & $<79$ & $<67$ & 28.6 & 13.9 \\
\hline & $\mathrm{Na}$ & 135000 & 134000 & 76300 & 138000 & 66800 \\
\hline & $\mathrm{Ni}$ & 270 & 1030 & 958 & 199 & 85.3 \\
\hline & $\mathrm{P}$ & 768 & 1610 & 1290 & 568 & 372 \\
\hline & $\mathrm{Pb}$ & $<302$ & 1030 & 1030 & 39.4 & 10.3 \\
\hline & $\mathrm{Si}$ & $<69$ & $<74$ & $<67$ & 15.5 & 7.7 \\
\hline & $\mathrm{Sn}$ & $<163$ & $<157$ & $<157$ & $<0.7$ & $<0.5$ \\
\hline & $\mathrm{Sr}$ & 5360 & 85500 & 85500 & 26.8 & 10.1 \\
\hline & $\mathrm{Ti}$ & $<69$ & $<67$ & $<67$ & $<0.3$ & $<0.3$ \\
\hline & $\mathrm{V}$ & $<69$ & $<67$ & $<67$ & $<0.3$ & $<0.3$ \\
\hline & $\mathrm{Zn}$ & $<163$ & $<158$ & $<157$ & 2.5 & $<0.7$ \\
\hline & $\mathrm{Zr}$ & $<23$ & 143 & 143 & 0.5 & 0.2 \\
\hline & $\mathrm{La}$ & $<324$ & $<315$ & $<314$ & $<1.4$ & $<1.4$ \\
\hline & $\mathrm{K}$ & 293 & $<957$ & $<224$ & 2100 & 843 \\
\hline & $\mathrm{S}$ & & 1240 & NM & 2830 & 1430 \\
\hline & $\mathrm{Nd}$ & $<232$ & $<225$ & $<224$ & 0.9 & 1.68 \\
\hline \multirow[t]{8}{*}{ Ion Chrom. (mg/L) } & $\mathrm{NO}_{2}^{-}$ & 50900 & 37000 & 18200 & 44000 & 21700 \\
\hline & $\mathrm{NO}_{3}^{-}$ & 134000 & 108000 & 57600 & 126000 & 57700 \\
\hline & $\mathrm{Cl}-$ & 3030 & 2280 & 1134 & 2780 & 1320 \\
\hline & $\mathrm{F}-$ & 1440 & 983 & 467 & 712 & 593 \\
\hline & $\mathrm{PO}_{4}^{-3}$ & 2680 & 2280 & 1090 & 2370 & 1370 \\
\hline & $\mathrm{SO}_{4}^{-2}$ & 7590 & 6970 & 3620 & 7010 & 3850 \\
\hline & formate & 5770 & 5750 & 3220 & 4870 & 2900 \\
\hline & oxalate & 1960 & 13200 & 10900 & 679 & 2610 \\
\hline \multicolumn{7}{|l|}{ Carbon (mg/L) } \\
\hline \multirow{3}{*}{\multicolumn{2}{|c|}{$\begin{array}{r}\text { Total Organic Carbon } \\
\text { Total Inorganic Carbon } \\
\text { Total Carbon }\end{array}$}} & 6220 & 5550 & 2980 & NM & 2960 \\
\hline & & 4950 & 5160 & 3340 & NM & 2090 \\
\hline & & 11100 & 10700 & 6320 & $\mathrm{NM}$ & 5050 \\
\hline \multirow{3}{*}{\multicolumn{2}{|c|}{$\begin{array}{r}\text { Total Solids (wt\%) } \\
\text { Insoluble Solids (wt\%) } \\
\text { Estimated Specific Gravity }\end{array}$}} & 33.61 & 44.98 & 35.06 & 33.30 & 33.61 \\
\hline & & 1.60 & 17.17 & 20.63 & NA & NA \\
\hline & & 1.26 & 1.40 & 1.28 & 1.26 & 1.26 \\
\hline
\end{tabular}

NM: not measured NA: not available <: measurement below detection limit 
WSRC-TR-2003-00056, REV. 0

SRT-RPP-2002-00231, REV. 0

Table 18 Rheological Properties of Initial Precipitates, Concentrated Slurries, and Permeates

\begin{tabular}{|c|c|c|c|c|c|c|c|}
\hline Batch & Sample & $\begin{array}{c}\text { Insoluble } \\
\text { Solids } \\
\text { (wt\%) }\end{array}$ & $\begin{array}{c}\text { Mean } \\
\text { Viscosity }{ }^{\# \#} \text { or } \\
\text { Consistency } \\
\text { Up } \\
\text { (cp) } \\
\end{array}$ & $\begin{array}{c}\text { Mean } \\
\text { Viscosity }{ }^{\# \#} \text { or } \\
\text { Consistency } \\
\text { Down } \\
\text { (cp) } \\
\end{array}$ & $\begin{array}{l}\text { Mean } \\
\text { Yield } \\
\text { Stress } \\
\text { Up } \\
(\mathrm{Pa}) \\
\end{array}$ & $\begin{array}{c}\text { Mean } \\
\text { Yield } \\
\text { Stress } \\
\text { Down } \\
(\mathrm{Pa}) \\
\end{array}$ & Fluid Behavior \\
\hline $\mathrm{R} 1 \mathrm{BC}$ & $\begin{array}{r}\text { Precipitate Batch \#5 } \\
\text { (fresh precipitate) }\end{array}$ & $1.45-1.60$ & 3.84 & 3.55 & none & none & Newtonian \\
\hline R2BCL & $\begin{array}{r}\text { Precipitate Batch } \\
\text { (fresh precipitate) }\end{array}$ & $1.30-1.60$ & 4.22 & 4.22 & none & none & Newtonian \\
\hline $\mathrm{R} 1 \mathrm{BC}$ & $\begin{array}{r}\text { Precipitate Batch \#1 } \\
\text { (subjected to filtration) }\end{array}$ & $1.45-1.60$ & 4.08 & 3.72 & none & none & Newtonian \\
\hline R1BC & Concentrated Slurry* & 13.3 & 11.7 & 11.8 & 4.94 & 3.60 & non-Newtonian \\
\hline & Concentrated Slurry* & 17.2 & 14.6 & 16.8 & 15.3 & 10.3 & non-Newtonian \\
\hline & Concentrated Slurry** & 19.3 & 15.2 & 20.7 & 23.2 & 14.5 & non-Newtonian \\
\hline Wash & ed Concentrated Slurry* & 20.6 & 8.4 & 15.7 & 61.7 & 51.5 & non-Newtonian \\
\hline \multirow[t]{2}{*}{ R2BCL } & Concentrated Slurry* & 14.8 & 11.6 & 12.1 & 4.14 & 2.72 & non-Newtonian \\
\hline & Concentrated Slurry* & 18.8 & 16.6 & 18.2 & 12.83 & 9.82 & non-Newtonian \\
\hline \multirow[t]{2}{*}{ R2NOC2 } & Concentrated Slurry* & 12.3 & 16.3 & 20.9 & 11.89 & 4.78 & non-Newtonian \\
\hline & Concentrated Slurry* & 18.5 & 43.3 & 64.2 & 65.2 & 33.5 & non-Newtonian \\
\hline \multirow[t]{2}{*}{ R1BC } & Permeate & none & 3.10 & NA & none & NA & Newtonian \\
\hline & Nashed Slurry Permeate & none & 1.55 & NA & none & NA & Newtonian \\
\hline
\end{tabular}

* Haake Z41 Double Concentric Geometry ** Haake $35 \mathrm{~mm}, 2^{\circ}$ Cone Geometry

\# Consistency for concentrated slurry samples $\quad$ \#\# Viscosity for dilute precipitate samples

NA: not applicable

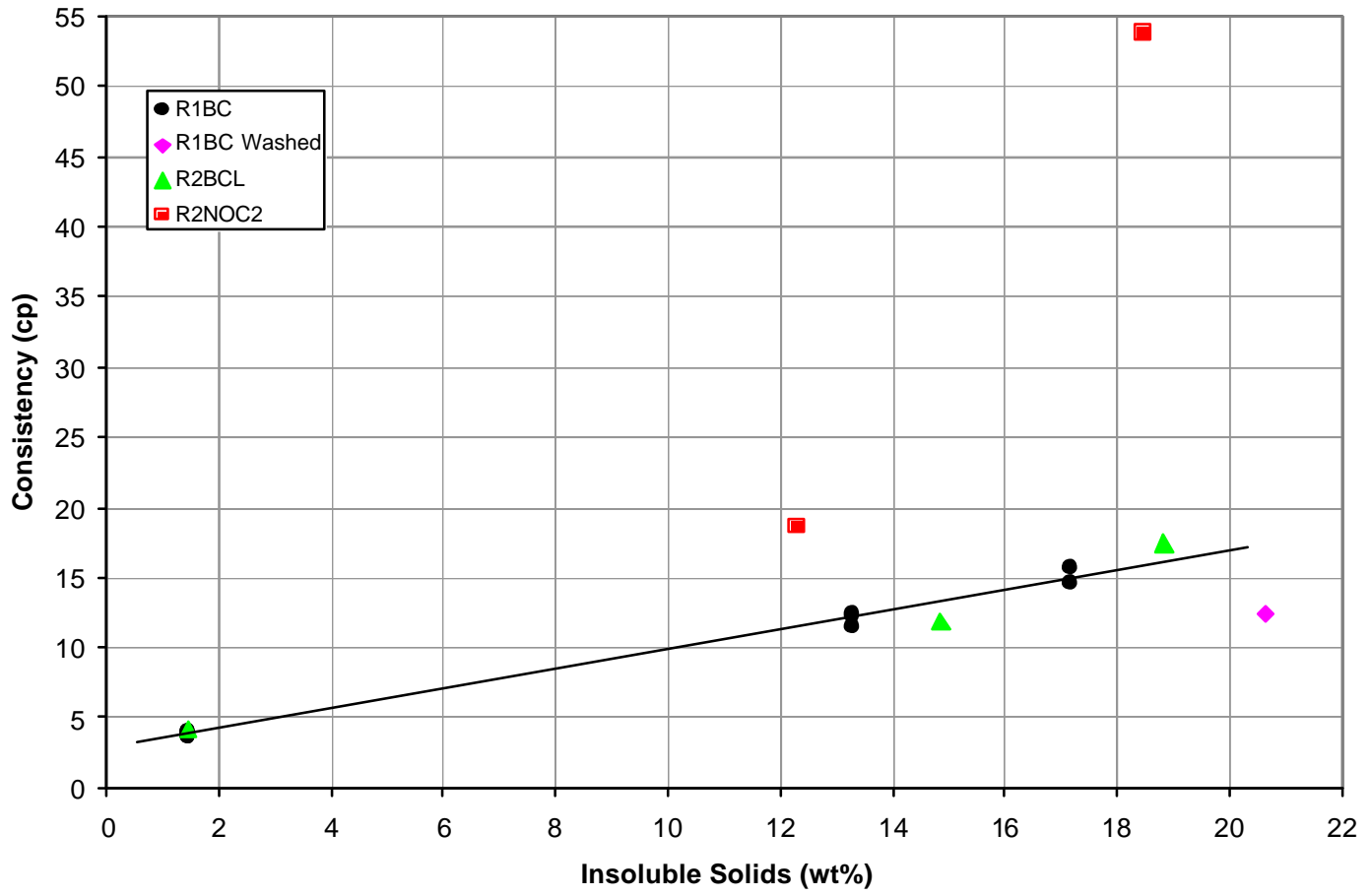

Figure 4 Slurry Consistencies 


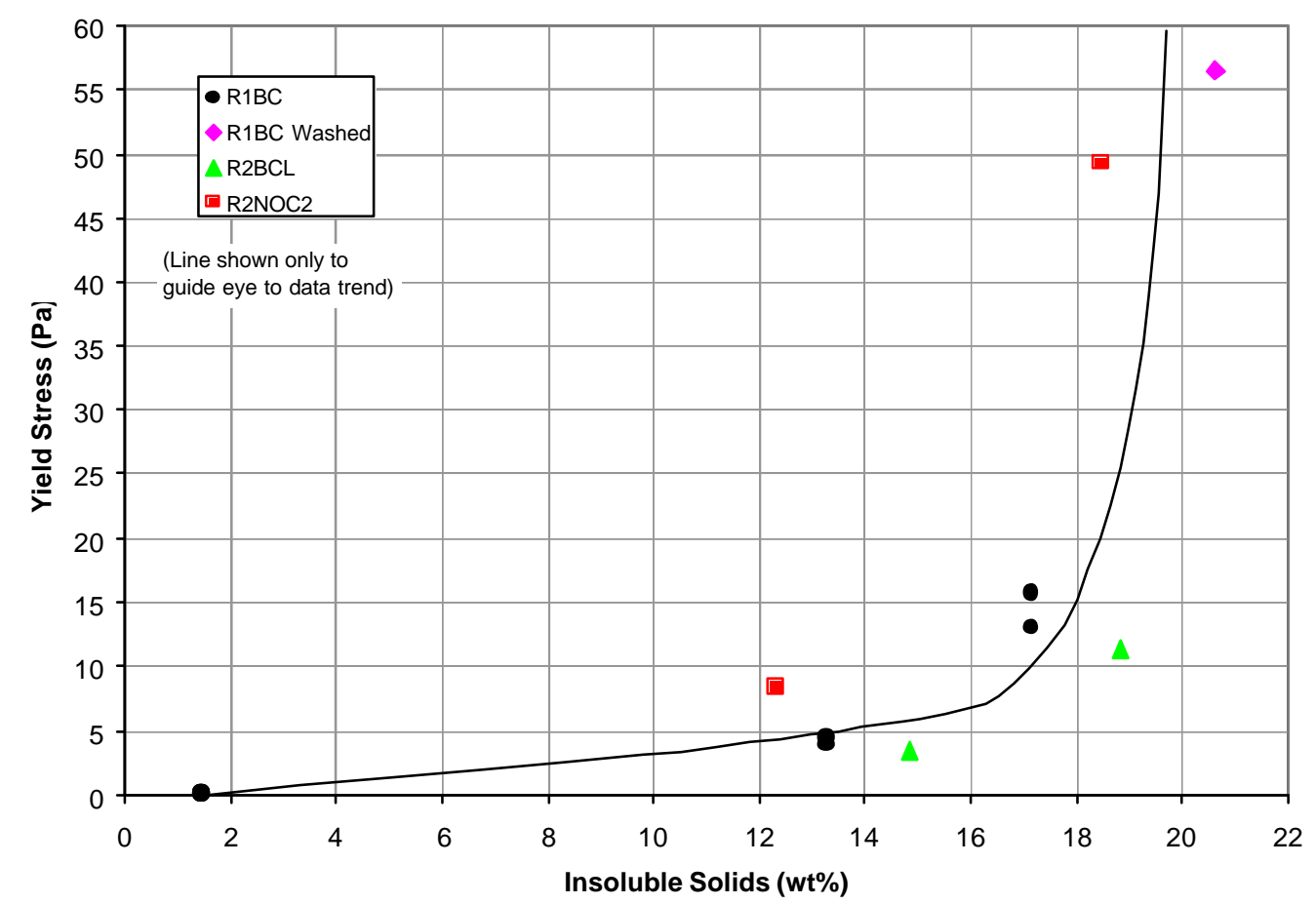

\section{Figure 5 Slurry Yield Stresses}

The high yield stresses for the more concentrated slurries made these difficult to mix, but still pumpable. The feed tank was agitated by a small turbine blade that was adequate at low concentrations, but provided poor mixing at high concentrations. The poor mixing at high solids concentrations resulted in short circuiting of the slurry flowing through the feed tank from the filter return to the pump inlet. Figure 6 shows a sketch of what appears to have probably been happening. The washed slurry, when concentrated to approximately $21 \mathrm{wt} \%$ insoluble solids, could not be mixed by the agitator. The yield stress of this material (51-62 $\mathrm{Pa}$ ) would indicate that it would not pour well (and it did not pour well) and would require positive displacement pumps, possibly with screw suction, to effectively transport it. Visibly, this material was similar to gelatin and did not flow in a bottle when turned upside down. The R2NOC2 concentrated slurry had similar behavior. A photo of mixing of the concentrated slurry is shown in Figure 7. The report CD-ROM also contains a short movie of the poor mixing ("Feed-Mixing.mpg").

As the concentration of the insoluble solids increased, the slurry changed from Newtonian to non-Newtonian and the viscosity or consistency and yield stress increased. Because of these increases, the flow regime in the filter and associated piping moved from turbulent or transition flow to laminar. The Reynolds number for the R1BC slurry is plotted versus insoluble solids in Figure 8. The flow of the dilute slurry at 11 and 15 fps velocity is fully turbulent, while at $7 \mathrm{fps}$ it is in the transition region. No data was taken on slurry properties in the region from 1.5-13 wt \% insoluble solids, but the fluid up to at least about $45 \mathrm{wt} \%$ insoluble solids was probably still Newtonian. The transition Reynolds number plotted was calculated per Hansen. ${ }^{10}$ 
WSRC-TR-2003-00056, REV. 0

SRT-RPP-2002-00231, REV. 0

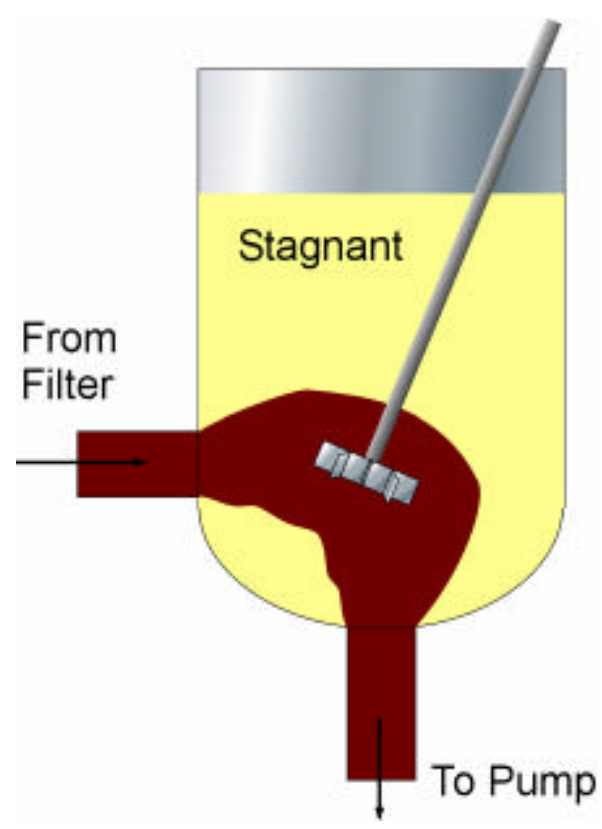

Figure 6 Feed Tank Sketch Showing Possible Stagnation

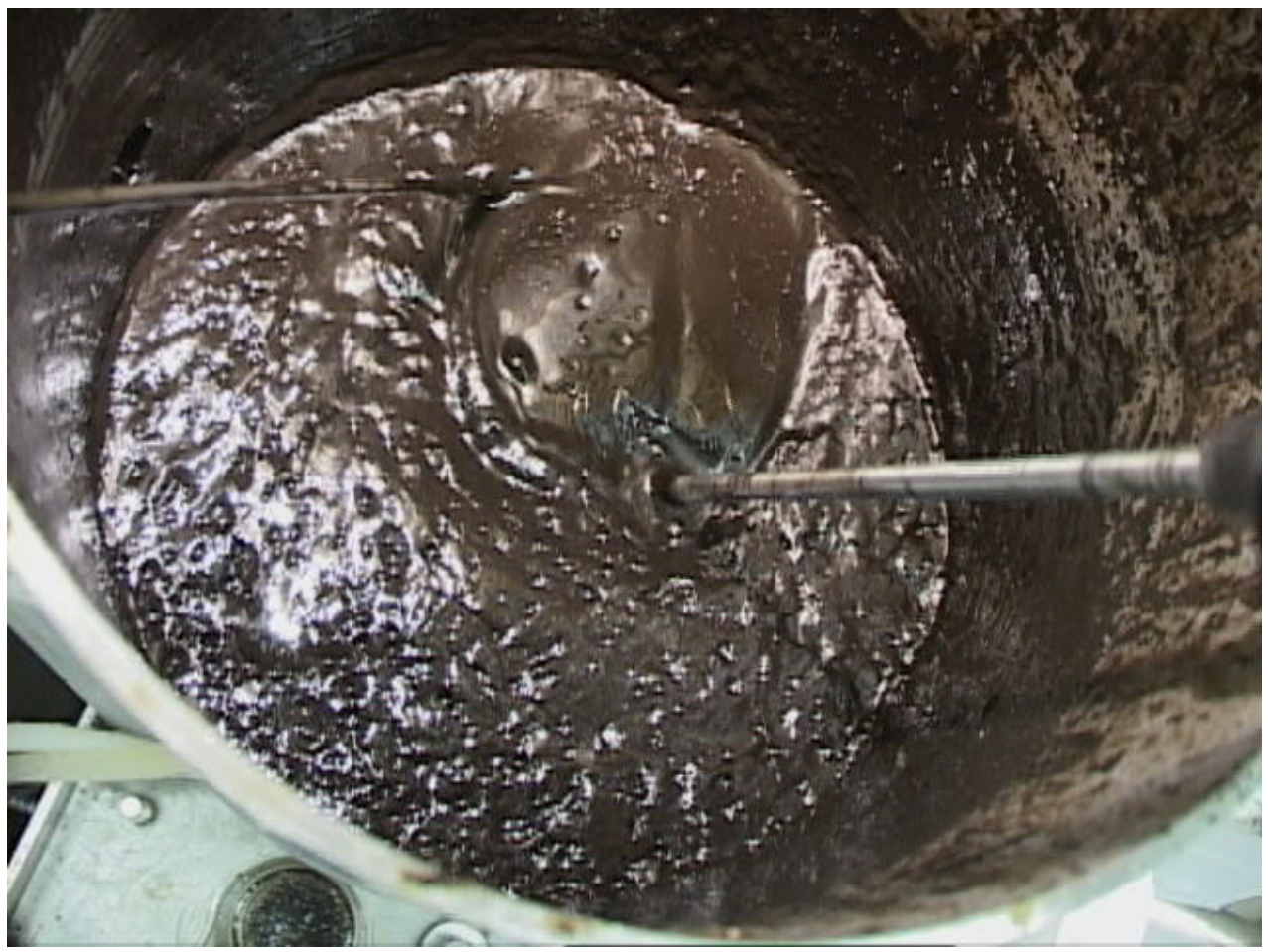

Figure 7 CUF Feed Slurry Mixing at Approximately 15-17 wt\% Insoluble Solids 
WSRC-TR-2003-00056, REV. 0

SRT-RPP-2002-00231, REV. 0

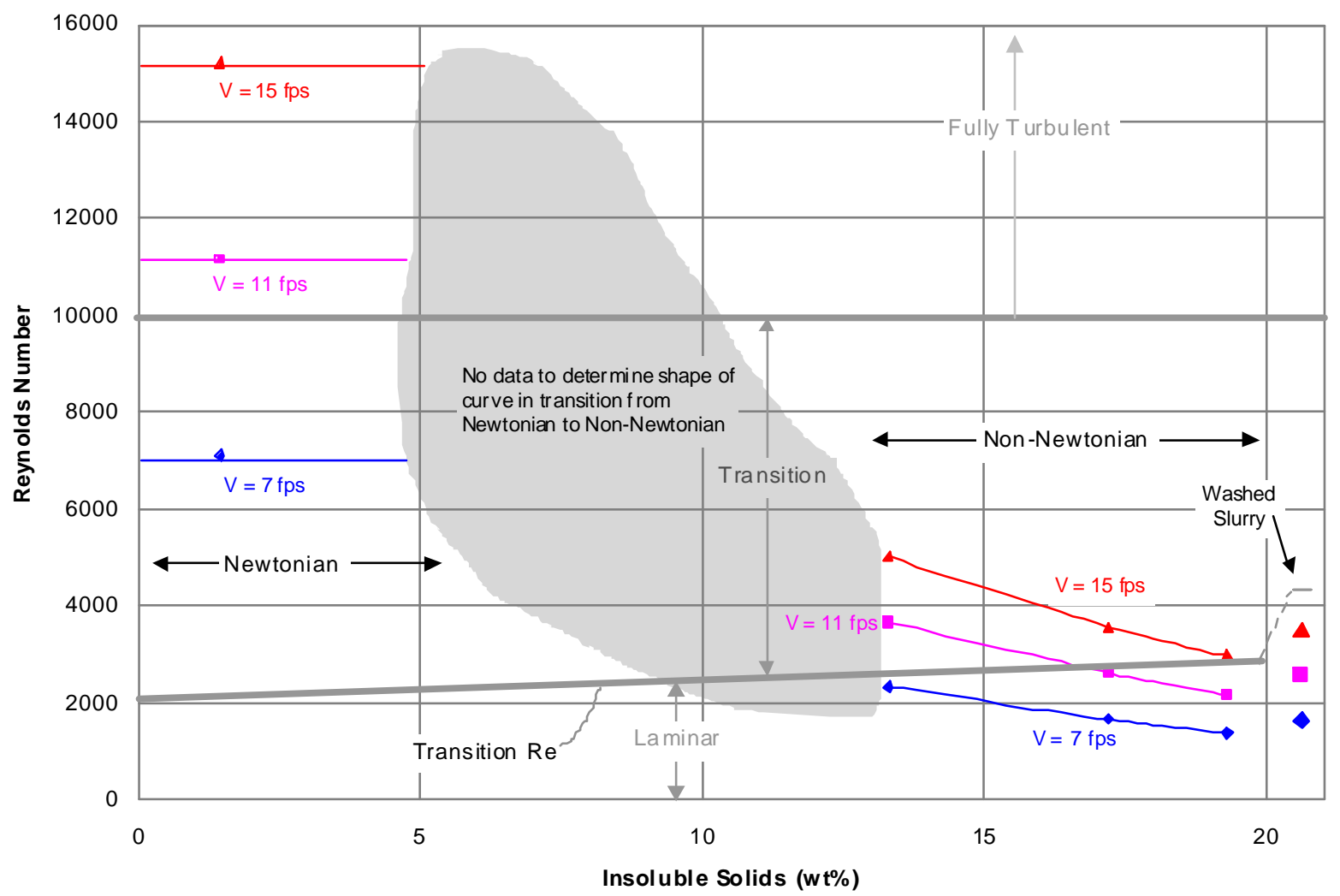

Figure 8 Reynolds Number in Filter Tube versus Insoluble Solids Content

\subsubsection{Heat Transfer}

At the high solids concentrations, the pump imparted significant thermal energy into the slurry, such that an auxiliary cooling mechanism had to be added to the CUF to keep the temperature in the required $20-30^{\circ} \mathrm{C}$ range. Heating of the slurry to $30^{\circ} \mathrm{C}$ occurred very quickly without the additional cooling. The heat load on the slurry cooler increased, indicating that the heat input into the slurry had increased. Given the increases in slurry consistency and yield stress, this energy increase is not surprising. During the first concentrations performed, the cooling system used was too small to maintain the temperature of the slurry below $30^{\circ} \mathrm{C}$ at the highest solids contents.

After the R1BC work, thermocouples were added to the inlet and outlet of both the slurry and cooling water sides of the cooler. Data were then taken periodically throughout the concentration of the R2NOC2 and R2BCL tests. Figure 9 shows the change in the heat load and the overall heat transfer coefficient while concentrating the R2NOC2 slurry. The overall heat transfer coefficients were calculated from the log-mean temperature differences across the heat exchanger and the cooling water flowrate. The values have a lot of scatter, partially due to variations in the cooling water flow that were not measured accurately; the cooling water flow was monitored periodically by measuring the volume collected over a time interval. The initial points on this figure (at $<13 \mathrm{wt} \%$ ) are plotted on the time axis, but these measurements were actually made during the several days preceding the $>13.4 \mathrm{wt} \%$ data; these points are plotted versus time so the magnitude can be compared. 


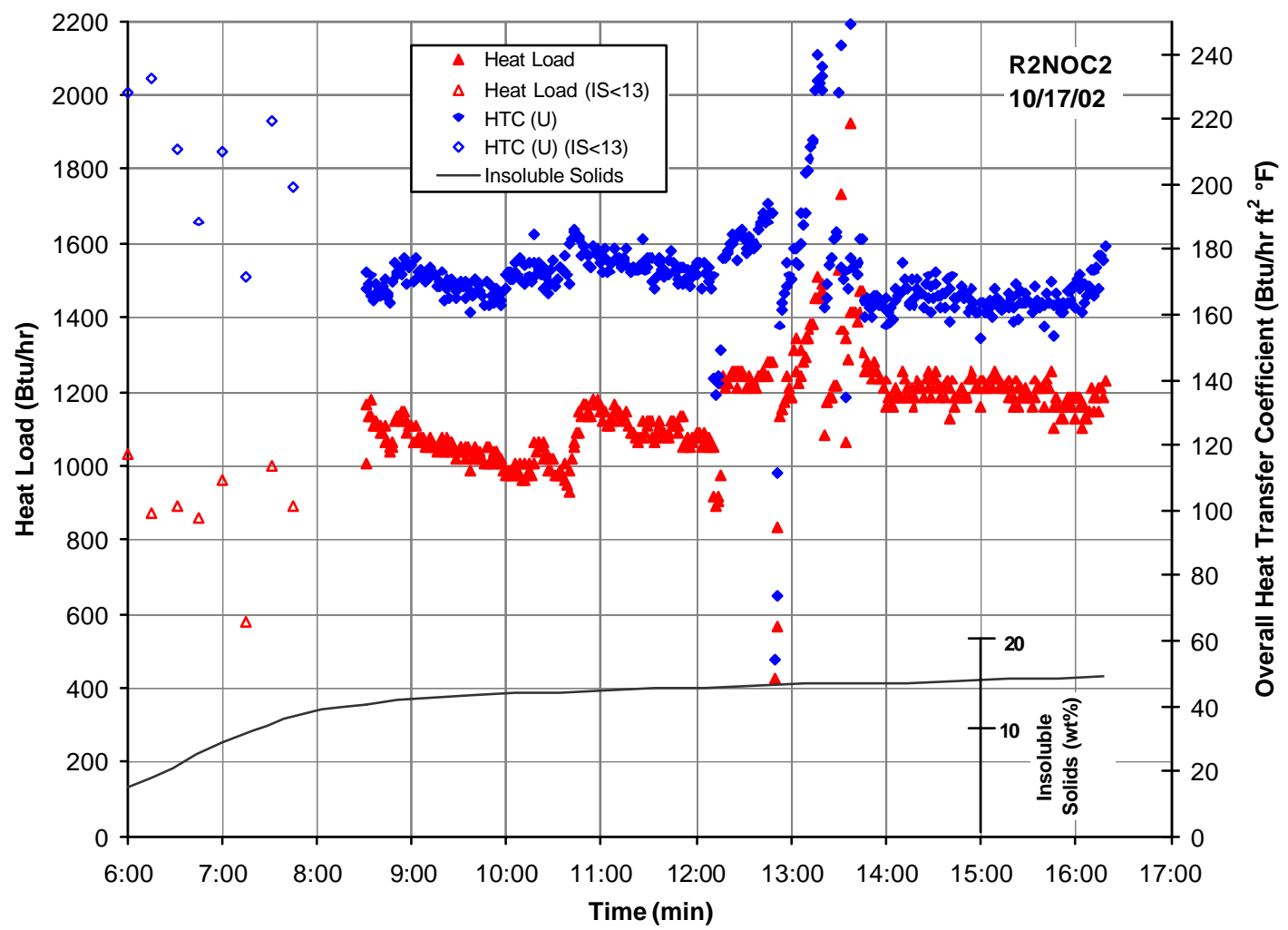

Figure 9 Heat Transfer During Concentration of R2NOC2 Slurry

\subsubsection{Particle Size Distributions}

The particle size distributions of samples from several of the runs were measured. Initially, the measurements were made by diluting the samples with deionized water. Later measurements were done by diluting with permeate from the R1BC run. The permeate should provide a better matrix match with samples and dissolution or precipitation due to $\mathrm{pH}$ or ionic strength changes should be minimized. The R1BC permeate was chosen because it was clear with no suspended solids (as determined by zeroing of the particle size instrument). The permeate from R2NOC2 was tried, but post-filtration precipitation was still occurring, which made this permeate unusable as a diluent. (The R1BC permeate had aged for several months.)

The particle size measurements were made using a Microtrac Particle Size Analyzer. This instrument has several measurement methods or modes, as shown in Table 19. 
Table 19 Microtrac Particle Size Analyzer Methods

\begin{tabular}{|c|c|c|c|}
\hline Method & Resolution & Range $(\mu \mathrm{m})$ & Assumptions \\
\hline \multirow{2}{*}{$\begin{array}{l}\text { SRA150, single laser } \\
\text { diffraction analysis }\end{array}$} & Standard, 20 channels & $0.7-700$ & None \\
\hline & High, 40 channels & $0.7-700$ & $\begin{array}{l}\text { Particle transparency: } \\
\text { - } \text { absorptive } \\
\text { - } \text { reflective } \\
\text { - } \quad \text { assumed refractive index }\end{array}$ \\
\hline $\begin{array}{l}\text { X100, tri-laser } \\
\text { diffraction analysis } \\
\text { by "Unified Scatter } \\
\text { Technique" }\end{array}$ & All, 40 channels & $0.04-704$ & $\begin{array}{l}\text { Particle transparency: } \\
\text { - absorptive } \\
\text { - reflective } \\
\text { - } \text { assumed refractive index }\end{array}$ \\
\hline
\end{tabular}

The resolution of the standard SRA150 method, for which no assumptions need be made, was not sufficient to show significant differences in particle size distribution between samples. Therefore, the high-resolution SRA150 method and the X100 method were tried. For these methods, the transparency of the particles must be assumed. The choices are reflective (such as metals), absorptive (opaque materials), or a specific refractive index can be assumed. The correct choice for the Sr/TRU precipitates was not known, so both the reflective and absorptive methods were used. No runs with an assumed refractive index were made.

Figure 10-Figure 13 show volume distribution plots using both the SRA150 and X100 highresolution modes. Each Figure shows a pair of samples: the initial unfiltered precipitate and the concentrated slurry. The SRA150 plots are generally sharper since particles smaller than $0.7 \mu \mathrm{m}$ are not quantified, whereas the $\mathrm{X} 100$ plots are broader since a larger range is measured.

In Figure 10a the volume distributions for the R1BC precipitate by the four methods are almost identical. Figure 10b shows the same material after filtration and concentration. The initial precipitate had a bimodal distribution with peaks at about 45 and $5 \mu \mathrm{m}$, whereas the filtered material was unimodal with a broad peak at $2-4 \mu \mathrm{m}$. For the filtered slurry, the X100 method showed a much broader distribution with more particles smaller than $1 \mu \mathrm{m}$ than in the initial sample. The amount of material in the $>10 \mu \mathrm{m}$ range decreased significantly.

Figure 11 compares the distributions for the R2NOC pilot-scale run. For this material, the initial bimodal distribution remained after filtration, with both the SRA150 and X100 methods showing increases in particles in the less than $4 \mu \mathrm{m}$ range. The R2NOC2 precipitate run in the CUF showed similar behavior, as shown in Figure 12. The R2BCL data shown in Figure 13 also shows similar trends, The bimodal distribution remains after filtration, but the amount of material $>10 \mu \mathrm{m}$ decreases and that at around $2-3 \mu \mathrm{m}$ increases. 
WSRC-TR-2003-00056, REV. 0

SRT-RPP-2002-00231, REV. 0
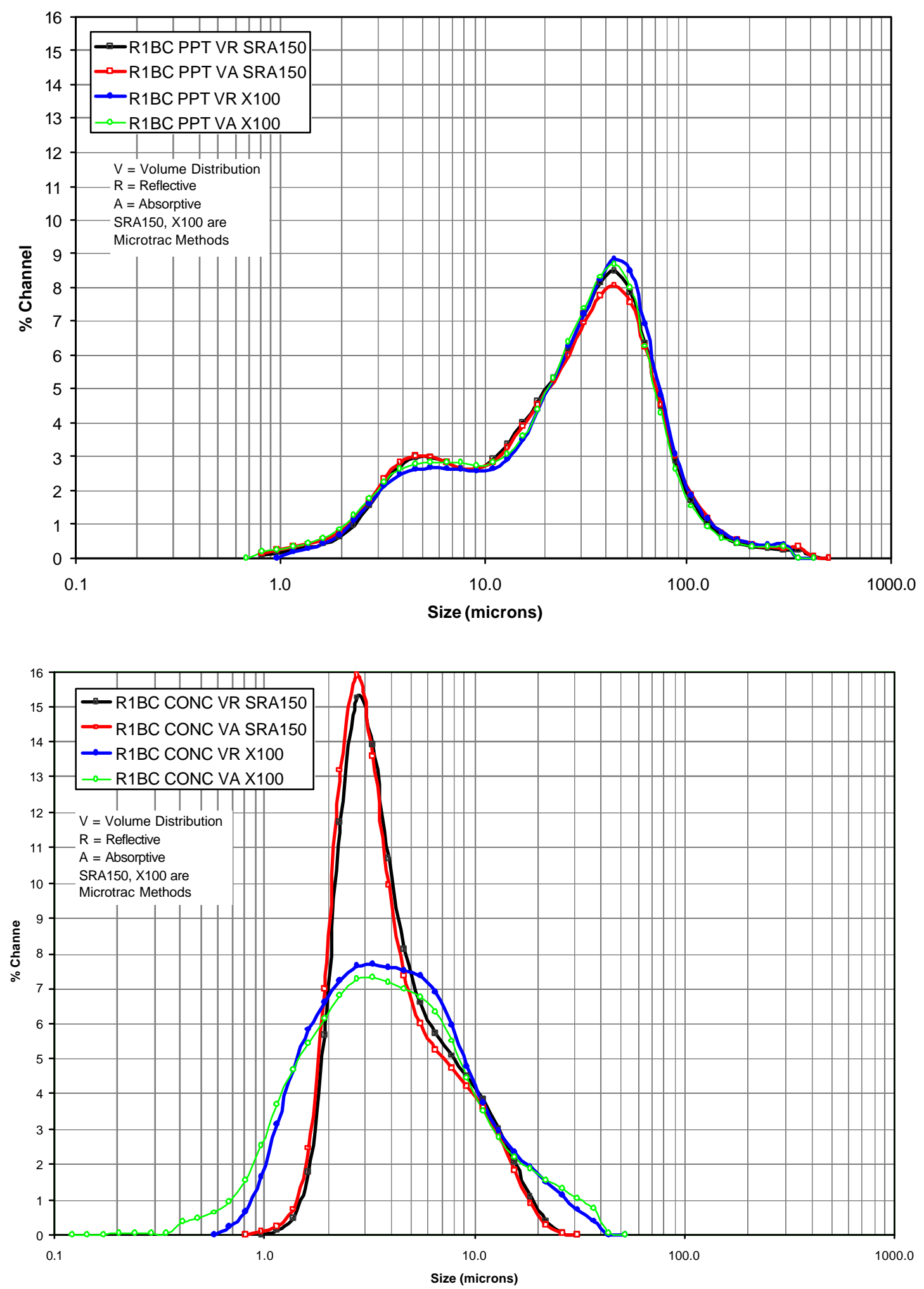

Figure 10 Particle Size Volume Distribution for R1BC Slurry 
WSRC-TR-2003-00056, REV. 0

SRT-RPP-2002-00231, REV. 0
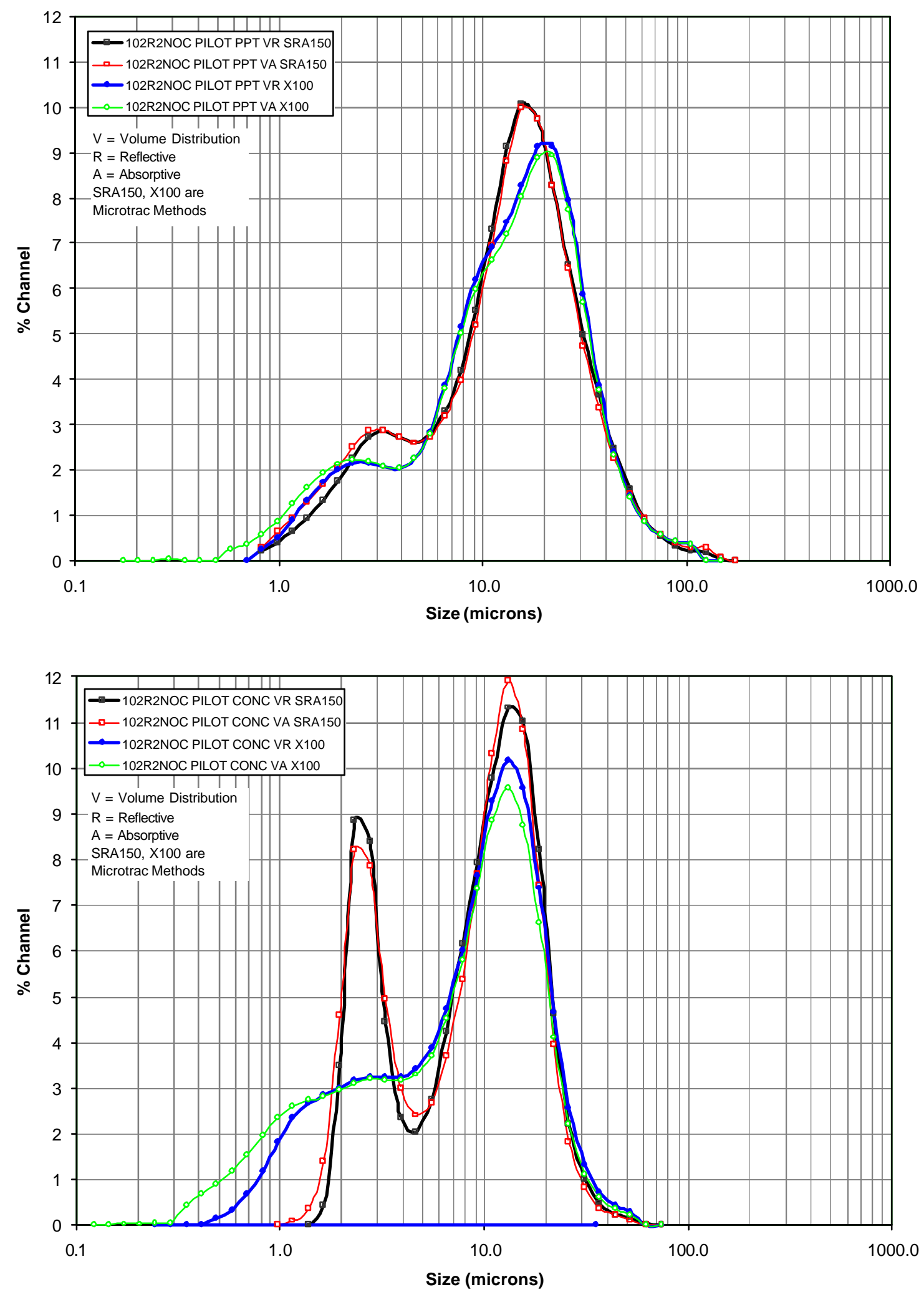

Figure 11 Particle Size Volume Distribution for R2NOC Pilot Scale Slurry 
WSRC-TR-2003-00056, REV. 0

SRT-RPP-2002-00231, REV. 0
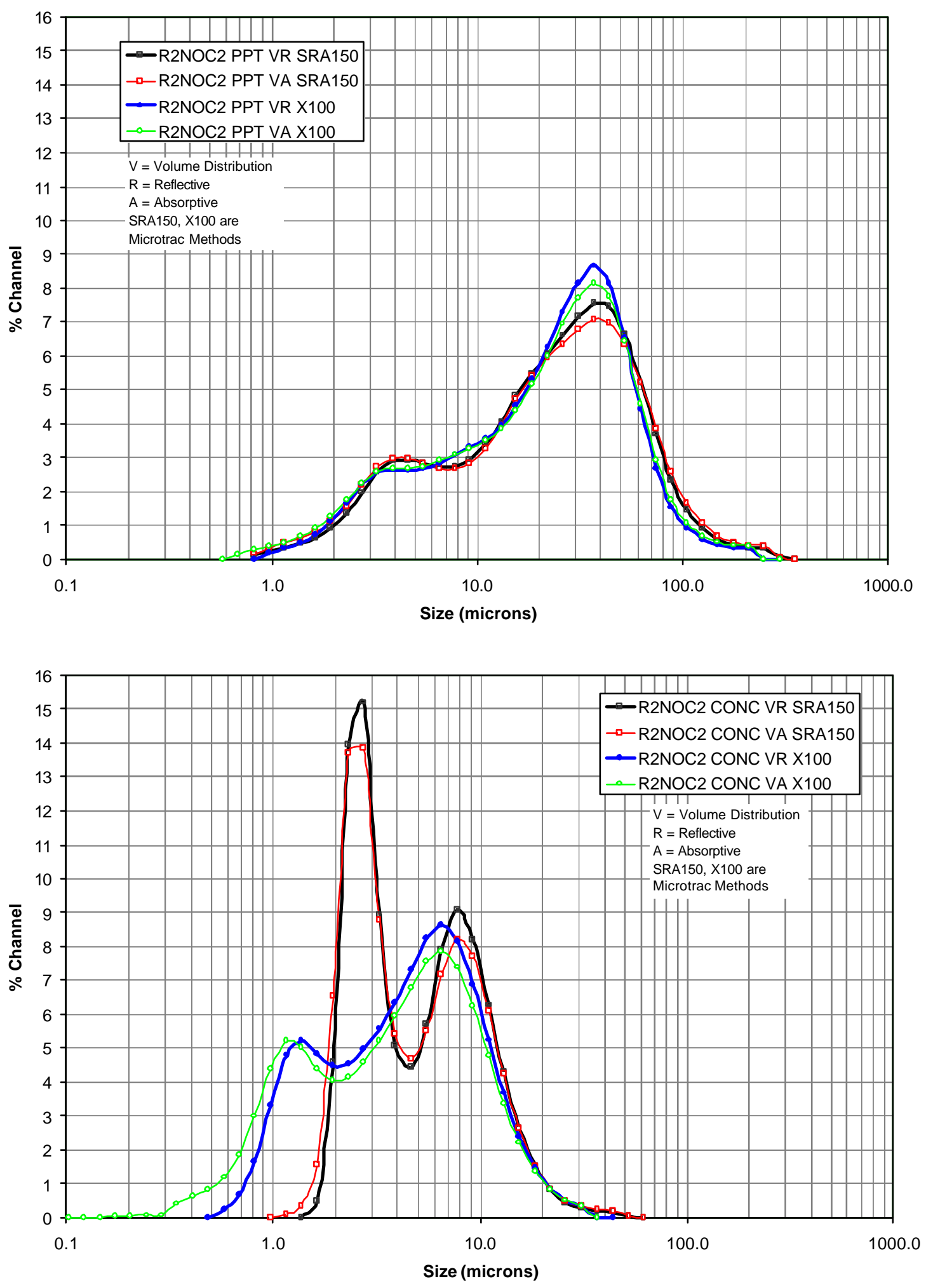

Figure 12 Particle Size Volume Distribution for R2NOC2 Slurry 
WSRC-TR-2003-00056, REV. 0

SRT-RPP-2002-00231, REV. 0
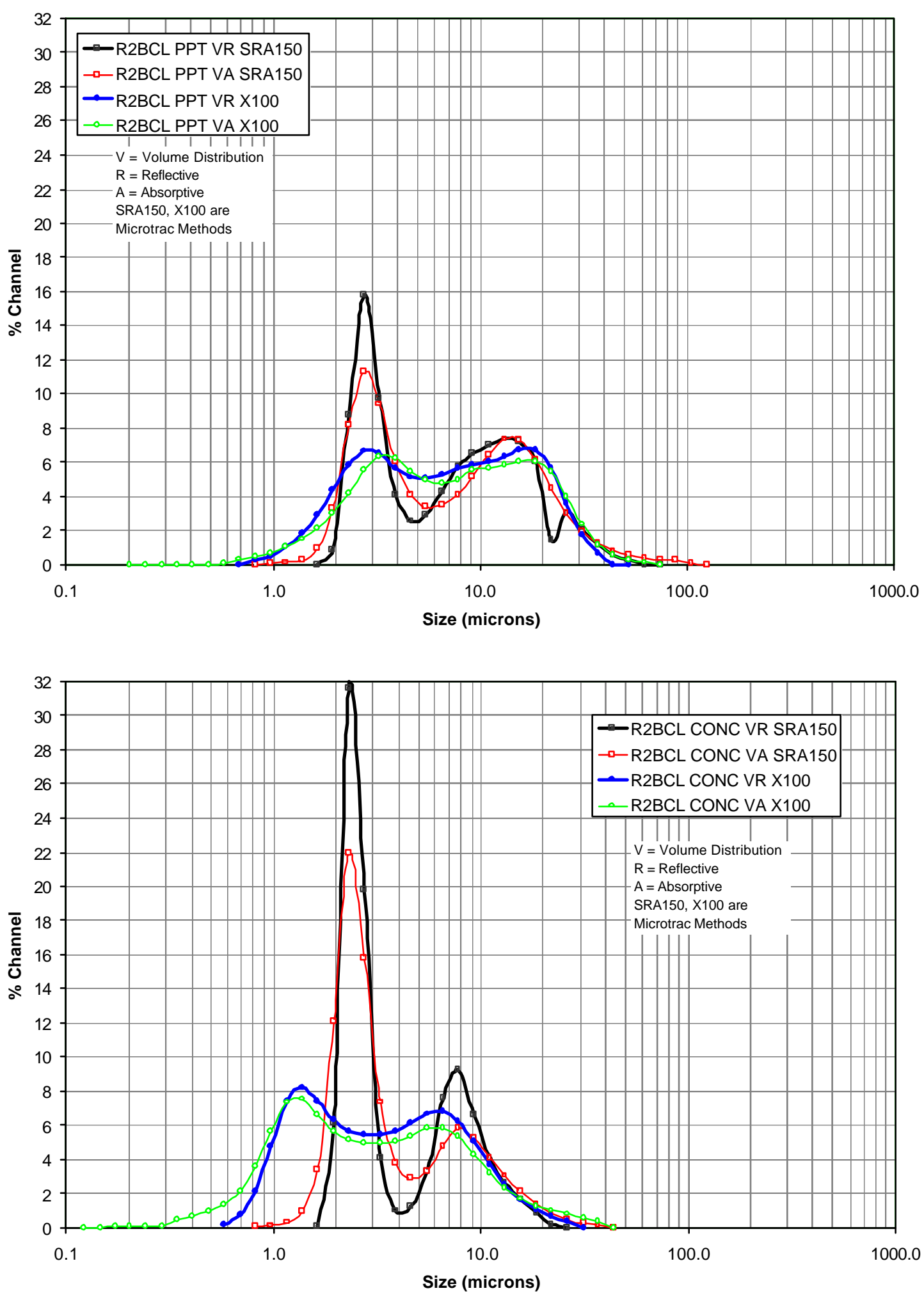

Figure 13 Particle Size Volume Distribution for R2BCL Slurry 


\section{WSRC-TR-2003-00056, REV. 0}

SRT-RPP-2002-00231, REV. 0

Overall, the R2NOC and R2BCL samples have similar distribution shapes. The R1BC data stands out as being unimodal after filtering. One factor that could affect the R1BC data is aging. These samples were about four months old, whereas the others were less than a month old; agglomeration of the R1BC samples may have occurred.

Due to the significant differences in filterability of these precipitates, we proposed that the particle size distribution may be a factor. We expected that the samples that filtered poorly might have more small particles. Figure 14 shows the volume particle size distribution of the filtered slurries measured by the X100 method assuming absorptive particles. The distributions are numbered in order of filterability, with " 1 " being the best. It appears that there may be a correlation between the approximate shape of the distribution and filterability. The same is seen the X100 reflective data. Surprisingly, the most filterable slurries appear to have more smaller particles in the $1-4 \mu \mathrm{m}$ range and in general have a flatter distribution of particle sizes.

However, the SRA150 method data does not show as strong a correlation; data for the reflective assumption are shown in Figure 15. The best and worst stand out as in the X100 data, but the two intermediate sets do not. In the absorptive mode for the SRA150 method, there was no correlation at all; all of the distributions looked essentially the same. Since the SRA150 method does not quantify particles smaller than $0.7 \mu \mathrm{m}$, any distributions plotted for materials with particles smaller than this would tend to be skewed towards larger particles, so the X100 data may be more applicable. Although filterability seems to correlate with the volumetric particle size distribution shape, there isn't really enough data to come to any firm conclusions about this relationship.

Figure 16 shows the $\mathrm{X} 100$ absorptive volume distribution for the initial precipitates. There is no correlation between filterability and the distribution, so prediction of filterability from initial particle size distribution does not appear to be possible. Additional volume distribution data plots are shown in the Appendix. Number distribution plots are also shown in the Appendix. For most of the samples, the number distribution data showed more smaller particles in the filtered slurries, as would be expected. There was not any apparent correlation between the number distribution data and filterability.

SEM photos of filtered samples from the R1BC and R2NOC1 runs are shown in Figure 17. Both photos were taken at approximately the same magnification. The samples were collected by dead-end filtration of the dilute precipitate slurries. The R2NOC1 slurry was about one week old, whereas the R1BC slurry was several months old. Both samples contain some sheet-like flat crystals, while R1BC contains numerous needle-like crystals (since R1BC sat for several months, crystallization may have occurred that would not be seen in the newer R2NOC1 material). There was no difference in appearance between the rest of the materials in either sample that would indicate why R1BC filtered so much better than R2NOC1. 
WSRC-TR-2003-00056, REV. 0

SRT-RPP-2002-00231, REV. 0

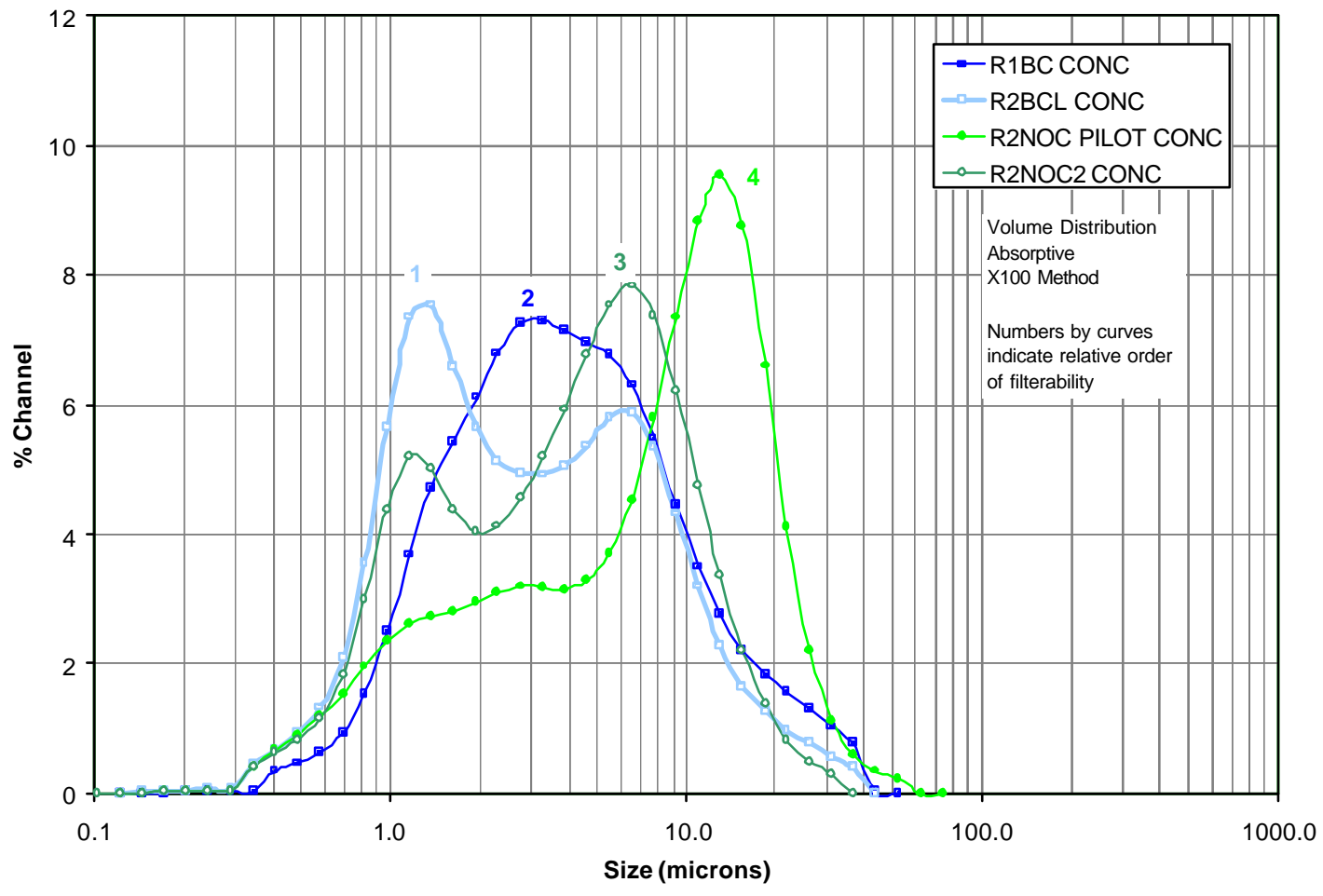

Figure 14 Volume Distributions of Concentrated Slurries by the X100 Absorptive Method

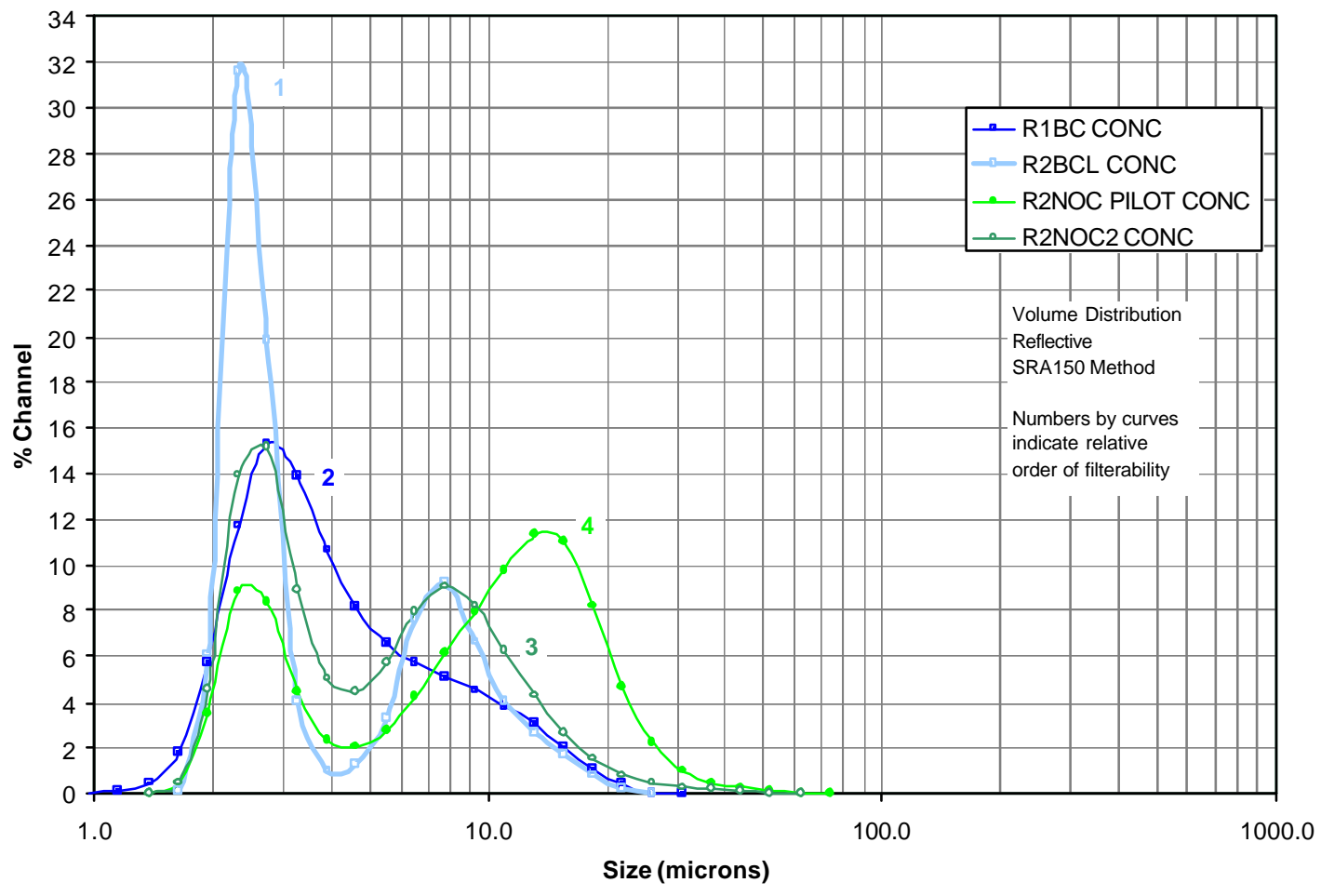

Figure 15 Volume Distributions of Concentrated Slurries by the SRA150 Reflective Method 


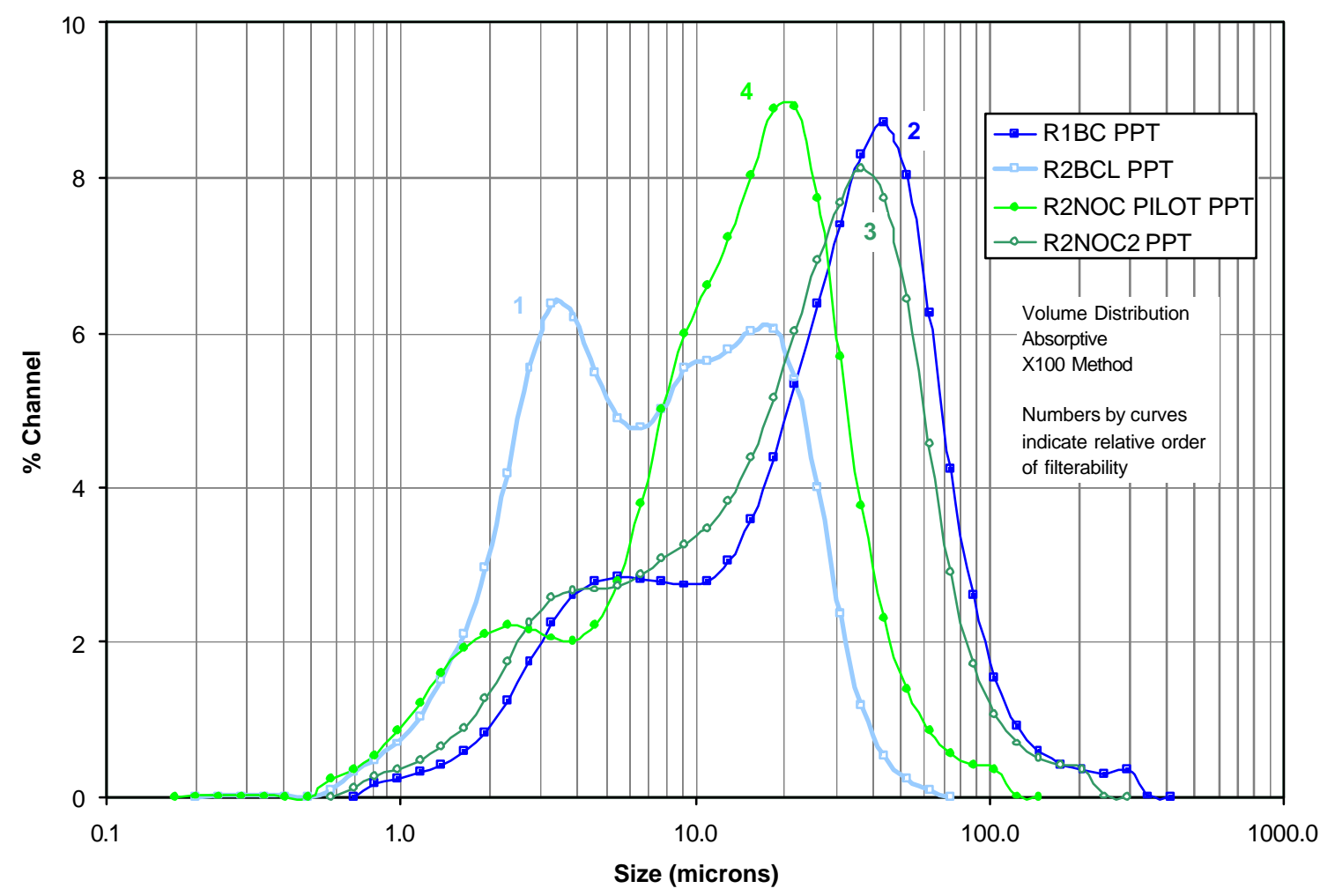

\subsubsection{Feed Decontamination - R1BC and R2NOC2 Data}

For the R1BC data, the average concentration is compared to the calculated and measured precipitate compositions in Table 20. Results for the R2NOC2 run are also shown in this table. The ratio of the concentration in the permeate to the concentration in the precipitate feed is also shown in this table. This value can be called the "percent retained" and is related to the decontamination factor (DF) as shown in Figure 18. This "percent retained" is referred to as "feed based" since it uses the permeate and feed concentrations. A "slurry based" DF uses the concentrated slurry concentration rather than the feed concentration and so is more indicative of the overall separation ability of the process. A "batch based" DF can also be defined. This DF uses the total amounts of materials separated rather than concentrations, and is this based on the processing of an individual batch. This "batch based" DF is used later in this report when the removal of soluble species from the final concentrated slurry is described. 
WSRC-TR-2003-00056, REV. 0

SRT-RPP-2002-00231, REV. 0

Figure 16 Volume Distributions of Initial Precipitates by the X100 Absorptive Method

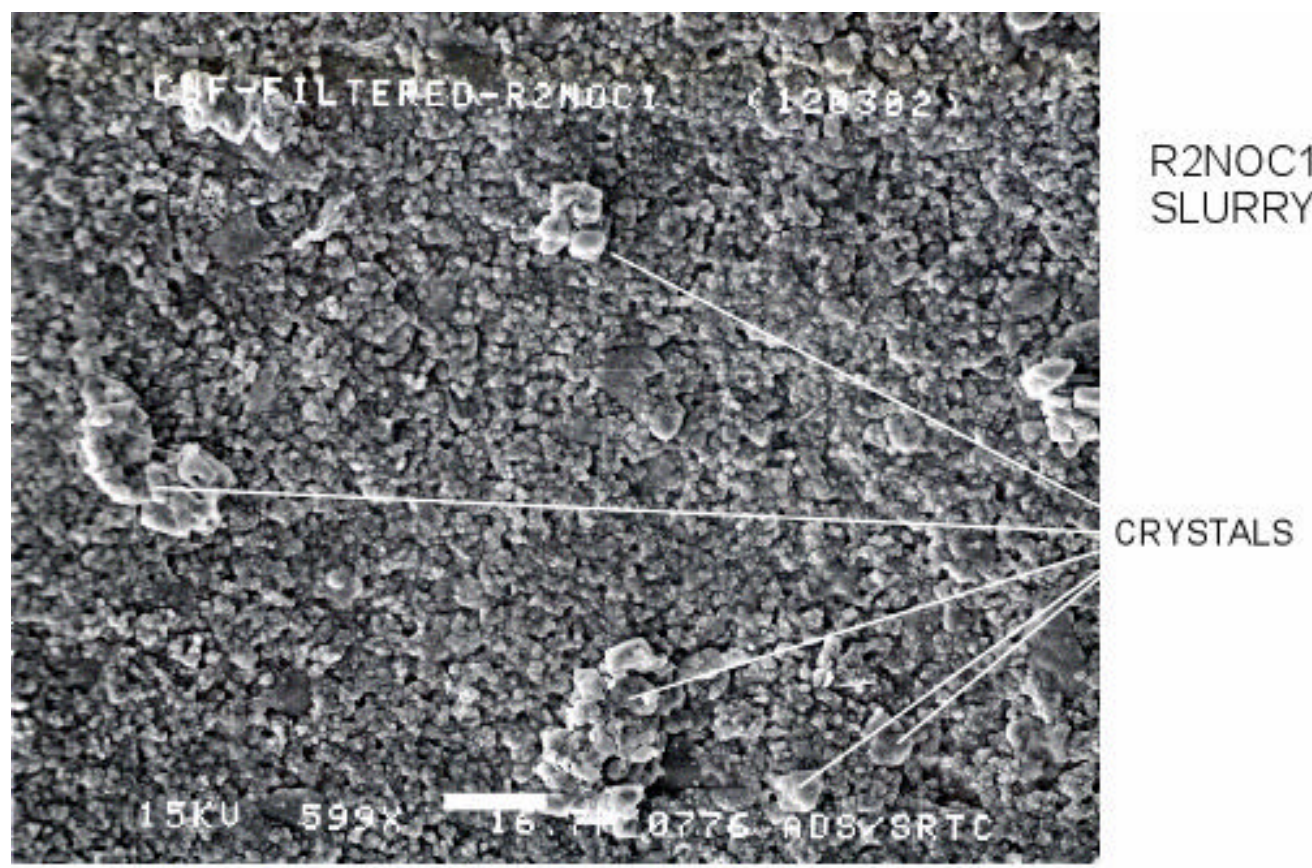

$16.7 \mu$

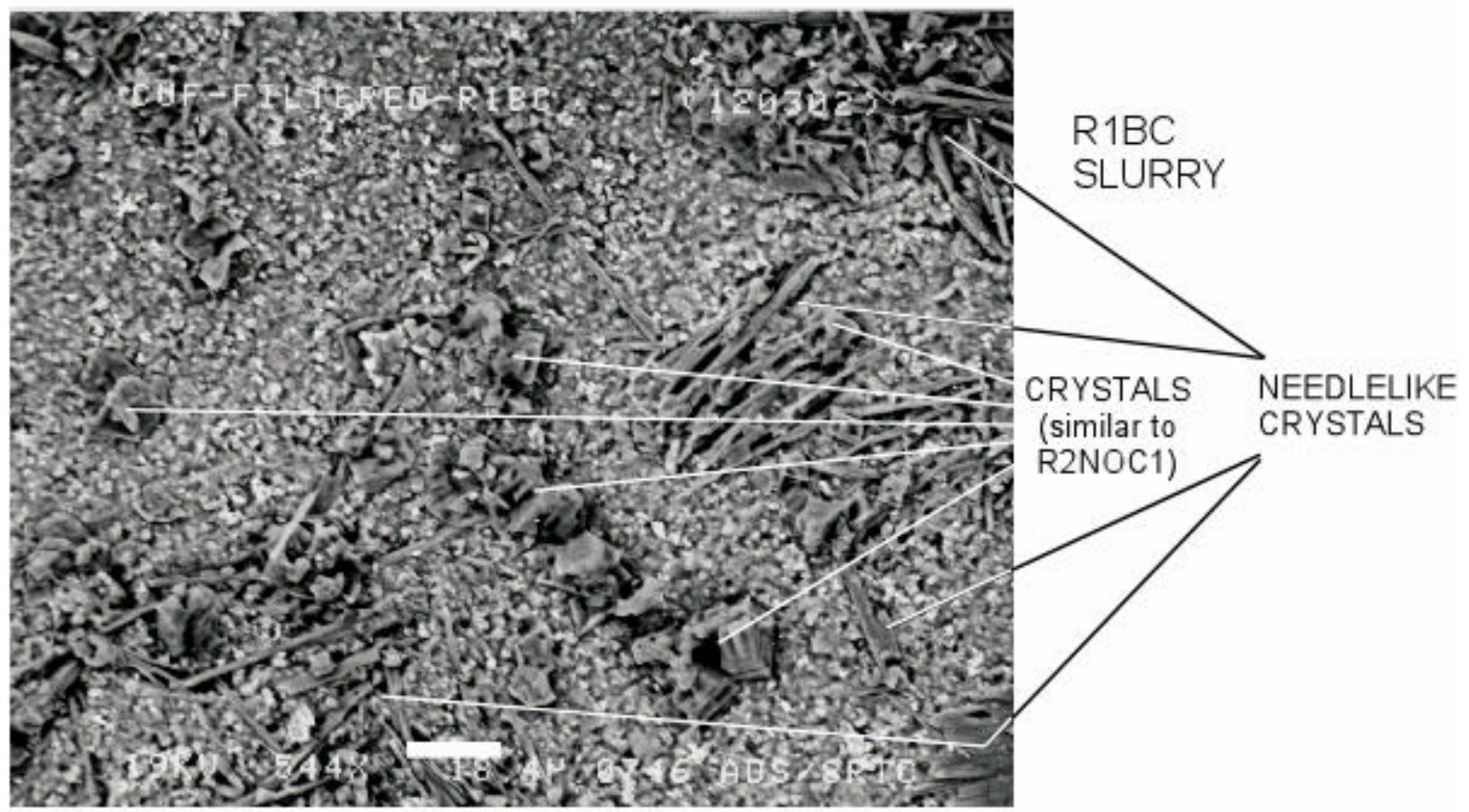

$18.4 \mu$

Figure 17 SEM Photo of Filtered R1BC \& R2NOC1 Slurries 
WSRC-TR-2003-00056, REV. 0

SRT-RPP-2002-00231, REV. 0

Table 20 Comparison of Permeate and Precipitate Compositions

\begin{tabular}{|c|c|c|c|c|c|c|c|}
\hline & \multicolumn{4}{|c|}{$\mathrm{R} 1 \mathrm{BC}$} & \multicolumn{3}{|c|}{ R2NOC2 } \\
\hline & $\begin{array}{l}\text { Average } \\
\text { Permeate }\end{array}$ & $\begin{array}{l}\text { Calculated } \\
\text { Precipitate }\end{array}$ & $\begin{array}{l}\text { Measured } \\
\text { Precipitate }\end{array}$ & $\begin{array}{c}\text { Percent } \\
\text { Retained in } \\
\text { Permeate } \\
\text { (Feed Based) }\end{array}$ & Permeate & $\begin{array}{l}\text { Measured } \\
\text { Precipitate }\end{array}$ & $\begin{array}{c}\text { Percent } \\
\text { Retained in } \\
\text { Permeate } \\
\text { (Feed Based) }\end{array}$ \\
\hline \multicolumn{8}{|l|}{ ICPES $(\mathrm{mg} / \mathrm{L})$} \\
\hline $\mathrm{Al}$ & 7530 & 7670 & 7540 & $98.2-99.9$ & 8980 & 8730 & 103 \\
\hline $\mathrm{B}$ & 23.4 & 22.9 & $<92$ & approx. 100 & 28.2 & 65.5 & 43.1 \\
\hline $\mathrm{Ba}$ & $<0.02$ & 0.1 & 189 & approx. 0 & $<0.02$ & 30.1 & approx. 0 \\
\hline $\mathrm{Ca}$ & 96.5 & 306 & 306 & 31.5-31.6 & 89.4 & 703 & 12.7 \\
\hline $\mathrm{Cd}$ & 36.07 & 37.9 & 36.1 & $95.1-99.8$ & 4.1 & 45.5 & 89.0 \\
\hline $\mathrm{Co}$ & $<0.088$ & 2.1 & $<35$ & NA & $<0.2$ & NA & NA \\
\hline $\mathrm{Cr}$ & 146 & 160 & 162 & $90.1-91.7$ & 146 & 173 & 84.3 \\
\hline $\mathrm{Cu}$ & 3.8 & 15.1 & $<35$ & 25.0 & 6.7 & 18.6 & 35.8 \\
\hline $\mathrm{Fe}$ & 0.5 & 30.2 & 196 & $0.28-1.79$ & 2.7 & 140 & 1.9 \\
\hline $\mathrm{Li}$ & 0.2 & 1.0 & $<47$ & 24.0 & $<0.2$ & NA & NA \\
\hline $\mathrm{Mg}$ & $<0.2$ & 0 & $<41$ & NA & $<0.2$ & 27.9 & $<0.6$ \\
\hline $\mathrm{Mn}$ & 0.3 & 2770 & 2320 & $0.012-0.014$ & 12.2 & 1870 & 0.7 \\
\hline Mo & 28.6 & 28.1 & $<69$ & 102.0 & 34.5 & 37.9 & 91.2 \\
\hline $\mathrm{Na}$ & 138000 & 135000 & 135000 & 102.0 & 136000 & 129000 & 106 \\
\hline $\mathrm{Ni}$ & 199 & 260 & 270 & 73.5-76.6 & 275 & 324 & 84.9 \\
\hline $\mathrm{P}$ & 568 & 1140 & 768 & 49.7-74.0 & 775 & 1220 & 63.6 \\
\hline $\mathrm{Pb}$ & 39.4 & 116 & $<302$ & 34.0 & 47.4 & 274 & 17.3 \\
\hline $\mathrm{Si}$ & 15.5 & 6.5 & $<69$ & 240.4 & 27.1 & 88.0 & 30.8 \\
\hline $\mathrm{Sn}$ & $<0.7$ & 0 & $<163$ & NA & 1.0 & 95.0 & 1.1 \\
\hline $\mathrm{Sr}$ & 26.8 & 6570 & 5360 & $0.41-0.50$ & 22.9 & 3210 & 0.7 \\
\hline $\mathrm{Ti}$ & $<0.3$ & 0 & $<69$ & NA & $<0.3$ & $\mathrm{NM}$ & NA \\
\hline $\mathrm{V}$ & $<0.3$ & 0 & $<69$ & NA & $<0.3$ & NM & NA \\
\hline $\mathrm{Zn}$ & 2.5 & 3.2 & $<163$ & 79.3 & 1.7 & 84.5 & 2.0 \\
\hline $\mathrm{Zr}$ & 0.5 & 8.5 & $<23$ & 5.78 & 3.2 & 10.0 & 31.5 \\
\hline $\mathrm{La}$ & 1.4 & 9.9 & $<324$ & 14.1 & 3.0 & 211 & 1.4 \\
\hline $\mathrm{K}$ & 2100 & 1270 & 293 & $\mathrm{NC}$ & 1840 & 1460 & 126 \\
\hline $\mathrm{S}$ & 2830 & 2640 & NM & 107.1 & 3180 & NM & NA \\
\hline $\mathrm{Nd}$ & 0.9 & 19.9 & $<232$ & 4.38 & 6.1 & 109 & 5.6 \\
\hline $\mathrm{Ce}, \mathrm{Cs}, \mathrm{Rb}, \mathrm{W}$ & NM & not shown & NM & $\mathrm{NC}$ & & & \\
\hline \multicolumn{8}{|l|}{ Ion Chrom. } \\
\hline $\mathrm{NO}_{2}^{-}$ & 44000 & 48100 & 5900 & 86.4-91.4 & 50500 & NA & NA \\
\hline $\mathrm{NO}_{3}^{-}$ & 126000 & 137000 & 134000 & $92.2-94.0$ & 124000 & NA & NA \\
\hline $\mathrm{Cl}^{-}$ & 2780 & 2980 & 3030 & $91.8-93.3$ & 3150 & NA & NA \\
\hline $\mathrm{F}^{-}$ & 712 & 1080 & 1440 & 49.4-65.8 & 1180 & NA & NA \\
\hline $\mathrm{PO}_{4}^{-3}$ & 2370 & 3500 & 2680 & $67.5-88.4$ & 3310 & NA & NA \\
\hline $\mathrm{SO}_{4}^{-2}$ & 7010 & 7910 & 7590 & $88.6-92.3$ & 8460 & NA & NA \\
\hline formate & 4870 & 5240 & 5770 & $84.3-93.0$ & 5860 & NA & NA \\
\hline oxalate & 679 & 397 & 1960 & 34.6-171.1 & 1020 & NA & NA \\
\hline
\end{tabular}

Bold indicates species with permeate concentrations significantly lower than in precipitate. 


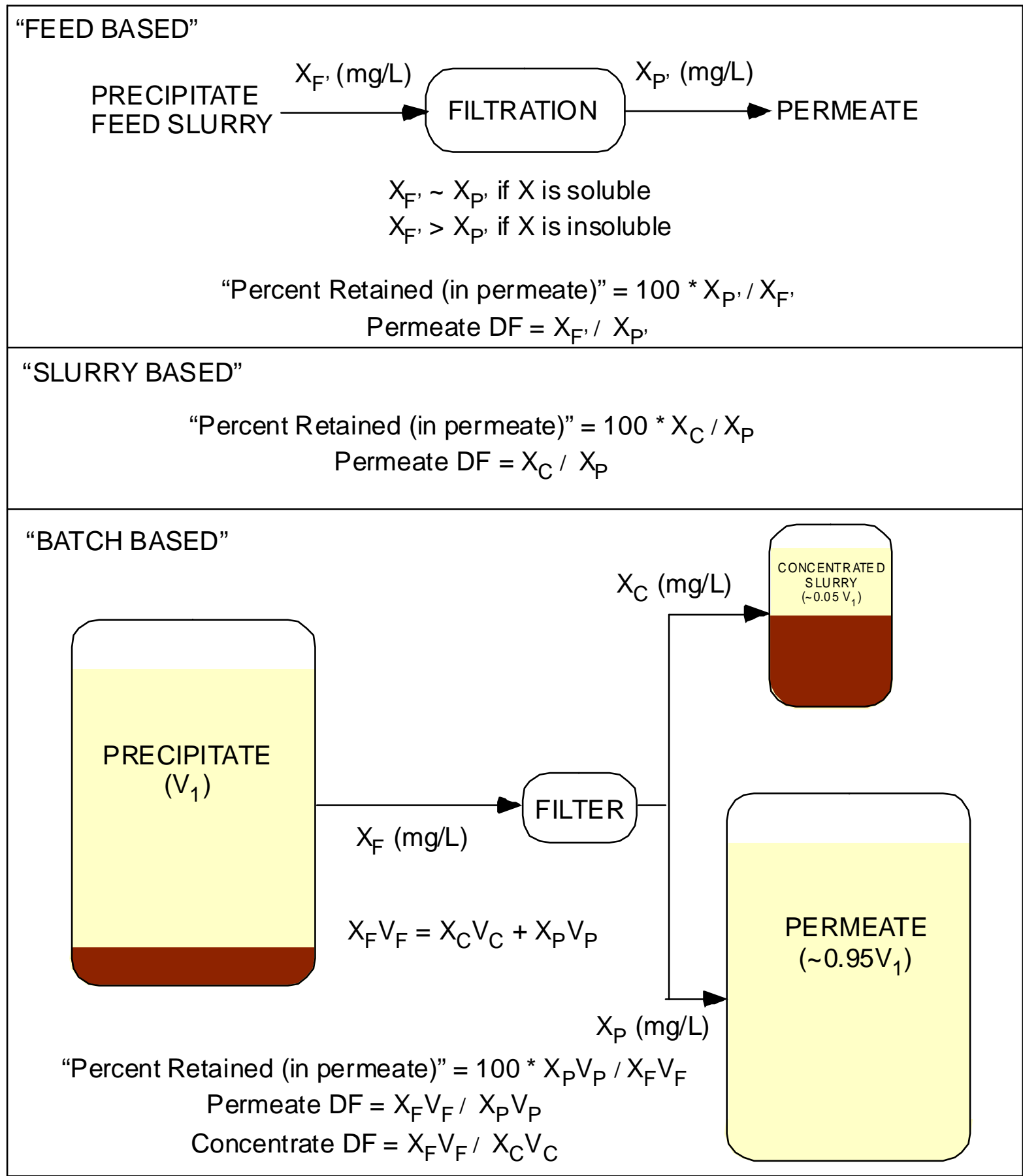

\section{Figure 18 Definitions for Percent Retained and Decontamination Factor}

The precipitate compositions in Table 20 for $\mathrm{R} 1 \mathrm{BC}$ are the batch \#1 calculated precipitate composition (adjusted for added $\mathrm{Na}$ and also for the dilution from the reagent additions) and the average measured composition; the R2NOC2 precipitate compositions shown are the measured values. Some species are precipitated along with $\mathrm{Sr}$ and $\mathrm{Mn}$ during the $\operatorname{Sr}\left(\mathrm{NO}_{3}\right)_{2}$ and $\mathrm{NaMnO}_{4}$ additions; these have a lower concentration in the permeate and are shown in bold face. The percent retained in the permeate (feed based) is given for both data sets. For both R1BC and R2NOC2, the species that appear to have been precipitated (in addition to $\mathrm{Sr}$ 
and $\mathrm{Mn}$ ) are $\mathrm{Ca}, \mathrm{Cu}, \mathrm{Fe}, \mathrm{P}\left(\mathrm{PO}_{4}^{-3}\right), \mathrm{Pb}, \mathrm{Zr}, \mathrm{La}, \mathrm{Nd}, \mathrm{Ni}, \mathrm{F}$, and oxalate. Zinc was also removed to some extent. In $\mathrm{R} 2 \mathrm{NOC} 2$, boron, $\mathrm{Mg}, \mathrm{Si}$, and $\mathrm{Sn}$ were also depleted in the permeate. The concentration of the remaining species are essentially the same in the permeate as in the precipitate. One exception is $\mathrm{K}$, but the analyses for K by ICPES have been determined to be unreliable.

As previously stated, phosphorus (as $\mathrm{PO}_{4}^{-3}$ ) and fluoride may have precipitated as sodium fluorophosphate. The drop in the fluoride concentration, on a molar basis, was greater than the drop in the phosphate, so this precipitate would not account for the entire amount of fluoride removed. Some of the $\mathrm{Ca}$ and most of the $\mathrm{La}, \mathrm{Nd}$, and $\mathrm{Zn}$ were added as the insoluble oxalates. $\mathrm{Zr}, \mathrm{Fe}$, and $\mathrm{Ni}$ were added as oxides and $\mathrm{Pb}$ as the sulfate. All of these are relatively insoluble, so these would be expected to be removed during filtration. $\mathrm{Cu}$, which was removed, was added as the nitrate, but could have formed the insoluble oxalate.

Table 21 shows the amount retained in the permeate (expressed as the fraction retained) and the feed based DFs compared to the DFs calculated for data from the Large C run. Data shown as ">" for fraction retained means the feed concentration was below the detection limit, whereas values shown as "<" had permeate concentrations below detection limits. Since the DF is the inverse of the fraction retained, the sign on the corresponding DF is the opposite of the fraction retained value.

$$
\text { Fraction Retained } \begin{aligned}
& =\frac{\mathrm{X}}{<\mathrm{Y}}=>\frac{\mathrm{X}}{\mathrm{Y}} \\
\text { or } & =\frac{<\mathrm{X}}{\mathrm{Y}}=<\frac{\mathrm{X}}{\mathrm{Y}} \\
\mathrm{DF} & =\frac{<\mathrm{Y}}{\mathrm{X}}=<\frac{\mathrm{Y}}{\mathrm{X}} \\
\text { or } & =\frac{>\mathrm{Y}}{\mathrm{X}}=>\frac{\mathrm{Y}}{\mathrm{X}}
\end{aligned}
$$

For the R1BC data, the permeate concentration used was the average of the concentrations measured and at 13.3 and $17.2 \mathrm{wt} \%$ insoluble solids. For the R2NOC2 data, the permeate composition was measured at approximately $10 \mathrm{wt} \%$ insoluble solids in the slurry. The DFs found in this work compare favorably with those found in the Large $\mathrm{C}$ work. In this work the $\mathrm{DF}$ for $\mathrm{Cu}$ was noticeably smaller, but the small amount present resulted in large uncertainty in the DF value. The DF for Fe was much higher here, and was similar to $\mathrm{Zr}$ and $\mathrm{Nd}$. The DFs for nitrite, nitrate, and chloride should all be about unity since most of these should be very soluble. The measured values are all around 1.08. The higher DFs for fluoride and phosphate could possibly be due to formation of sodium fluorophosphate, which has been found in the simulant. ${ }^{6}$ 
WSRC-TR-2003-00056, REV. 0

SRT-RPP-2002-00231, REV. 0

Table 21 Decontamination Factors and Fraction Retained

\begin{tabular}{|c|c|c|c|c|c|c|c|}
\hline & \multicolumn{4}{|c|}{ R1BC } & \multirow[t]{2}{*}{ Hot CUF } & \multirow{2}{*}{\multicolumn{2}{|c|}{$\begin{array}{c}\text { R2NOC2 } \\
\text { Based on Measured Feed } \\
\text { Composition } \\
\end{array}$}} \\
\hline & \multicolumn{2}{|c|}{$\begin{array}{c}\text { Based on Calculated Feed } \\
\text { Composition }\end{array}$} & \multicolumn{2}{|c|}{$\begin{array}{c}\text { Based on Measured Feed } \\
\text { Composition }\end{array}$} & & & \\
\hline & $\begin{array}{c}\text { Fraction } \\
\text { Retained in } \\
\text { Permeate }\end{array}$ & DF & $\begin{array}{c}\text { Fraction } \\
\text { Retained in } \\
\text { Permeate }\end{array}$ & DF & DF & $\begin{array}{c}\text { Fraction } \\
\text { Retained in } \\
\text { Permeate }\end{array}$ & DF \\
\hline $\mathrm{Al}$ & 0.98 & 1.02 & 1.00 & 1.00 & 0.9 & 1.03 & 0.97 \\
\hline B & 1.02 & 0.98 & $>0.254$ & $<3.9$ & & 0.43 & 2.32 \\
\hline $\mathrm{Ca}$ & 0.32 & 3.17 & 0.32 & 3.17 & 2.4 & 0.13 & 7.86 \\
\hline $\mathrm{Cd}$ & 0.95 & 1.05 & 1.00 & 1.00 & & 0.89 & 1.12 \\
\hline $\mathrm{Cr}$ & 0.92 & 1.09 & 0.90 & 1.11 & & 0.84 & 1.19 \\
\hline $\mathrm{Cu}$ & 0.25 & 4.00 & $>0.11$ & $<9.3$ & $>10$ & 0.36 & 2.79 \\
\hline $\mathrm{Fe}$ & 0.018 & 55.8 & 0.0028 & 363 & 5.3 & 0.02 & 52.8 \\
\hline $\mathrm{La}$ & $<0.14$ & $>7.1$ & $>0.0043$ & $<231$ & & $>0.014$ & $<71$ \\
\hline$* \mathrm{Mn}$ & 0.013 & 74.7 & NA & NA & & NA & NA \\
\hline$* * \mathrm{Mn}$ & 0.00012 & 8250 & 0.00015 & 6920 & & 0.0065 & 153 \\
\hline Mo & 1.02 & 0.98 & $>0.42$ & $<2.4$ & & 0.91 & 1.10 \\
\hline $\mathrm{Na}$ & 1.02 & 0.98 & 1.02 & 0.98 & & 1.06 & 0.95 \\
\hline $\mathrm{Ni}$ & 0.77 & 1.31 & 0.74 & 1.35 & 1.0 & 0.85 & 1.18 \\
\hline $\mathrm{P}$ & 0.50 & 2.01 & 0.74 & 1.36 & 1.1 & 0.64 & 1.57 \\
\hline $\mathrm{Pb}$ & 0.34 & 2.94 & $>0.13$ & $<7.7$ & & $>0.17$ & $<5.8$ \\
\hline $\mathrm{Si}$ & 2.40 & 0.42 & $>0.23$ & $<4.4$ & & 0.31 & 3.24 \\
\hline$* \mathrm{Sr}$ & 13.2 & 0.076 & NA & NA & & NA & NA \\
\hline$* * \mathrm{Sr}$ & 0.0041 & 245 & 0.0050 & 200 & & 0.0071 & 140 \\
\hline $\mathrm{Zn}$ & 0.79 & 1.26 & $>0.016$ & $<64$ & 1.3 & $>0.020$ & $<51$ \\
\hline $\mathrm{Zr}$ & 0.058 & 17.3 & $>0.021$ & $<47$ & & $>0.32$ & $<3.2$ \\
\hline $\mathrm{K}$ & 1.65 & 0.60 & $\mathrm{NC}$ & $\mathrm{NC}$ & & 1.26 & 0.79 \\
\hline $\mathrm{S}$ & 1.07 & 0.93 & $\mathrm{NC}$ & $\mathrm{NC}$ & 1.0 & $\mathrm{NC}$ & $\mathrm{NC}$ \\
\hline $\mathrm{Nd}$ & 0.044 & 22.9 & $>0.0037$ & $<267$ & & 0.056 & 18.0 \\
\hline $\mathrm{NO}_{2}^{-}$ & 0.91 & 1.09 & 0.86 & 1.16 & & NA & NA \\
\hline $\mathrm{NO}_{3}^{-}$ & 0.92 & 1.08 & 0.94 & 1.06 & & NA & NA \\
\hline $\mathrm{Cl}-$ & 0.93 & 1.07 & 0.92 & 1.09 & & NA & NA \\
\hline F- & 0.66 & 1.52 & 0.49 & 2.03 & & NA & NA \\
\hline $\mathrm{PO}_{4}^{-3}$ & 0.68 & 1.48 & 0.88 & 1.13 & & NA & NA \\
\hline $\mathrm{SO}_{4}^{-2}$ & 0.89 & 1.13 & 0.92 & 1.08 & & NA & NA \\
\hline
\end{tabular}

* Mn and $\mathrm{Sr}$ values based on concentrations before additional of $\operatorname{Sr}\left(\mathrm{NO}_{3}\right)_{2}$ and $\mathrm{NaMnO}_{4}$. ** $\mathrm{Mn}$ and $\mathrm{Sr}$ values based on concentrations after addition of $\mathrm{Sr}\left(\mathrm{NO}_{3}\right)_{2}$ and $\mathrm{NaMnO}_{4}$.

$\mathrm{NC}=$ not calculated; $\mathrm{NA}=$ not available; see text for explanation of "<" and ">" values.

Whereas the goal of the precipitation is to remove Sr and TRU from the LAW (permeate) to minimize the volume of HLW produced, minimization of the amount of soluble non-radioactive species in the concentrated slurry is also required. The "permeate batch DF" or "batch percent retained" defined earlier is a good measure of the overall separation of the process. To calculate these measures, we can use either of the following equations, which should be equivalent: 
Permeate Batch DF $=\frac{x_{F} V_{F}}{x_{P} V_{P}}=\frac{x_{F} V_{F}}{x_{F} V_{F}-x_{C} V_{C}}$

where $x_{F}=$ concentrat ion in feed slurry, $\mathrm{mg} / \mathrm{L}$

$\mathrm{X}_{\mathrm{P}}=$ concentrat ion in permeate, $\mathrm{mg} / \mathrm{L}$

$\mathrm{x}_{\mathrm{C}}=$ concentrat ion in concentrat ed slurry, $\mathrm{mg} / \mathrm{L}$

$\mathrm{V}_{\mathrm{F}}=$ volume of feed slurry, $\mathrm{L}$

$\mathrm{V}_{\mathrm{P}}=$ volume of permeate, $\mathrm{L}$

$\mathrm{V}_{\mathrm{C}}=$ volume of concentrat ed slurry, $\mathrm{L}$

However, due to measurement errors of both compositions and volumes, these are not equal. To judge the consistency of the data, the final washed slurry concentrations can be calculated from the initial slurry and permeate compositions and volumes:

$\mathrm{x}_{\mathrm{C}}=\frac{\mathrm{x}_{\mathrm{F}} \mathrm{V}_{\mathrm{F}}-\mathrm{x}_{\mathrm{P}} \mathrm{V}_{\mathrm{P}}}{\mathrm{V}_{\mathrm{C}}}$

The measured and calculated washed slurry compositions are shown in Table 22. The calculated washed slurry values for $\mathrm{Al}, \mathrm{Ca}, \mathrm{Cd}, \mathrm{Dr}, \mathrm{Mn}, \mathrm{Ni}$, and $\mathrm{Sr}$ match reasonably well. Other data shows more deviation due to the error in taking the differences between large numbers. Particularly, the calculated values for the anion data are all high. Other calculations were not reliable since below detection limit values had to be used.

Table 23 shows the batch basis DFs based on both the measured and calculated composition. The DFs for both permeate and concentrated slurry bases are given. The values calculated by differences (shown in italics) are less accurate. The DFs are not shown for species that required the use of data below instrumental detection limits to determine the DFs.

Table 22 Measured and Calculated Concentrated Washed Slurry Concentrations

\begin{tabular}{|r|rr|r|rr|r|rc|}
\hline & $\begin{array}{c}\text { Measured } \\
(\mathrm{mg} / \mathrm{L})\end{array}$ & $\begin{array}{c}\text { Calculated } \\
(\mathrm{mg} / \mathrm{L})\end{array}$ & & $\begin{array}{c}\text { Measured } \\
(\mathrm{mg} / \mathrm{L})\end{array}$ & $\begin{array}{c}\text { Calculated } \\
(\mathrm{mg} / \mathrm{L})\end{array}$ & & $\begin{array}{c}\text { Measured } \\
(\mathrm{mg} / \mathrm{L})\end{array}$ & $\begin{array}{c}\text { Calculated } \\
(\mathrm{mg} / \mathrm{L})\end{array}$ \\
\hline $\mathrm{Al}$ & 4730 & 4570 & $\mathrm{Mo}$ & $<67$ & 664 & $\mathrm{La}$ & $<314$ & 5170 \\
\hline $\mathrm{B}$ & $<90$ & 1110 & $\mathrm{Na}$ & 76300 & 34700 & $\mathrm{~K}$ & $<224$ & $\mathrm{NC}$ \\
\hline $\mathrm{Ba}$ & 2440 & 3020 & $\mathrm{Ni}$ & 958 & 1280 & $\mathrm{Nd}$ & $<224$ & 3700 \\
\hline $\mathrm{Ca}$ & 3040 & 3410 & $\mathrm{P}$ & 1290 & 3390 & $\mathrm{NO}_{2}^{-}$ & 18200 & 135000 \\
\hline $\mathrm{Cd}$ & 45.3 & 19.6 & $\mathrm{~Pb}$ & 1030 & 4240 & $\mathrm{NO}_{3}^{-}$ & 57600 & 205000 \\
\hline $\mathrm{Co}$ & $<34$ & 560 & $\mathrm{Si}$ & $<67$ & 865 & $\mathrm{Cl}^{-}$ & 1130 & 5620 \\
\hline $\mathrm{Cr}$ & 251 & 343 & $\mathrm{Sn}$ & $<157$ & 2600 & $\mathrm{~F}^{-}$ & 467 & 11800 \\
\hline $\mathrm{Cu}$ & 174 & 505 & $\mathrm{Sr}$ & 85500 & 85400 & $\mathrm{PO}_{4}^{-3}$ & 1090 & 6000 \\
\hline $\mathrm{Fe}$ & 673 & 3140 & $\mathrm{Ti}$ & $<67$ & 1100 & $\mathrm{SO}_{4}^{-2}$ & 3620 & 12800 \\
\hline $\mathrm{Li}$ & $<45$ & 749 & $\mathrm{~V}$ & $<67$ & 1100 & formate & 3220 & 16500 \\
\hline $\mathrm{Mg}$ & 234 & 654 & $\mathrm{Zn}$ & $<157$ & 2570 & oxalate & 10900 & 17800 \\
\hline $\mathrm{Mn}$ & 37300 & 37200 & $\mathrm{Zr}$ & 143 & 361 & & & \\
\hline
\end{tabular}

Values with "<" were below the detection limits. Values shown in small blue italics were calculated from one or more below detection limit $(<)$ measurements. 
Table 23 Permeate and Concentrate Decontamination Factors

\begin{tabular}{|c|c|c|c|c|}
\hline & $\begin{array}{c}\text { Permeate DF } \\
\text { (from measured } \\
\text { permeate and } \\
\text { initial slurry) }\end{array}$ & $\begin{array}{c}\text { Permeate DF } \\
\text { (from measured } \\
\text { concentrate and } \\
\text { initial slurry) }\end{array}$ & $\begin{array}{c}\text { Concentrate DF } \\
\text { (from measured } \\
\text { permeate and } \\
\text { initial slurry) }\end{array}$ & $\begin{array}{c}\text { Concentrate DF } \\
\text { (from measured } \\
\text { concentrate and } \\
\text { initial slurry) }\end{array}$ \\
\hline $\mathrm{Al}$ & 1.04 & 1.04 & 26.4 & 25.5 \\
\hline $\mathrm{Ca}$ & 3.28 & 2.63 & 1.44 & 1.61 \\
\hline $\mathrm{Cd}$ & 1.04 & 1.08 & 29.6 & 12.8 \\
\hline $\mathrm{Cr}$ & 1.15 & 1.11 & 7.58 & 10.4 \\
\hline $\mathrm{Fe}$ & 387 & 1.27 & 1.00 & 4.68 \\
\hline $\mathrm{Mn}$ & 6290 & $N A$ & 1.00 & 1.00 \\
\hline $\mathrm{Na}$ & 1.02 & 1.04 & 62.3 & 28.4 \\
\hline $\mathrm{Ni}$ & 1.42 & 1.28 & 3.39 & 4.52 \\
\hline $\mathrm{P}$ & 1.38 & 1.12 & 3.63 & 9.54 \\
\hline $\mathrm{Sr}$ & 209 & 221 & 1.00 & 1.00 \\
\hline $\mathrm{NO}_{2}^{-}$ & 1.20 & 1.02 & $N C$ & $\mathrm{NC}$ \\
\hline $\mathrm{NO}_{3}^{-}$ & 1.11 & 1.03 & $N C$ & $\mathrm{NC}$ \\
\hline $\mathrm{Cl}^{-}$ & 1.13 & 1.02 & $N C$ & $\mathrm{NC}$ \\
\hline $\mathrm{F}$ & 2.04 & 1.02 & $N C$ & $\mathrm{NC}$ \\
\hline $\mathrm{PO}_{4}^{-3}$ & 1.16 & 1.03 & $N C$ & $\mathrm{NC}$ \\
\hline $\mathrm{SO}_{4}^{-2}$ & 1.12 & 1.03 & $N C$ & $\mathrm{NC}$ \\
\hline formate & 1.22 & 1.04 & $N C$ & $\mathrm{NC}$ \\
\hline oxalate & 2.31 & 1.53 & $N C$ & $\mathrm{NC}$ \\
\hline
\end{tabular}

blue italics: calculated by differences, thus less accurate

\subsubsection{Filtration - Remediation 1 Baseline Conditions}

\subsubsection{Clean Water and Strontium Carbonate Fluxes}

"Clean water" and strontium carbonate fluxes were measured both before and after these experiments were started, per Table 24 . The "clean water" fluxes were actually measured using deionized water filtered through a $0.1 \mu \mathrm{m}$ filter followed by addition of reagent grade $\mathrm{NaOH}$ to a concentration of approximately $0.01 \mathrm{M}$. Herein, this material will be referred to as "inhibited water" and the fluxes measured with it as "clean water" fluxes.

Prior to measuring the clean water and $\mathrm{SrCO}_{3}$ fluxes, the CUF unit was cleaned by soaking in approximately $2 \mathrm{M}$ nitric acid. After soaking, the unit was flushed with several feed tank volumes of inhibited water to remove residual nitric acid. The $\mathrm{pH}$ of the water was checked during the flushing with inhibited water to assure that acid present was neutralized and flushed out. The clean water fluxes measured are shown in Figure 19. (The data reported was taken during the R1BC runs; data from the later runs with $\mathrm{R} 2$ simulant are similar, but are not reported here.) 
Table 24 Factorial Design Test Conditions for R1BC

\begin{tabular}{|c|c|c|c|c|c|c|c|}
\hline $\begin{array}{c}\text { Test No. } \\
\text { (Lab } \\
\text { Book) }\end{array}$ & $\begin{array}{c}\text { Task } \\
\text { Plan } \\
\text { Test No. }\end{array}$ & $\begin{array}{c}\text { Trans- } \\
\text { membrane } \\
\text { Pressure } \\
\text { (psi) }\end{array}$ & $\begin{array}{c}\text { Crossflow } \\
\text { Velocity } \\
\text { (ft/s) }\end{array}$ & $\begin{array}{c}\text { Test No. } \\
\text { (Lab } \\
\text { Book) }\end{array}$ & $\begin{array}{c}\text { Task } \\
\text { Plan } \\
\text { Test No. }\end{array}$ & $\begin{array}{c}\text { Trans- } \\
\text { membrane } \\
\text { Pressure } \\
\text { (psi) }\end{array}$ & $\begin{array}{c}\text { Crossflow } \\
\text { Velocity } \\
(\mathrm{ft} / \mathrm{s})\end{array}$ \\
\hline \multicolumn{4}{|c|}{$0.1 \mu \mathrm{m}$ Filtered Deionized Inhibited Water } & \multicolumn{4}{|c|}{ At approx. $15 \mathrm{wt} \%$ Insoluble Solids } \\
\hline & 1.0 & $10,20,30$ & 11 & $15-\mathrm{a}$ & 1.17 & 40 & 11 \\
\hline \multicolumn{4}{|c|}{$5 \%$ wt Strontium Carbonate in $0.01 \mathrm{M} \mathrm{NaOH}$} & $15-b$ & $1.29 \mathrm{a}$ & 50 & 12 \\
\hline & 1.1 & $10,20,30$ & 11 & $15-\mathrm{c}$ & 1.20 & 30 & 9 \\
\hline \multicolumn{4}{|c|}{$0.1 \mu \mathrm{m}$ Filtered Deionized Inhibited Water } & $15-d$ & $1.29 \mathrm{~b}$ & 30 & 15 \\
\hline & 1.2 & 20 & 11 & $15-\mathrm{e}$ & $1.29 \mathrm{c}$ & 70 & 9 \\
\hline \multicolumn{4}{|l|}{ Feed } & $15-\mathrm{f}$ & 1.22 & 50 & 13 \\
\hline $1-\mathrm{a}$ & 1.3 & 40 & 11 & $15-\mathrm{g}$ & 1.18 & 40 & 11 \\
\hline $1-b$ & $1.15 \mathrm{a}$ & 50 & 12 & $15-\mathrm{h}$ & 1.21 & 30 & 13 \\
\hline $1-\mathrm{c}$ & 1.6 & 30 & 9 & $15-\mathrm{i}$ & 1.23 & 50 & 9 \\
\hline $1-d$ & $1.15 b$ & 30 & 15 & $15-\mathrm{j}$ & 1.25 & 40 & 7 \\
\hline $1-\mathrm{e}$ & $1.15 \mathrm{c}$ & 70 & 9 & $15-\mathrm{k}$ & 1.24 & 40 & 11 \\
\hline $1-\mathrm{f}$ & 1.8 & 50 & 13 & $15-1$ & 1.27 & 20 & 11 \\
\hline $1-\mathrm{g}$ & 1.4 & 40 & 11 & $15-m$ & 1.29 & 40 & 11 \\
\hline $1-\mathrm{h}$ & 1.7 & 30 & 13 & $15-n$ & 1.26 & 40 & 15 \\
\hline $1-\mathrm{i}$ & 1.9 & 50 & 9 & $15-0$ & 1.19 & 40 & 11 \\
\hline $1-j$ & 1.11 & 40 & 7 & $15-\mathrm{p}$ & 1.28 & 60 & 11 \\
\hline $1-\mathrm{k}$ & 1.10 & 40 & 11 & \multicolumn{4}{|c|}{ Caustic Leaching/Washing } \\
\hline $1-1$ & 1.13 & 20 & 11 & \multicolumn{4}{|c|}{ Dewatering } \\
\hline $1-\mathrm{m}$ & 1.15 & 40 & 11 & & 1.30 & 50 & 12 \\
\hline $1-n$ & 1.12 & 40 & 15 & \multicolumn{4}{|c|}{ Water Flush and 2M nitric acid cleaning } \\
\hline $1-0$ & 1.5 & 40 & 11 & & 1.31 & N/A & N/A \\
\hline $1-\mathrm{p}$ & 1.14 & 60 & 11 & \multicolumn{4}{|c|}{$0.1 \mu \mathrm{m}$ Filtered Deionized Inhibited Water } \\
\hline \multicolumn{4}{|c|}{ Dewatering to approx. $15 \mathrm{wt} \%$ Insoluble Solids } & & 1.32 & 20 & 11 \\
\hline & 1.16 & 50 & 12 & \multicolumn{4}{|c|}{$5 \%$ wt Strontium Carbonate in $0.01 \mathrm{M} \mathrm{NaOH}$} \\
\hline & & & & & 1.33 & $10,20,30$ & 11 \\
\hline & & & & \multicolumn{4}{|c|}{$0.1 \mu \mathrm{m}$ Filtered Deionized Inhibited Water } \\
\hline & & & & & 1.34 & $10,20,30$ & 11 \\
\hline
\end{tabular}

The system was initially cleaned by flushing with inhibited water, then soaked in approximately $2 \mathrm{M}$ nitric acid, and then flushed with inhibited water. The first clean water flux measured is shown as "Pre-Test \#1". The flux was approximately $1.3 \mathrm{gpm} / \mathrm{ft}^{2}$ at about 18 psi TMP. Higher TMPs could not be achieved due to high backpressure in the permeate lines that was caused by the very high flowrate. After the clean water test, the first $\mathrm{SrCO}_{3}$ test was performed. $\mathrm{SrCO}_{3}$ results are shown below. The clean water flux after the $\mathrm{SrCO}_{3}$ with only water flushing is shown as "Pre-Test \#2". This flux is significantly lower than the first water flux. Subsequent water fluxes performed immediately after $\mathrm{SrCO}_{3}$ tests were consistently lower than after acid cleaning and fell within the blue band shown in Figure 19. The system was cleaned with nitric acid after $\mathrm{SrCO}_{3}$ test \#2 and the water flux after cleaning was very high (Pre-Test \#3) at more than $2 \mathrm{gpm} / \mathrm{ft}^{2}$ at $20 \mathrm{psi}$ TMP. These data show that only water flushing after $\mathrm{SrCO}_{3}$ to be inadequate to return the clean water flux to the original value; cleaning with nitric acid or acidification is required to eliminate all residual $\mathrm{SrCO}_{3}$ slurry. 


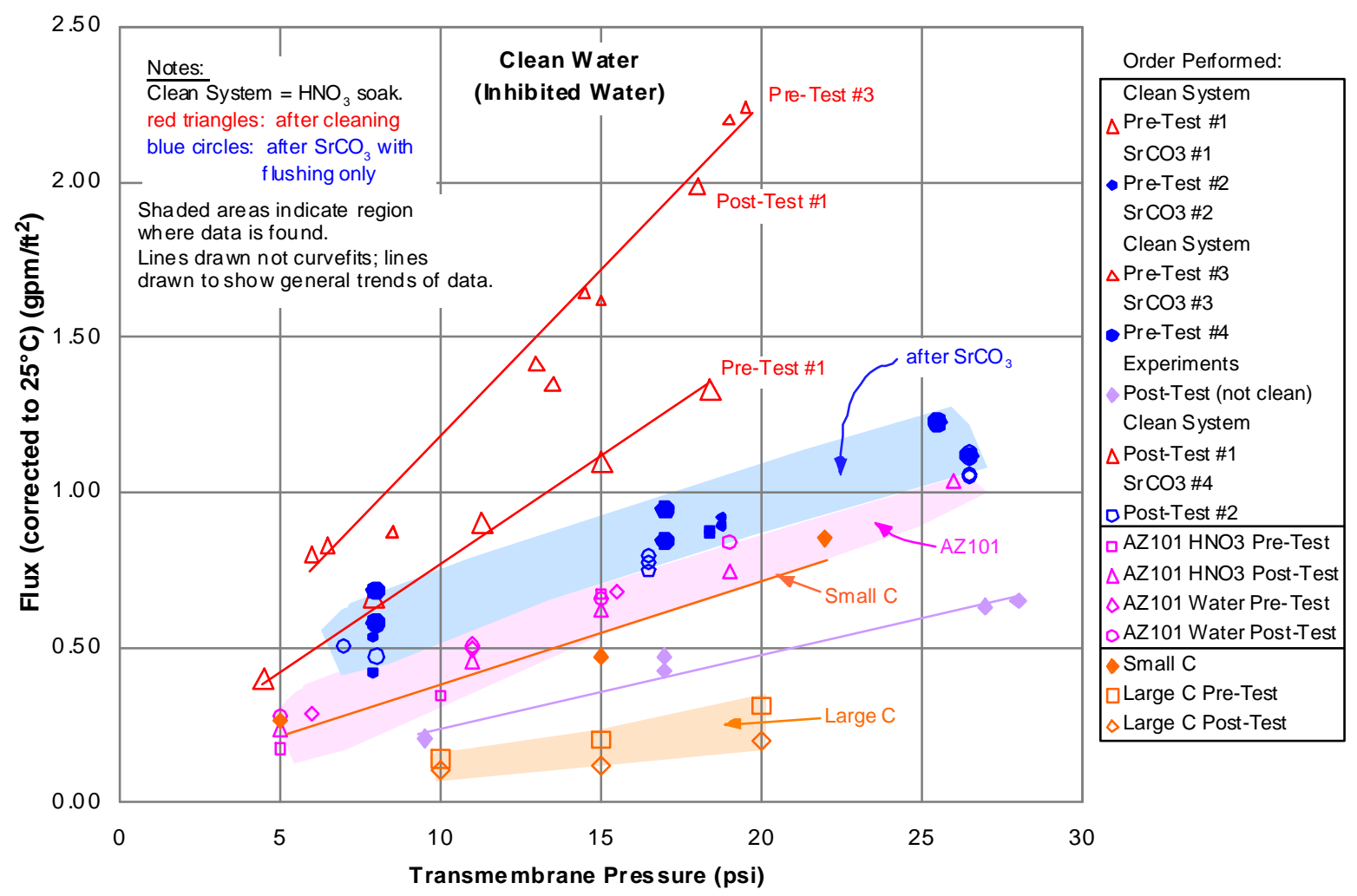

Figure 19 Clean Water Fluxes - R1BC Run

After completing all of the tests with the R1BC simulant slurry, including concentration and washing, the clean water fluxes were again measured. The first clean water test (Post-Test, not clean) gave results well below the previously determined values. These fluxes were measured after two flushes with inhibited water. The water in this test had visible solids, so the low result is not surprising. After cleaning, the clean water flux (Post-Test \#1) returned to the same values as Pre-Test \#3. For comparison, the clean water fluxes determined in the AZ101 ${ }^{11}$ simulant filtration, Small C, ${ }^{12}$ and Large $\mathrm{C}^{3}$ are also shown. The AZ101 and Small $C$ values are essentially the same, while the Large $C$ values are much lower than any of the other values. All of the values shown from previous work are much lower than those found in this work.

Clean water fluxes and $\mathrm{SrCO}_{3}$ fluxes for this work are shown in Figure 20. The $\mathrm{SrCO}_{3}$ fluxes (green band) were approximately one-third the fluxes determined for clean water (Pre-Test \#1 and Post-Test \#1). The "clean water" fluxes determined after only flushing out of the $\mathrm{SrCO}_{3}$ (no dissolving with acid) were only about $30 \%$ higher (blue band). In general, the $\mathrm{SrCO}_{3}$ fluxes were repeatable to within about $\pm 0.2 \mathrm{gpm} / \mathrm{ft}^{2}$. 
WSRC-TR-2003-00056, REV. 0

SRT-RPP-2002-00231, REV. 0

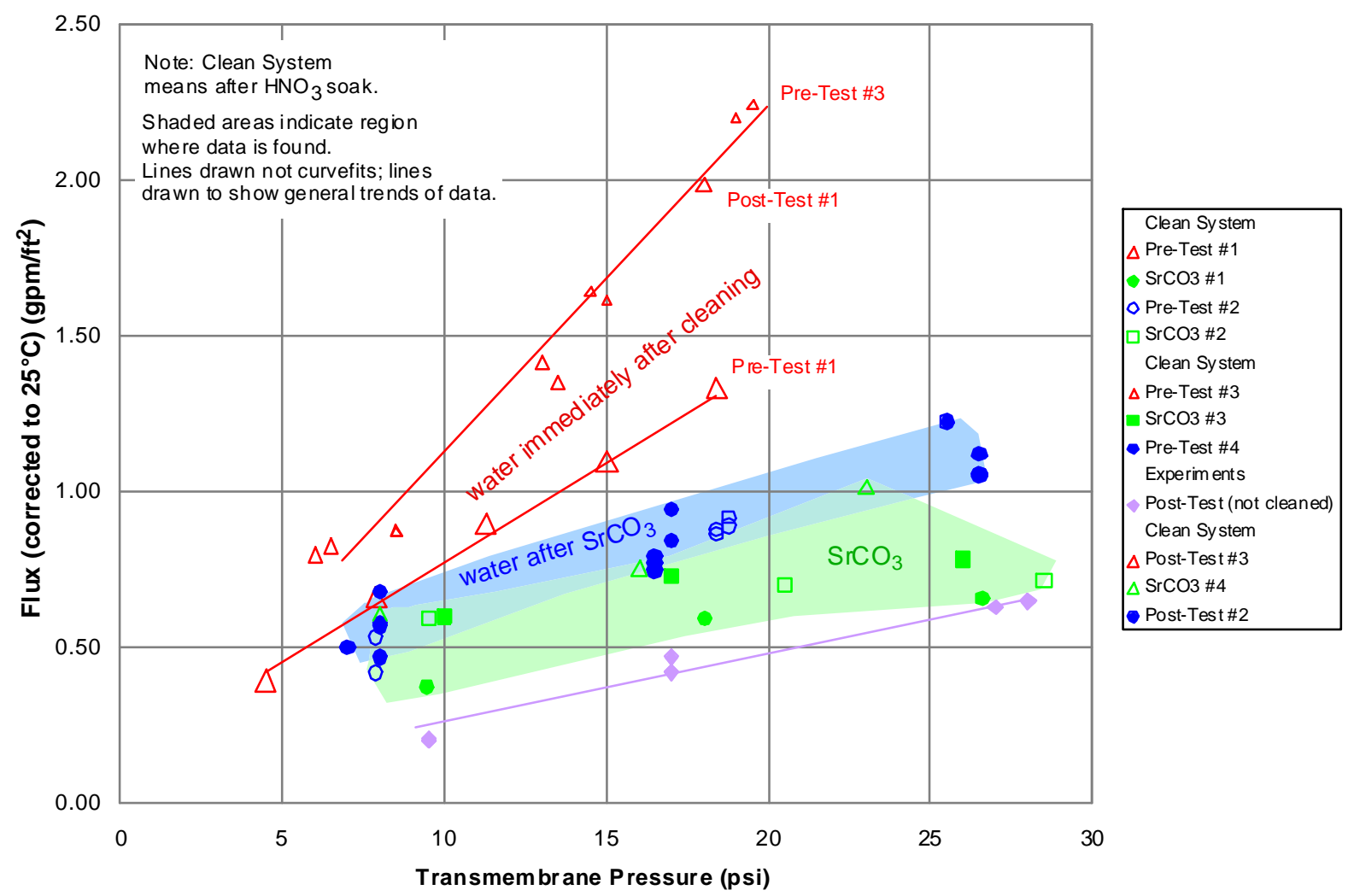

Figure 20 Clean Water and $\mathrm{SrCO}_{3}$ Fluxes - R1BC Run

\subsubsection{Factorial Design Tests - R1BC}

The factorial design conditions for low solids concentration (slurry from precipitate batch\#1), pre- and post-run flux tests, and design conditions for the runs with concentrated slurry (at $17.2 \mathrm{wt} \%$ insoluble solids) are shown in Table 24 . The factorial design used at both low and high solids concentrations is also shown graphically in Figure 21. The factorial arrangement points are shown in solids symbols, while those added to match the Large $\mathrm{C}$ filtration work are shown as open symbols.

Each factorial design point was started with multiple backpulses at 45 psi. Filtration at the specified conditions was then started. Several plots of flux versus time are shown in Figure 22-Figure 24. In Figure 22, the fluxes in the first two runs of the set of factorials (1a, 1a') are much higher than the subsequent values. Generally, it was seen that the first one or two runs immediately after cleaning are always much higher than later ones. This result is consistent with the observations of Nash et. al. ${ }^{3}$ Figure 22 also shows that there was little effect of pressure on the flux and that the flux between runs decreases with time. The data in Figure 23 show that at $30 \mathrm{psi}$ TMP, the flux increased with velocity. Overall, the flux was found to increase with velocity but to be for the most part independent of pressure. The effect of run order is shown in Figure 24 where the flux at 40 psi TMP and 11 fps velocity decreases with run order. A complete set of tabulated data and plots of the flux versus time for the low solids factorial and the factorial at $17.2 \mathrm{wt} \%$ are given in the Appendix. 
WSRC-TR-2003-00056, REV. 0

SRT-RPP-2002-00231, REV. 0

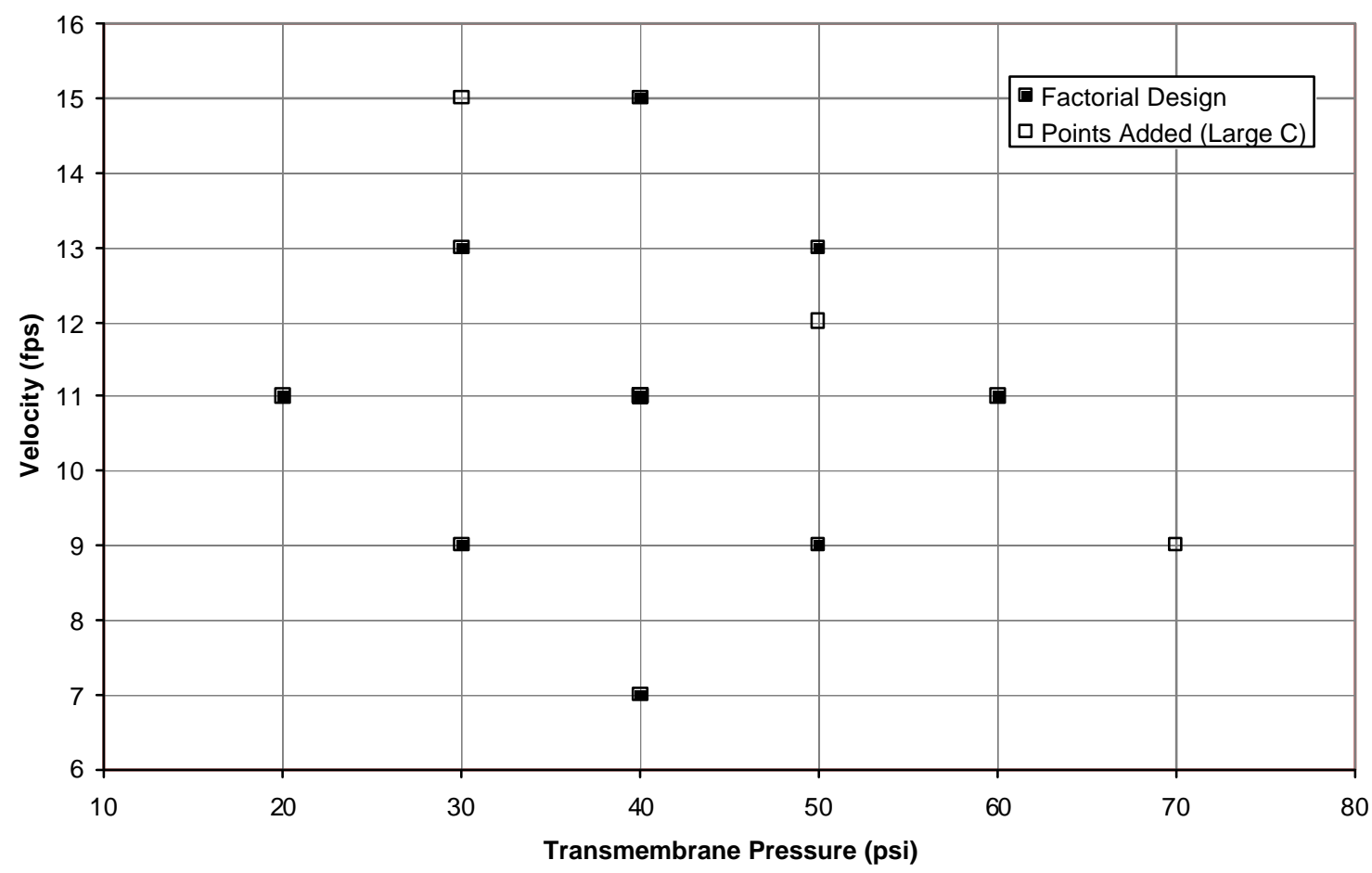

Figure 21 Factorial Design Arrangement: Low and High Solids Concentrations

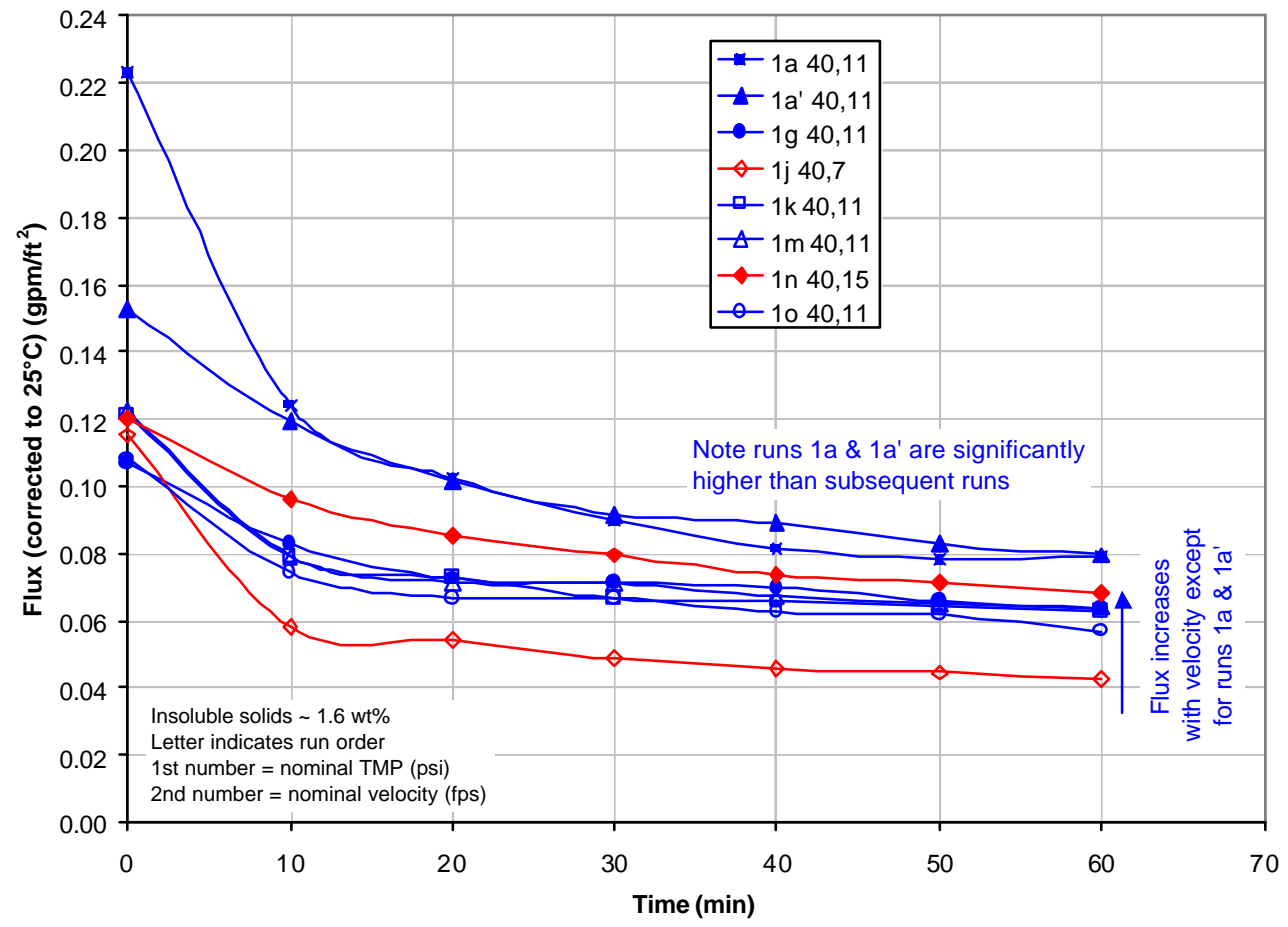

Figure 22 Low Solids Factorial: Flux versus Time at $11 \mathrm{fps}$ Velocity. 
WSRC-TR-2003-00056, REV. 0

SRT-RPP-2002-00231, REV. 0

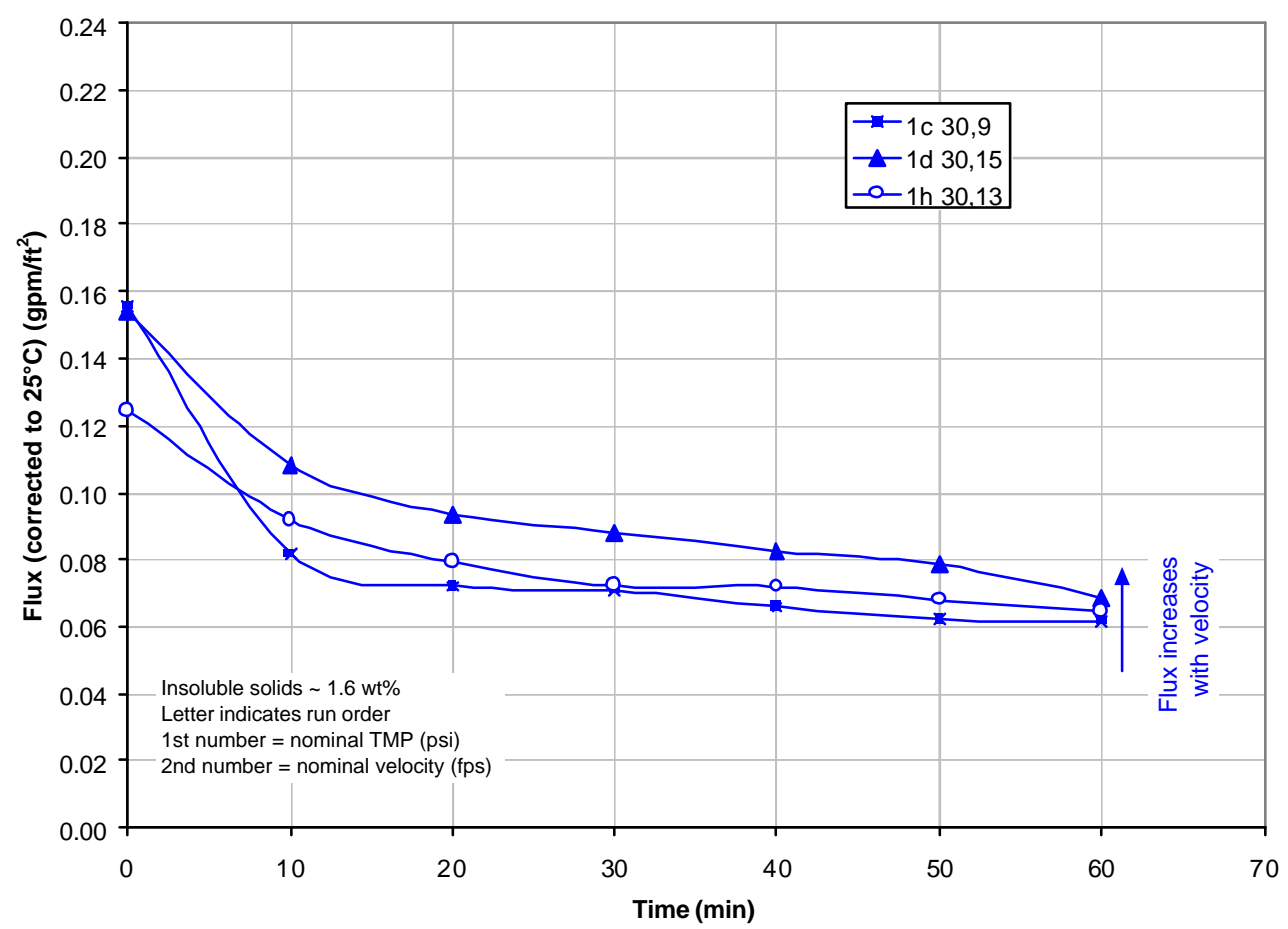

Figure 23 Low Solids Factorial: Flux versus Time at 30 psi TMP.

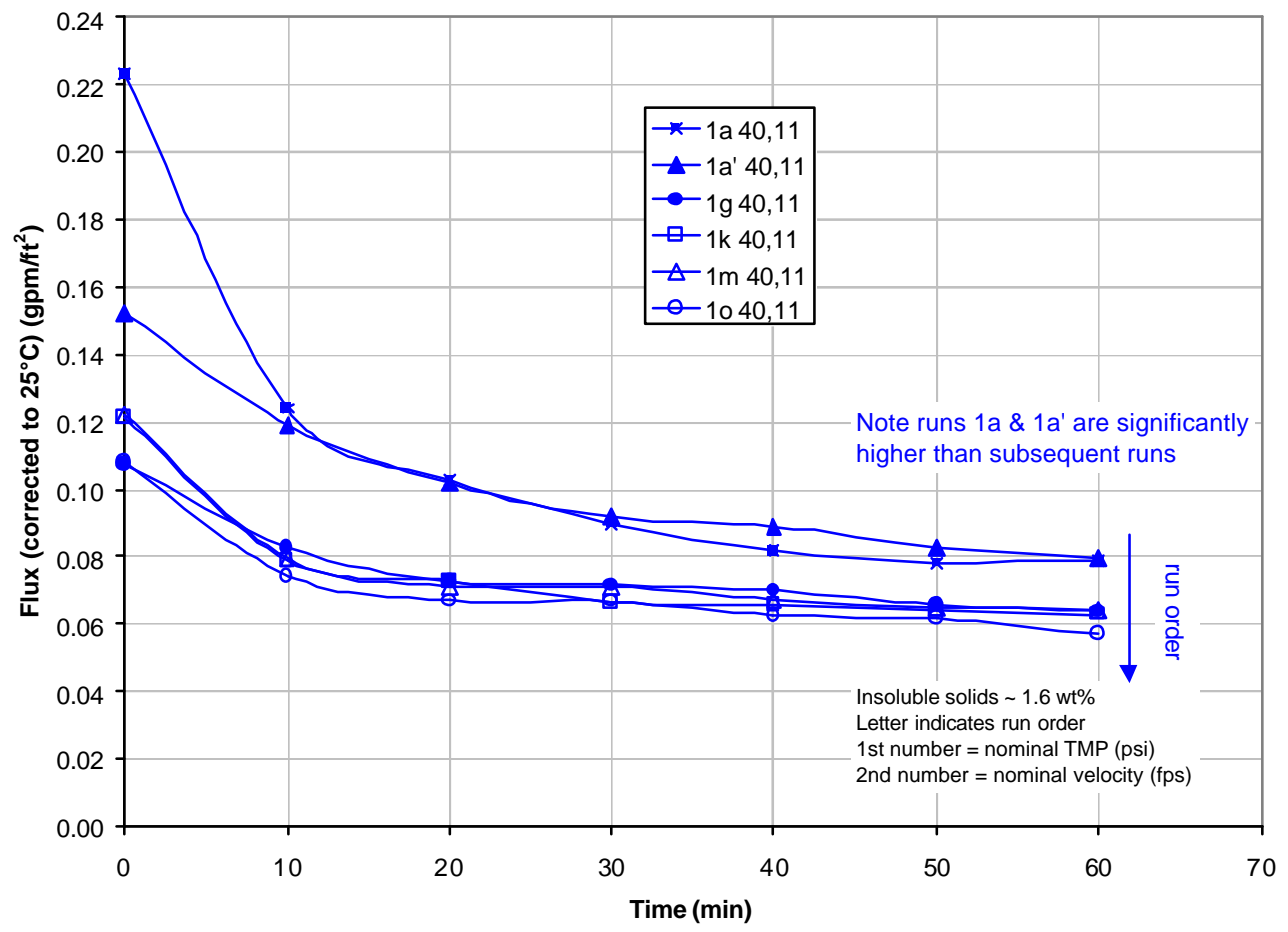

Figure 24 Low Solids Factorial: Flux versus Time at 11 fps Velocity, 40 psi TMP.

The data at the center point of the factorial design ( $40 \mathrm{psi}$ TMP, $11 \mathrm{fps}$ velocity) are plotted versus time along with data from the $\mathrm{AN}-102$ Small $\mathrm{C}$ filtration ${ }^{12}$ and the $\mathrm{AN}-107$ pilot-scale simulant filtration ${ }^{13}$ in Figure 25. The AN-107 data was fit to an exponential, while the Small 
$\mathrm{C}$ data was fit to two bounding linear equations shown by the red region on the graph. The pilot AN-107 results are almost exactly the same as the results for this work.

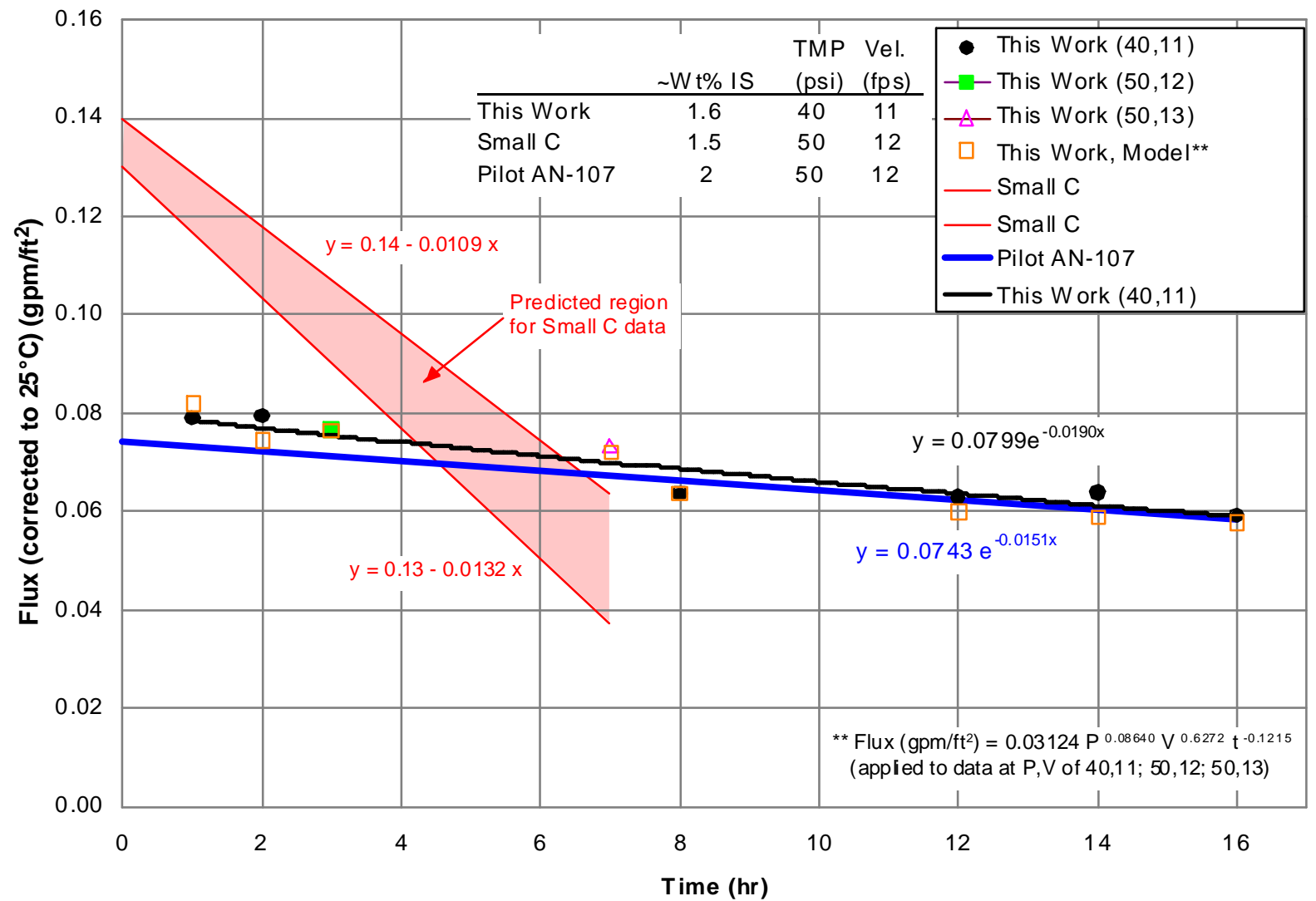

Figure 25 Comparison of Fluxes for this Work, AN-102 Small C, and AN-107 Pilot Simulant Filtration

The flux data at the low solids concentration and after concentration to $17.2 \mathrm{wt} \%$ were fit to models with TMP, velocity, and run time as variables. The best fit for the low concentration data was:

Flux $\left(\mathrm{gpm} / \mathrm{ft}{ }^{2}\right)=0.01324 \mathrm{P}^{0.08640} \mathrm{~V}^{0.6272} \mathrm{t}^{-0.1215}$

where $\mathrm{P}=$ transmembrane pressure $(\mathrm{psi})$

$\mathrm{V}=$ velocity (fps)

$\mathrm{t}=$ elapsed filtration time since start of task (hr)

The effect of pressure was only marginally statistically insignificant at a $95 \%$ confidence, so it was left in the model. This model predicts that the maximum flux is achieved at the highest velocity and pressure and the lowest elapsed time. Of the conditions tested, the highest velocity was $15 \mathrm{fps}$, while the TMP was 40 psi, so this is the optimum set of conditions that were tested. The model predicts that even higher velocities and TMPs would give larger fluxes, but these conditions were not actually tested; these predictions are extrapolations beyond the range of the data. 
Since the effect of pressure was marginally statistically insignificant, the data was also fit without the pressure dependence. The resulting prediction equation was:

Flux $\left(\mathrm{gpm} / \mathrm{ft}{ }^{2}\right)=0.01990 \mathrm{~V}^{0.5897} \mathrm{t}^{-0.1227}$

Eq. 1a

The velocity and time exponents are both similar to the values found when the pressure effect was included.

At $17.2 \mathrm{wt} \%$ insoluble solids, the best fit of the flux data was:

Flux $\left(\mathrm{gpm} / \mathrm{ft}^{2}\right)=1.1519 \mathrm{~V}^{0.5025} \mathrm{t}^{-1.6473}$ Eq. 2

In this case, the effect of pressure was not significant. The highest flux is therefore predicted to occur at the highest velocity. Again, the highest velocity tested was $15 \mathrm{fps}$. Therefore, for both low and high solids concentrations, the flux is a function of velocity and elapsed filtration time.

The flux at $17.2 \mathrm{wt} \%$ insoluble solids was also fit to the same form of model, but with the time dependence found for the low insoluble solids slurry $\left(\mathrm{t}^{-0.1215}\right)$. The fit of the data with this model was not nearly as good as when the exponent on time was allowed to vary. However, the velocity dependence was closer to that seen at low insoluble solids concentrations:

Flux $\left(\mathrm{gpm} / \mathrm{ft}^{2}\right)=0.0008942 \mathrm{~V}^{0.6265} \mathrm{t}^{-0.1215}$

Eq. $2 \mathrm{a}$

The $95 \%$ confidence intervals on the exponents on the velocity terms are:

$\begin{array}{lll}\text { Low Concentration: } & 0.6272 \pm 0.1496 & \text { (from Eq. 1) } \\ & 0.5897 \pm 0.1624 & \text { (from Eq. 1a) } \\ \text { High Concentration: } & 0.5025 \pm 0.2330 & \text { (from Eq. 2) } \\ & 0.6265 \pm 0.5275 & \text { (from Eq. 2a) }\end{array}$

These confidence intervals overlap, so it cannot be concluded that the dependence on the velocity at the low and high insoluble solids concentrations is different. Therefore, this dependence may be the same in both cases. The exponents on the time (Eq. 1 or 1a vs. 2) are different because each set of factorial data (low and high concentration) was fit separately to the available data. Figure 26 shows a comparison of the time dependencies at high insoluble solids. The dependence $\mathrm{t}^{-1.6473}$ is stronger than $\mathrm{t}^{-0.1215}$, but as shown graphically, this difference in effects is in reality rather insignificant. 


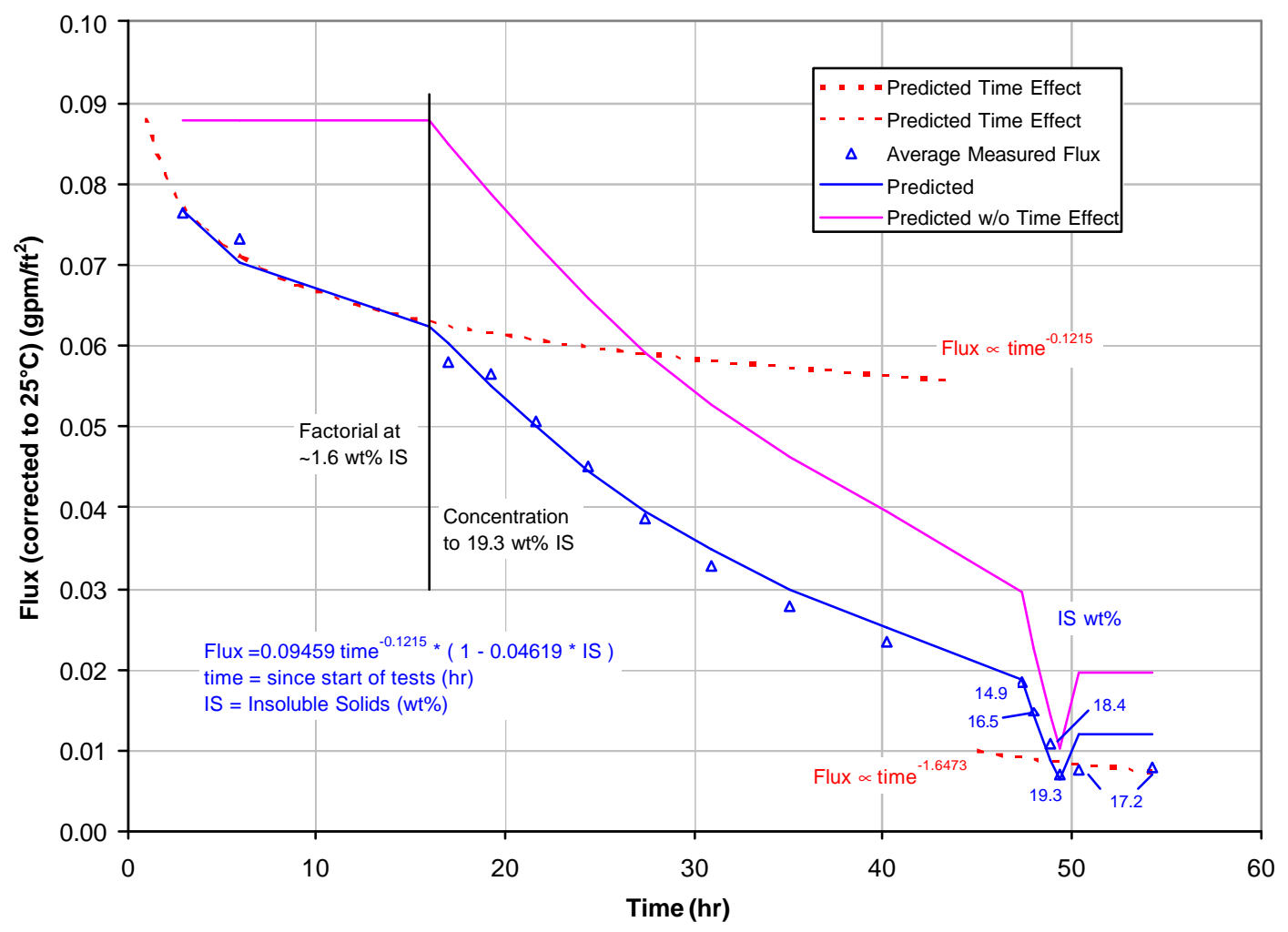

Figure 26 Predicted Flux versus Time for Concentration of Unwashed Slurry

\subsubsection{Flux versus Insoluble Solids Concentration}

After completing the factorial experiments on the first precipitate batch of the R1BC slurry, eight more batches were added and concentrated. The concentrating step of each batch was operated to maintain approximately a constant level in the filter feed tank by matching the permeate flowrate. Each addition of a precipitate batch was preceded by a backpulse. The flux versus time for all of the batches is shown in Figure 27. Note that the concentration steps were all conducted at nominally $50 \mathrm{psi}$ TMP and $12 \mathrm{fps}$ velocity. For each batch concentration, the flux started out higher and dropped to lower values with time, as expected. At the higher concentrations (starting at about $25 \mathrm{hr}$ ), this drop is not seen in the data because it took up to 20 minutes to get the first permeate flow reading after backpulsing (time was required to fill the permeate side of the filter and the associated tubing). 
WSRC-TR-2003-00056, REV. 0

SRT-RPP-2002-00231, REV. 0

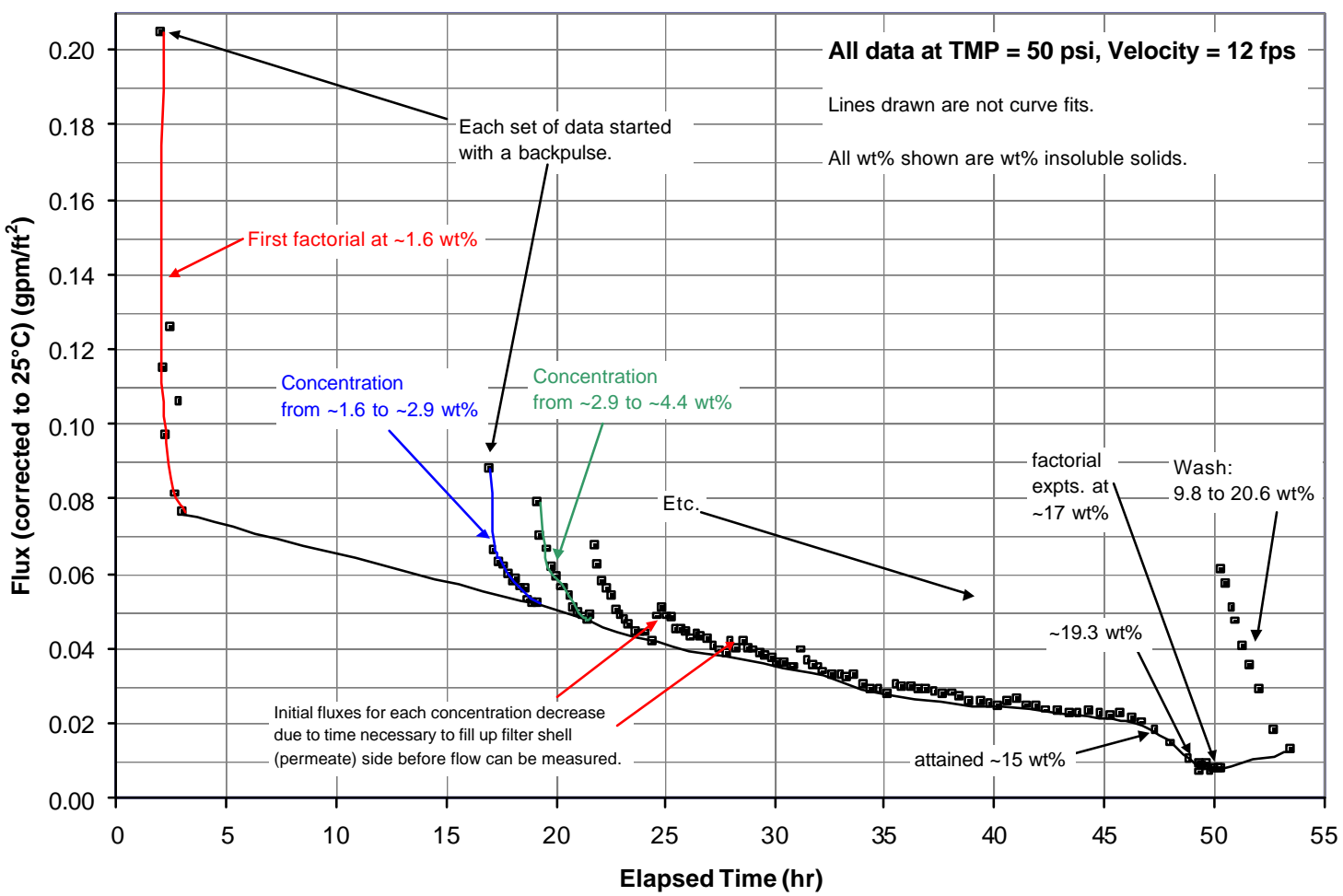

Figure 27 Flux During Concentration Showing Flux Decline

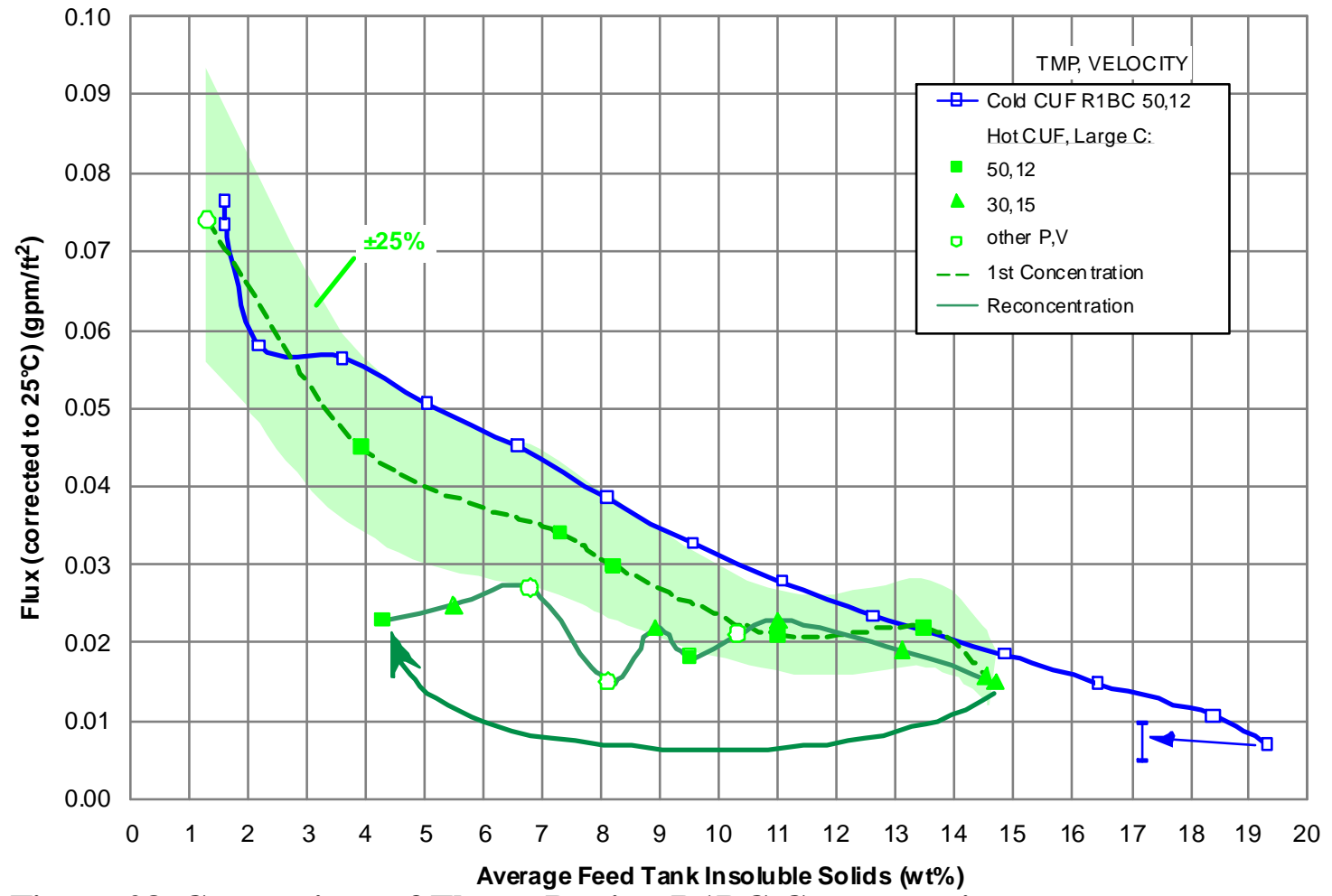

Figure 28 Comparison of Fluxes During R1BC Concentration 
Figure 28 shows the R1BC data compared to fluxes measured during the AN-102 Large C work. The green band is a $\pm 25 \%$ interval around the fluxes measured during the first concentration step in Large $\mathrm{C}$; the other points for Large $\mathrm{C}$ were taken during re-concentration after the concentrated slurry was diluted. Eleven of fifteen of the R1BC data points are within this interval while the other four are within 32\%. Four points for the Large $\mathrm{C}$ data at $\mathrm{P}=30, \mathrm{~V}=15$ are also within the interval. Figure 28 also shows that the flux in the Large $\mathrm{C}$ work did not recover to the previous values at a given insoluble solids concentration; the R1BC runs show a similar occurrence when the slurry was diluted back to approximately $17.3 \mathrm{wt} \%$ insoluble solids for the factorial experiments. Figure 29 shows the R1BC data from Figure 28 along with the flux data taken during re-concentration after washing the concentrated slurry with inhibited water.

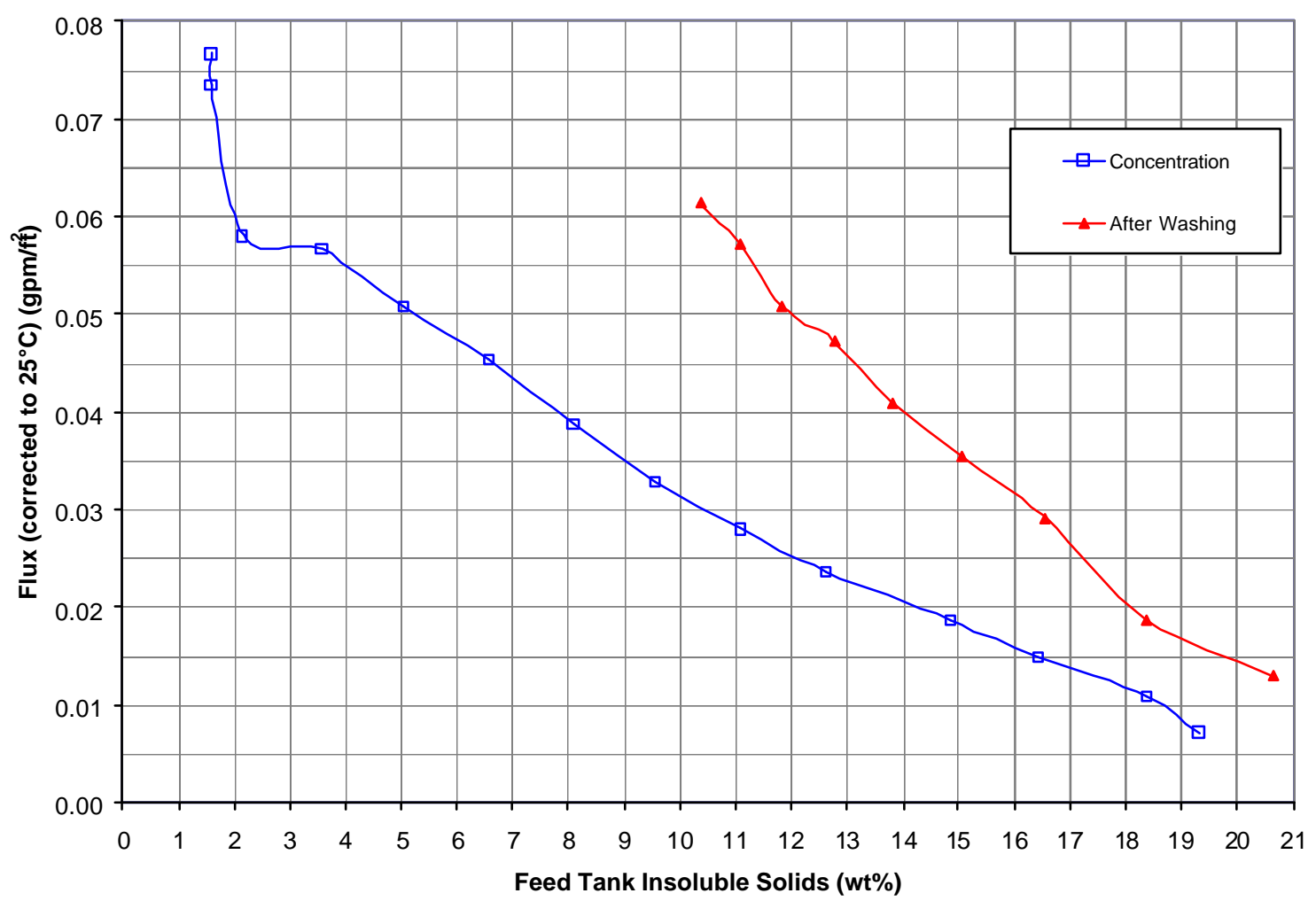

Figure 29 Fluxes for R1BC Concentration and Re-Concentration of Washed Slurry

The minimum average flux for the WTP for the AN-102 waste during dewatering is $0.02 \mathrm{gpm} / \mathrm{ft}^{2}{ }^{2}$ All of the measured fluxes for R1BC for insoluble solids contents below 15 wt $\%$ were greater than this value. From 15 to approximately $19.3 \mathrm{wt} \%$, the flux dropped below this value to about $0.007 \mathrm{gpm} / \mathrm{ft}^{2}$. Even with these low values, the time averaged flux during dewatering, $0.036 \mathrm{gpm} / \mathrm{ft}^{2}$, was much greater than $0.02 \mathrm{gpm} / \mathrm{ft}^{2}$.

A simple model of the flux dependence on the insoluble solids content was developed for the R1BC data; this model used the flux decline with time predicted from the low solids factorial data. As shown in Figure 26, the power function drop in flux versus time $\left(\propto \mathrm{t}^{-0.1215}\right)$ was 
superimposed on the fluxes measured versus insoluble solids content. When the time effect was backed out, the was found to be a linear function of insoluble solids:

Flux $\left(\mathrm{gpm} / \mathrm{ft}^{2}\right)=0.09459 \mathrm{t}^{-0.1215}(1-0.04619$ IS $)$

This function predicted all data points quite well, except for those taken during the high concentration factorial, which was performed after re-dilution. As stated previously, the flux after re-dilution was expected to rebound to the previous value at a similar solids content, but it did not. The predicted and measured fluxes are plotted versus insoluble solids content in Figure 30.

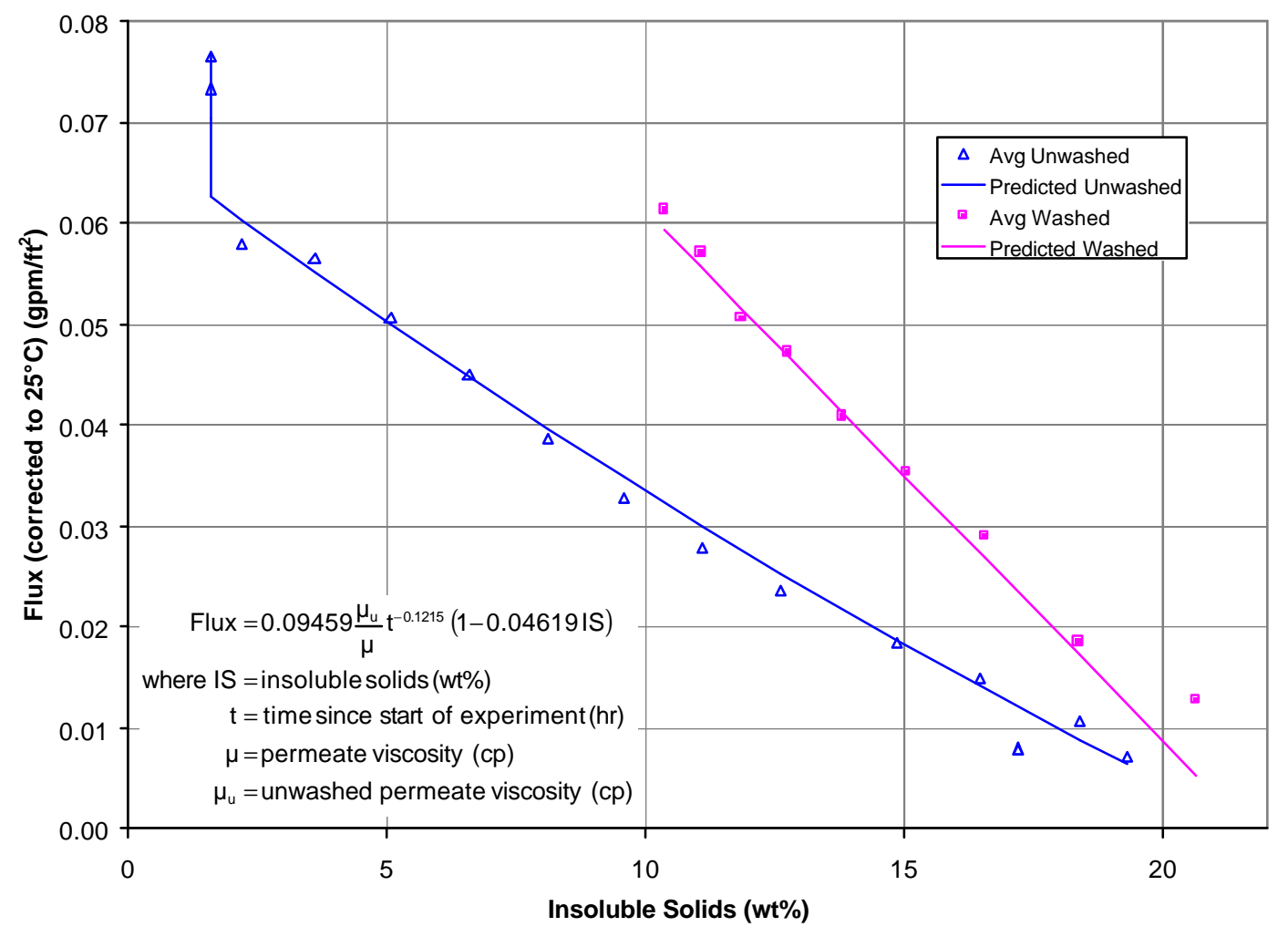

Figure 30 Predicted Flux versus Insoluble Solids Content

After dilution back to $17.2 \mathrm{wt} \%$, the high concentration factorial design was performed, and then the slurry was washed with an equal volume of inhibited water. The flux versus insoluble solids for the concentration of the washed slurry was shown in Figure 28. The permeate viscosities measured were 3.10 and $1.55 \mathrm{cp}$ before and after washing, respectively. Filter flux has been shown to be inversely proportional to permeate viscosity, ${ }^{14}$ so a model with viscosity as a parameter was examined. A term for the effects of permeate viscosity was added to the model. The results are shown in Figure 30-Figure 31. The fit of the model is very good for both unwashed and washed slurry. Therefore, the overall model is: 
Flux $=0.09459 \frac{\mu_{\mathrm{u}}}{\mu} \mathrm{t}^{-0.1215}(1-0.04619 \mathrm{IS})$

where IS $=$ insoluble solids $(\mathrm{wt} \%)$

$$
\begin{aligned}
\mathrm{t} & =\text { time since start of experiment }(\mathrm{hr}) \\
\mu & =\text { permeate viscosity }(\mathrm{cp}) \\
\mu_{\mathrm{u}} & =\text { unwashed permeate viscosity (cp) }
\end{aligned}
$$

The fit of this model is also shown by plotting the measured fluxes adjusted for the time factor and the permeate viscosity in Figure 32.

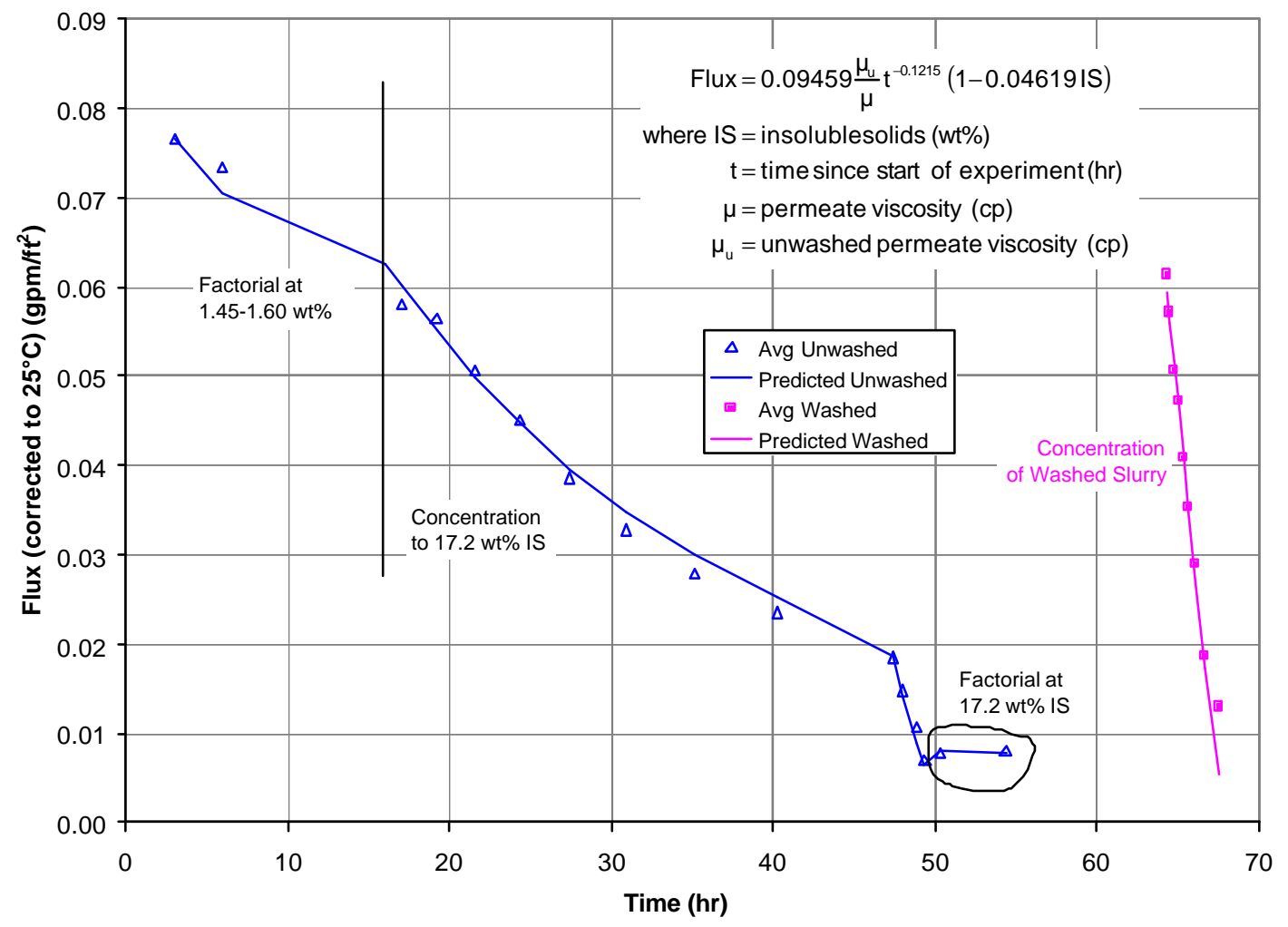

Figure 31 Predicted Flux versus Time for Concentration of Unwashed \& Washed Slurry 


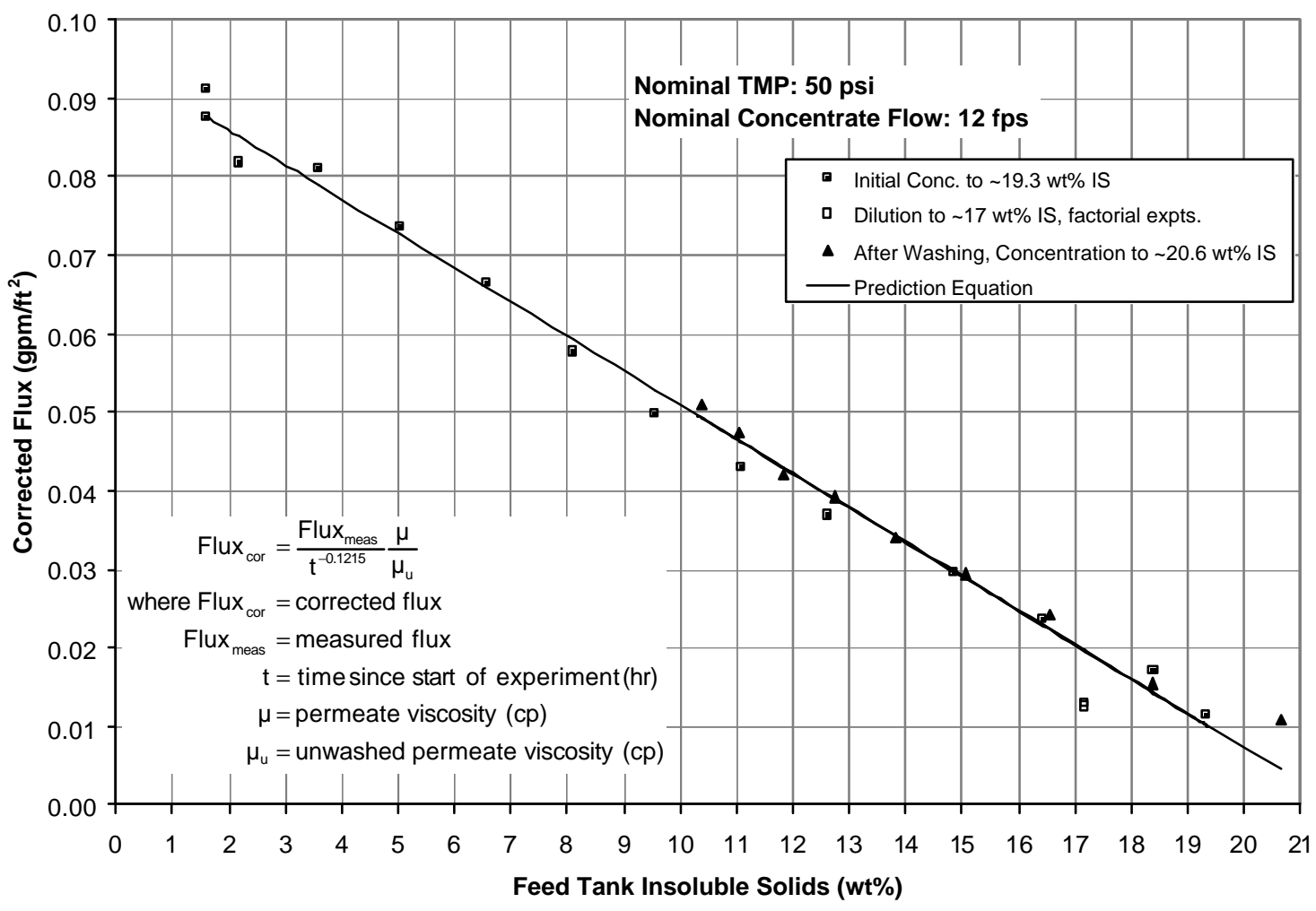

Figure 32 Flux Corrected for Time \& Viscosity

\subsubsection{Filtration - Remediation 2 Runs}

The filtration fluxes versus insoluble solids content for the R2NOC runs (R2NOC1, R2NOC small, R2NOC2, pilot R2NOC) are shown in Figure 33. The initial R2NOC1 fluxes were less than the minimum $0.02 \mathrm{gpm} / \mathrm{ft}^{2}$, so this run was immediately stopped. the small R2NOC run initial flux was about $0.067 \mathrm{gpm} / \mathrm{ft}^{2}$, so the precipitation was repeated (R2NOC2). The initial flux was $>0.119 \mathrm{gpm} / \mathrm{ft}^{2}$ and it remained greater than $0.02 \mathrm{gpm} / \mathrm{ft}^{2}$ until about $8 \mathrm{wt} \%$ insoluble solids was reached. After this, the flux dropped to approximately $0.007 \mathrm{gpm} / \mathrm{ft}^{2}$ and the time-averaged flux was $0.013 \mathrm{gpm} / \mathrm{ft}^{2}$. In Figure 33, the fluxes from a parallel run of the R2NOC conditions in the pilot unit are shown. (NOTE: The pilot unit fluxes given in this report are preliminary data and were not published at the time of this report. Refer to the pilot filtration program report (to be published) for the most accurate values. In the pilot unit, the flux dropped almost immediately below $0.02 \mathrm{gpm} / \mathrm{ft}^{2}$, so the performance of the CUF and the pilot was not comparable with a similar feed. The CUF data, after about $5 \mathrm{wt} \%$ insoluble solids, was less than $50-65 \%$ of the Large C fluxes, while the pilot was only about $15-20 \%$ of the Large $\mathrm{C}$ results.

The R2 simulant with baseline conditions results are shown in Figure 34. The R2BC CUF and pilot runs were made using the same precipitate produced in the pilot precipitation unit. The CUF fluxes were typically twice both the Large $\mathrm{C}$ and the pilot unit results. The pilot results agreed very well with the Large $\mathrm{C}$ results. Figure 35 shows the CUF baseline conditions runs compared to the Large $\mathrm{C}$ results. One major difference between the R2BCL 
and the R1BC and Large $\mathrm{C}$ runs was that for R1BC and Large C, individual small batches of precipitate were made each day and then filtered so that little aging of the newly produced precipitate occurred. In contrast, the R2BCL run used material that was all produced at the same time, so the material used later in the concentration step was aged more than the earlier material.

For the same feed material, the cold CUF fluxes were always about a factor of two or higher than the pilot unit results. Possible reasons for this behavior can be given, but at this point are only hypotheses. The three possible reasons are:

1. The particle shear of the pilot centrifugal pump is greater than the CUF progressive cavity pump, resulting in smaller particles or a different particle size distribution.

2. The shear stress at the wall for the same axial velocity is higher in the CUF than in the pilot, which would be expected to result in higher fluxes.

3. The pilot unit tubes are longer than the CUF tubes. Therefore, a higher percentage of the length of the CUF tubes is subject to entrance effects, which would tend to give higher fluxes in the CUF.

All of these reasons result in higher fluxes in the CUF compared to the pilot unit.

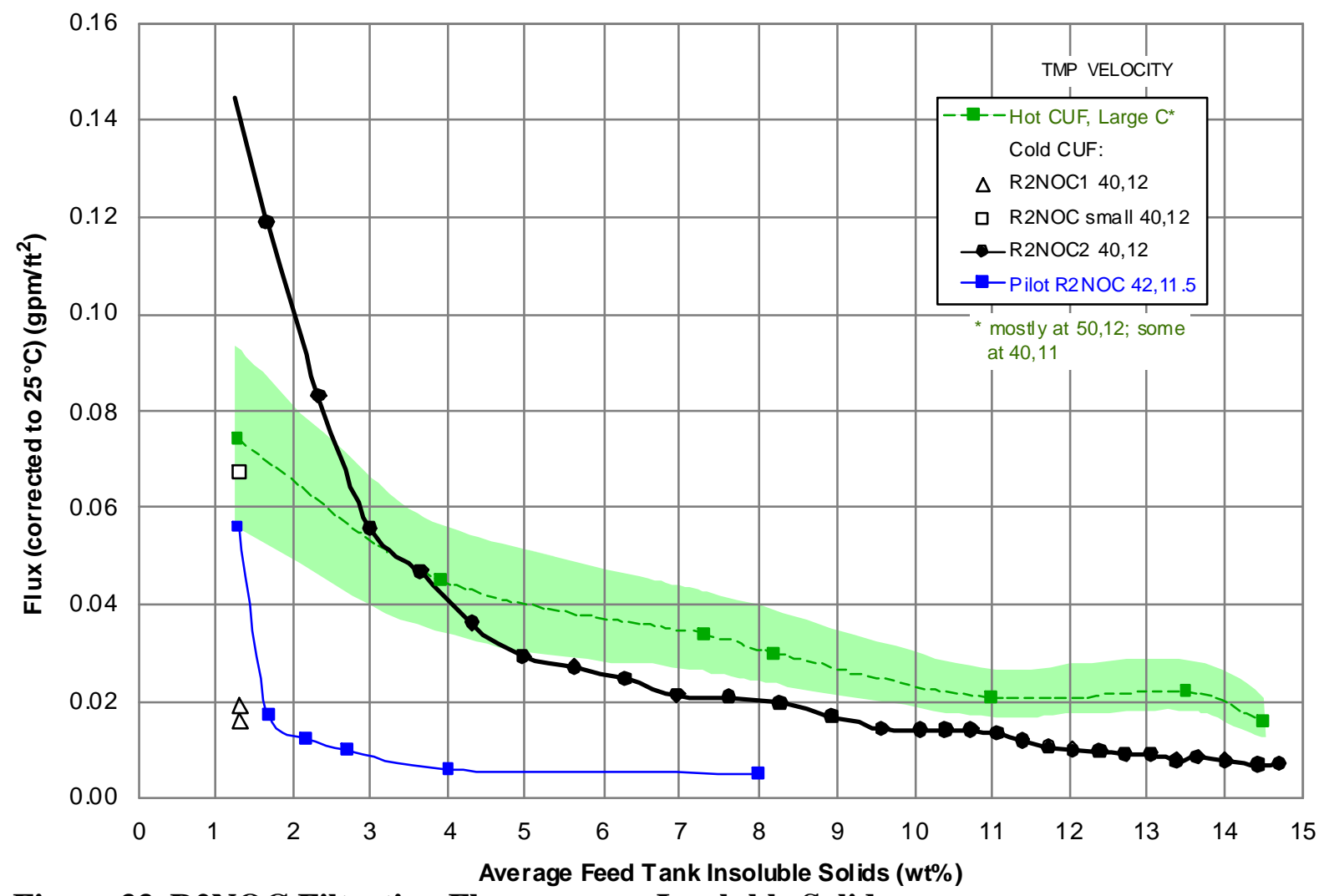

Figure 33 R2NOC Filtration Fluxes versus Insoluble Solids 
WSRC-TR-2003-00056, REV. 0

SRT-RPP-2002-00231, REV. 0

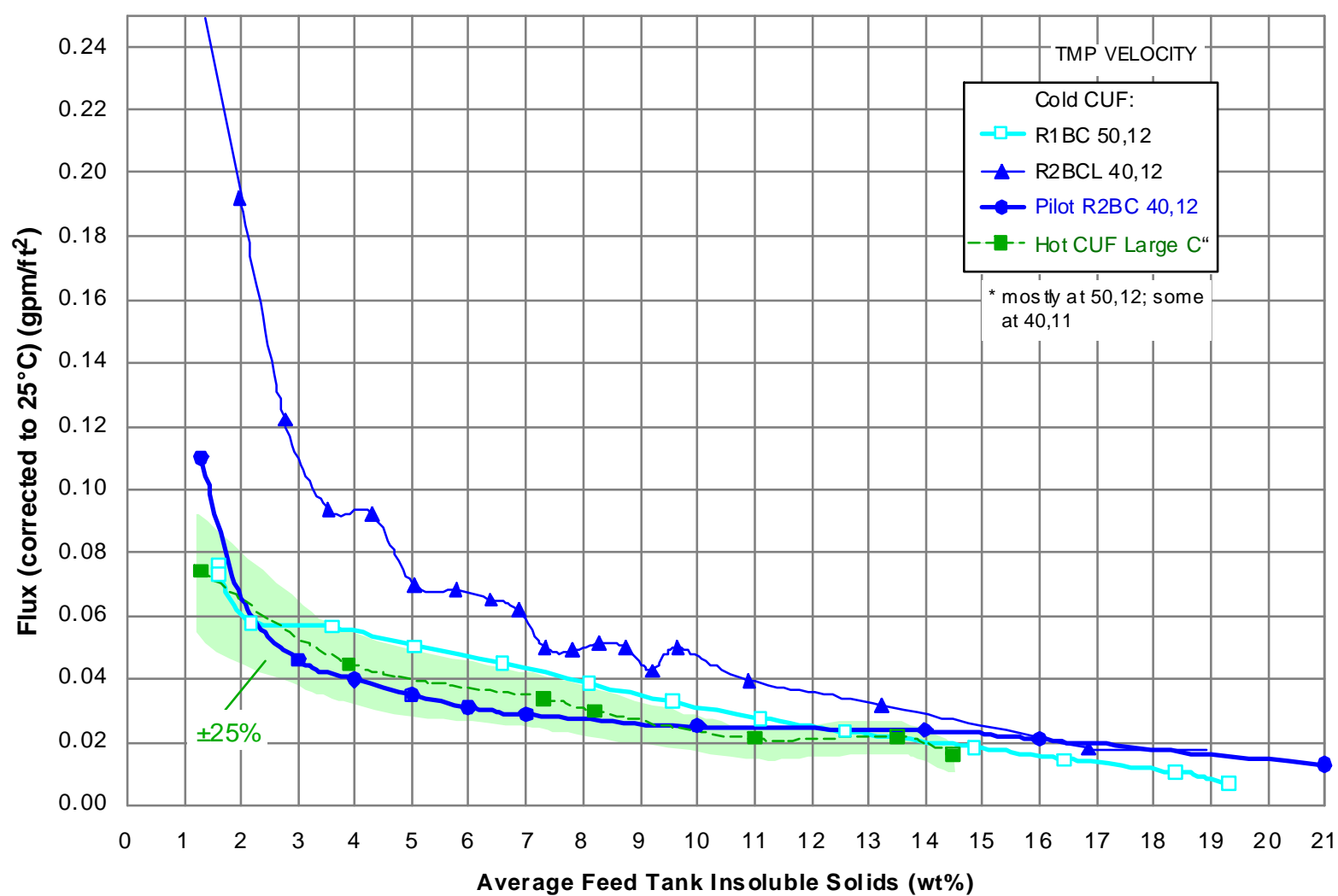

Figure 34 Baseline Conditions Fluxes versus Insoluble Solids

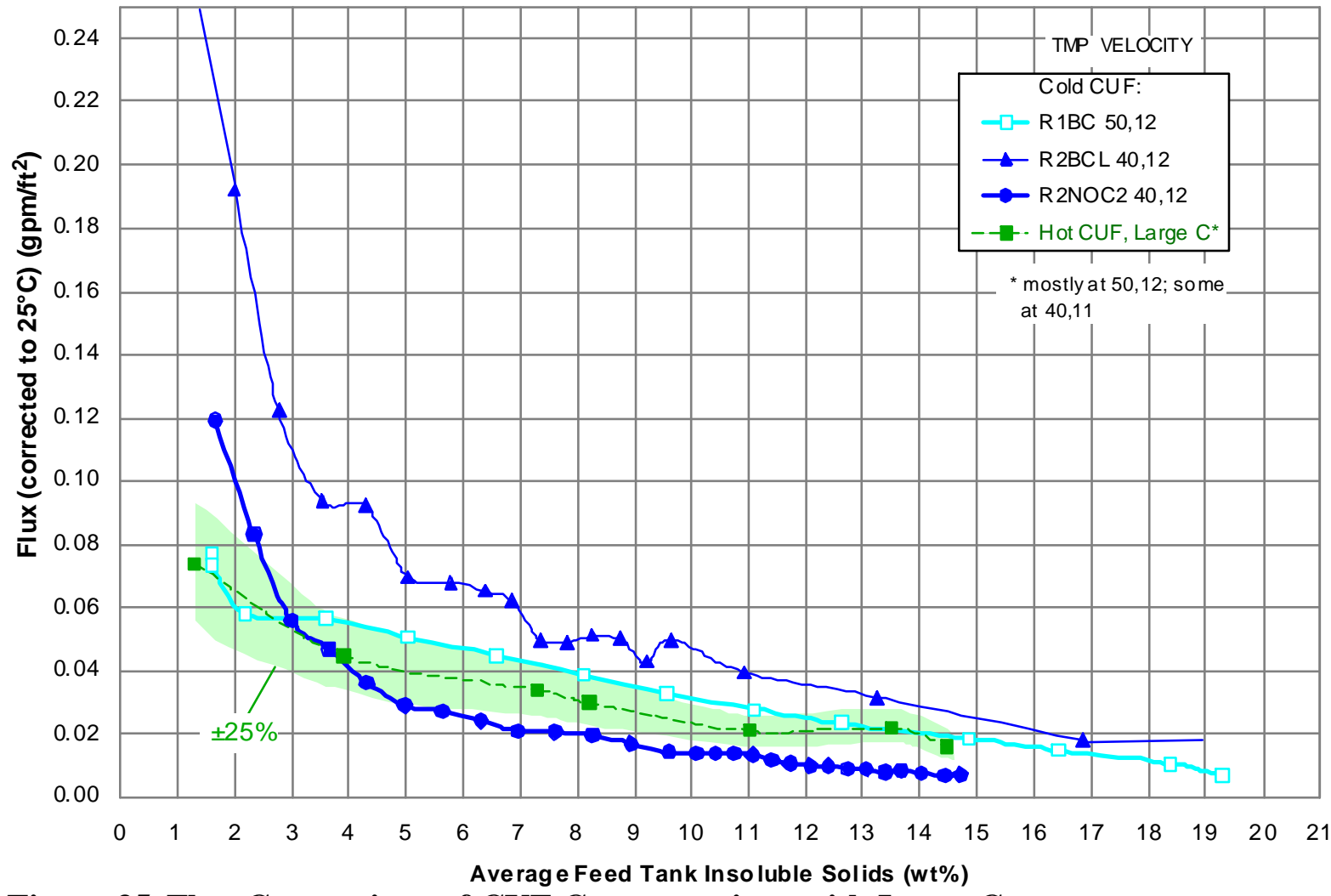

Figure 35 Flux Comparison of CUF Concentrations with Large C 


\subsection{FUTURE WORK}

SRTC recommends the following further work:

1. Experimental work, probably on a large scale, should be performed to assure that the precipitation vessel will have adequate mixing so that the precipitate formed is filterable.

2. Related to item 1 , the effect of mixing on the filterability of the precipitate should be investigated to determine if mixing has a significant influence on filtration.

3. Future optimization of the precipitation reactions should be coupled with crossflow filter tests to assure that the precipitate will be filterable. These tests should take the precipitate to at least $10 \mathrm{wt} \%$ insoluble solids, and preferably beyond.

4. The adequacy of mixing in the filter feed vessel should be tested with concentrated slurry (15 wt $\%$ or greater). The high consistency and especially the high yield stresses found for the concentrated slurry will make assuring adequate mixing difficult. 
WSRC-TR-2003-00056, REV. 0

SRT-RPP-2002-00231, REV. 0

\subsection{REFERENCES}

1 P. S. Townson, AN-102 Simulant Sr/TRU Precipitation and Ultrafiltration Test Specification, 24590-WTP-TSP-RT-01-019, Rev. 0, River Protection Project - Waste Treatment Plant, Richland, WA (2001).

2 M. R. Poirier, Task Technical and Quality Assurance Plan for AN-102 Simulant Sr/TRU Precipitation and Ultrafiltration, SRT-RPP-2002-00007, Rev. 0, (WSRC-TR-200200038, Rev. 0), Savannah River Site, Aiken, SC (2002).

3 C. A. Nash, H. H. Saito, W. R. Wilmarth, Strontium-Transuranic Precipitation and Crossflow Filtration of 241-AN-102 Large C, WSRC-TR-2000-00506, Rev. 0 (SRT-RPP-2001-00006, Rev. 0), Savannah River Site, Aiken, SC (2000).

4 M. R. Williams, Task Technical and Quality Assurance Plan for RPP-WTP Pilot-Scale Precipitation Testing, SRT-RPP-2000-0050, Rev 2 Savannah River Site, Aiken, SC (2002).

5 P. S. Townson, AN-102 Simulant Pilot Scale Ultrafiltration Test Specification, 24590WTP-TSP-RT-01-029, Rev. 0, River Protection Project - Waste Treatment Plant, Richland, WA (2002).

6 R. E. Eibling, Development of a Supernate Simulant for Hanford Tank 241-AN-102 Waste, SRT-RPP-2002-00012. Rev. 0, DRAFT B (WSRC-TR-2002-00040, Rev. 0, DRAFT B), Savannah River Site, Aiken, SC (2002).

7 C. J. Bannochie, Standardized Baseline Precipitation Procedure for Hanford RPP Studies, WSRC-TR-2002-00138, Rev. 0 (SRT-RPP-2002-00073, Rev. 0), Savannah River Site, Aiken, SC (2002).

8 P. S. Townson, electronic mail to J. R. Zamecnik, dated 4/22/02 (attached in Appendices).

9 W. R. Wilmarth, V. H. Dukes, J. J. Mills, F. F. Fondeur, C. C. DiPrete and D. P. DiPrete, Optimization Study for Strontium and Actinide Removal from 241-AN-107 Supernate, SRT-RPP-2002-00136. Rev. 0 (WSRC-TR-2002-00258, Rev. 0), Savannah River Site, Aiken, SC (2002).

10 E. K. Hansen, Pipe Pressure Drop Calculation for Bingham Plastic, Power Law and Newtonian Fluids, SRT-RPP-2001-00226, Rev. 1, Savannah River Site, Aiken, SC (2002).

11 J. R. Zamecnik, M. A. Baich, Evaluating The Effects Of Tri-Butyl Phosphate And Normal Paraffin Hydrocarbon In Simulated Low-Activity Waste Solution On Ultrafiltration, SRT-RPP-2002-00041, Rev. 0, WSRC-TR-2002-00108, Rev. 0, Savannah River Site, Aiken, SC (2002).

12 C. A. Nash, S. W. Rosencrance, W. R. Wilmarth, Entrained Solids, StrontiumTransuranic Precipitation, and Crossflow Filtration of AN102 Small C, SRT-RPP-20000003, Rev. 0 (WSRC-TR-2000-00341, Rev. 0), Savannah River Site (2000). 


\subsection{REFERENCES (CONTINUED)}

13 M. R. Duignan, Final Report: Pilot-scale Cross-flow Ultrafiltration Test Using a Hanford Site Tank 241-AN-107 Waste Simulant - Envelope C + Entrained Solids + Strontium-Transuranic Precipitation, BNF-003-98-0226, Rev. 0, Savannah River Site (2000).

14 M. C. Porter, Handbook of Industrial Membrane Technology, Noyes Publications, Park Ridge, NJ, p. 77 (1990). 


\section{APPENDIX A1. GRAPHICAL FLUX DATA}

Graphs with data points numbered "1_" are for the low concentration slurry (approximately 1.45-1.60 wt\% IS) factorial, whereas those numbered "15_" are for the factorial at about 17.2 wt $\%$ insoluble solids. 
WSRC-TR-2003-00056, REV. 0

SRT-RPP-2002-00231, REV. 0
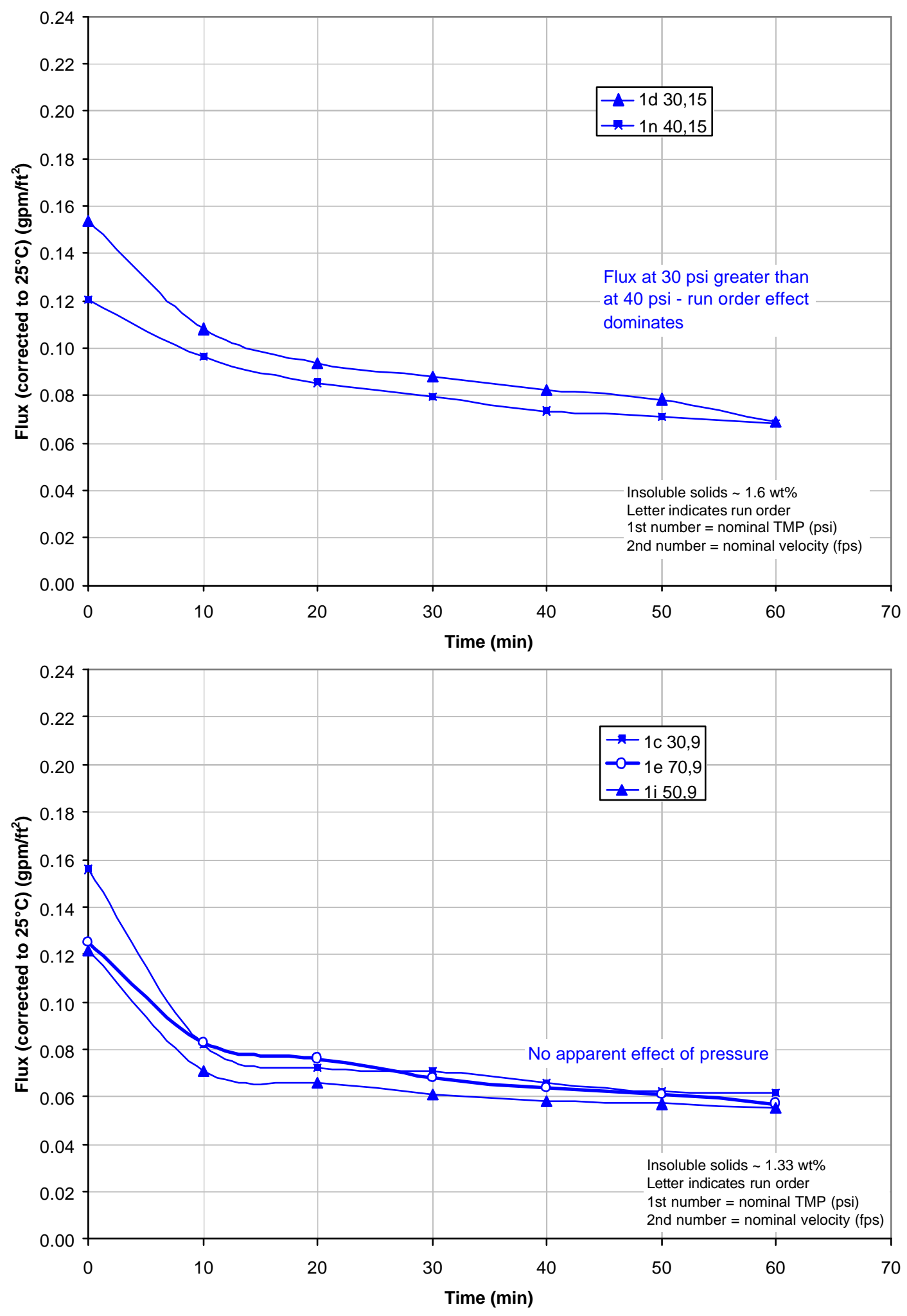
WSRC-TR-2003-00056, REV. 0

SRT-RPP-2002-00231, REV. 0
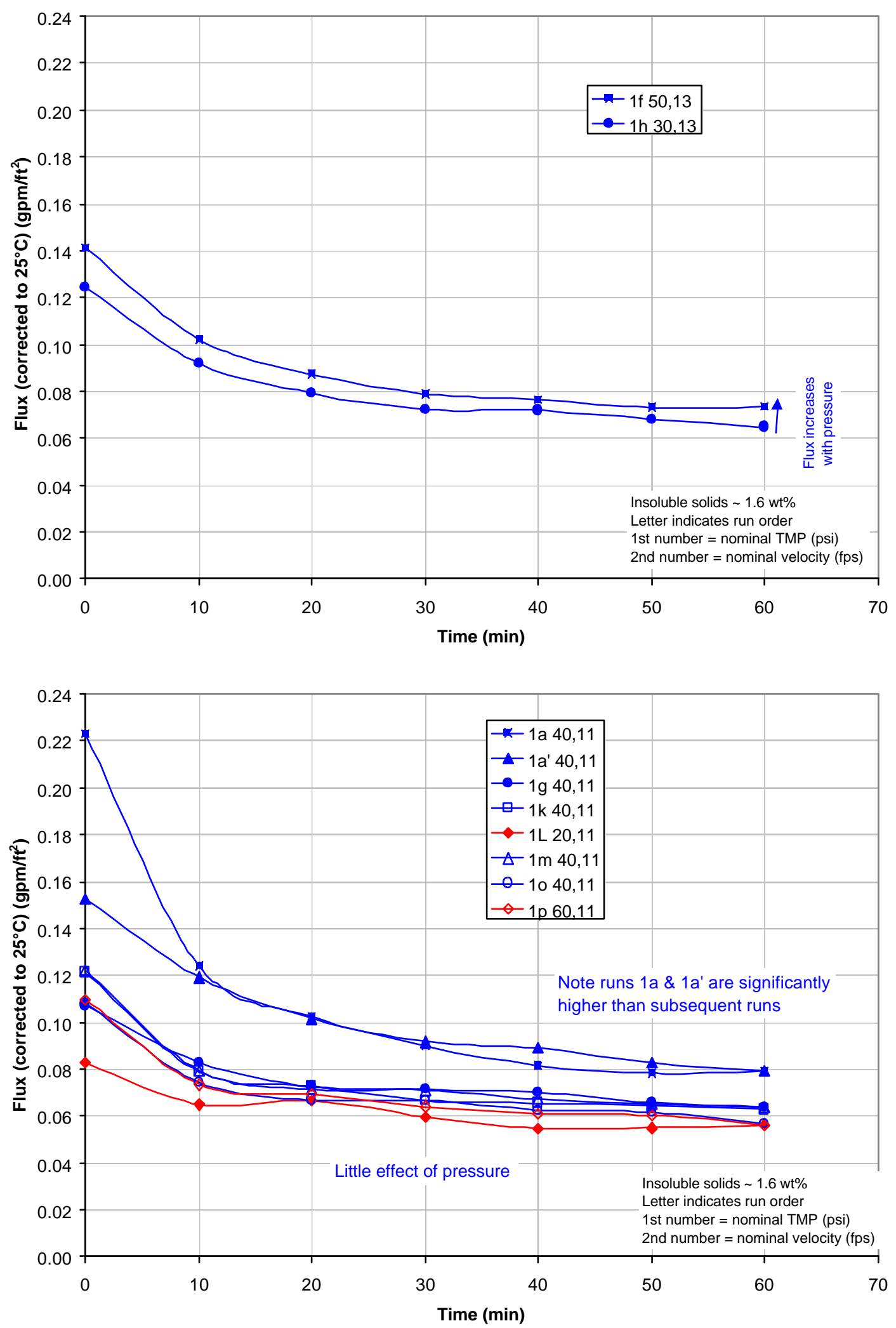
WSRC-TR-2003-00056, REV. 0

SRT-RPP-2002-00231, REV. 0
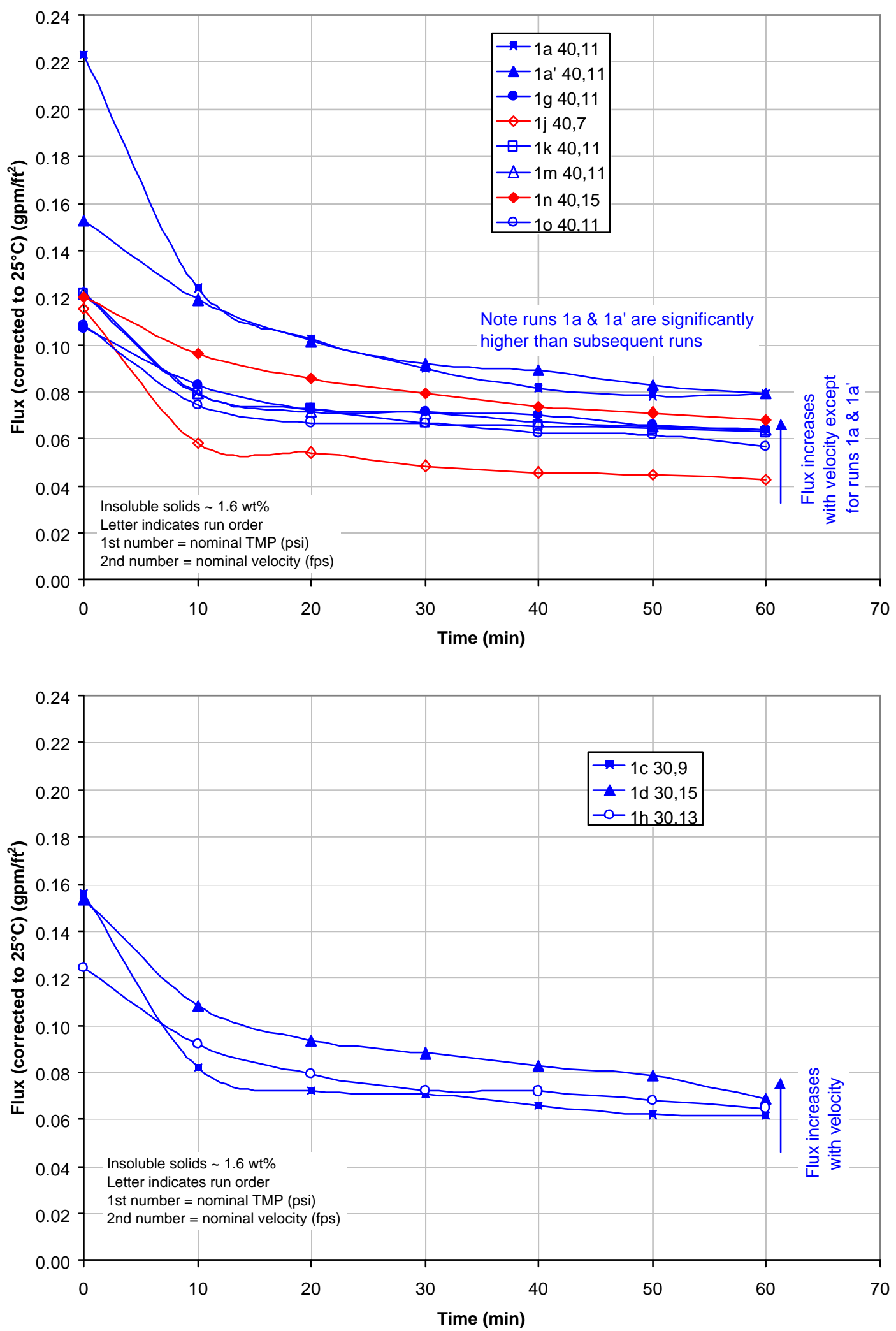

Page 71 of 124 
WSRC-TR-2003-00056, REV. 0

SRT-RPP-2002-00231, REV. 0
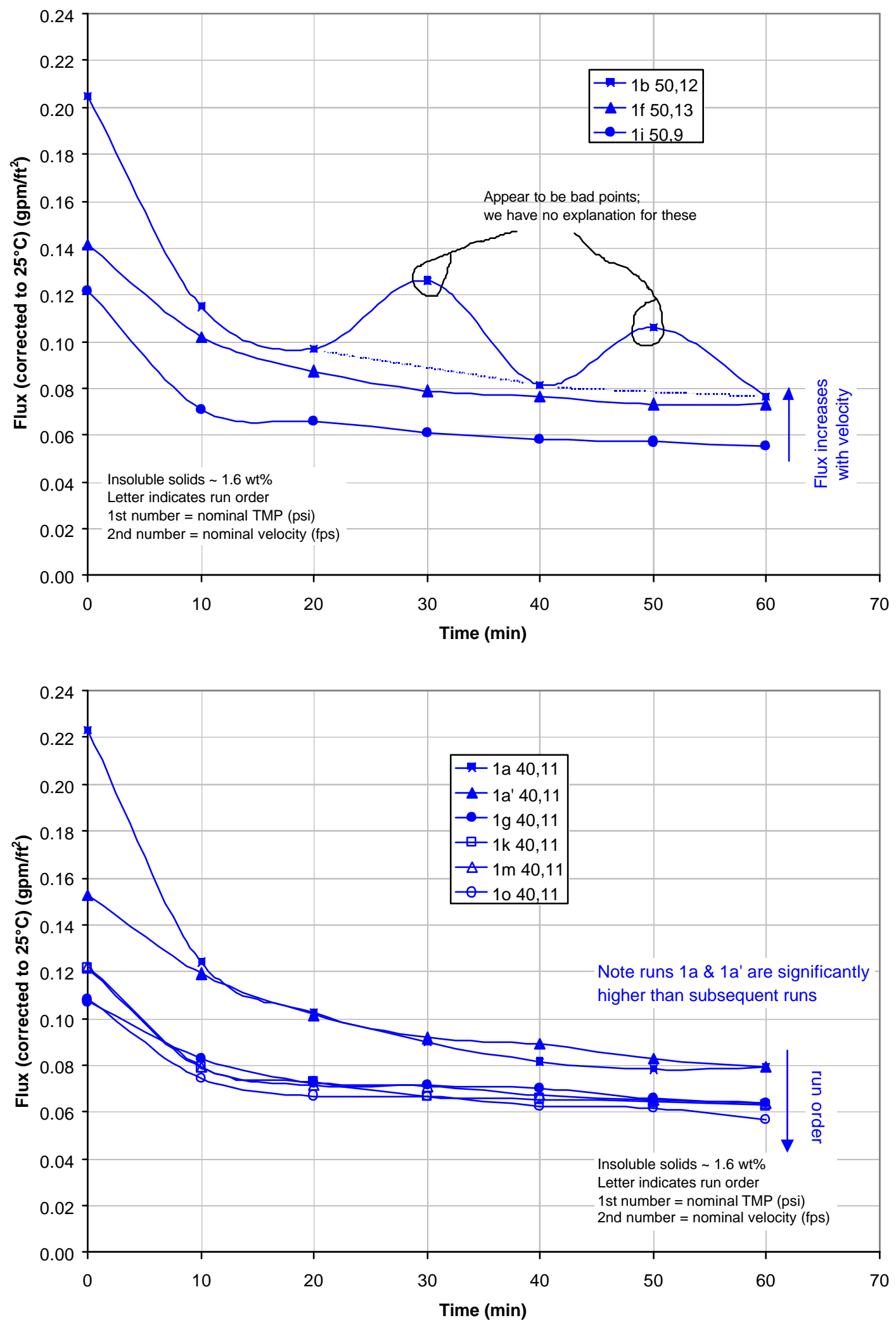

Page 72 of 124 
WSRC-TR-2003-00056, REV. 0

SRT-RPP-2002-00231, REV. 0
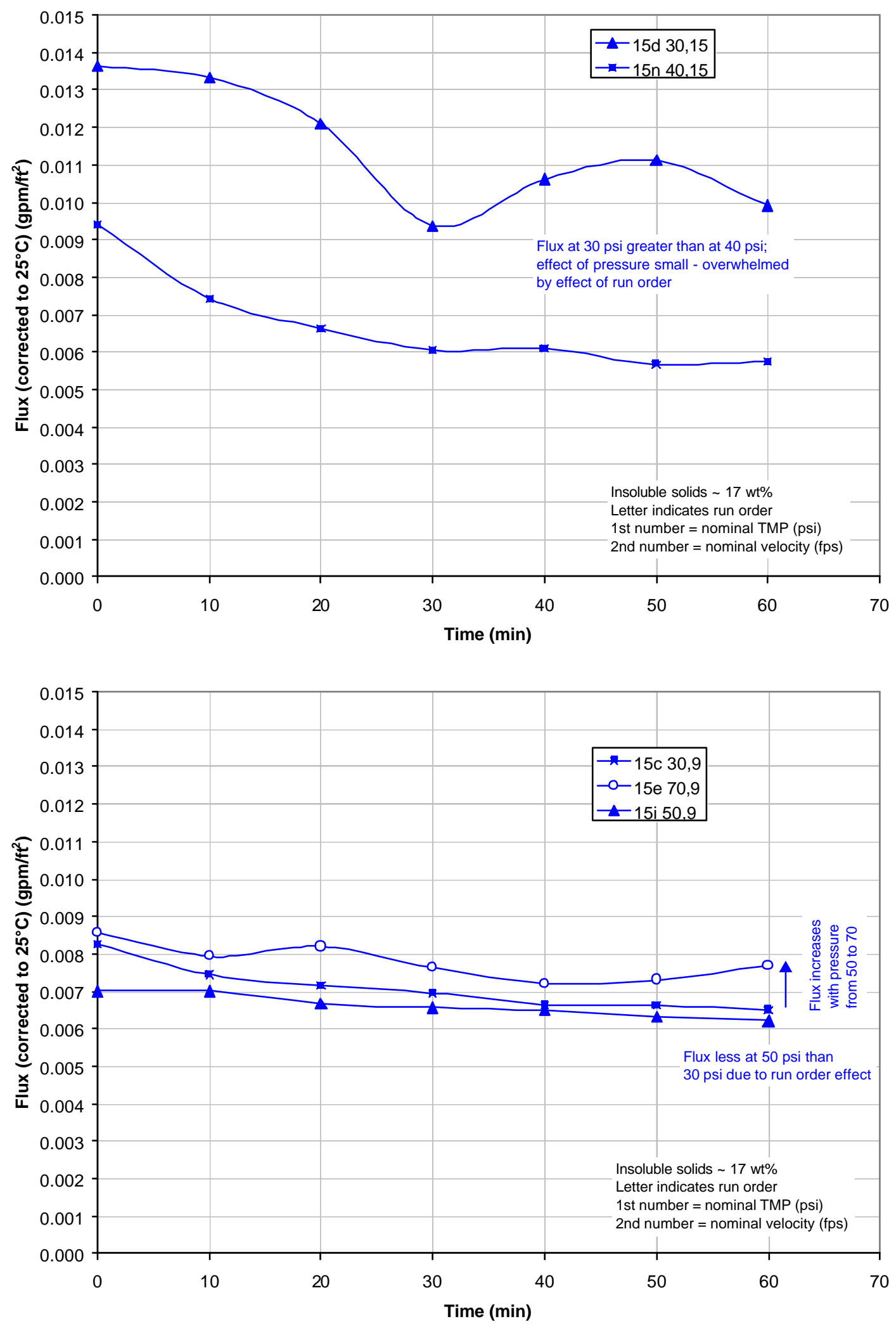

Page 73 of 124 
WSRC-TR-2003-00056, REV. 0

SRT-RPP-2002-00231, REV. 0
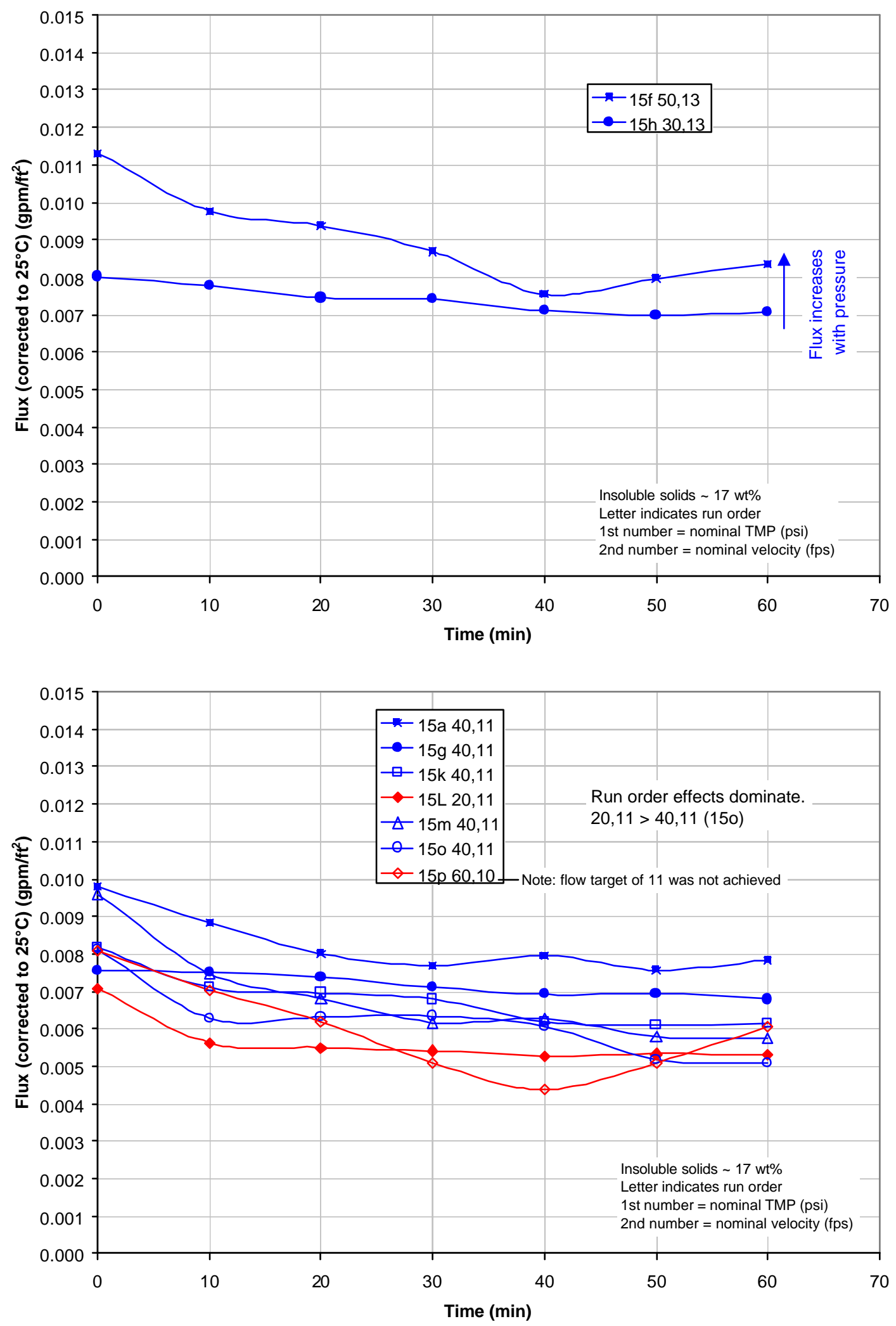
WSRC-TR-2003-00056, REV. 0

SRT-RPP-2002-00231, REV. 0
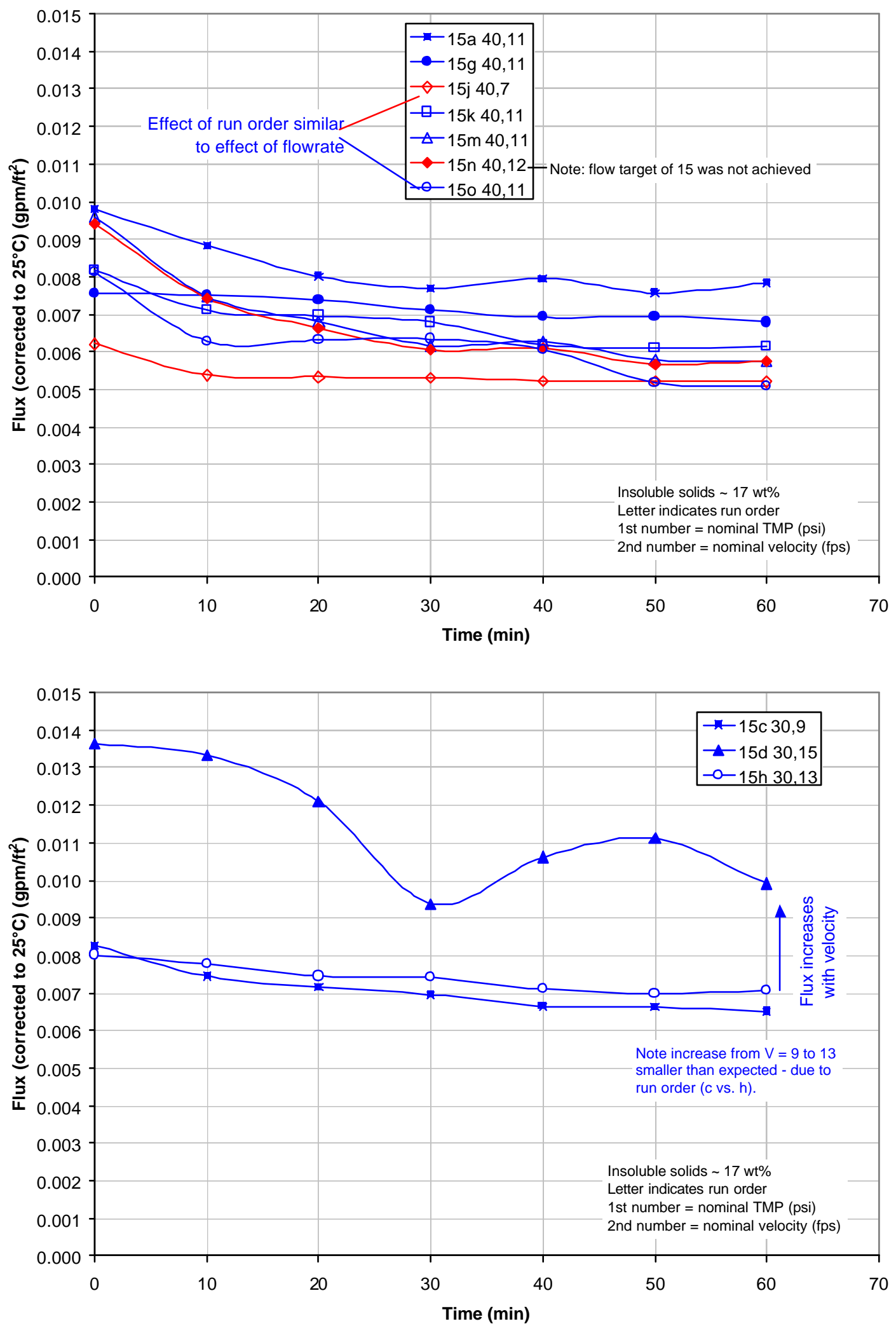
WSRC-TR-2003-00056, REV. 0

SRT-RPP-2002-00231, REV. 0
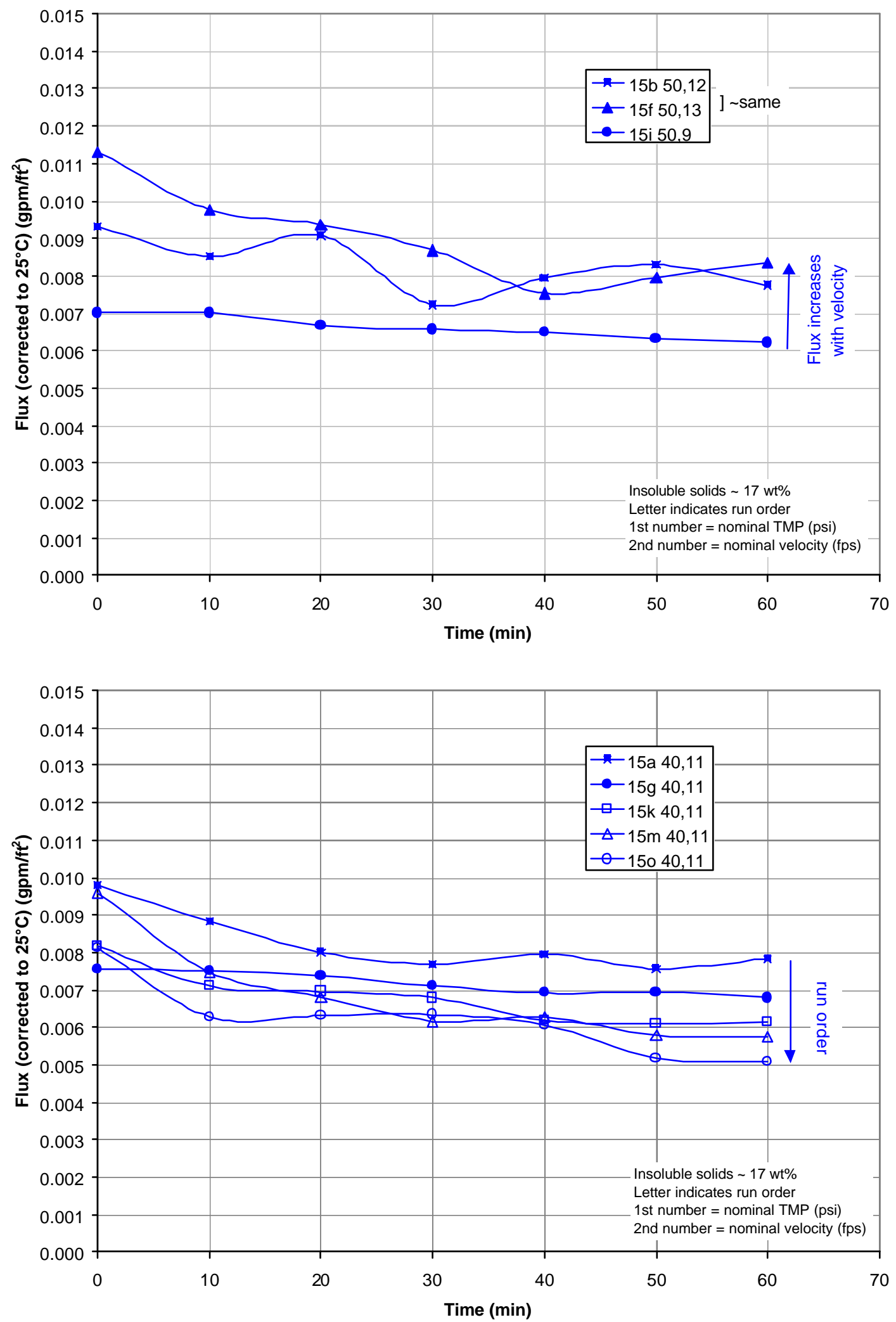
WSRC-TR-2003-00056, REV. 0

SRT-RPP-2002-00231, REV. 0

\section{APPENDIX A2. RAW FLUX DATA}

\begin{tabular}{|c|c|c|c|c|c|c|c|c|c|c|c|c|c|c|c|c|c|c|}
\hline $\begin{array}{l}\# \\
\text { 草 } \\
\end{array}$ & 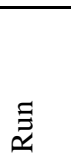 & 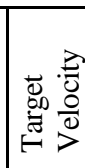 & 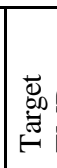 & 罗 & $\frac{3}{3}$ & $\frac{3}{3}$ & $\frac{\partial}{\frac{\Delta}{\Xi}}$ & 竞 & 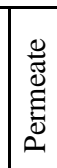 & $\sum_{k}$ & 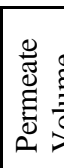 & 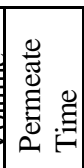 & 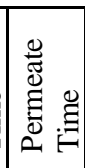 & 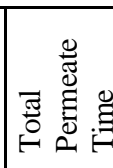 & $\frac{x}{\partial}$ & 离 & 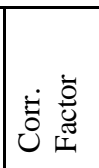 & 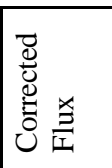 \\
\hline & & $\stackrel{\mathscr{a}}{\Leftrightarrow}$ & क्षै & 春 & छิ & $\stackrel{\mathscr{a}}{\Leftrightarrow}$ & $\begin{array}{l}.00 \\
.00 \\
\text { हn }\end{array}$ & $\frac{\partial 0}{0}$ & $\begin{array}{l}\frac{000}{0} \\
\text { ân }\end{array}$ & $\stackrel{\overparen{\hat{n}}}{\hat{\sigma}}$ & $\widehat{\widehat{\Xi}}$ & 覓 & 总 & 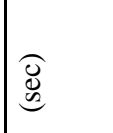 & 蛋 & 0 & & 氖 \\
\hline & & & & & & & & & & & & & & & & & & \\
\hline 1.17 & $15-\mathrm{a}$ & & & 0 & 3.85 & 11.18 & 44 & 37 & 2 & 39 & 40 & 5 & 39 & 339 & 0.0095 & 24 & 1.0286 & 0.00980 \\
\hline & & & & 10 & 3.72 & \begin{tabular}{|l|}
10.81 \\
\end{tabular} & 44 & 37 & 2 & 39 & 40 & 5 & 56 & 356 & 0.0091 & 26 & \begin{tabular}{|l|l|}
0.9723 \\
\end{tabular} & 0.00882 \\
\hline & & & & 20 & 3.70 & 10.75 & 44 & 38 & 3 & 38 & 40 & 6 & 43 & 403 & 0.0080 & 25 & 1.0000 & \begin{tabular}{|l}
0.00801 \\
\end{tabular} \\
\hline & & & & 30 & 3.74 & 10.86 & 45 & 39 & 2 & 40 & 40 & 7 & 0 & 420 & 0.0077 & 25 & 1.0000 & \begin{tabular}{|l|}
0.00769 \\
\end{tabular} \\
\hline & & & & 40 & 3.86 & 11.21 & 43 & 38 & 2 & 39 & 40 & 6 & 46 & 406 & 0.0080 & 25 & 1.0000 & 0.00795 \\
\hline & & & & 50 & 3.88 & 11.27 & 44 & 38 & 2 & 39 & 40 & 6 & 55 & 415 & 0.0078 & 26 & 0.9723 & \begin{tabular}{|l|}
0.00757 \\
\end{tabular} \\
\hline & & & & 60 & 3.74 & \begin{tabular}{|l|l|}
10.86 \\
\end{tabular} & 44 & 38 & 2 & 39 & 40 & 6 & 52 & 412 & 0.0078 & 25 & 1.0000 & 0.00784 \\
\hline & & 40 & 11 & Means: & 3.78 & 10.99 & & & & 38.79 & & & & & & & \begin{tabular}{|l|} 
SS \\
FLUX
\end{tabular} & 0.00757 \\
\hline & & & & & & & & & & & & & & & & & & \\
\hline $1.29 \mathrm{a}$ & $15-b$ & & & 0 & 4.06 & 11.79 & 51 & 46 & 2 & 47 & 40 & 5 & 28 & 328 & 0.0098 & 27 & \begin{tabular}{|l|l|}
0.9456 \\
\end{tabular} & \begin{tabular}{|l}
0.00931 \\
\end{tabular} \\
\hline & & & & 10 & 4.18 & $\mid 12.14$ & 53 & 45 & 2 & 47 & 40 & 6 & 30 & 390 & 0.0083 & 24 & 1.0286 & 0.00852 \\
\hline & & & & 20 & 4.08 & 11.85 & 52 & 45 & 2 & 47 & 40 & 6 & 6 & 366 & 0.0088 & 24 & 1.0286 & 0.00908 \\
\hline & & & & 30 & 4.10 & \begin{tabular}{|l|}
11.91 \\
\end{tabular} & 50 & 45 & 2 & 46 & 40 & 7 & 15 & 435 & \begin{tabular}{|l|}
0.0074 \\
\end{tabular} & 26 & \begin{tabular}{|l|l|}
0.9723 \\
\end{tabular} & 0.00722 \\
\hline & & & & 40 & 4.09 & \begin{tabular}{|l|}
11.88 \\
\end{tabular} & 53 & 46 & 2 & 48 & 40 & 6 & 25 & 385 & 0.0084 & 27 & 0.9456 & 0.00793 \\
\hline & & & & 50 & 4.09 & \begin{tabular}{|l|}
11.88 \\
\end{tabular} & 54 & 45 & 2 & 48 & 40 & 6 & 29 & 389 & 0.0083 & 25 & 1.0000 & 0.00830 \\
\hline & & & & 60 & 4.08 & 11.85 & 54 & 47 & 2 & 49 & 40 & 6 & 45 & 405 & 0.0080 & 26 & 0.9723 & \begin{tabular}{|l}
0.00775 \\
\end{tabular} \\
\hline & & 50 & 12 & Means: & 4.10 & 11.90 & & & & \begin{tabular}{|l}
47.00 \\
\end{tabular} & & & & & & & \begin{tabular}{|l} 
SS \\
FLUX
\end{tabular} & 0.00775 \\
\hline & & & & & & & & & & & & & & & & & & \\
\hline \begin{tabular}{|l|}
1.20 \\
\end{tabular} & $15-\mathrm{c}$ & & & 0 & 3.21 & 9.32 & 36 & 30 & 2 & 31 & 20 & 3 & 27 & 207 & 0.0078 & 23 & 1.0583 & 0.00826 \\
\hline & & & & 10 & 3.23 & \begin{tabular}{|l|}
9.38 \\
\end{tabular} & 34 & 30 & 2 & 30 & 20 & 3 & 43 & 223 & 0.0072 & 24 & 1.0286 & \begin{tabular}{|l}
0.00745 \\
\end{tabular} \\
\hline & & & & 20 & 3.25 & 9.44 & 34 & 30 & 2 & 30 & 20 & 3 & 52 & 232 & 0.0070 & 24 & 1.0286 & \begin{tabular}{|l|l|}
0.00716 \\
\end{tabular} \\
\hline & & & & 30 & 3.24 & 9.41 & 34 & 30 & 2 & 30 & 20 & 3 & 59 & 239 & 0.0068 & 24 & 1.0286 & 0.00695 \\
\hline & & & & 40 & 3.23 & 9.38 & 34 & 30 & 2 & 30 & 20 & 4 & 3 & 243 & 0.0066 & 25 & 1.0000 & \begin{tabular}{|l|l}
0.00664 \\
\end{tabular} \\
\hline & & & & 50 & 3.21 & 9.32 & 34 & 30 & 2 & 30 & 20 & 4 & 4 & 244 & 0.0066 & 25 & 1.0000 & 0.00662 \\
\hline & & & & 60 & 3.22 & 9.35 & 34 & 30 & 2 & 30 & 20 & 4 & 8 & \begin{tabular}{|l|}
248 \\
\end{tabular} & \begin{tabular}{|l}
0.0065 \\
\end{tabular} & 25 & \begin{tabular}{|l|l|}
1.0000 \\
\end{tabular} & \begin{tabular}{|l|}
0.00651 \\
\end{tabular} \\
\hline & & 30 & 9 & Means: & 3.23 & 9.37 & & & & 30.14 & & & & & & & \begin{tabular}{|l} 
SS \\
FLUX
\end{tabular} & 0.00651 \\
\hline & & & & & & & & & & & & & & & & & & \\
\hline \begin{tabular}{|l|}
$1.29 \mathrm{~b}$ \\
\end{tabular} & $15-d$ & & & 0 & 5.11 & 14.84 & 34 & 28 & 2 & 29 & 40 & 4 & 18 & 258 & 0.0125 & 22 & 1.0891 & 0.01363 \\
\hline & & & & 10 & 5.16 & \begin{tabular}{|l|}
14.99 \\
\end{tabular} & 34 & 28 & 2 & 29 & 40 & 4 & 24 & 264 & 0.0122 & 22 & 1.0891 & 0.01332 \\
\hline & & & & 20 & 5.14 & 14.93 & 33 & 28 & 2 & 29 & 40 & 4 & 27 & 267 & $\mid 0.0121$ & 25 & 1.0000 & 0.01209 \\
\hline & & & & 30 & 5.11 & 14.84 & 34 & 28 & 2 & 29 & 40 & 5 & 35 & 335 & 0.0096 & 26 & 0.9723 & 0.00937 \\
\hline & & & & 40 & \begin{tabular}{|l|}
5.07 \\
\end{tabular} & 14.73 & 33 & 27 & 2 & 28 & 40 & 5 & 22 & 322 & 0.0100 & 23 & 1.0583 & \begin{tabular}{|l|}
0.01061 \\
\end{tabular} \\
\hline & & & & 50 & \begin{tabular}{|l|}
5.08 \\
\end{tabular} & 14.76 & 33 & 27 & 2 & 28 & 40 & 4 & 59 & \begin{tabular}{|l|}
299 \\
\end{tabular} & \begin{tabular}{|l|}
0.0108 \\
\end{tabular} & 24 & \begin{tabular}{|l|}
1.0286 \\
\end{tabular} & \begin{tabular}{|l|}
0.01111 \\
\end{tabular} \\
\hline & & & & 60 & 5.06 & 14.70 & 33 & 27 & 2 & \begin{tabular}{|l|}
28 \\
\end{tabular} & 40 & 5 & \begin{tabular}{|l|}
8 \\
\end{tabular} & 308 & \begin{tabular}{|l}
0.0105 \\
\end{tabular} & 27 & \begin{tabular}{|l|}
0.9456 \\
\end{tabular} & \begin{tabular}{|l|}
0.00991 \\
\end{tabular} \\
\hline & & 30 & 15 & Means: & 5.10 & \begin{tabular}{|l|}
14.83 \\
\end{tabular} & & & & 28.50 & & & & & & & \begin{tabular}{|l} 
SS \\
FLUX
\end{tabular} & 0.00991 \\
\hline
\end{tabular}


WSRC-TR-2003-00056, REV. 0

SRT-RPP-2002-00231, REV. 0

\begin{tabular}{|c|c|c|c|c|c|c|c|c|c|c|c|c|c|c|c|c|c|c|}
\hline $\begin{array}{l}\# \\
\text { E } \\
\hat{E}\end{array}$ & $\stackrel{\Xi}{\cong}$ & 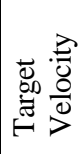 & 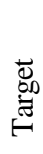 & 节 & $\frac{3}{\frac{3}{I}}$ & $\frac{3}{0}$ & 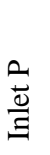 & 号 & 造 & $\sum_{i}^{q}$ & 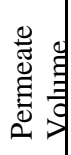 & 离 & 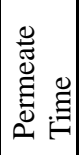 & 宽 & $\stackrel{x}{\stackrel{2}{2}}$ & 害 & $\dot{\overrightarrow{0}} \dot{\overrightarrow{0}}$ & 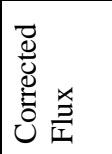 \\
\hline & & 気 & क्ञै & 产 & ह્ळ్ & 氙 & $\begin{array}{l}.000 \\
\hat{b}\end{array}$ & है⿴囗十) & $\begin{array}{l}.00 \\
0 \\
0 \\
0\end{array}$ & 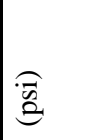 & ह્छ & 春 & 总 & 总 & 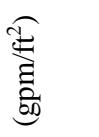 & ర0 & & $\begin{array}{l}\text { 蛋 } \\
\text { 氮 }\end{array}$ \\
\hline \multirow[t]{8}{*}{$1.29 \mathrm{c}$} & 15-e & & & 0 & 3.08 & 8.95 & 73 & 68 & 2 & 69 & 40 & 5 & 56 & 356 & 0.0091 & 27 & 0.9456 & $\mid 0.00858$ \\
\hline & & & & 10 & 3.06 & \begin{tabular}{|l|}
8.89 \\
\end{tabular} & 74 & 68 & 2 & 69 & 40 & 6 & 25 & 385 & 0.0084 & 27 & \begin{tabular}{|l|}
0.9456 \\
\end{tabular} & 0.00793 \\
\hline & & & & 20 & 3.08 & 8.95 & 73 & 67 & 2 & 68 & 40 & 6 & 23 & 383 & 0.0084 & 26 & \begin{tabular}{|l}
0.9723 \\
\end{tabular} & \begin{tabular}{|l|}
0.00820 \\
\end{tabular} \\
\hline & & & & 30 & 3.09 & \begin{tabular}{|l|}
8.98 \\
\end{tabular} & 74 & 68 & 2 & 69 & 40 & 6 & 40 & 40 & 0.0081 & 27 & \begin{tabular}{|l}
0.9456 \\
\end{tabular} & \begin{tabular}{|l}
0.00763 \\
\end{tabular} \\
\hline & & & & 40 & 3.12 & 9.06 & $\overline{73}$ & 67 & 3 & 67 & 40 & 7 & 4 & 424 & 0.0076 & 27 & \begin{tabular}{|l|}
0.9456 \\
\end{tabular} & 0.00720 \\
\hline & & & & 50 & 3.11 & 9.03 & 73 & 67 & 3 & 67 & 40 & 7 & 10 & 430 & 0.0075 & 26 & \begin{tabular}{|l|}
0.9723 \\
\end{tabular} & 0.00730 \\
\hline & & & & 60 & 3.10 & 9.01 & 74 & 67 & 3 & 68 & 40 & 6 & 48 & 408 & 0.0079 & 26 & \begin{tabular}{|l|}
0.9723 \\
\end{tabular} & 0.00770 \\
\hline & & 70 & 9 & Means: & 3.09 & 8.98 & & & & 68.00 & & & & & & & \begin{tabular}{|l|} 
SS \\
FLUX:
\end{tabular} & 0.00730 \\
\hline & & & & & & & & & & & & & & & & & & \\
\hline \multirow[t]{8}{*}{1.22} & 15-f & & & 0 & 4.45 & 12.93 & 53 & 48 & 2 & 49 & 40 & 4 & 38 & 278 & 0.0116 & 26 & 0.9723 & 0.01129 \\
\hline & & & & 10 & 4.48 & 13.01 & 54 & 49 & 2 & 50 & 40 & 4 & 56 & 296 & 0.0109 & 29 & \begin{tabular}{|l|}
0.8948 \\
\end{tabular} & 0.00976 \\
\hline & & & & 20 & 4.45 & 12.93 & 53 & $\overline{50}$ & 2 & 50 & 40 & 5 & 0 & 300 & 0.0108 & 30 & \begin{tabular}{|l|}
0.8707 \\
\end{tabular} & \begin{tabular}{|l}
0.00937 \\
\end{tabular} \\
\hline & & & & 30 & \begin{tabular}{|l|}
4.48 \\
\end{tabular} & 13.01 & 54 & 49 & 2 & 50 & 40 & 5 & 24 & 324 & 0.0100 & 30 & \begin{tabular}{|l|}
0.8707 \\
\end{tabular} & \begin{tabular}{|l|}
0.00868 \\
\end{tabular} \\
\hline & & & & 40 & 4.43 & 12.87 & 54 & 48 & 2 & 49 & 40 & 6 & 45 & 405 & 0.0080 & 27 & \begin{tabular}{|l|}
0.9456 \\
\end{tabular} & \begin{tabular}{|l|}
0.00754 \\
\end{tabular} \\
\hline & & & & 50 & 44.41 & 12.81 & 53 & 46 & 3 & 47 & 40 & 6 & \begin{tabular}{|l|}
57 \\
\end{tabular} & \begin{tabular}{|l|}
417 \\
\end{tabular} & 0.0077 & 24 & \begin{tabular}{|l|}
1.0286 \\
\end{tabular} & \begin{tabular}{|l|}
0.00797 \\
\end{tabular} \\
\hline & & & & 60 & 4.41 & 12.81 & 52 & 46 & 3 & 46 & 40 & 6 & 6 & 366 & 0.0088 & 27 & \begin{tabular}{|l|}
0.9456 \\
\end{tabular} & 0.00834 \\
\hline & & 50 & 13 & Means: & 4.44 & 12.91 & & & & 48.36 & & & & & & & \begin{tabular}{|l} 
SS \\
FLUX:
\end{tabular} & 0.00795 \\
\hline & & & & & & & & & & & & & & & & & & \\
\hline \multirow[t]{8}{*}{1.18} & $15-\mathrm{g}$ & & & 0 & 3.80 & 11.04 & 44 & 39 & 2 & 40 & 20 & 3 & 34 & 214 & 0.0075 & 25 & 1.0000 & 0.00755 \\
\hline & & & & 10 & 3.83 & 11.13 & 44 & 39 & 2 & 40 & 20 & 3 & 35 & 215 & 0.0075 & 25 & \begin{tabular}{|l|}
1.0000 \\
\end{tabular} & 0.00751 \\
\hline & & & & 20 & 3.87 & 11.24 & 44 & 39 & 2 & 40 & 20 & 3 & 33 & 213 & 0.0076 & 26 & \begin{tabular}{|l|}
0.9723 \\
\end{tabular} & \begin{tabular}{|l|}
0.00737 \\
\end{tabular} \\
\hline & & & & 30 & 3.84 & 11.15 & 45 & 40 & 2 & 41 & 20 & 3 & 47 & \begin{tabular}{|l|}
227 \\
\end{tabular} & 0.0071 & 25 & 1.0000 & \begin{tabular}{|l|}
0.00711 \\
\end{tabular} \\
\hline & & & & 40 & 3.74 & 10.86 & 44 & 38 & 2 & 39 & 20 & 4 & 0 & 240 & 0.0067 & 24 & \begin{tabular}{|l|}
1.0286 \\
\end{tabular} & 0.00692 \\
\hline & & & & 50 & 3.78 & 10.98 & 45 & 38 & 2 & 40 & 20 & 3 & 46 & 226 & 0.0071 & 26 & \begin{tabular}{|l|}
0.9723 \\
\end{tabular} & \begin{tabular}{|l|}
0.00695 \\
\end{tabular} \\
\hline & & & & 60 & 3.78 & 10.98 & 45 & 40 & 2 & 41 & 20 & 3 & \begin{tabular}{|l|}
58 \\
\end{tabular} & 238 & 0.0068 & 25 & 1.0000 & \begin{tabular}{|l}
0.00678 \\
\end{tabular} \\
\hline & & 40 & 11 & Means: & 3.81 & 11.06 & & & & 39.71 & & & & & & & \begin{tabular}{|l|} 
SS \\
FLUX:
\end{tabular} & 0.00678 \\
\hline & & & & & & & & & & & & & & & & & & \\
\hline \multirow[t]{8}{*}{1.21} & 15-h & & & 0 & 4.47 & 12.98 & 35 & 27 & 3 & 28 & 20 & 3 & 16 & 196 & 0.0082 & 26 & \begin{tabular}{|l|}
0.9723 \\
\end{tabular} & 0.00801 \\
\hline & & & & 10 & 4.45 & 12.93 & 34 & 27 & 2 & 29 & 20 & 3 & 28 & 208 & 0.0078 & 25 & \begin{tabular}{|l|}
1.0000 \\
\end{tabular} & 0.00776 \\
\hline & & & & 20 & 4.45 & 12.93 & 35 & 27 & 2 & 29 & 20 & 3 & 37 & 217 & 0.0074 & 25 & \begin{tabular}{|l|}
1.0000 \\
\end{tabular} & 0.00744 \\
\hline & & & & 30 & 4.40 & 12.78 & 34 & 27 & 2 & 29 & 20 & 3 & 38 & 218 & 0.0074 & 25 & \begin{tabular}{|l|}
1.0000 \\
\end{tabular} & 0.00741 \\
\hline & & & & 40 & 4.40 & 12.78 & 34 & 27 & 2 & 29 & 20 & 3 & 41 & 221 & 0.0073 & 26 & \begin{tabular}{|l|}
0.9723 \\
\end{tabular} & \begin{tabular}{|l|}
0.00710 \\
\end{tabular} \\
\hline & & & & 50 & 4.46 & 12.96 & 34 & 27 & 2 & 29 & 20 & 3 & 45 & 225 & 0.0072 & 26 & \begin{tabular}{|l|}
0.9723 \\
\end{tabular} & \begin{tabular}{|l|}
0.00698 \\
\end{tabular} \\
\hline & & & & 60 & 4.50 & 13.07 & 34 & 27 & 2 & 29 & 20 & 3 & 36 & 216 & 0.0075 & 27 & 0.9456 & \begin{tabular}{|l|}
0.00707 \\
\end{tabular} \\
\hline & & 30 & 13 & Means: & 4.45 & 12.92 & & & & 28.50 & & & & & & & \begin{tabular}{|l|} 
SS \\
FLUX:
\end{tabular} & 0.00707 \\
\hline \multirow{10}{*}{1.23} & & & & & & & & & & & & & & & & & & \\
\hline & $15-1$ & & & \begin{tabular}{|l|}
0 \\
10
\end{tabular} & \begin{tabular}{|l}
3.19 \\
311
\end{tabular} & $\begin{array}{l}9.27 \\
9.03\end{array}$ & $\frac{53}{55}$ & $\frac{47}{51}$ & $\frac{3}{3}$ & \begin{tabular}{|l|}
47 \\
50
\end{tabular} & $\frac{20}{20}$ & $\frac{3}{3}$ & \begin{tabular}{|l|}
57 \\
57
\end{tabular} & \begin{tabular}{|l|}
237 \\
237
\end{tabular} & $\frac{0.0068}{0.0068}$ & $\frac{24}{24}$ & \begin{tabular}{|l|}
1.0286 \\
1.0286
\end{tabular} & $\mid \begin{array}{l}0.00701 \\
000701\end{array}$ \\
\hline & & & & $\frac{10}{20}$ & \begin{tabular}{|l|}
3.11 \\
3.14 \\
\end{tabular} & $\begin{array}{l}9.05 \\
9.12\end{array}$ & \begin{tabular}{|l|}
54 \\
54
\end{tabular} & $\frac{31}{50}$ & \begin{tabular}{|l|}
3 \\
\end{tabular} & \begin{tabular}{|l|}
30 \\
49 \\
\end{tabular} & $\frac{20}{20}$ & $\mid \frac{3}{4}$ & $\frac{97}{9}$ & \begin{tabular}{|l}
249 \\
\end{tabular} & $\begin{array}{l}0.00606 \\
0.005\end{array}$ & $\frac{24}{24}$ & \begin{tabular}{|l|l|}
1.02806 \\
\end{tabular} & \begin{tabular}{|l|}
0.00667 \\
\end{tabular} \\
\hline & & & & 30 & 3.15 & \begin{tabular}{|l|}
9.15 \\
\end{tabular} & 54 & 50 & 3 & 49 & 20 & 4 & 6 & 246 & 0.0066 & 25 & \begin{tabular}{|l|}
1.0000 \\
\end{tabular} & \begin{tabular}{|l|l}
0.00656 \\
\end{tabular} \\
\hline & & & & 40 & 3.13 & \begin{tabular}{|l|}
9.09 \\
\end{tabular} & 54 & 50 & 3 & 49 & 20 & 4 & 9 & 249 & 0.0065 & 25 & \begin{tabular}{|l|}
1.0000 \\
\end{tabular} & \begin{tabular}{|l|}
0.00648 \\
\end{tabular} \\
\hline & & & & 50 & 3.14 & 9.12 & 54 & 50 & 3 & 49 & 20 & 4 & 15 & 255 & 0.0063 & 25 & \begin{tabular}{|l|}
1.0000 \\
\end{tabular} & 0.00633 \\
\hline & & & & 60 & 3.09 & 8.98 & 54 & 50 & 3 & 49 & 20 & 4 & 13 & 253 & 0.0064 & 26 & 0.9723 & 0.00621 \\
\hline & & 50 & 9 & Means: & 3.14 & 9.11 & & & & 48.86 & & & & & & & \begin{tabular}{|l|} 
SS \\
FLUX:
\end{tabular} & \begin{tabular}{|l|}
0.00621 \\
\end{tabular} \\
\hline & & & & & & & & & & & & & & & & & & \\
\hline & & & & & & & & & & & & & & & & & & \\
\hline
\end{tabular}


WSRC-TR-2003-00056, REV. 0

SRT-RPP-2002-00231, REV. 0

\begin{tabular}{|c|c|c|c|c|c|c|c|c|c|c|c|c|c|c|c|c|c|c|}
\hline $\begin{array}{l}\# \\
\text { 荀 } \\
\end{array}$ & 吉 & 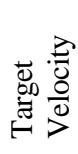 & 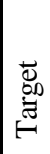 & 音 & $\frac{3}{0}$ & $\frac{3}{2}$ & $\frac{a}{\frac{\omega}{J}}$ & $\frac{a}{0}$ & 莺 & $\sum_{i=1}^{e}$ & 总 & 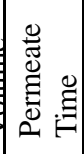 & 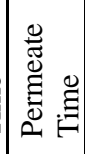 & 总 & 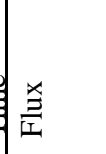 & 苛 & 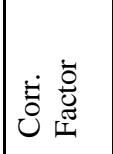 & 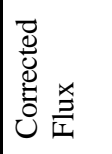 \\
\hline & & $\stackrel{\mathscr{A}}{\Leftrightarrow}$ & 危 & 刍 & 㻤 & $\hat{\mathscr{a}}$ & 告 & $\frac{.00}{6}$ & $\begin{array}{l}.00 \\
0.00 \\
0\end{array}$ & 氞 & ह્ิ & 奉 & $\begin{array}{l}\mathscr{\mathscr { d }} \\
\text { G }\end{array}$ & 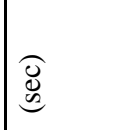 & 卧 & 0 & & 䆖 \\
\hline 1.25 & $15-\mathrm{j}$ & & & 0 & 2.39 & 6.94 & 43 & 39 & 3 & 38 & 20 & 4 & 13 & 253 & 0.0064 & 26 & 0.9723 & 0.00621 \\
\hline & & & & 10 & 2.38 & 6.91 & 43 & 39 & 3 & 38 & 20 & 4 & 52 & 292 & 0.0055 & 26 & 0.9723 & 0.00538 \\
\hline & & & & 20 & 2.39 & 6.94 & 43 & 39 & 3 & 38 & 20 & 5 & 3 & 303 & 0.0053 & 25 & 1.0000 & 0.00533 \\
\hline & & & & 30 & 2.38 & \begin{tabular}{|l|}
6.91 \\
\end{tabular} & 44 & 40 & 3 & 39 & 20 & 5 & 13 & 313 & 0.0052 & 24 & 1.0286 & \begin{tabular}{|l|}
0.00531 \\
\end{tabular} \\
\hline & & & & 40 & 2.34 & 6.80 & 44 & 40 & 3 & 39 & 20 & 5 & 18 & 318 & 0.0051 & 24 & 1.0286 & 0.00522 \\
\hline & & & & 50 & 2.43 & 7.06 & 44 & 40 & 3 & 39 & 20 & 5 & 28 & 328 & \begin{tabular}{|l|l|}
0.0049 \\
\end{tabular} & 23 & 1.0583 & 0.00521 \\
\hline & & & & 60 & 2.41 & 7.00 & 44 & 40 & 3 & 39 & 20 & 5 & 29 & 329 & 0.0049 & 23 & 1.0583 & \begin{tabular}{|l}
0.00519 \\
\end{tabular} \\
\hline & & 40 & 7 & Means: & 2.39 & 6.94 & & & & 38.57 & & & & & & & \begin{tabular}{|l|} 
SS \\
FLUX:
\end{tabular} & 0.00519 \\
\hline & & & & & & & & & & & & & & & & & & \\
\hline & & & & & & & & & & & & & & & & & & \\
\hline 1.24 & $15-\mathrm{k}$ & & & 0 & 3.83 & 11.13 & 43 & 38 & 3 & 38 & 20 & 3 & 18 & 198 & 0.0082 & 25 & 1.0000 & 0.00815 \\
\hline & & & & 10 & 3.72 & 10.8 & 43 & 38 & 3 & 38 & 20 & 3 & 54 & 234 & 0.0069 & 24 & 1.0286 & $\mid 0.00710$ \\
\hline & & & & 20 & 3.74 & 10.86 & 44 & 39 & 3 & 39 & 20 & 3 & 59 & 239 & 0.0068 & 24 & 1.0286 & 0.00695 \\
\hline & & & & 30 & 3.79 & 111.0 & 44 & 39 & 3 & 39 & 20 & 3 & 58 & 238 & 0.0068 & 25 & 1.0000 & 0.00678 \\
\hline & & & & 40 & 3.77 & 10.94 & 44 & 39 & 3 & 39 & 20 & 4 & 14 & 254 & 0.0064 & 26 & 0.9723 & 0.00618 \\
\hline & & & & 50 & 3.76 & 10.92 & 44 & 38 & 3 & 38 & 20 & 4 & 17 & 257 & 0.0063 & 26 & \begin{tabular}{|l}
0.9723 \\
\end{tabular} & 0.00611 \\
\hline & & & & 60 & 3.75 & 10.8 & 44 & 38 & 3 & 38 & 20 & 4 & 16 & 256 & 0.0063 & 26 & 0.9723 & 0.00613 \\
\hline & & 40 & 11 & Means: & 3.77 & 10.9 & & & & 38.07 & & & & & & & \begin{tabular}{|l|} 
SS \\
FLUX:
\end{tabular} & 0.00613 \\
\hline & & & & & & & & & & & & & & & & & & \\
\hline 1.27 & $15-\mathrm{L}$ & & & 0 & 3.75 & 10.8 & 23 & 19 & 3 & 18 & 20 & 3 & 36 & 216 & 0.0075 & 27 & 0.9456 & 0.00707 \\
\hline & & & & 10 & 3.73 & 10.8 & 23 & 18 & 3 & 18 & 20 & 4 & 39 & 279 & 0.0058 & 26 & 0.9723 & 0.00563 \\
\hline & & & & 20 & 3.68 & 10.6 & 23 & 19 & 3 & 18 & 20 & 4 & 54 & 294 & 0.0055 & 25 & 1.0000 & 0.00549 \\
\hline & & & & 30 & 3.74 & 10.86 & 23 & 18 & 3 & 18 & 20 & 5 & 7 & 307 & 0.0053 & 24 & 1.0286 & 0.00541 \\
\hline & & & & 40 & 3.69 & 10.72 & 23 & 18 & 3 & 18 & 20 & 5 & 15 & 315 & 0.0051 & 24 & 1.0286 & 0.00527 \\
\hline & & & & 50 & 3.81 & $11.0^{\prime}$ & 23 & 19 & 3 & 18 & 20 & 5 & 12 & 312 & 0.0052 & 24 & 1.0286 & 0.00532 \\
\hline & & & & 60 & 3.73 & 10.8 & 23 & 19 & 3 & 18 & 20 & 5 & 13 & 313 & 0.0052 & 24 & 1.0286 & \begin{tabular}{|l|}
0.00531 \\
\end{tabular} \\
\hline & & 20 & 11 & Means: & 3.73 & \begin{tabular}{|l|}
10.8 \\
\end{tabular} & & & & \begin{tabular}{|l|}
17.79 \\
\end{tabular} & & & & & & & \begin{tabular}{|l|} 
SS \\
FLUX:
\end{tabular} & 0.00531 \\
\hline & & & & & & & & & & & & & & & & & & \\
\hline 1.29 & $15-\mathrm{m}$ & & & 0 & 3.71 & 10.78 & 42 & 38 & 3 & 37 & 20 & 2 & 53 & 173 & 0.0093 & 24 & 1.0286 & 0.00960 \\
\hline & & & & 10 & 3.73 & 10.8 & 44 & 39 & 3 & 39 & 20 & 3 & 42 & 222 & 0.0073 & 24 & 1.0286 & 0.00748 \\
\hline & & & & 20 & 3.72 & 10.8 & 43 & 38 & 3 & 38 & 20 & 3 & 57 & 237 & 0.0068 & 25 & 1.0000 & 0.00681 \\
\hline & & & & 30 & 3.70 & 10.75 & 44 & 39 & 3 & 39 & 20 & 4 & 22 & 262 & 0.0062 & 25 & 1.0000 & 0.00616 \\
\hline & & & & 40 & 3.68 & 10.6 & 44 & 39 & 3 & 39 & 20 & 4 & 25 & 265 & 0.0061 & 24 & 1.0286 & 0.00627 \\
\hline & & & & 50 & 3.74 & $10.8 \mathrm{c}$ & 43 & 38 & 3 & 38 & 20 & 4 & 39 & 279 & 0.0058 & 25 & 1.0000 & $\mid 0.00579$ \\
\hline & & & & 60 & 3.71 & 10.78 & 43 & 38 & 3 & 38 & 20 & 4 & 49 & 289 & 0.0056 & 24 & \begin{tabular}{|l}
1.0286 \\
\end{tabular} & 0.00575 \\
\hline & & 40 & 11 & Means: & 3.71 & 10.7 & & & & 37.86 & & & & & & & \begin{tabular}{|l|} 
SS \\
FLUX:
\end{tabular} & 0.00575 \\
\hline 1.26 & 15-n & & & 0 & 4.24 & 12.3 & 44 & 38 & $\sqrt{3}$ & 38 & 20 & 2 & 47 & \begin{tabular}{|l|l|}
167 \\
\end{tabular} & 0.0097 & 26 & 09723 & 000940 \\
\hline & & & & 10 & 4.18 & $\mid 12.12$ & 44 & 39 & 3 & \begin{tabular}{|l|}
39 \\
39
\end{tabular} & $\frac{20}{20}$ & $\mid \begin{array}{l}2 \\
3\end{array}$ & \begin{tabular}{|l|}
20 \\
\end{tabular} & \begin{tabular}{|l|}
200 \\
200
\end{tabular} & \begin{tabular}{|l|}
0.0081 \\
\end{tabular} & $\frac{28}{28}$ & \begin{tabular}{|l|}
0.9198 \\
\end{tabular} & \begin{tabular}{|l}
0.00743 \\
\end{tabular} \\
\hline & & & & 20 & 4.20 & 12.21 & 43 & 37 & 3 & 37 & 20 & 3 & 38 & 218 & 0.0074 & 29 & 0.8948 & 0.00663 \\
\hline & & & & 30 & 4.17 & 12.1 & 44 & 38 & 3 & 38 & 20 & 3 & 59 & 239 & 0.0068 & 29 & \begin{tabular}{|l|}
0.8948 \\
\end{tabular} & 0.00605 \\
\hline & & & & 40 & 4.13 & 12.0 & 44 & 37 & 3 & 38 & 20 & 3 & \begin{tabular}{|l|}
57 \\
\end{tabular} & 237 & 0.0068 & 29 & 0.8948 & 0.00610 \\
\hline & & & & 50 & 4.24 & 12.32 & 43 & 37 & 3 & 37 & 20 & 4 & 22 & 262 & \begin{tabular}{|l|}
0.0062 \\
\end{tabular} & 28 & \begin{tabular}{|l|}
0.9198 \\
\end{tabular} & \begin{tabular}{|l}
0.00567 \\
\end{tabular} \\
\hline & & & & 60 & 4.17 & 12.1 & 43 & 37 & 3 & 37 & 20 & 4 & 18 & 258 & 0.0063 & 28 & 0.9198 & 0.00576 \\
\hline & & 40 & 15 & Means: & 4.19 & 12.17 & & & & 37.57 & & & & & & & $\begin{array}{l}\text { SS } \\
\text { FLUX: }\end{array}$ & 0.00576 \\
\hline & & & & & & & & & & & & & & & & & & \\
\hline
\end{tabular}


WSRC-TR-2003-00056, REV. 0

SRT-RPP-2002-00231, REV. 0

\begin{tabular}{|c|c|c|c|c|c|c|c|c|c|c|c|c|c|c|c|c|c|c|}
\hline 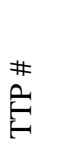 & 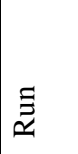 & 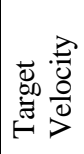 & 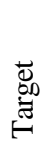 & $\ddot{g}$ & $\frac{3}{0}$ & $\frac{3}{0}$ & $\frac{Q}{\frac{0}{\omega}}$ & $\begin{array}{l}\frac{a}{0} \\
\frac{\vec{\omega}}{\bar{\Xi}} \\
0\end{array}$ & 苋 & $\sum_{i=1}^{i}$ & 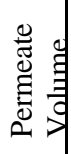 & 竘 & 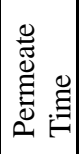 & 总 & 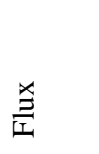 & 害 & 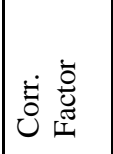 & 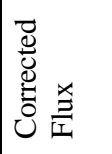 \\
\hline & & 总 & 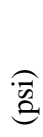 & 急 & 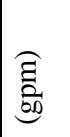 & 芴 & .0.00 & $\begin{array}{l}\frac{000}{0} \\
\frac{0}{3}\end{array}$ & $\begin{array}{l}.00 \\
\text { a } \\
\text { a }\end{array}$ & है & छ्छ & 衰 & 总 & 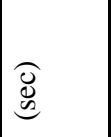 & 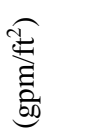 & ô & & $\begin{array}{l}\text { 趈 } \\
\text { 馬 }\end{array}$ \\
\hline \multirow[t]{8}{*}{1.19} & 15-o & & & 0 & 3.78 & 10.98 & 43 & 39 & 3 & 38 & 20 & 3 & 8 & 188 & 0.0086 & 27 & \begin{tabular}{|l}
0.9456 \\
\end{tabular} & $\mid 0.00812$ \\
\hline & & & & 10 & 3.70 & 10.75 & 43 & 38 & 3 & 38 & 20 & 4 & 3 & 243 & 0.0066 & 27 & 0.9456 & 0.00628 \\
\hline & & & & 20 & 3.72 & 10.81 & 42 & 37 & 3 & 37 & 20 & 4 & 2 & 242 & 0.0067 & 27 & 0.9456 & 0.00631 \\
\hline & & & & 30 & 3.76 & 10.92 & 43 & 37 & 3 & 37 & 20 & 4 & 1 & 241 & 0.0067 & 27 & 0.9456 & \begin{tabular}{|l|}
0.00634 \\
\end{tabular} \\
\hline & & & & 40 & 3.76 & 10.92 & 43 & 38 & 3 & 38 & 20 & 4 & 5 & 245 & 0.0066 & 28 & \begin{tabular}{|l|}
0.9198 \\
\end{tabular} & 0.00606 \\
\hline & & & & 50 & 3.70 & 10.75 & 43 & 37 & 3 & 37 & 20 & 4 & 39 & 279 & 0.0058 & 29 & \begin{tabular}{|l|}
0.8948 \\
\end{tabular} & \begin{tabular}{|l|}
0.00518 \\
\end{tabular} \\
\hline & & & & 60 & 3.70 & 10.75 & 43 & 37 & 3 & 37 & 20 & 4 & 52 & 292 & 0.0055 & 28 & \begin{tabular}{|l|}
0.9198 \\
\end{tabular} & \begin{tabular}{|l}
0.00509 \\
\end{tabular} \\
\hline & & 40 & 11 & Means: & 3.73 & 10.84 & & & & 37.21 & & & & & & & \begin{tabular}{|l|} 
SS \\
FLUX:
\end{tabular} & 0.00509 \\
\hline & & & & & & & & & & & & & & & & & & \\
\hline \multirow[t]{8}{*}{1.28} & $15-p$ & & & 0 & 3.60 & 10.46 & 63 & 57 & 3 & 57 & 20 & 3 & 14 & 194 & 0.0083 & 26 & \begin{tabular}{|l|}
0.9723 \\
\end{tabular} & 0.00809 \\
\hline & & & & 10 & 3.51 & 10.20 & 63 & 58 & 3 & 58 & 20 & 3 & 37 & \begin{tabular}{|l|l}
217 \\
\end{tabular} & 0.0074 & 27 & 0.9456 & \begin{tabular}{|l|}
0.00704 \\
\end{tabular} \\
\hline & & & & 20 & 3.56 & 10.34 & 62 & 56 & 3 & 56 & 20 & 3 & 53 & 233 & 0.0069 & 29 & \begin{tabular}{|l|}
0.8948 \\
\end{tabular} & 0.00620 \\
\hline & & & & 30 & 3.57 & 10.37 & 63 & 56 & 3 & 57 & 20 & 4 & 37 & \begin{tabular}{|l|}
277 \\
\end{tabular} & 0.0058 & 30 & \begin{tabular}{|l|}
0.8707 \\
\end{tabular} & \begin{tabular}{|l}
0.00508 \\
\end{tabular} \\
\hline & & & & 40 & 3.47 & 10.08 & 62 & 56 & 3 & 56 & 20 & 5 & 30 & \begin{tabular}{|l|}
330 \\
\end{tabular} & 0.0049 & 29 & 0.8948 & \begin{tabular}{|l}
0.00438 \\
\end{tabular} \\
\hline & & & & 50 & 3.41 & 9.91 & 62 & 56 & 3 & 56 & 20 & 5 & 0 & 300 & 0.0054 & 27 & 0.9456 & \begin{tabular}{|l|}
0.00509 \\
\end{tabular} \\
\hline & & & & 60 & 3.36 & 9.76 & 63 & 56 & 3 & 57 & 20 & 4 & \begin{tabular}{|l|}
19 \\
\end{tabular} & 259 & 0.0062 & 26 & \begin{tabular}{|l|}
0.9723 \\
\end{tabular} & \begin{tabular}{|l|l}
0.00606 \\
\end{tabular} \\
\hline & & 60 & 11 & Means: & 3.50 & 10.16 & & & & 56.50 & & & & & & & \begin{tabular}{|l} 
SS \\
FLUX:
\end{tabular} & 0.00518 \\
\hline
\end{tabular}


WSRC-TR-2003-00056, REV. 0

SRT-RPP-2002-00231, REV. 0

\section{APPENDIX A3. ANALYTICAL DATA}

\begin{tabular}{|c|c|c|c|c|c|}
\hline ADS \# & USER ID & Description & Analyses & Value & Units \\
\hline \multirow{6}{*}{300180741} & CCUF-AN102-SL-SIMUL2 & supernate simulant & aluminate & \begin{tabular}{|l}
0.497 \\
\end{tabular} & $\mathrm{M}$ \\
\hline & & & free $\mathrm{OH}$ & 0.235 & $\mathrm{M}$ \\
\hline & & & carbonate & 0.456 & $\mathrm{M}$ \\
\hline & & & $\mathrm{sp}$ gr & 1.32 & \\
\hline & & & total base & 1.186 & $\mathrm{M}$ \\
\hline & & & total solids & 37.22 & $w t \%$ \\
\hline \multirow[t]{2}{*}{300184313} & CCUF-AN102-SIMUL2 & supernate simulant & suspended solids & 0.31 & $w t \%$ \\
\hline & & & total solids & 37.20 & $w t \%$ \\
\hline \multirow[t]{8}{*}{300178724} & CCUF-AN102-PE-BAT1 & permeate & $\mathrm{F}$ & 733 & $\mathrm{mg} / \mathrm{L}$ \\
\hline & & & formate & 4880 & $\mathrm{mg} / \mathrm{L}$ \\
\hline & & & $\mathrm{Cl}$ & 2770 & $\mathrm{mg} / \mathrm{L}$ \\
\hline & & & NO2- & 44700 & $\mathrm{mg} / \mathrm{L}$ \\
\hline & & & NO3- & 126000 & $\mathrm{mg} / \mathrm{L}$ \\
\hline & & & PO4-3 & 2360 & $\mathrm{mg} / \mathrm{L}$ \\
\hline & & & $\mathrm{SO} 4=$ & 7080 & $\mathrm{mg} / \mathrm{L}$ \\
\hline & & & oxalate & 702 & $\mathrm{mg} / \mathrm{L}$ \\
\hline \multirow[t]{9}{*}{300178725} & CCUF-AN102-PE-10\% & permeate & $F$ & 46100 & $\mathrm{mg} / \mathrm{L}$ \\
\hline & & & formate & 129000 & $\mathrm{mg} / \mathrm{L}$ \\
\hline & & & $\mathrm{Cl}$ & 2790 & $\mathrm{mg} / \mathrm{L}$ \\
\hline & & & $\mathrm{NO2-}$ & 732 & $\mathrm{mg} / \mathrm{L}$ \\
\hline & & & NO3- & 2240 & $\mathrm{mg} / \mathrm{L}$ \\
\hline & & & PO4-3 & 7400 & $\mathrm{mg} / \mathrm{L}$ \\
\hline & & & $\mathrm{SO} 4=$ & 4820 & $\mathrm{mg} / \mathrm{L}$ \\
\hline & & & oxalate & 712 & $\mathrm{mg} / \mathrm{L}$ \\
\hline & & & total solids & 33.30 & $w t \%$ \\
\hline \multirow[t]{9}{*}{300178726} & CCUF-AN102-PE-15\% & permate & $\mathrm{F}$ & 41100 & $\mathrm{mg} / \mathrm{L}$ \\
\hline & & & formate & 124000 & $\mathrm{mg} / \mathrm{L}$ \\
\hline & & & $\mathrm{Cl}$ & 2770 & $\mathrm{mg} / \mathrm{L}$ \\
\hline & & & $\mathrm{NO2-}$ & 672 & $\mathrm{mg} / \mathrm{L}$ \\
\hline & & & NO3- & 2500 & $\mathrm{mg} / \mathrm{L}$ \\
\hline & & & PO4-3 & 6540 & $\mathrm{mg} / \mathrm{L}$ \\
\hline & & & $\mathrm{SO} 4=$ & 4900 & $\mathrm{mg} / \mathrm{L}$ \\
\hline & & & oxalate & 623 & $\mathrm{mg} / \mathrm{L}$ \\
\hline & & & total solids & 33.61 & $\mathrm{wt} \%$ \\
\hline \multirow[t]{8}{*}{300178727} & CCUF-AN102-PE-WASH & $\begin{array}{l}\text { permeate from } \\
\text { washed slurry }\end{array}$ & $\mathrm{F}$ & 21700 & $\mathrm{mg} / \mathrm{L}$ \\
\hline & & & formate & 57700 & $\mathrm{mg} / \mathrm{L}$ \\
\hline & & & $\mathrm{Cl}$ & 1320 & $\mathrm{mg} / \mathrm{L}$ \\
\hline & & & NO2- & 593 & $\mathrm{mg} / \mathrm{L}$ \\
\hline & & & NO3- & 1370 & $\mathrm{mg} / \mathrm{L}$ \\
\hline & & & PO4-3 & 3850 & $\mathrm{mg} / \mathrm{L}$ \\
\hline & & & $\mathrm{SO} 4=$ & 2900 & $\mathrm{mg} / \mathrm{L}$ \\
\hline & & & oxalate & 2610 & $\mathrm{mg} / \mathrm{L}$ \\
\hline \multirow[t]{14}{*}{300178715} & CCUF-AN102-SL-BAT1-WET & batch 1 precipitate & $F$ & 36300 & $\mathrm{mg} / \mathrm{L}$ \\
\hline & & & formate & 95900 & $\mathrm{mg} / \mathrm{L}$ \\
\hline & & & $\mathrm{Cl}$ & 2160 & $\mathrm{mg} / \mathrm{L}$ \\
\hline & & & NO2- & 1030 & $\mathrm{mg} / \mathrm{L}$ \\
\hline & & & NO3- & 1910 & $\mathrm{mg} / \mathrm{L}$ \\
\hline & & & PO4-3 & 5420 & $\mathrm{mg} / \mathrm{L}$ \\
\hline & & & $\mathrm{SO} 4=$ & 4120 & $\mathrm{mg} / \mathrm{L}$ \\
\hline & & & oxalate & 1400 & $\mathrm{mg} / \mathrm{L}$ \\
\hline & & & total carbon & 10000 & $\mathrm{mg} / \mathrm{L}$ \\
\hline & & & inorganic carbon & 4440 & $\mathrm{mg} / \mathrm{L}$ \\
\hline & & & organic carbon & 5580 & $\mathrm{mg} / \mathrm{L}$ \\
\hline & & & total solids & 33.59 & $\mathrm{wt} \%$ \\
\hline & & & total solids & 33.10 & $\mathrm{wt} \%$ \\
\hline & & & suspended solids & 1.88 & $w t \%$ \\
\hline
\end{tabular}




\section{WSRC-TR-2003-00056, REV. 0}

SRT-RPP-2002-00231, REV. 0

\begin{tabular}{|c|c|c|c|c|c|}
\hline ADS \# & USER ID & Description & Analyses & Value & Units \\
\hline \multirow[t]{13}{*}{300178716} & CCUF-AN102-SL-WASH-WET & washed slurry & $\mathrm{F}$ & 14200 & $\mathrm{mg} / \mathrm{kg}$ slurry \\
\hline & & & formate & 45000 & $\mathrm{mg} / \mathrm{kg}$ slurry \\
\hline & & & $\mathrm{Cl}$ & 886 & $\mathrm{mg} / \mathrm{kg}$ slurry \\
\hline & & & NO2- & 365 & $\mathrm{mg} / \mathrm{kg}$ slurry \\
\hline & & & NO3- & 855 & $\mathrm{mg} / \mathrm{kg}$ slurry \\
\hline & & & PO4-3 & 2830 & $\mathrm{mg} / \mathrm{kg}$ slurry \\
\hline & & & $\mathrm{SO} 4=$ & 2520 & $\mathrm{mg} / \mathrm{kg}$ slurry \\
\hline & & & oxalate & 8530 & $\mathrm{mg} / \mathrm{kg}$ slurry \\
\hline & & & total carbon & 6320 & $\mathrm{mg} / \mathrm{L}$ \\
\hline & & & inorganic carbon & 3340 & $\mathrm{mg} / \mathrm{L}$ \\
\hline & & & organic carbon & 2980 & $\mathrm{mg} / \mathrm{L}$ \\
\hline & & & total solids & 35.06 & wt $\%$ \\
\hline & & & suspended solids & 20.63 & wt\% \\
\hline \multirow[t]{2}{*}{300178729} & CCUF-AN102-SL-10\% & slurry at $\sim 10 \mathrm{wt} \%$ IS & total solids & 42.14 & wt\% \\
\hline & & & suspended solids & 13.33 & wt\% \\
\hline \multirow[t]{2}{*}{300178728} & CCUF-AN102-SL-BAT5 & batch 5 percipitate & total solids & 33.56 & $w t \%$ \\
\hline & & & suspended solids & 1.60 & $w t \%$ \\
\hline \multirow[t]{2}{*}{300178730} & CCUF-AN102-SL-15\% & slurry at $\sim 15 w t \%$ IS & total solids & 44.98 & $w t \%$ \\
\hline & & & suspended solids & 17.17 & wt\% \\
\hline
\end{tabular}


WSRC-TR-2003-00056, REV. 0

SRT-RPP-2002-00231, REV. 0

\begin{tabular}{|c|c|c|c|c|}
\hline \multicolumn{5}{|c|}{ Notebook WSRC-NB-2002-93 p. 45} \\
\hline \multicolumn{5}{|c|}{\begin{tabular}{|l|l} 
File $=$ Zamecnik Report 8-6-2002.xls & \\
\end{tabular}} \\
\hline \multicolumn{5}{|c|}{ Concentration in original sample in ug/g (ppm) } \\
\hline & & & & \\
\hline \multirow[t]{3}{*}{ USER ID } & $\begin{array}{l}\text { CCUF-AN102-SL- } \\
\text { BAT1-AQREG }\end{array}$ & $\begin{array}{l}\text { CCUF-AN102-SL- } \\
\text { WASH-AQREG }\end{array}$ & $\begin{array}{l}\text { CCUF-AN102-SL- } \\
\text { BAT1-NA2O2 }\end{array}$ & $\begin{array}{l}\text { CCUF-AN102-SL- } \\
\text { WASH-NA2O2 }\end{array}$ \\
\hline & slurry batch 1 & washed slurry & slurry batch 1 & washed slurry \\
\hline & aqua regia & aqua regia & sodium peroxide & sodium peroxide \\
\hline ADS 300- & 178720 & 178721 & 178717 & 178718 \\
\hline $\mathrm{Al}$ & 16200 & 10300 & 16300 & 10800 \\
\hline $\mathrm{B}$ & $<200$ & $<200$ & $<200$ & $<200$ \\
\hline $\mathrm{Ba}$ & 395 & 5260 & 419 & 5610 \\
\hline $\mathrm{Ca}$ & 661 & 6630 & 2030 & 6930 \\
\hline $\mathrm{Cd}$ & 79 & 102 & 77 & 100 \\
\hline Co & $<75$ & $<75$ & $<75$ & $<75$ \\
\hline $\mathrm{Cr}$ & 346 & 468 & 355 & 650 \\
\hline $\mathrm{Cu}$ & $<75$ & 376 & $<75$ & 398 \\
\hline $\mathrm{Fe}$ & 280 & 1440 & 567 & 1560 \\
\hline $\mathrm{Li}$ & $<100$ & $<100$ & $<100$ & $<100$ \\
\hline $\mathrm{Mg}$ & $<90$ & 539 & $<90$ & 506 \\
\hline $\mathrm{Mn}$ & 5290 & 80800 & 4710 & 85500 \\
\hline Mo & $<150$ & $<150$ & $<150$ & $<150$ \\
\hline $\mathrm{Na}$ & 291000 & 170000 & NA & NA \\
\hline $\mathrm{Ni}$ & 601 & 2120 & 565 & 2150 \\
\hline $\mathrm{P}$ & 1880 & 3080 & 1430 & 2670 \\
\hline $\mathrm{Pb}$ & $<650$ & 2180 & $<650$ & 2390 \\
\hline $\mathrm{Si}$ & $<150$ & $<150$ & $<150$ & $<150$ \\
\hline $\mathrm{Sn}$ & $<350$ & $<350$ & $<350$ & $<350$ \\
\hline $\mathrm{Sr}$ & 13000 & 191000 & 10100 & 190000 \\
\hline $\mathrm{Ti}$ & $<150$ & $<150$ & $<150$ & $<150$ \\
\hline V & $<150$ & $<150$ & $<150$ & $<150$ \\
\hline $\mathrm{Zn}$ & $<350$ & $<350$ & $<350$ & $<350$ \\
\hline $\mathrm{Zr}$ & $<50$ & 318 & NA & NA \\
\hline $\mathrm{La}$ & $<700$ & $<700$ & $<700$ & $<700$ \\
\hline $\mathrm{K}$ & 632 & $<500$ & NA & NA \\
\hline $\mathrm{Nd}$ & $<500$ & $<500$ & $<500$ & $<500$ \\
\hline
\end{tabular}

Use sp gr and total solids content to convert to $\mathrm{mg} / \mathrm{L}$. 


\begin{tabular}{|c|c|c|c|}
\hline \multicolumn{4}{|c|}{ Notebook WSRC-NB-2002-93 p. 35} \\
\hline \multicolumn{4}{|c|}{ File = Zamecnik Report 7-18-2002.xls } \\
\hline \multicolumn{4}{|c|}{ Concentration in original sample in mg/L (ppm) } \\
\hline & & & \\
\hline USER ID & $\begin{array}{c}\text { CCUF-AN102- } \\
\text { PE-BAT1 }\end{array}$ & $\begin{array}{c}\text { CCUF-AN102- } \\
\text { PE-10\% }\end{array}$ & $\begin{array}{c}\text { CCUF-AN102- } \\
\text { PE- } 15 \%\end{array}$ \\
\hline Permeate & batch 1 & $@ 13 w t \%$ & $@ 17 w t \%$ \\
\hline ADS 300- & 178724 & 178725 & 178726 \\
\hline $\mathrm{Al}$ & 7350 & 7540 & 7700 \\
\hline $\mathrm{B}$ & 22.4 & 23.5 & 24.2 \\
\hline $\mathrm{Ba}$ & $<0.024$ & $<0.024$ & $<0.024$ \\
\hline $\mathrm{Ca}$ & 91.7 & 95.8 & 102 \\
\hline Cd & 34.5 & 35.6 & 38.1 \\
\hline Co & $<0.088$ & $<0.088$ & $<0.088$ \\
\hline $\mathrm{Cr}$ & 149 & 153 & 137 \\
\hline $\mathrm{Cu}$ & 3.49 & 3.67 & 4.15 \\
\hline $\mathrm{Fe}$ & 0.53 & 0.46 & 0.63 \\
\hline $\mathrm{Li}$ & 0.24 & 0.26 & 0.22 \\
\hline $\mathrm{Mg}$ & $<0.168$ & $<0.168$ & $<0.168$ \\
\hline $\mathrm{Mn}$ & 0.17 & 0.34 & 0.50 \\
\hline Mo & 28.4 & 28.5 & 29.0 \\
\hline $\mathrm{Na}$ & 133000 & 138000 & 142000 \\
\hline $\mathrm{Ni}$ & 195 & 200 & 201 \\
\hline$P$ & 573 & 577 & 553 \\
\hline $\mathrm{Pb}$ & 36.2 & 39.9 & 42.1 \\
\hline $\mathrm{Si}$ & 15.3 & 15.2 & 16.2 \\
\hline Sn & $<0.7$ & $<0.7$ & $<0.7$ \\
\hline $\mathrm{Sr}$ & 28.0 & 26.1 & 26.4 \\
\hline $\mathrm{Ti}$ & $<0.28$ & $<0.28$ & $<0.28$ \\
\hline $\mathrm{V}$ & $<0.26$ & $<0.26$ & $<0.26$ \\
\hline $\mathrm{Zn}$ & 3.03 & 2.24 & 2.35 \\
\hline $\mathrm{Zr}$ & 0.47 & 0.44 & 0.55 \\
\hline $\mathrm{La}$ & $<1.4$ & $<1.4$ & $<1.4$ \\
\hline $\mathrm{K}$ & 1770 & 2150 & 2380 \\
\hline$S$ & 2750 & 2820 & 2910 \\
\hline $\mathrm{Nd}$ & 0.64 & 1.21 & 0.76 \\
\hline
\end{tabular}




\begin{tabular}{|c|c|c|c|}
\hline \multicolumn{3}{|c|}{ Notebook WSRC-NB-2002-93 p. 42} & \\
\hline \multicolumn{4}{|c|}{\begin{tabular}{|l|l|} 
File = Zamecnik Report 8-12-2002.xls & \\
\end{tabular}} \\
\hline \multicolumn{4}{|c|}{ Concentration in original sample in $\mathrm{mg} / \mathrm{L}(\mathrm{ppm})$} \\
\hline & & & \\
\hline USER ID & $\begin{array}{c}\text { CCUF-AN102-PE- } \\
\text { WASH }\end{array}$ & & \\
\hline & $\begin{array}{l}\text { permeate from } \\
\text { washed slurry }\end{array}$ & & \\
\hline ADS 300- & 178727 & & \\
\hline $\mathrm{Al}$ & 3510 & & \\
\hline $\mathrm{B}$ & 11.3 & & \\
\hline $\mathrm{Ba}$ & $<0.024$ & & \\
\hline $\mathrm{Ca}$ & 50.5 & & \\
\hline $\mathrm{Cd}$ & 18.8 & & \\
\hline Co & $<0.088$ & & \\
\hline $\mathrm{Cr}$ & 69.6 & & \\
\hline $\mathrm{Cu}$ & 0.44 & & \\
\hline $\mathrm{Fe}$ & $<0.088$ & & \\
\hline $\mathrm{Li}$ & $<0.2$ & & \\
\hline $\mathrm{Mg}$ & $<0.168$ & & \\
\hline $\mathrm{Mn}$ & 0.69 & & \\
\hline Mo & 13.9 & & \\
\hline $\mathrm{Na}$ & 66800 & & \\
\hline $\mathrm{Ni}$ & 85.3 & & \\
\hline $\mathrm{P}$ & 372 & & \\
\hline $\mathrm{Pb}$ & 10.3 & & \\
\hline $\mathrm{Si}$ & 7.69 & & \\
\hline Sn & $<0.52$ & & \\
\hline $\mathrm{Sr}$ & 10.10 & & \\
\hline $\mathrm{Ti}$ & $<0.28$ & & \\
\hline $\mathrm{V}$ & $<0.26$ & & \\
\hline $\mathrm{Zn}$ & $<0.74$ & & \\
\hline $\mathrm{Zr}$ & 0.22 & & \\
\hline $\mathrm{La}$ & $<1.4$ & & \\
\hline $\mathrm{K}$ & 843 & & \\
\hline $\mathrm{Re}$ & $<0.1$ & & \\
\hline S & 1430 & & \\
\hline $\mathrm{Nd}$ & 1.68 & & \\
\hline $\mathrm{Ag}$ & $<0.6$ & & \\
\hline
\end{tabular}


WSRC-TR-2003-00056, REV. 0

SRT-RPP-2002-00231, REV. 0

\begin{tabular}{|c|c|c|c|c|c|c|c|c|c|c|}
\hline DESCRIPTION & $\begin{array}{l}\text { 102R2 } \\
\text { NOC1 }\end{array}$ & $\begin{array}{l}\text { 102R2 } \\
\text { NOC1 }\end{array}$ & 102R2 NOC1 & 102R2 NOC1 & $\begin{array}{l}\text { 102R2 } \\
\text { NOC1 }\end{array}$ & $\begin{array}{l}\text { 102R2 } \\
\text { NOC1 }\end{array}$ & $\begin{array}{l}\text { 102R2 } \\
\text { NOC1 }\end{array}$ & $\begin{array}{l}\text { 102R2 } \\
\text { NOC1 }\end{array}$ & $\begin{array}{l}\text { 102R2 } \\
\text { NOC1 }\end{array}$ & $\begin{array}{l}\text { 102R2 } \\
\text { NOC1 }\end{array}$ \\
\hline & $\begin{array}{l}\text { R2NOC1 } \\
\text { PPT }\end{array}$ & $\begin{array}{l}\text { R2NOC1 } \\
\text { PPT }\end{array}$ & R2NOC1 PPT & R2NOC1 PPT & $\begin{array}{l}\text { R2NOC1 } \\
\text { PPT }\end{array}$ & $\begin{array}{l}\text { R2NOC1 } \\
\text { PPT }\end{array}$ & $\begin{array}{l}\text { R2NOC1 } \\
\text { PPT }\end{array}$ & $\begin{array}{l}\text { R2NOC1 } \\
\text { PPT }\end{array}$ & $\begin{array}{l}\text { R2NOC1 } \\
\text { PPT } \\
\text { SOLIDS }\end{array}$ & $\begin{array}{l}\text { R2NOC1 } \\
\text { PERMEATE }\end{array}$ \\
\hline & $\begin{array}{l}\text { 102R2-SL- } \\
\text { INIT-X }\end{array}$ & $\begin{array}{l}\text { 102R2-SL- } \\
\text { INIT-X }\end{array}$ & $\begin{array}{l}\text { 102R2-SL-INIT. } \\
x\end{array}$ & 102R2-SL-INIT-X & $\begin{array}{l}\text { 102R2-SL- } \\
\text { INIT-X }\end{array}$ & $\begin{array}{l}\text { 102R2-SL- } \\
\text { INIT-X }\end{array}$ & $\begin{array}{l}\text { 102R2-SL- } \\
\text { INIT-X }\end{array}$ & $\begin{array}{l}\text { 102R2-SL- } \\
\text { INIT-X }\end{array}$ & $\begin{array}{l}\text { 102R2-SL- } \\
\text { INIT-SOL }\end{array}$ & $\begin{array}{l}\text { 102R2-P. } \\
\text { INIT-X }\end{array}$ \\
\hline ADS $\# 300$ - or MOBILE LAB & $\begin{array}{l}185115 \\
185181 \\
185114\end{array}$ & & $\begin{array}{l}185115 \\
185179 \\
185114\end{array}$ & & $\begin{array}{l}\text { MOBILE } \\
\text { LAB }\end{array}$ & $\begin{array}{l}\text { MOBILE } \\
\text { LAB }\end{array}$ & $\begin{array}{l}\text { MOBILE } \\
\text { LAB }\end{array}$ & 188650 & 185181 & 185182 \\
\hline \multicolumn{11}{|c|}{ ICPES mg/L } \\
\hline Units & $\mathrm{mg} / \mathrm{kg}$ slurry & $\mathrm{mg} / \mathrm{L}$ & $\mathrm{mg} / \mathrm{kg}$ slurry & $\mathrm{mg} / \mathrm{L}$ & & & & & $\mathrm{mg} / \mathrm{kg}$ & $\mathrm{mg} / \mathrm{L}$ \\
\hline Dissolution & $\mathrm{NA} 2 \mathrm{O} 2$ & $\mathrm{NA} 2 \mathrm{O} 2$ & AQUA REGIA & AQUA REGIA & & & & & & \\
\hline $\mathrm{Al}$ & 6830 & 8875 & 6780 & 8810 & & & & & 30300 & 8050 \\
\hline $\mathrm{B}$ & 51.3 & 66.7 & 57.1 & 74.2 & & & & & 235 & $\quad 24.4$ \\
\hline $\mathrm{Ba}$ & $<5.0$ & $<6$ & $<5.0$ & $<6$ & & & & & 138 & $<0.024$ \\
\hline $\mathrm{Ca}$ & 391 & 508 & 289 & 376 & & & & & 14000 & 79.1 \\
\hline $\mathrm{Cd}$ & 32.6 & 42.4 & 33.4 & 43.4 & & & & & 192 & 32.8 \\
\hline $\mathrm{Co}$ & $<10$ & $<13$ & $<10$ & $<13$ & & & & & 114 & $<0.30$ \\
\hline $\mathrm{Cr}$ & 237 & 308 & 143 & 186 & & & & & 881 & 159 \\
\hline $\mathrm{Cu}$ & 17.0 & 22.2 & 16.2 & 21.0 & & & & & 580 & 5.75 \\
\hline $\mathrm{Fe}$ & 409 & 531 & 38.3 & 49.7 & & & & & 3030 & 2.28 \\
\hline $\mathrm{Li}$ & $<20$ & $<26$ & $<20$ & $<26$ & & & & & $<100$ & 0.270 \\
\hline $\mathrm{Mg}$ & 13.8 & $\begin{array}{ll}3 & 17.9\end{array}$ & 15.3 & 19.9 & & & & & 944 & $<0.168$ \\
\hline $\mathrm{Mn}$ & 1290 & 1676 & 1330 & 1728 & & & & & 80600 & 14.0 \\
\hline Mo & 32.8 & 42.6 & 22.5 & 29.2 & & & & & $<100$ & 30.4 \\
\hline $\mathrm{Na}$ & NA & & 103000 & 133845 & & & & & NA & 125000 \\
\hline \multicolumn{11}{|c|}{$\mathrm{Na} A \mathrm{~A}$} \\
\hline $\mathrm{Ni}$ & 301 & 391 & 234 & 305 & & & & & 2340 & 221 \\
\hline $\mathrm{P}$ & 2150 & 2794 & 1730 & 2248 & & & & & 13300 & 870 \\
\hline $\mathrm{Pb}$ & $<150$ & $<195$ & $<150$ & $<195$ & & & & & 4000 & 41.5 \\
\hline $\mathrm{Si}$ & 37.7 & 48.9 & $<20$ & $<26$ & & & & & 1220 & 12.7 \\
\hline $\mathrm{Sn}$ & $<50$ & $<65$ & $<50$ & $<65$ & & & & & $<250$ & $<0.60$ \\
\hline $\mathrm{Sr}$ & 1760 & 2287 & 2100 & 2729 & & & & & 104000 & 50.2 \\
\hline $\mathrm{Ti}$ & $<20$ & $<26$ & $<20$ & $<26$ & & & & & $<20$ & $<0.28$ \\
\hline $\mathrm{V}$ & $<20$ & $<26$ & $<20$ & $<26$ & & & & & $<20$ & $<0.26$ \\
\hline $\mathrm{Zn}$ & $<50$ & $<65$ & $<50$ & $<65$ & & & & & $<50$ & 1.18 \\
\hline $\mathrm{Zr}$ & NA & & $<15$ & & & & & & NA & 2.27 \\
\hline $\mathrm{La}$ & $<100$ & $<130$ & $<100$ & $<130$ & & & & & $<650$ & $<1.4$ \\
\hline K & NA & & 1260 & & & & & & NA & 1680 \\
\hline \multicolumn{11}{|c|}{$\mathrm{KAA}$} \\
\hline$S$ & & & & & & & & & & 2930 \\
\hline Nd & $<50$ & $<65$ & $<50$ & $<65$ & & & & & 975 & 0.947 \\
\hline $\mathrm{Ce}$ & & & & & & & & & & $<1.54$ \\
\hline & & & & & & & & & & \\
\hline \multicolumn{11}{|l|}{$\mathrm{Rb}$} \\
\hline \multicolumn{11}{|l|}{ W } \\
\hline \multicolumn{11}{|c|}{ Ion Chrom (mg/L or $\mathrm{mg} / \mathrm{kg})$} \\
\hline Units & $\mathrm{mg} / \mathrm{kg}$ & $\mathrm{mg} / \mathrm{L}$ & $\mathrm{mg} / \mathrm{kg}$ & $\mathrm{mg} / \mathrm{L}$ & & & & & & \\
\hline NO2- & 41900 & 54448 & 48700 & 63284 & & & & & & \\
\hline NO3- & 106000 & 137743 & 123000 & 159834 & & & & & & \\
\hline $\mathrm{Cl}$ & 2730 & 3548 & 3340 & 4340 & & & & & & \\
\hline $\mathrm{F}$ & 910 & 1183 & 603 & 784 & & & & & & \\
\hline $\mathrm{PO4}[-3]$ & 3200 & 4158 & 3760 & 4886 & & & & & & \\
\hline $\mathrm{SO} 4=$ & 6590 & 8563 & 8810 & 11448 & & & & & & \\
\hline $\mathrm{COOH}-$ & 4840 & 6289 & 4720 & 6133 & & & & & & \\
\hline $\mathrm{C} 2 \mathrm{O} 4=$ & 1230 & 1598 & 1410 & 1832 & & & & & & \\
\hline \multicolumn{11}{|l|}{ Carbon $(\mathrm{mg} / \mathrm{L})$} \\
\hline TOC & 10500 & & & & & & & & & 9890 \\
\hline $\mathrm{TIC}$ & 7370 & & & & & & & & & 7710 \\
\hline $\mathrm{TC}$ & 17900 & & & & & & & & & 17600 \\
\hline Wet Chem & & & & & & & & & & \\
\hline $\mathrm{CO}=(\mathrm{M})$ & 0.550 & & & & & & & & & \\
\hline $\mathrm{CO} 3=\mathrm{mg} / \mathrm{L}$ & 33005 & & & & & & & & & \\
\hline FREE OH- (M) & 0.150 & & & & & & & & & \\
\hline FREE OH- (mg/L) & & & & & & & & & & \\
\hline TOTAL BASE (M) & 1.50 & & & & & & & & & \\
\hline & & & & & & & & & & \\
\hline TOTAL SOLIDS (wt \%) & & & & MOBILE LAB -> & 36.6 & 35.6 & 33.4 & 33.0 & & \\
\hline TOTAL SOLIDS (wt \%) & & & & MOBILE LAB -> & 37.2 & 35.9 & 33.4 & & & \\
\hline TOTAL SOLIDS (wt \%) & & & & & & & & & & \\
\hline TOTAL SOLIDS (wt \%) & & & & & & & & & & \\
\hline & & & & & & & & & & \\
\hline SUSPENDED SOLIDS (wt \%) & & & & MOBILE LAB -> & 6.00 & 4.56 & 1.19 & 0.740 & & \\
\hline SUSPENDED SOLIDS (wt \%) & & & & MOBILE LAB -> & 5.20 & 4.96 & 1.33 & & & \\
\hline SUSPENDED SOLIDS (wt\%) & & & & & & & & & & \\
\hline SUSPENDED SOLIDS (wt\%) & & & & filtration, still wet -> & 4.04 & & & & & \\
\hline & & & & & & & & & & \\
\hline SPECIFIC GRAVITY & & & & lab measurement $->$ & 1.27 & & & 1.27 & & 1.19 \\
\hline
\end{tabular}


WSRC-TR-2003-00056, REV. 0

SRT-RPP-2002-00231, REV. 0

\begin{tabular}{|c|c|c|c|c|c|c|c|c|c|c|}
\hline \multirow[t]{3}{*}{ DESCRIPTION } & $\begin{array}{l}102 R 2 \\
\text { NOC2 }\end{array}$ & $\begin{array}{l}102 \mathrm{R} 2 \\
\mathrm{NOC2}\end{array}$ & $\begin{array}{l}102 \mathrm{R} 2 \\
\mathrm{NOC2}\end{array}$ & 102R2 NOC2 & 102R2 NOC2 & $\begin{array}{l}\text { 102R2 } \\
\text { NOC2 }\end{array}$ & 102R2 NOC2 & & & 102R2 NOC2 \\
\hline & $\begin{array}{l}\text { R2NOC2 } \\
\text { PPT }\end{array}$ & & $\begin{array}{l}\text { R2NOC2 } \\
\text { PPT }\end{array}$ & & $\begin{array}{l}\text { R2NOC2 } \\
\text { SLURRY ALL } \\
\text { FED }\end{array}$ & $\begin{array}{l}\text { R2NOC2 } \\
\text { SLURRY } \\
\sim 20 \%\end{array}$ & $\begin{array}{l}\text { PERMEATE } \\
\text { AT } 2 / 3 \text { FED }\end{array}$ & & & $\begin{array}{l}\text { PERMEATE } \\
\text { AT } \sim 20 \%\end{array}$ \\
\hline & $\begin{array}{l}\text { 102R2NOC } \\
\text { 2-SL-INIT-X }\end{array}$ & $\begin{array}{l}\text { 102R2NOC } \\
2-S L-I N I T-X\end{array}$ & $\begin{array}{l}\text { 102R2NOC } \\
\text { 2-SL-INIT-X }\end{array}$ & $\begin{array}{l}\text { 102R2NOC2-SL- } \\
\text { INIT-X }\end{array}$ & $\begin{array}{l}102 \mathrm{R} 2 \mathrm{NOC} 2- \\
\text { SL-15X }\end{array}$ & $\begin{array}{l}\text { 102R2NO } \\
\text { C2-SL- } \\
20 X\end{array}$ & $\begin{array}{l}\text { 102R2NOC2- } \\
\text { P-2/3B }\end{array}$ & $\begin{array}{l}\text { 102R2NOC2- } \\
\text { SL-INIT-X }\end{array}$ & $\begin{array}{l}\text { 102R2NOC2- } \\
\text { SL-INIT-X }\end{array}$ & $\begin{array}{l}\text { 102R2NOC2- } \\
\text { P-20 }\end{array}$ \\
\hline & $\begin{array}{l}186089 \\
186090 \\
186091 \\
198092\end{array}$ & & & & 186094 & 186095 & 186093 & & & 187817 \\
\hline \multicolumn{11}{|c|}{ ICPES mg/L } \\
\hline $\begin{array}{l}\text { Units } \\
\end{array}$ & $\mathrm{mg} / \mathrm{kg}$ & $\mathrm{mg} / \mathrm{L}$ & $\mathrm{mg} / \mathrm{kg}$ & $\mathrm{mg} / \mathrm{L}$ & & & & $\mathrm{mg} / \mathrm{L}$ & $\mathrm{mg} / \mathrm{L}$ & \\
\hline \multicolumn{11}{|c|}{ Dissolution } \\
\hline $\mathrm{Al}$ & 20900 & 8848 & 6830 & 8606 & & & 8980 & 8848 & 8606 & \\
\hline $\mathrm{B}$ & $<220$ & $<93$ & $<30$ & $<38$ & & & 28.2 & 93.0 & 38.0 & \\
\hline $\mathrm{Ba}$ & 95.2 & 40.3 & 15.8 & 19.9 & & & $<0.024$ & 40.3 & 19.9 & \\
\hline $\mathrm{Ca}$ & 2620 & 1109 & 235 & 296 & & & 89.4 & 1109 & 296 & \\
\hline $\mathrm{Cd}$ & 110 & 46.6 & 35.2 & 44.4 & & & 40.5 & 46.6 & 44.4 & \\
\hline $\mathrm{Co}$ & $<50$ & $<21$ & $<10$ & $<13$ & & & $<0.20$ & & & \\
\hline $\mathrm{Cr}$ & 460 & 195 & 120 & 152 & & & 146 & 195 & 152 & \\
\hline $\mathrm{Cu}$ & $<50$ & $<21$ & 12.8 & 16.2 & & & 6.65 & 21.0 & 16.2 & \\
\hline $\mathrm{Fe}$ & 478 & 202 & 61.7 & 77.7 & & & 2.65 & 202 & 77.7 & \\
\hline $\mathrm{Li}$ & $<100$ & $<42$ & $<20$ & $<25$ & & & $<0.2$ & & & \\
\hline $\mathrm{Mg}$ & $<85$ & $<36$ & 15.7 & 19.8 & & & $<0.168$ & 36.0 & 19.8 & \\
\hline $\mathrm{Mn}$ & 4560 & 1931 & 1430 & 1802 & & & 12.2 & 1931 & 1802 & \\
\hline Mo & 97.2 & 41.2 & 27.5 & 34.6 & & & 34.5 & 41.2 & 34.6 & \\
\hline $\mathrm{Na}$ & NA & & 102000 & 128520 & & & 136000 & & 128520 & \\
\hline \multicolumn{11}{|c|}{$\mathrm{Na} A \mathrm{~A}$} \\
\hline $\mathrm{Ni}$ & 806 & 341 & 244 & 307 & & & 275 & 341 & 307 & \\
\hline $\mathrm{P}$ & 3290 & 1393 & 829 & 1044 & & & 775 & 1393 & 1044 & \\
\hline $\mathrm{Pb}$ & $<700$ & $<296$ & $<200$ & $<252$ & & & 47.4 & 296 & 252 & \\
\hline $\mathrm{Si}$ & 352 & 149 & 21.4 & 27.0 & & & 27.1 & 149 & 27.0 & \\
\hline $\mathrm{Sn}$ & $<300$ & $<127$ & $<50$ & $<63$ & & & 1.03 & 127 & 63.0 & \\
\hline $\mathrm{Sr}$ & 8850 & 3747 & 2120 & 2671 & & & 22.9 & 3747 & 2671 & \\
\hline $\mathrm{Ti}$ & $<100$ & $<42$ & $<20$ & $<25$ & & & $<0.28$ & & & \\
\hline $\mathrm{V}$ & 186 & 78.7 & $<20$ & $<25$ & & & $<0.26$ & & & \\
\hline $\mathrm{Zn}$ & $<250$ & $<106$ & $<50$ & $<63$ & & & 1.67 & 106 & 63.0 & \\
\hline $\mathrm{Zr}$ & NA & & $<8.0$ & $<10$ & & & 3.15 & & 10.0 & \\
\hline $\mathrm{La}$ & $<700$ & $<296$ & $<100$ & $<126$ & & & 2.97 & 296 & 126 & \\
\hline K & 3640 & 1541 & 1090 & 1373 & & & 1840 & 1541 & 1373 & \\
\hline \multicolumn{11}{|l|}{ KAA } \\
\hline $\mathrm{S}$ & & & & & & & 3180 & & & \\
\hline Nd & 324 & 137 & 64.9 & 81.8 & & & 6.07 & 137 & 81.8 & \\
\hline $\mathrm{Ce}$ & & & & & & & 8.95 & & & \\
\hline \multicolumn{11}{|l|}{ Cs } \\
\hline \multicolumn{11}{|l|}{$\mathrm{Rb}$} \\
\hline W & & & & & & & & & & \\
\hline Ion Chrom (mg/L or mg/kg) & & & & & & & & & & \\
\hline Units & $\mathrm{mg} / \mathrm{kg}$ & $\mathrm{mg} / \mathrm{L}$ & & & & & & & & \\
\hline NO2- & 38500 & 48510 & & & & & 50500 & & & \\
\hline NO3- & 92100 & 116046 & & & & & 124000 & & & \\
\hline $\mathrm{Cl}$ & 2490 & 3137 & & & & & 3150 & & & \\
\hline $\mathrm{F}$ & 971 & 1223 & & & & & 1180 & & & \\
\hline $\mathrm{PO4}[-3]$ & 2900 & 3654 & & & & & 3310 & & & \\
\hline $\mathrm{SO} 4=$ & 6590 & 8303 & & & & & 8460 & & & \\
\hline $\mathrm{COOH}-$ & 4510 & 5683 & & & & & 5860 & & & \\
\hline $\mathrm{C} 2 \mathrm{O} 4=$ & 1260 & 1588 & & & & & 1020 & & & \\
\hline Carbon (mg/L) & & & & & & & & & & \\
\hline TOC & 10100 & & & & & & & & & \\
\hline $\mathrm{TIC}$ & 9610 & & & & & & & & & \\
\hline $\mathrm{TC}$ & 19700 & & & & & & & & & \\
\hline Wet Chem & & & & & & & & & & \\
\hline $\mathrm{CO} 3=(\mathrm{M})$ & & & & & & & & & & \\
\hline $\mathrm{CO}=\mathrm{mg} / \mathrm{L}$ & & & & & & & & & & \\
\hline FREE OH- (M) & & & & & & & & & & \\
\hline FREE OH- (mg/L) & & & & & & & & & & \\
\hline TOTAL BASE (M) & & & & & & & & & & \\
\hline & & & & & & & & & & \\
\hline TOTAL SOLIDS (wt\%) & 33.6 & & & ADS & 43.1 & 47.4 & & & & 35.4 \\
\hline TOTAL SOLIDS (wt \%) & & & & MOBILE LAB-> & 43.6 & & & & & \\
\hline TOTAL SOLIDS (wt \%) & & & & & & & & & & \\
\hline TOTAL SOLIDS (wt \%) & & & & ADS & 42.5 & & & & & \\
\hline & & & & & & & & & & \\
\hline SUSPENDED SOLIDS (wt \%) & 1.32 & & & ADS & 12.3 & 18.5 & CALC & & & \\
\hline SUSPENDED SOLIDS (wt \%) & & & & MOBILE LAB-> & 13.9 & & & & & \\
\hline SUSPENDED SOLIDS (wt\%) & & & & & & & & & & \\
\hline SUSPENDED SOLIDS (wt \%) & & & & & & & & & & \\
\hline & & & & & & & & & & \\
\hline SPECIFIC GRAVITY & 1.26 & & & & 1.37 & & & & & \\
\hline
\end{tabular}




\section{APPENDIX A4. RHEOLOGICAL DATA}

\section{R1BC Slurries:}
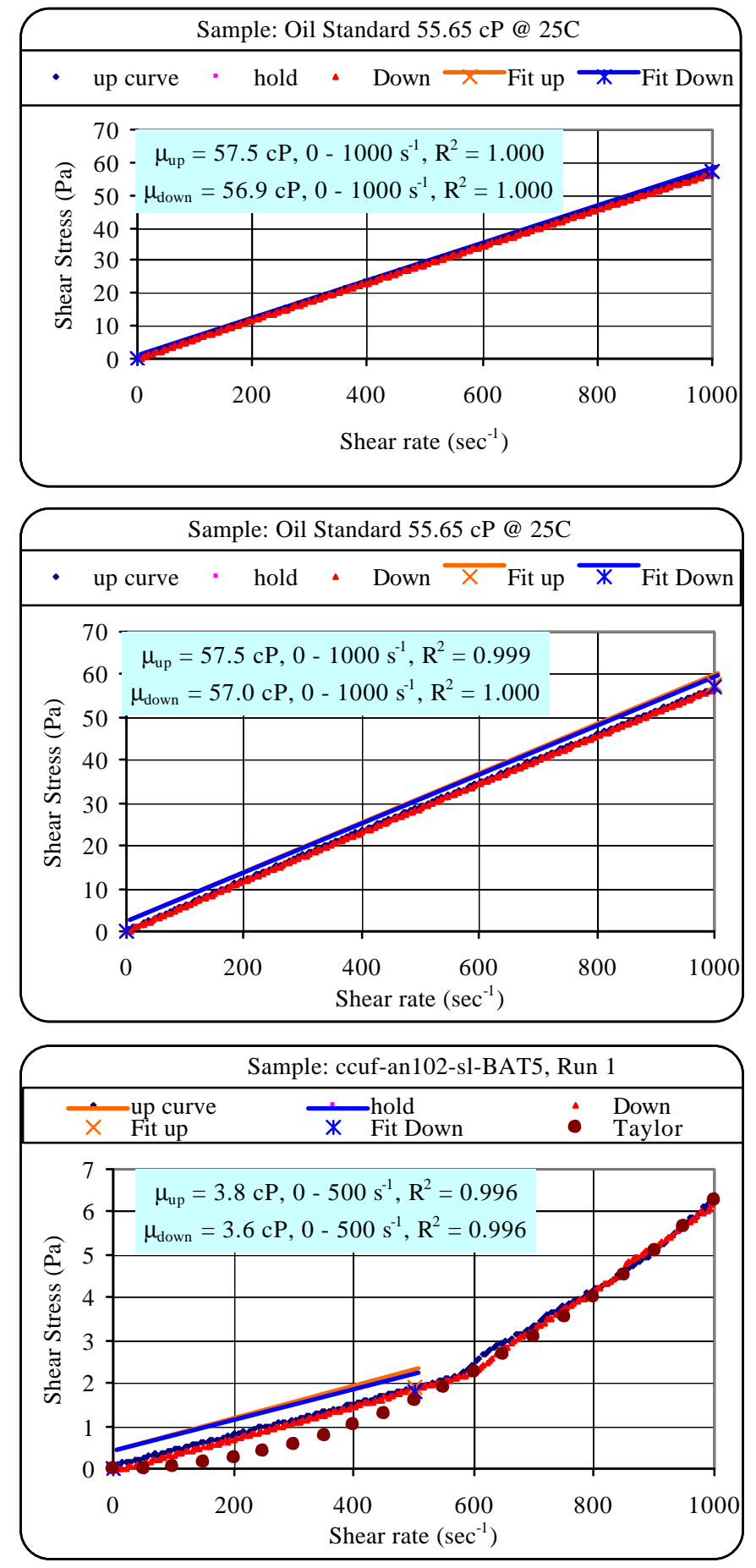

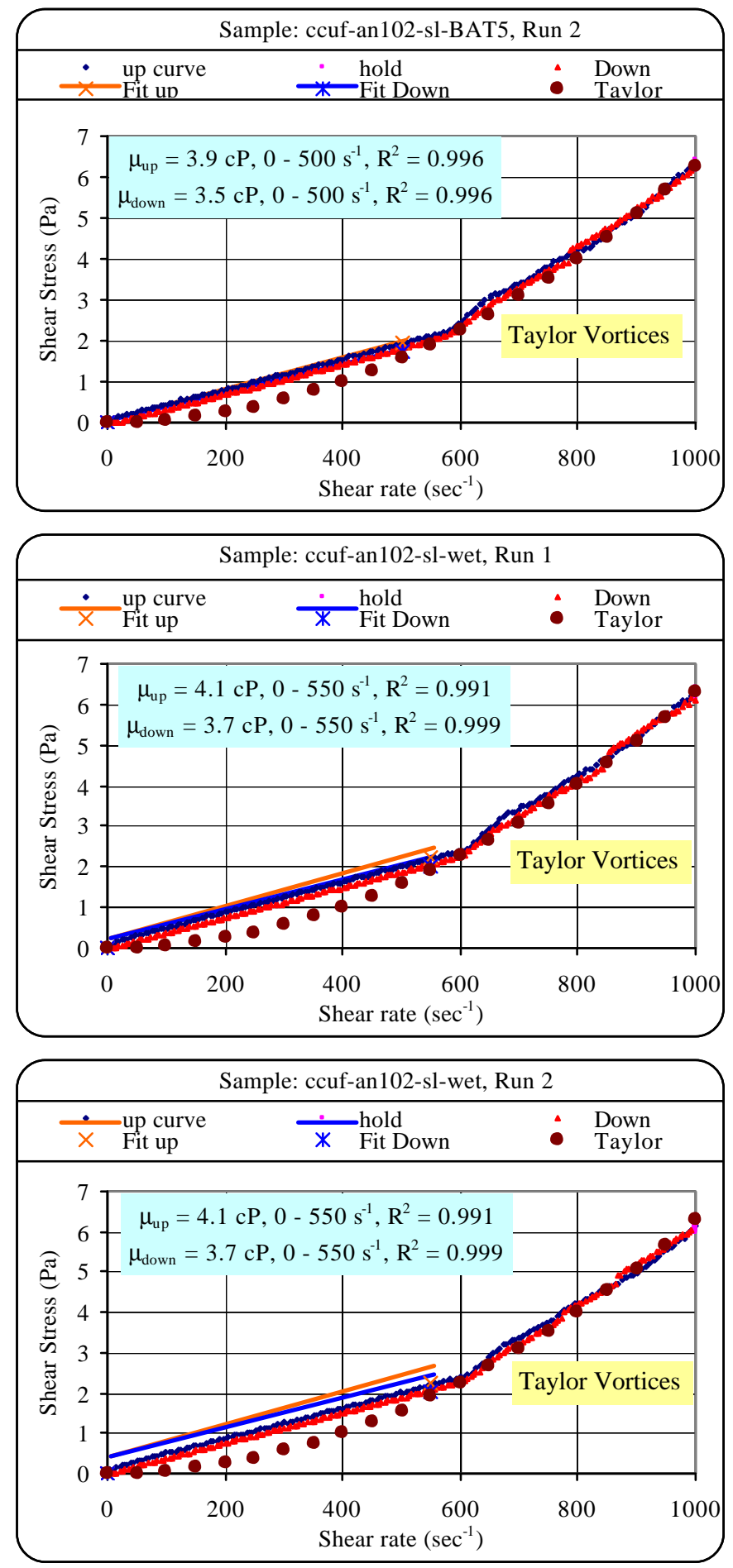

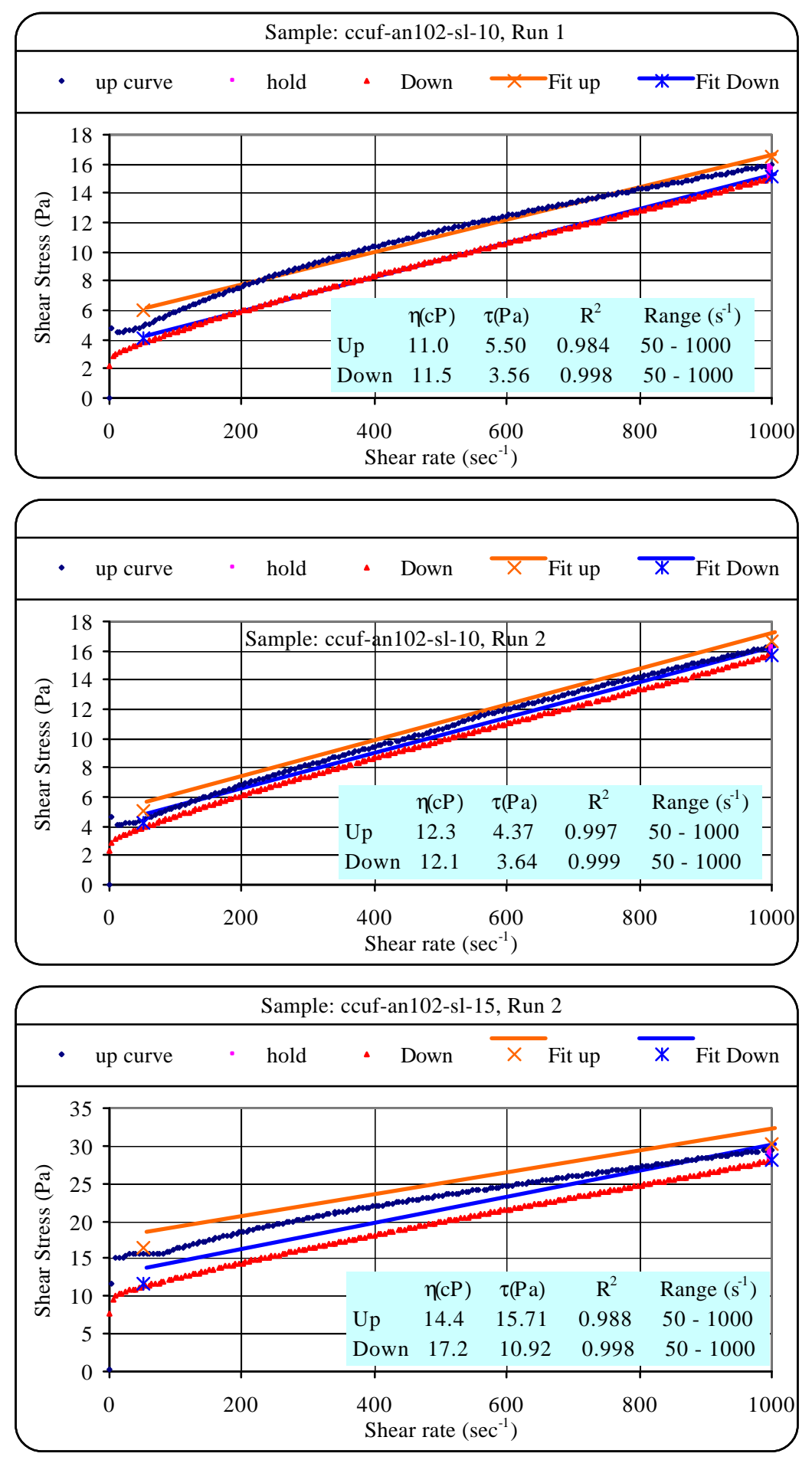

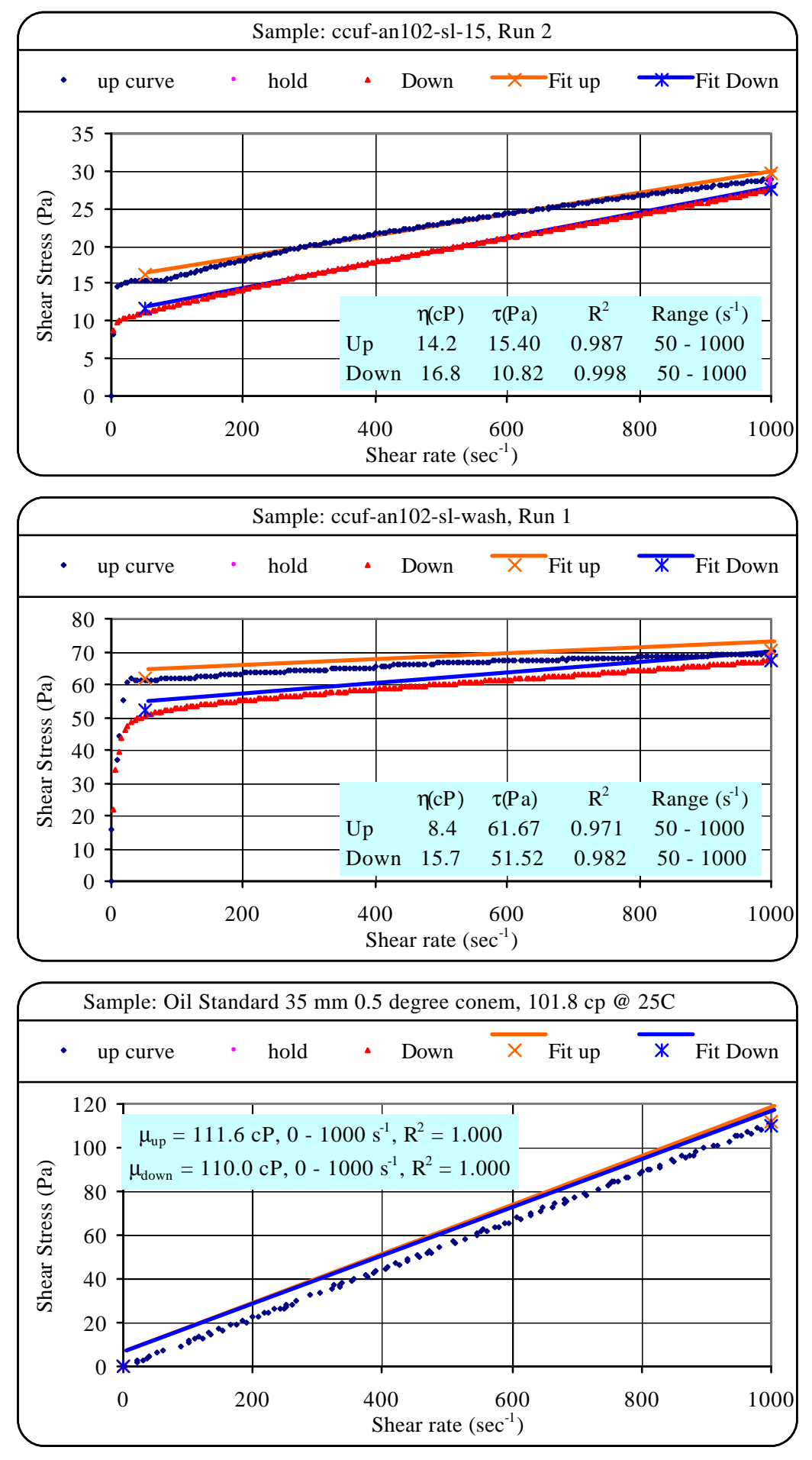


\section{WSRC-TR-2003-00056, REV. 0 \\ SRT-RPP-2002-00231, REV. 0}

Outlier points in the graphs following are due to an instrument communication problem. The number of outlier points is insignificant to the fitted viscosity or consistency and yield stress values.
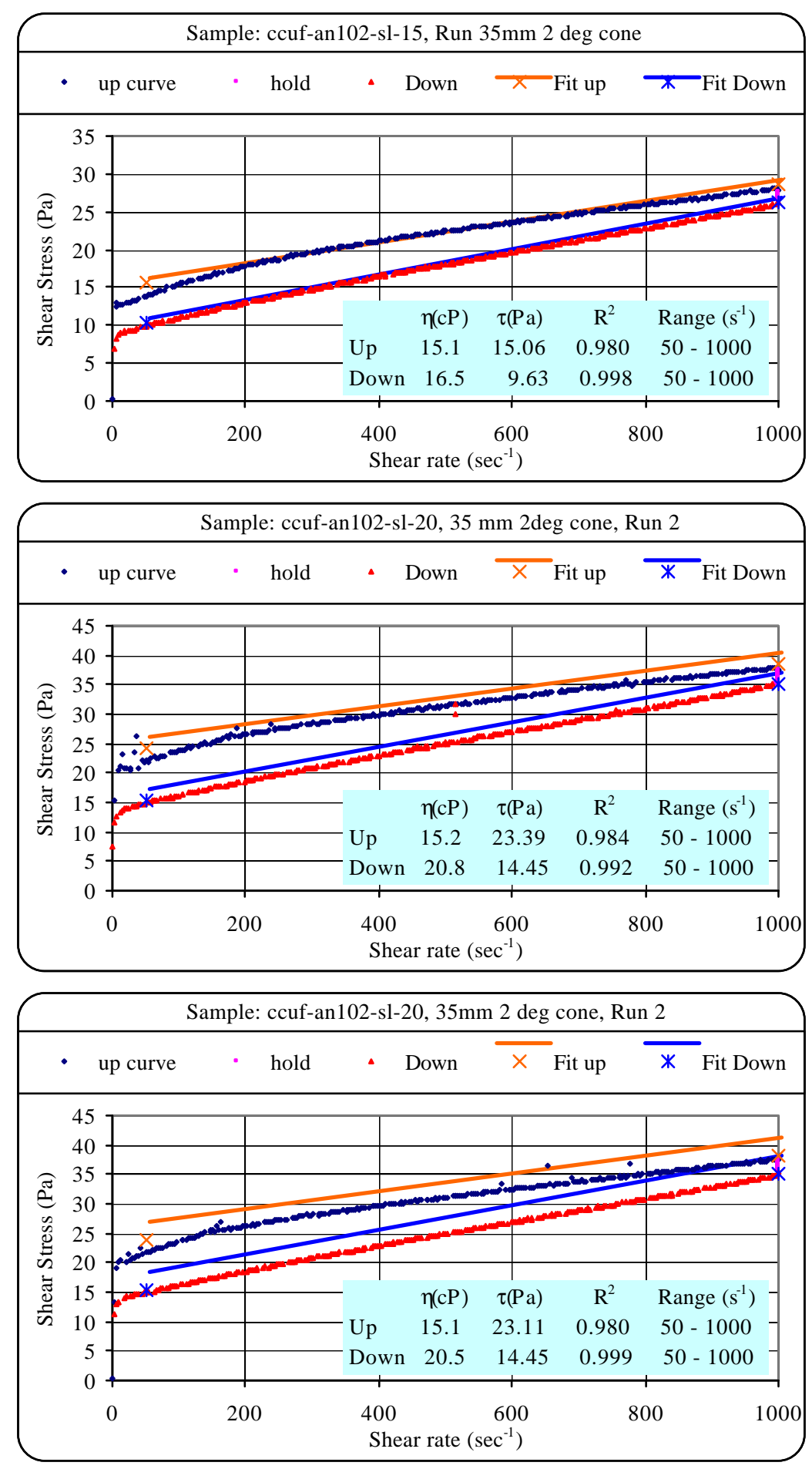

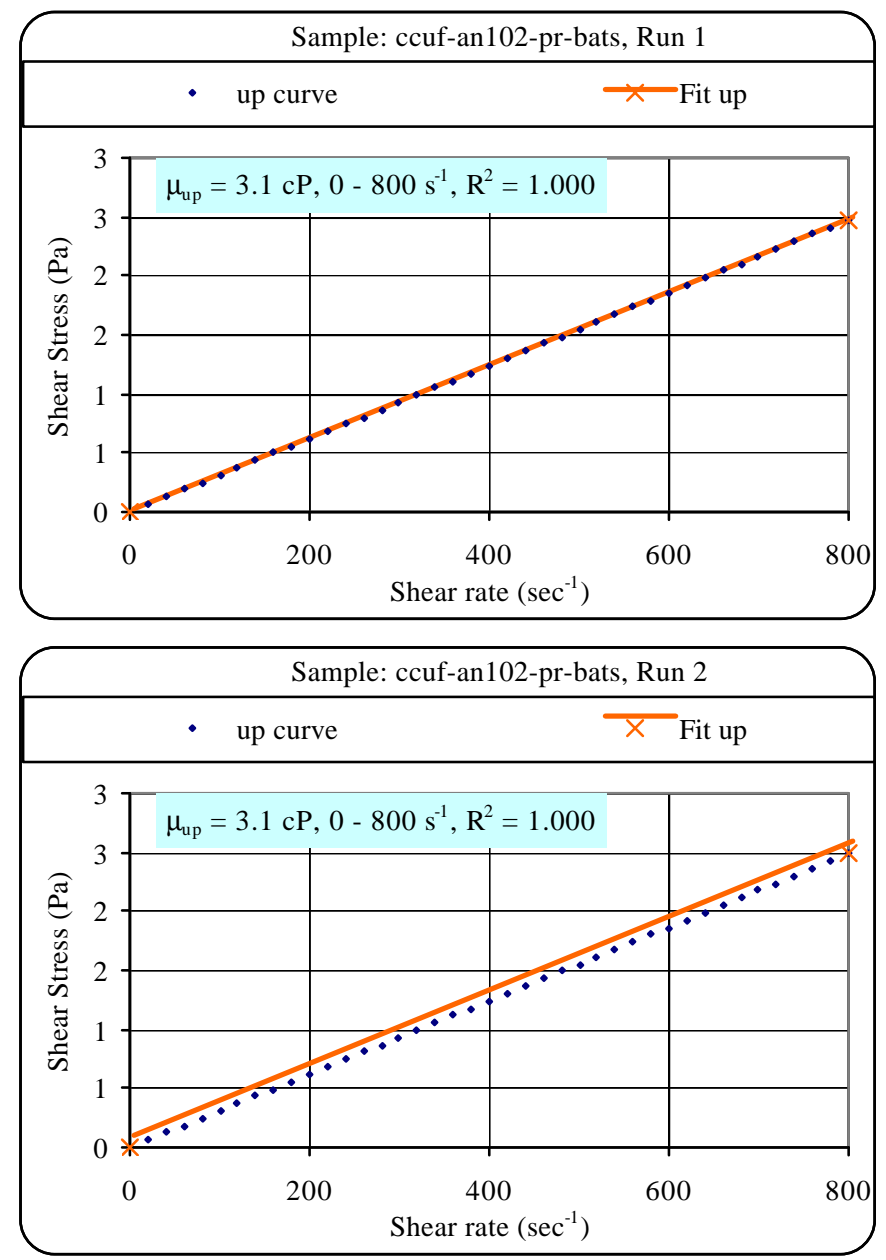

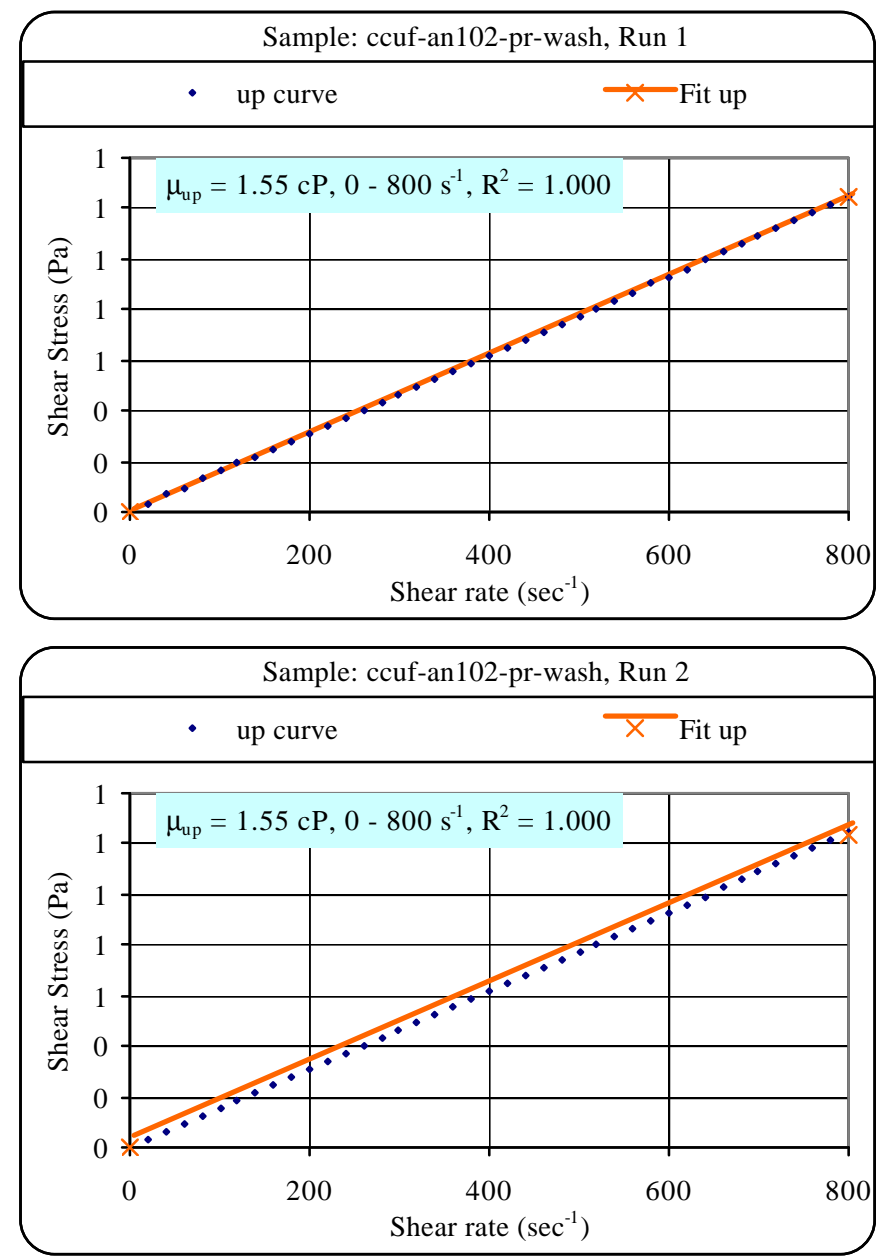


\section{R2BCL and R2NOC2 Slurries:}
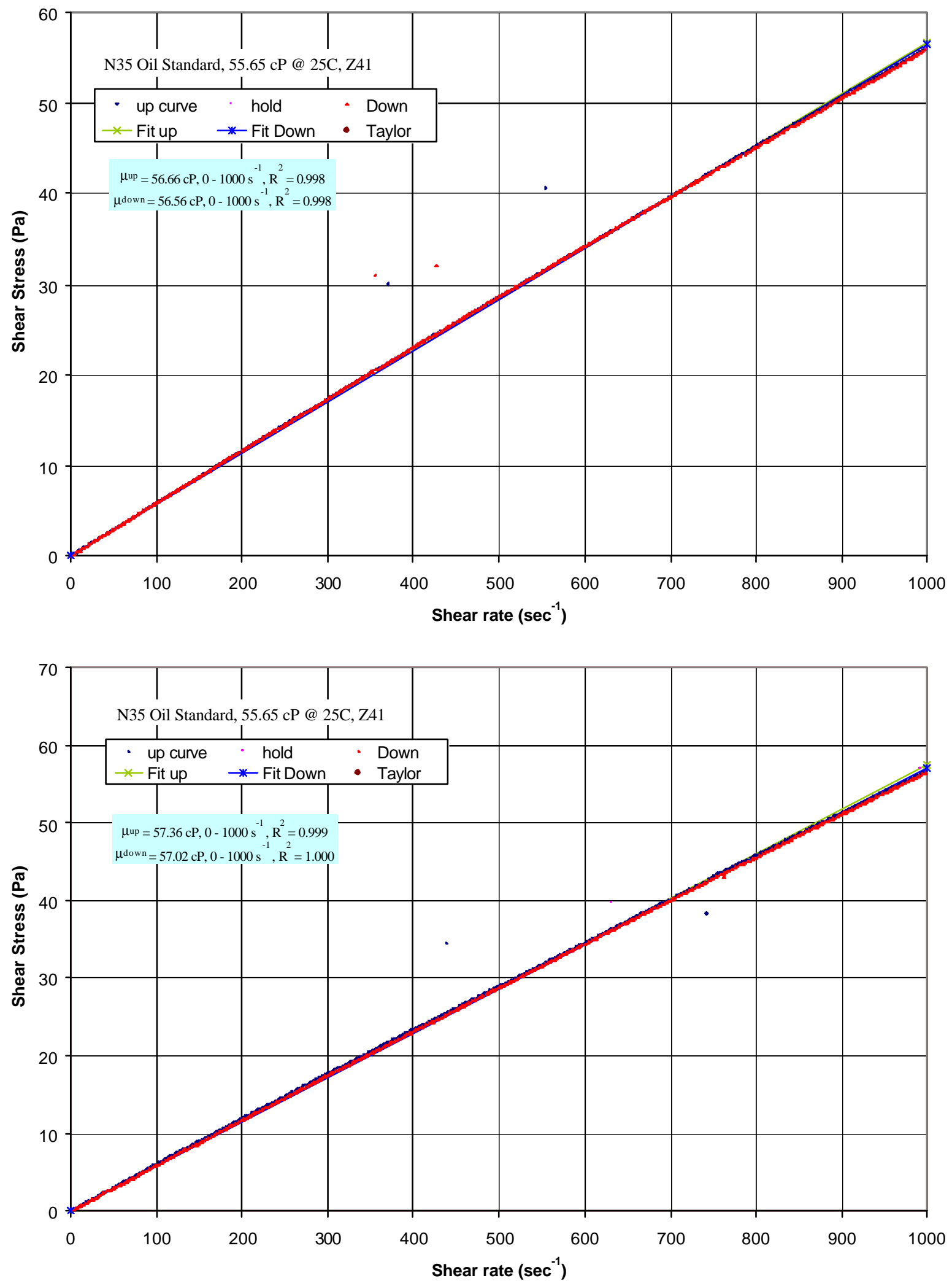

Page 95 of 124 
WSRC-TR-2003-00056, REV. 0

SRT-RPP-2002-00231, REV. 0
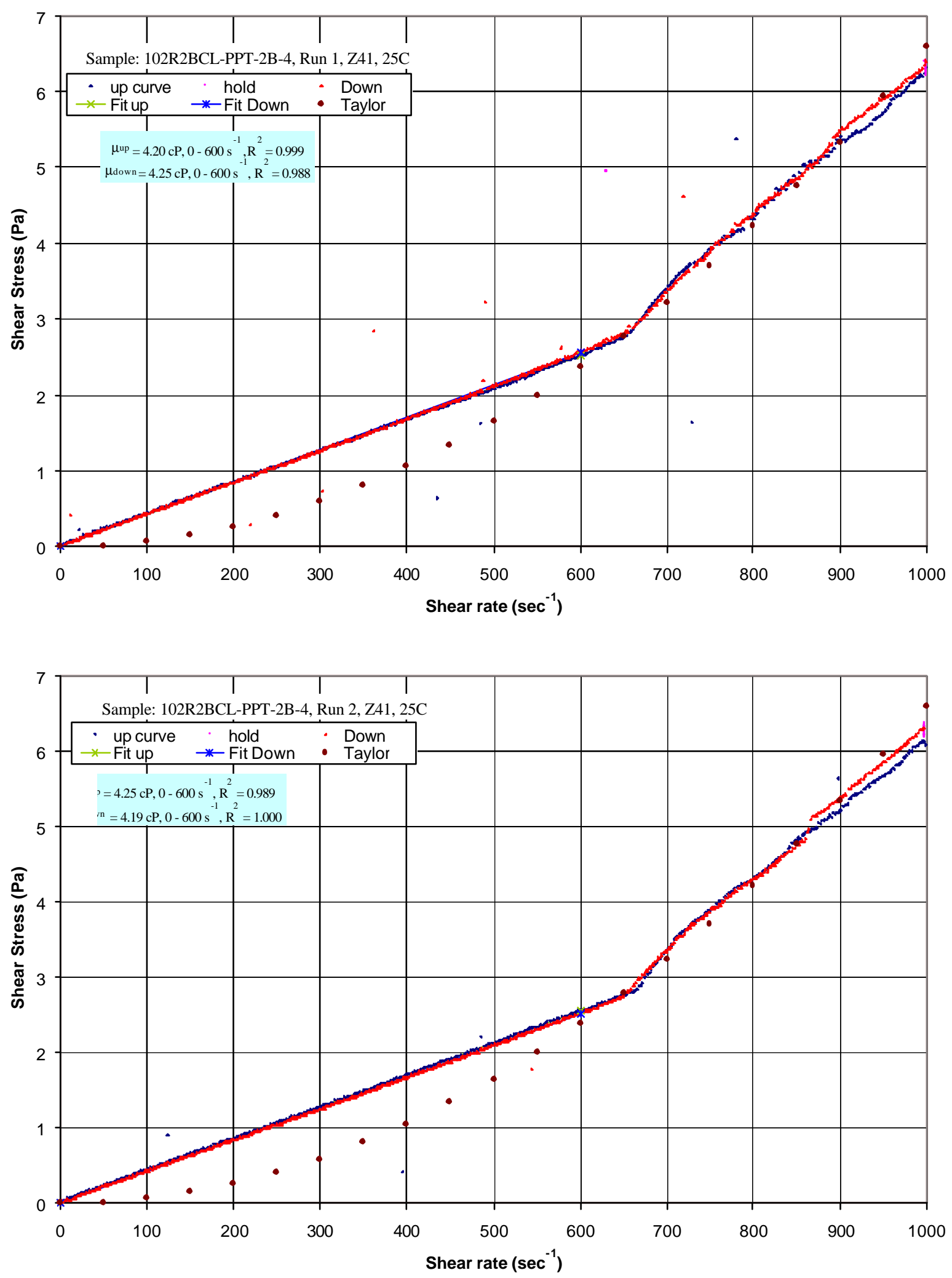
WSRC-TR-2003-00056, REV. 0

SRT-RPP-2002-00231, REV. 0
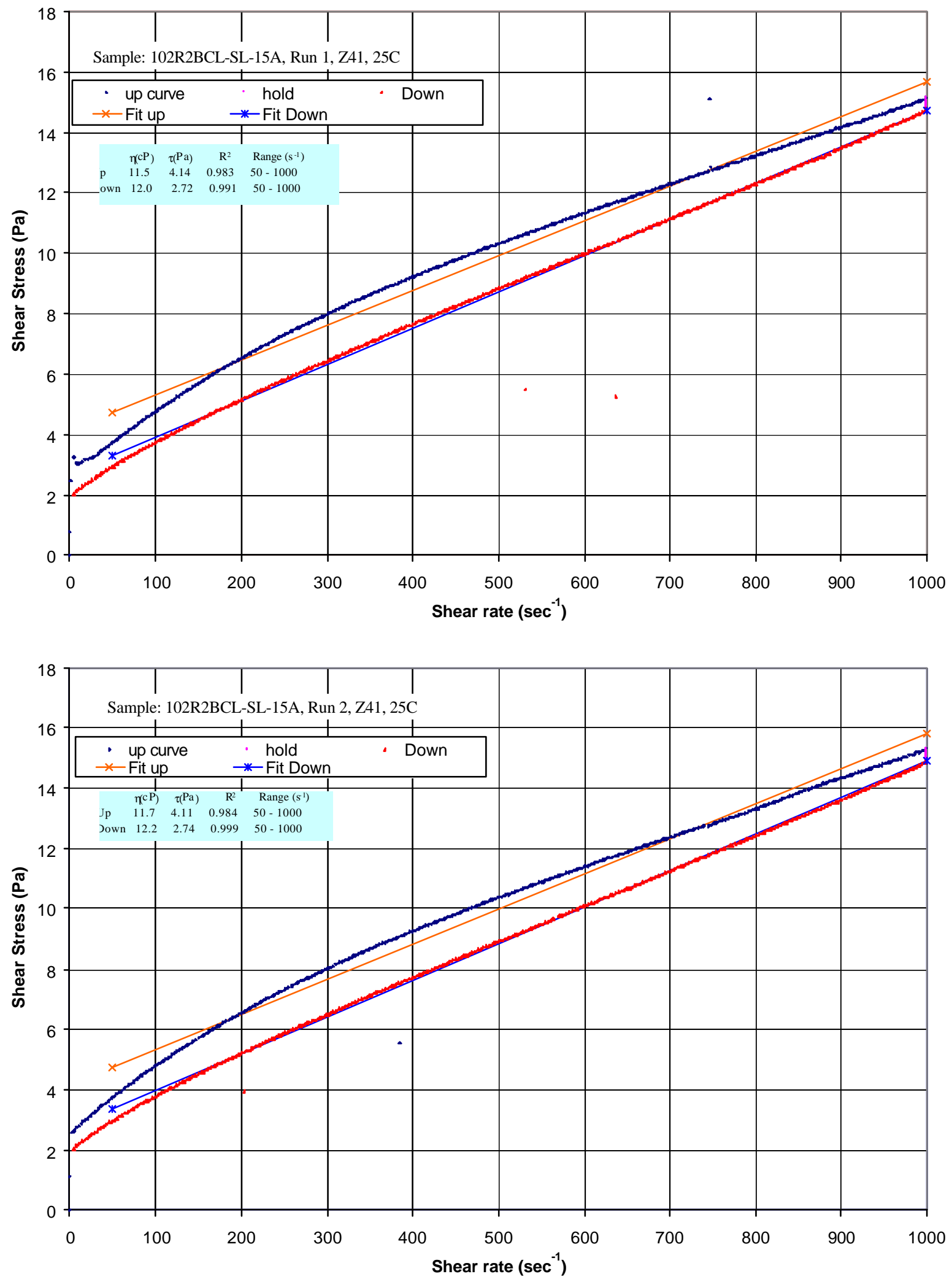
WSRC-TR-2003-00056, REV. 0

SRT-RPP-2002-00231, REV. 0
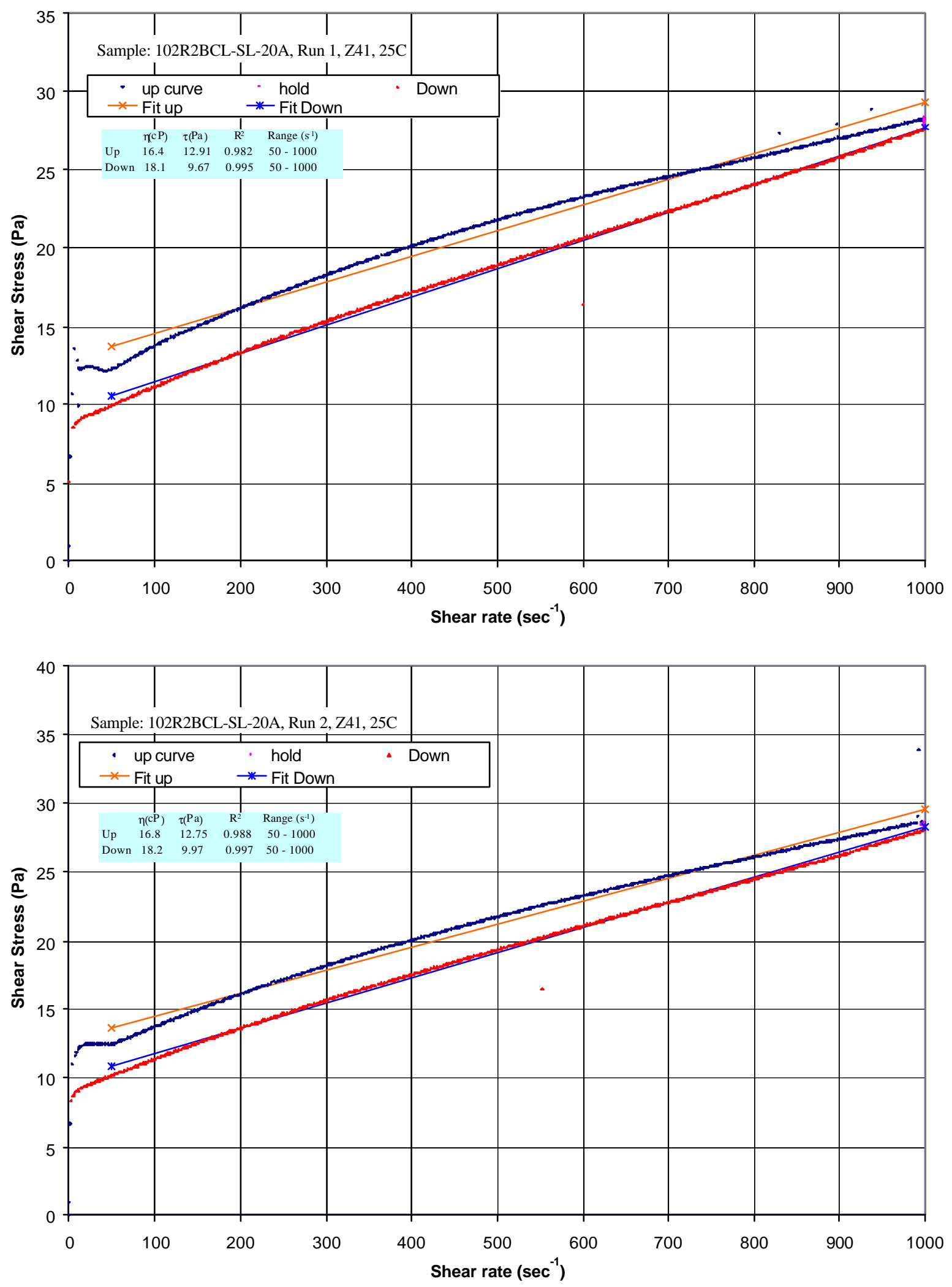
WSRC-TR-2003-00056, REV. 0

SRT-RPP-2002-00231, REV. 0
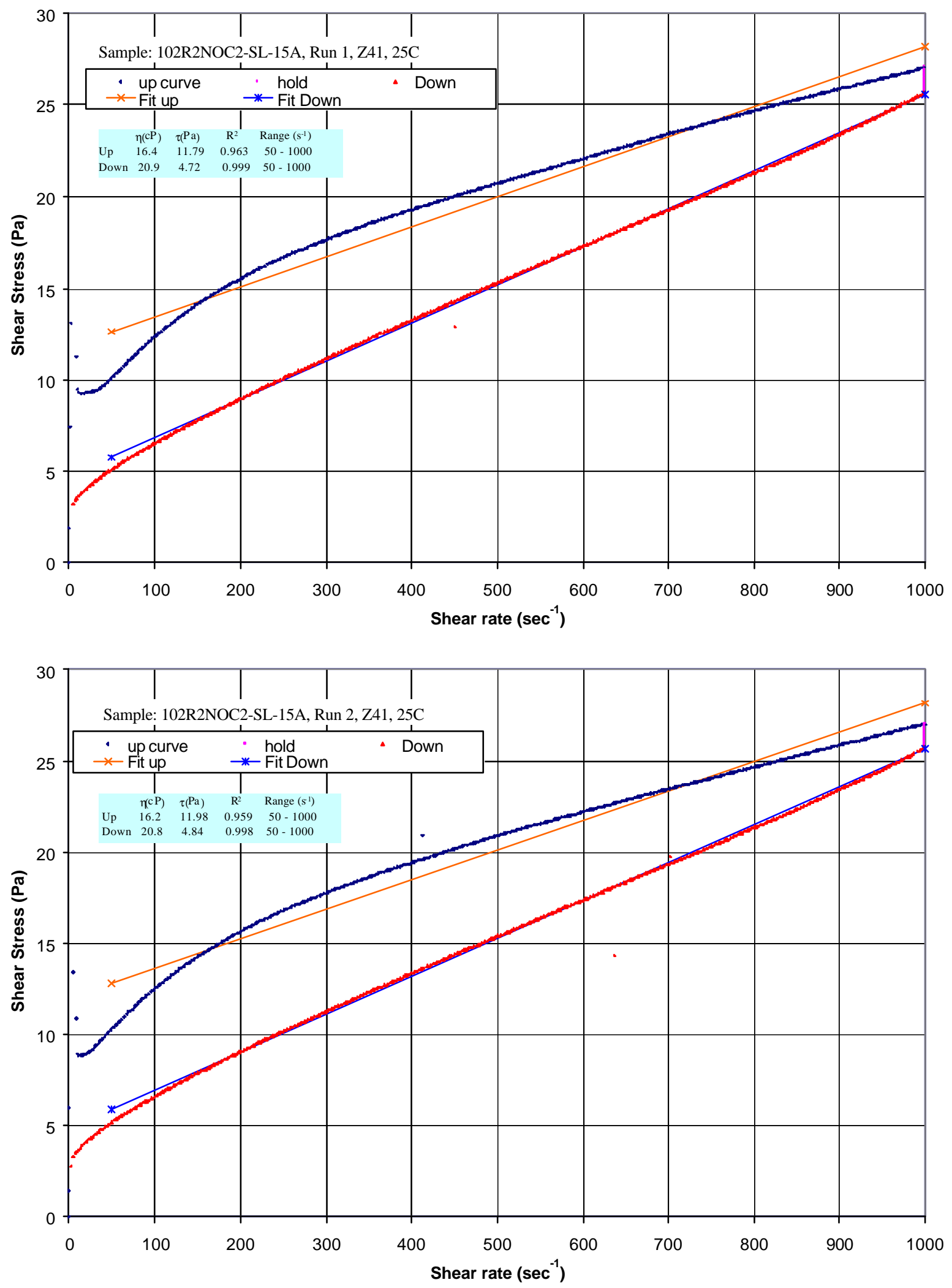
WSRC-TR-2003-00056, REV. 0

SRT-RPP-2002-00231, REV. 0
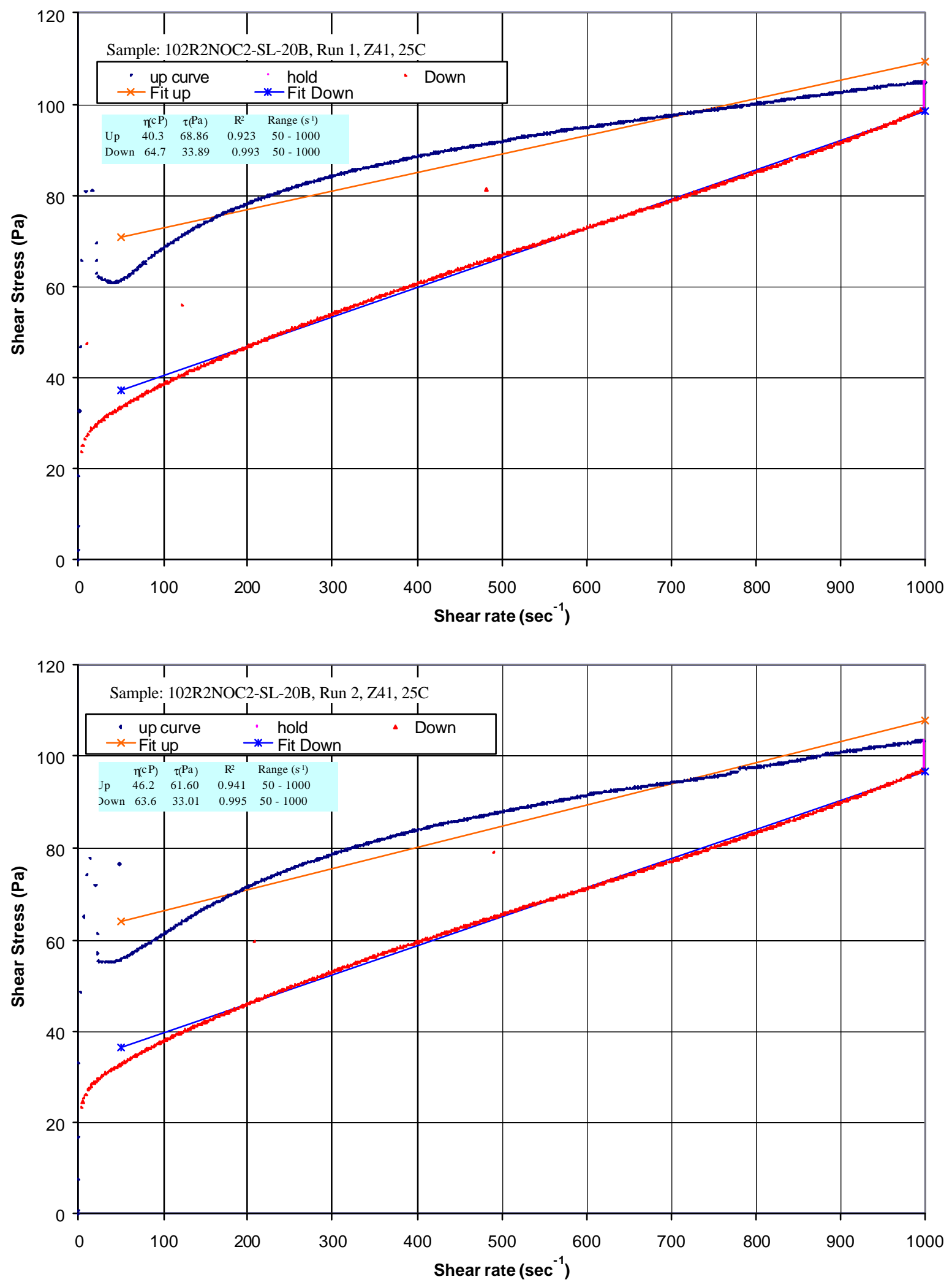
WSRC-TR-2003-00056, REV. 0

SRT-RPP-2002-00231, REV. 0

\section{APPENDIX A5. JMP CURVE FITTING DATA}

\section{AN102R1BC DATA \\ LOW WT\% SOLIDS FACTORIAL}

$\ln \mathrm{F}=\mathrm{a}+\mathrm{v} \ln \mathrm{V}+\mathrm{p} \ln \mathrm{P}+\mathrm{u} \ln \mathrm{t}$

or

$F=e^{a} V^{v} P^{p} t^{u}$

$\mathrm{F}=$ flux $\left(\mathrm{gpm} / \mathrm{ft}^{2}\right)$

$\mathrm{V}=$ velocity (fps)

$\mathrm{P}=\mathrm{TMP}(\mathrm{psi})$

$\mathrm{t}=$ time since start of tests $(\mathrm{hr})$

$\mathrm{a}, \mathrm{v}, \mathrm{p}, \mathrm{u}=$ parameters

\section{Summary of Fit}

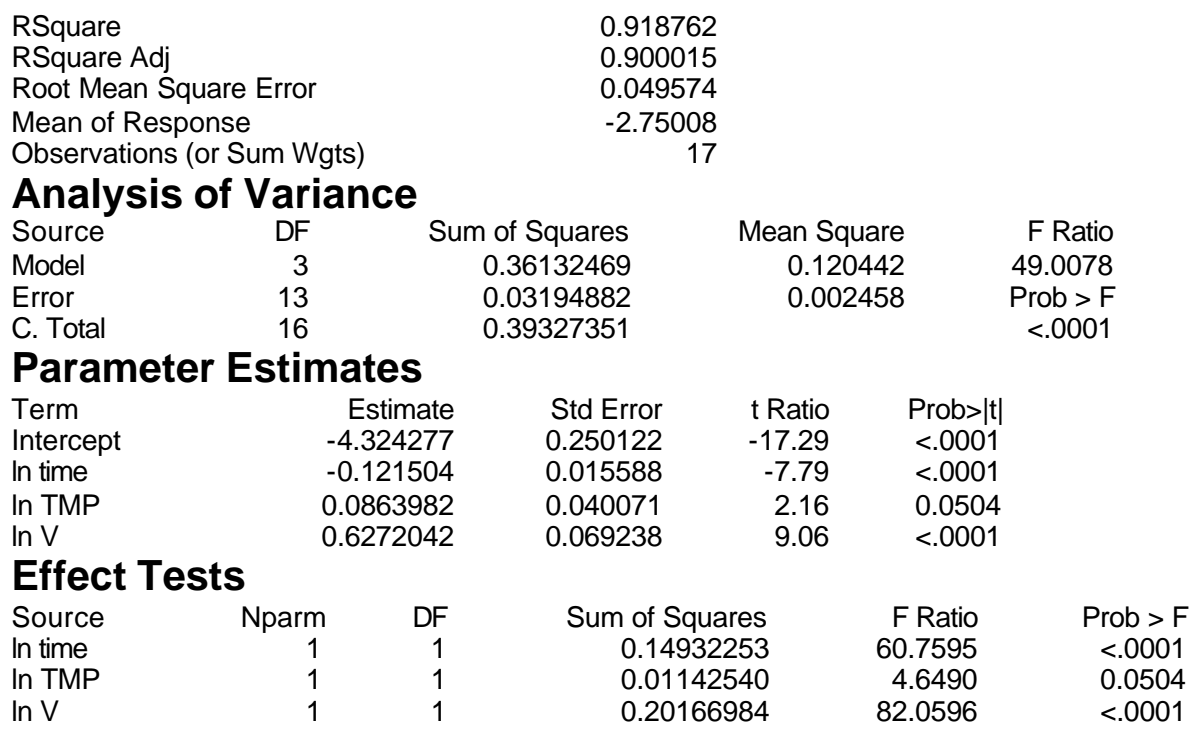

\section{Correlation of Estimates}

Corr

Intercept

In time

In TMP

In V
Intercept

1.0000

$-0.163$

$-0.755$

$-0.812$
In time

$-0.163$

1.0000

0.0356

0.0288
In TMP

$-0.755$

0.0356

1.0000

0.2515
In V

$-0.812$

0.0288

0.2515

1.0000 


\section{Actual by Predicted Plot}

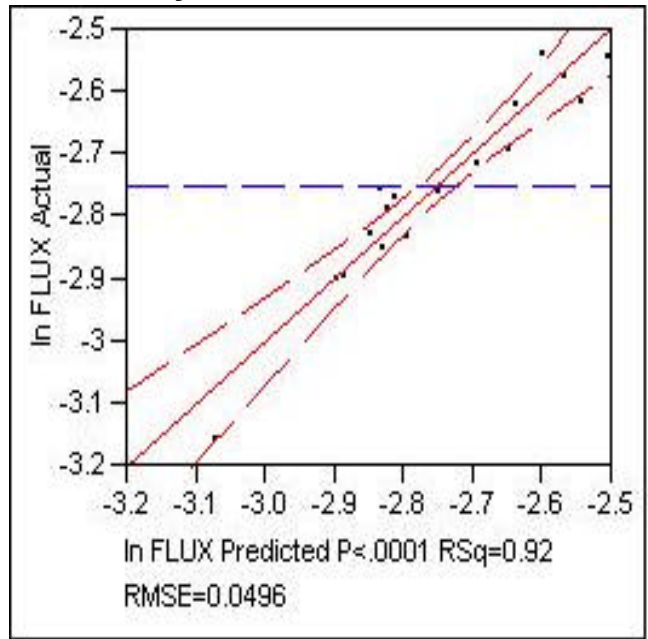

\section{Residual by Predicted Plot}

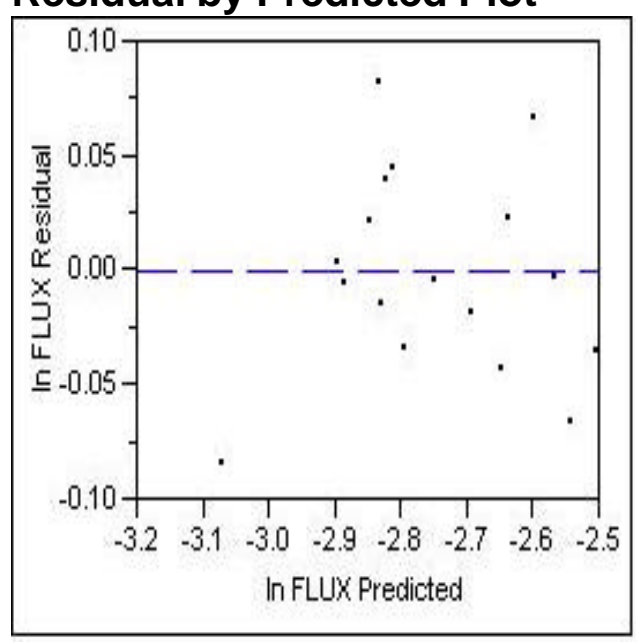

\section{In time}

Leverage Plot

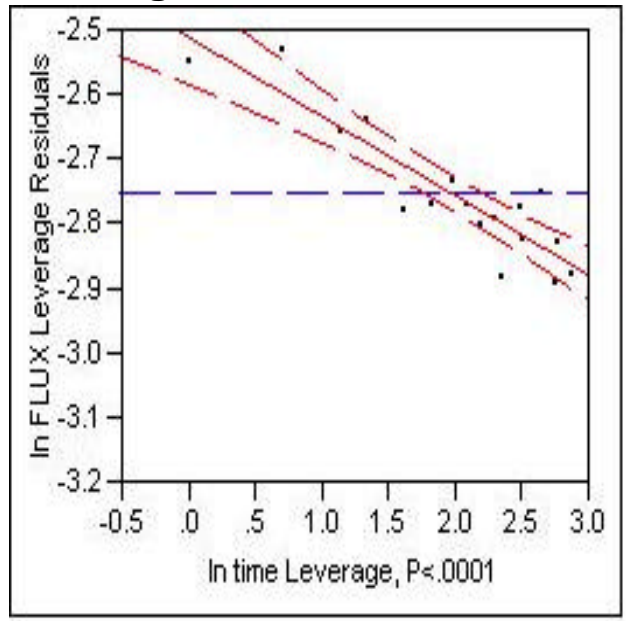

Page 102 of 124 


\section{In TMP}

\section{Leverage Plot}

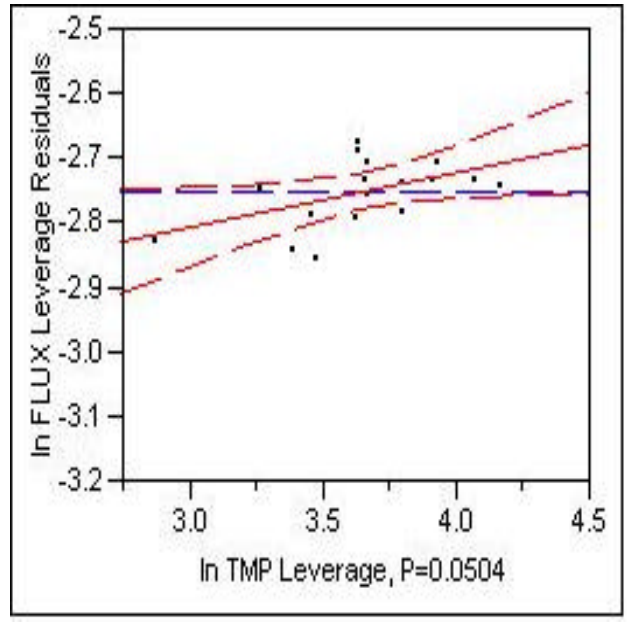

In V

Leverage Plot

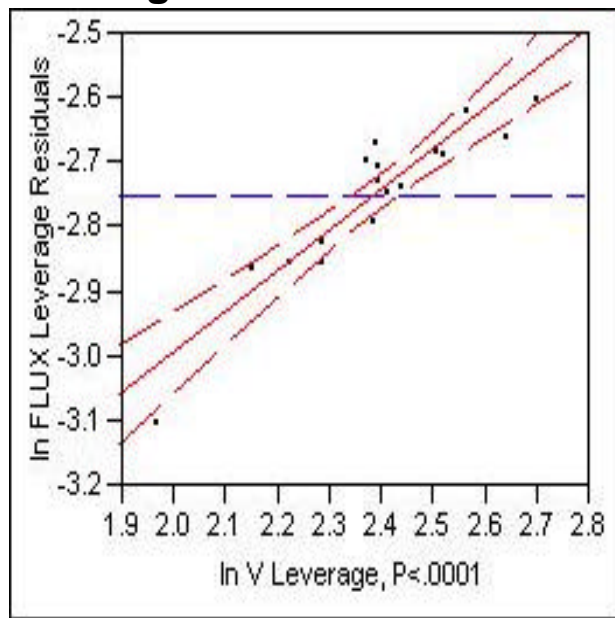

Page 103 of 124 


\title{
AN102R1BC DATA
}

HIGH WT\% (approximately 17.2) SOLIDS FACTORIAL

$\ln \mathrm{F}=\mathrm{a}+\mathrm{v} \ln \mathrm{V}+\mathrm{u} \ln \mathrm{t}$

or

$F=e^{a} V^{v} t^{u}$

$\mathrm{F}=$ flux $\left(\mathrm{gpm} / \mathrm{ft}^{2}\right)$

$V=$ velocity (fps)

$P=\operatorname{TMP}(\mathrm{psi})$

$\mathrm{t}=$ time since start of tests $(\mathrm{hr})$

$\mathrm{a}, \mathrm{v}, \mathrm{p}, \mathrm{u}=$ parameters

Note: pressure was not statistically significant

\section{Summary of Fit}

RSquare

RSquare Adj

Root Mean Square Error

Mean of Response

Observations (or Sum Wgts)

Analysis of Variance

$\begin{array}{lrr}\text { Source } & \text { DF } & \text { Sum of Squares } \\ \text { Model } & 2 & 0.46194402 \\ \text { Error } & 13 & 0.06855413 \\ \text { C. Total } & 15 & 0.53049814\end{array}$

0.870774

0.850893

0.072618

$-5.04014$

16

Parameter Estimates

$\begin{array}{lr}\text { Term } & \text { Estimate } \\ \text { Intercept } & 0.4159563\end{array}$

In time

In V

Effect Tests

Source Nparm

In time

In V

$-1.647299$

0.50251

\begin{abstract}
Std Error
0.980182

0.225335

0.106916
\end{abstract}
Mean Square

$$
0.230972
$$
0.005273
F Ratio
43.7995
Prob $>$ F $<.0001$

\section{Correlation of Estimates}

Corr

Intercept

In time

Intercept

In time

1.0000

$-0.966$

$-0.396$
Sum of Squares
0.28182351
0.11649086
F Ratio
53.4425
22.0903

$\begin{array}{rr}t \text { Ratio } & \text { Prob }>|t| \\ 0.42 & 0.6782 \\ -7.31 & <.0001 \\ 4.70 & 0.0004\end{array}$

Prob $>\mathrm{F}$

$<.0001$

0.0004 


\section{Actual by Predicted Plot}

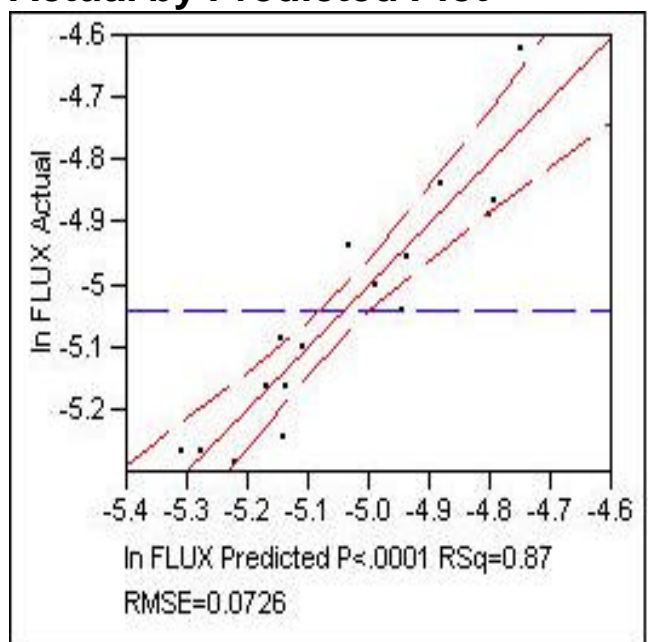

\section{Residual by Predicted Plot}

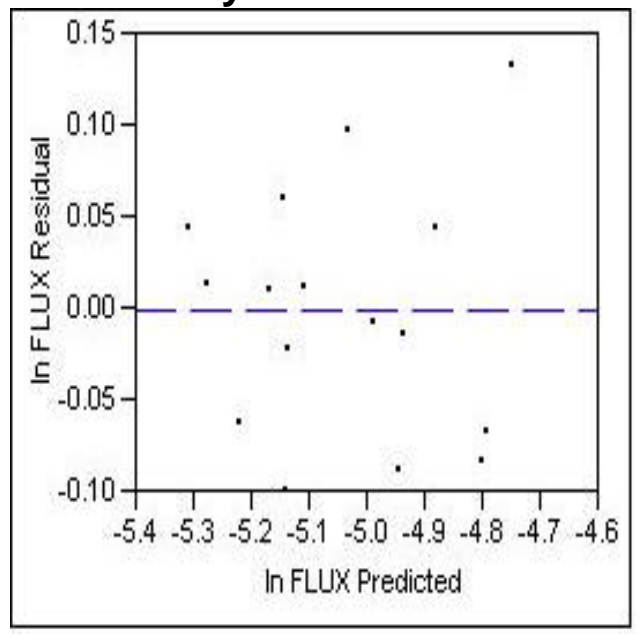

\section{In time}

\section{Leverage Plot}

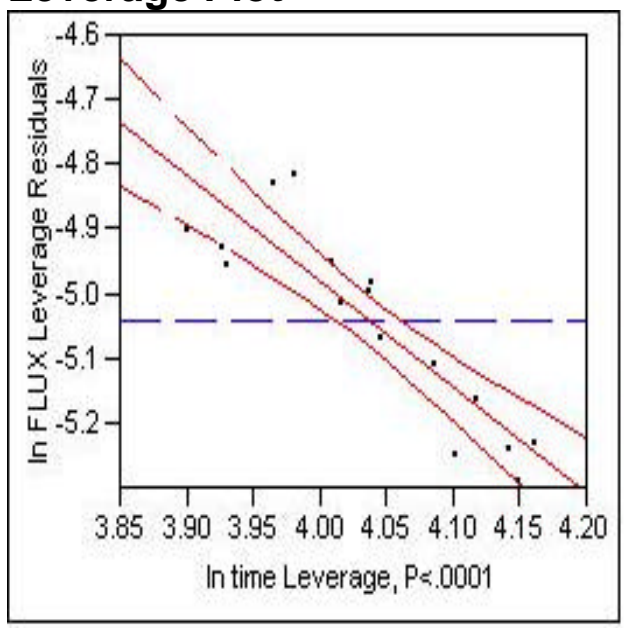


WSRC-TR-2003-00056, REV. 0

SRT-RPP-2002-00231, REV. 0

\section{In V}

Leverage Plot

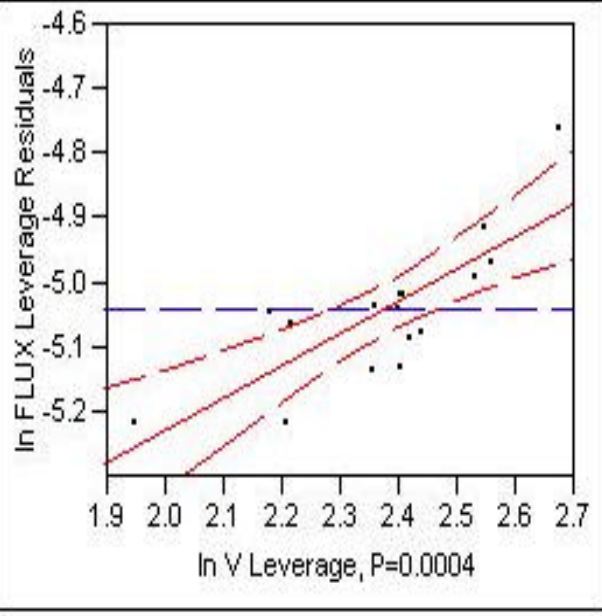

Page 106 of 124 
Flux versus Time for Concentration of Slurry

$F=a(1-b S-c R) t^{-0.1215}$

$\mathrm{F}=\mathrm{flux}\left(\mathrm{gpm} / \mathrm{ft}^{2}\right)$

$\mathrm{t}=$ time since start of tests $(\mathrm{hr})$

$\mathrm{S}=$ insoluble solids (wt\%)

$\mathrm{R}=0$ if before redilution back to $17.2 \mathrm{wt} \%$; = 1 if after ( 2 data points)

$\mathrm{a}, \mathrm{b}, \mathrm{c}=$ parameters

$\mathrm{R}$ factor used to account for flux after redilution that did not return to previous value at same solids content.

\section{Nonlinear Fit}

Converged in the Gradient

Criterion

Iteration

Shortening

Obj Change

Prm Change

Gradient

Parameter

a

b

c

SSE $=0.0000325408$

$\mathrm{N}=16$

Alpha $=0.050$

Convergence Criterion $=0.00001$

Goal SSE for $\mathrm{CL}=0.0000442235$

\section{Solution}

\begin{tabular}{|c|c|}
\hline & DFE \\
\hline Parameter & Estimate \\
\hline a & 0.0945850528 \\
\hline b & 0.046194566 \\
\hline & 0.0716954074 \\
\hline
\end{tabular}

$a$
$b$
$c$

Correlation of Estimates

b

1.0000

0.4945

$-0.2090$

$\begin{array}{rr}\text { Current } & \text { Stop Limit } \\ 2 & 60 \\ 0 & 15 \\ 0.0000864071 & 0.0000001 \\ 0.0022076205 & 0.0000001 \\ 8.6407135 \mathrm{e}-9 & 0.000001\end{array}$

Current Value

0.0945850528

0.046194566

0.0716954074

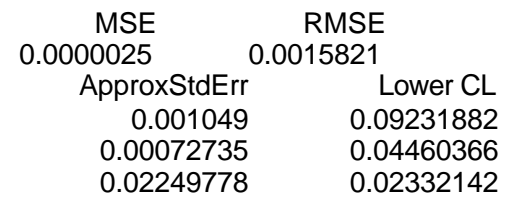

$b$
0.4945
1.0000

$-0.5232$

$-0.2090$

$-0.5232$

1.0000
Upper CL 0.09685128 0.04774819

0.12055594 


\section{APPENDIX A6. SIMULANT RECIPES}

\section{AN102 REMEDIATION 1 (R1)}

\section{Final SRS AN102 at 6.5 Molar Sodium recipe}

Volume of Feed

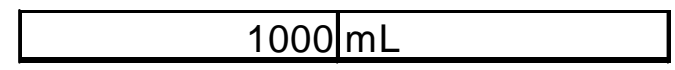

$0.5 \%$ Accuracy on masses and volumes is sufficient

\begin{tabular}{|l|l|l|}
\hline \multicolumn{2}{|c|}{ Tare Weight } & \multicolumn{2}{l|}{ grams } \\
\cline { 2 - 3 } \multicolumn{1}{c|}{} & grams & Actual Wt, grams \\
\hline Water & 200 & \\
\hline
\end{tabular}

Transition Metals and Complexing agents

\begin{tabular}{|l|l|r|l|}
\hline Compounds & Formula & Mass Needed & Actual Wt, grams \\
\hline Cadmium Nitrate & $\mathrm{Cd}(\mathrm{NO} 3) 2.4 \mathrm{H} 2 \mathrm{O}$ & 0.14 & \\
\hline Calcium Nitrate & $\mathrm{Ca}(\mathrm{NO} 3) 2.4 \mathrm{H} 2 \mathrm{O}$ & 2.36 & \\
\hline Cerium Nitrate & $\mathrm{Ce}(\mathrm{NO} 3) 3.6 \mathrm{H} 2 \mathrm{O}$ & 0.00 & \\
\hline Cesium Nitrate & $\mathrm{CsNO} 3$ & 0.019 & \\
\hline Cobalt Nitrate & $\mathrm{Co}(\mathrm{NO} 3) 2.6 \mathrm{H} 2 \mathrm{O}$ & 0.01 & \\
\hline Copper Nitrate & $\mathrm{Cu}(\mathrm{NO} 3) 2.2 .5 \mathrm{H} 2$ & 0.07 & \\
\hline Ferric Nitrate & $\mathrm{Fe}(\mathrm{NO} 3) 3.9 \mathrm{H} 2 \mathrm{O}$ & 0.25 & \\
\hline Lanthanum Nitrate & $\mathrm{La}(\mathrm{NO} 3) 3.6 \mathrm{H} 2 \mathrm{O}$ & 0.04 & \\
\hline Lead nitrate & $\mathrm{Pb}(\mathrm{NO} 3) 2$ & 0.24 & \\
\hline Magnesium Nitrate & $\mathrm{Mg}(\mathrm{NO} 3) 2.6 \mathrm{H} 2 \mathrm{O}$ & 0.00 & \\
\hline Manganous Chloride & $\mathrm{MnCl} 2.4 \mathrm{H} 2 \mathrm{O}$ & 0.09 & \\
\hline Neodymium Nitrate & $\mathrm{Nd}(\mathrm{NO} 3) 3.6 \mathrm{H} 2 \mathrm{O}$ & 0.08 & \\
\hline Nickel Nitrate & $\mathrm{Ni}(\mathrm{NO} 3) 2.6 \mathrm{H} 2 \mathrm{O}$ & 1.68 & \\
\hline Potassium Nitrate & $\mathrm{KNO} 3$ & 4.11 & \\
\hline Rubidium Nitrate & $\mathrm{RbNO3}$ & 0.01 & \\
\hline Strontium Nitrate & $\mathrm{Sr}(\mathrm{NO} 3) 2$ & 0.005 & \\
\hline Zinc Nitrate & $\mathrm{Zn}(\mathrm{NO} 3) 2.6 \mathrm{H} 2 \mathrm{O}$ & 0.02 & \\
\hline Zirconyl Nitrate & $\mathrm{ZrO}(\mathrm{NO} 3) 2 . \mathrm{H} 2 \mathrm{O}$ & 0.03 & \\
\hline Disodium Ethylenediaminetetra & $\mathrm{Na} 2 \mathrm{C} 10 \mathrm{H} 14 \mathrm{~N} 208.2 \mathrm{H} 2 \mathrm{O}$ & 2.92 & \\
\hline n-(2- & & & \\
Hydroxyethyl)ethylenediaminet & & 0.30 & \\
riacetic acid & $\mathrm{C} 10 \mathrm{H} 18 \mathrm{~N} 2 \mathrm{O} 7$ & 1.34 & \\
\hline Sodium Gluconate & $\mathrm{HOCH} 2(\mathrm{CHOH}) 4 \mathrm{COONa}$ & 4.22 & \\
\hline Citric Acid & $\mathrm{C} 6 \mathrm{H} 8 \mathrm{O} 7 . \mathrm{H} 2 \mathrm{O}$ & 0.21 & \\
\hline Nitrilotriacetic Acid & $\mathrm{C} 6 \mathrm{H} 9 \mathrm{NO} 6$ & 3.71 & \\
\hline Iminodiacetic Acid & $\mathrm{C} 4 \mathrm{H} 7 \mathrm{NO} 4$ & 0.03 & \\
\hline Succinic Acid & $\mathrm{C} 4 \mathrm{H} 6 \mathrm{O} 4$ & 0.05 & \\
\hline Glutaric Acid & $\mathrm{C} 5 \mathrm{H} 8 \mathrm{O} 4$ & 0.20 & \\
\hline Adipic Acid & $\mathrm{C} 6 \mathrm{H} 10 \mathrm{O} 4$ & 0.85 & \\
\hline Azelaic Acid & $\mathrm{C} 9 \mathrm{H} 16 \mathrm{O} 4$ & & \\
\hline & & & \\
\hline
\end{tabular}


WSRC-TR-2003-00056, REV. 0

SRT-RPP-2002-00231, REV. 0

\begin{tabular}{|l|l|r|l|}
\hline Suberic Acid & $\mathrm{C} 8 \mathrm{H} 14 \mathrm{O} 4$ & 1.49 & \\
\hline Ammonium Acetate & $\mathrm{NH} 4 \mathrm{CH} 3 \mathrm{COO}$ & 0.51 & \\
\hline Boric acid & $\mathrm{H} 3 \mathrm{BO} 3$ & 0.17 & \\
\hline Sodium Chloride & $\mathrm{NaCl}$ & 6.38 & \\
\hline Sodium Fluoride & $\mathrm{NaF}$ & 3.09 & \\
\hline Sodium Sulfate & $\mathrm{Na2SO} 4$ & 15.22 & \\
\hline Potassium Molybdate & $\mathrm{K} 2 \mathrm{MoO} 4$ & 0.09 & \\
\hline
\end{tabular}

In separate container mix the following

\begin{tabular}{|l|l|r|r|}
\hline Add & Formula & Mass Needed & Actual Wt, grams \\
\hline Sodium Hydroxide & $\mathrm{NaOH}$ & 79.31 & \\
\hline Aluminum Nitrate & $\mathrm{Al}(\mathrm{NO} 3) 3.9 \mathrm{H} 2 \mathrm{O}$ & 139.03 & \\
\hline Sodium Phosphate & $\mathrm{Na3} \mathrm{PO} 4.12 \mathrm{H} 2 \mathrm{O}$ & 18.01 & \\
\hline Sodium Tungstate & $\mathrm{Na} 2 \mathrm{WO} 4.2 \mathrm{H} 2 \mathrm{O}$ & 0.25 & \\
\hline Sodium Metasilicate & $\mathrm{Na2SiO} 3.9 \mathrm{H} 2 \mathrm{O}$ & 0.08 & \\
\hline Sodium formate & $\mathrm{NaHCOO}$ & 10.36 & \\
\hline Sodium Glycolate & $\mathrm{HOCH} 2 \mathrm{COONa}$ & 11.14 & \\
\hline Sodium Acetate & $\mathrm{NaCH} 3 \mathrm{COO} .3 \mathrm{H} 2$ & 0.55 & \\
\hline Sodium Oxalate & $\mathrm{Na2C} 2 \mathrm{O} 4$ & 0.57 & \\
\hline
\end{tabular}

\begin{tabular}{|l|l|l|}
\hline Add & grams & Actual Wt, grams \\
\hline Water & 200 & \\
\hline
\end{tabular}

Mix thoroughly. Then add this solution to the Vessel

\begin{tabular}{|l|l|r|l|}
\hline Add & Formula & Mass Needed & Actual Wt, grams \\
\hline Sodium Chromate & $\mathrm{Na} 2 \mathrm{CrO} 4$ & 0.64 & \\
\hline Sodium Carbonate & $\mathrm{Na2CO} 3$ & 48.45 & \\
\hline
\end{tabular}

Mix thoroughly.

\begin{tabular}{|l|l|r|l|}
\hline Mix & Formula & Mass Needed & Actual Wt, grams \\
\hline Sodium Nitrate & NaNO3 & 119.84 & \\
\hline Sodium Nitrite & NaNO2 & 94.49 & \\
\hline Water & & 100 & \\
\hline
\end{tabular}

Add and Mix thoroughly.

\begin{tabular}{|c|c|c|c|}
\hline Add & Formula & Mass Needed & Actual Wt, grams \\
\hline Water & $\mathrm{H} 2 \mathrm{O}$ & 236.53 & \\
\hline Record Final Weight & & grams & \\
\hline
\end{tabular}


WSRC-TR-2003-00056, REV. 0

SRT-RPP-2002-00231, REV. 0

Note: the Final water addition is based on Measure the Density $1.309 \mathrm{~g} / \mathrm{mL}$ density. For INFO ONLY The final addition of water would be a density of $1.30855 \mathrm{~g} / \mathrm{mL}$.

Solution Labeling

Final AN-102 Simulant at $6.5 \mathrm{M} \mathrm{Na}$ 
WSRC-TR-2003-00056, REV. 0

SRT-RPP-2002-00231, REV. 0

AN102 REMEDIATION 2 (R2)

Final SRS AN102R2 at 6.5 Molar Sodium recipe

Volume of Feed

$1000 / \mathrm{mL}$

$0.5 \%$ Accuracy on masses and volumes is sufficient

Tare Weight

Igrams

\begin{tabular}{|l|c|c|}
\cline { 2 - 3 } \multicolumn{1}{c|}{} & grams & Actual Wt, grams \\
\hline Water & 200 & \\
\hline
\end{tabular}

Transition Metals and Complexing agents

\begin{tabular}{|c|c|c|c|}
\hline Compounds & Formula & Mass Needed & Actual Wt, grams \\
\hline Cadmium Nitrate & $\mathrm{Cd}(\mathrm{NO} 3) 2.4 \mathrm{H} 2 \mathrm{O}$ & 0.14 & \\
\hline Calcium Nitrate & $\mathrm{Ca}(\mathrm{NO} 3) 2.4 \mathrm{H} 2 \mathrm{O}$ & 2.36 & \\
\hline Cerium Nitrate & $\mathrm{Ce}(\mathrm{NO} 3) 3.6 \mathrm{H} 2 \mathrm{O}$ & 0.00 & \\
\hline Cesium Nitrate & CsNO3 & 0.019 & \\
\hline Cobalt Nitrate & $\mathrm{Co}(\mathrm{NO} 3) 2.6 \mathrm{H} 2 \mathrm{O}$ & 0.01 & \\
\hline Copper Nitrate & $\mathrm{Cu}(\mathrm{NO} 3) 2.2 .5 \mathrm{H} 2 \mathrm{C}$ & 0.07 & \\
\hline Ferric Nitrate & $\mathrm{Fe}(\mathrm{NO} 3) 3.9 \mathrm{H} 2 \mathrm{O}$ & 0.25 & \\
\hline Lanthanum Nitrate & $\mathrm{La}(\mathrm{NO} 3) 3.6 \mathrm{H} 2 \mathrm{O}$ & 0.04 & \\
\hline Lead nitrate & $\mathrm{Pb}(\mathrm{NO} 3) 2$ & 0.24 & \\
\hline Magnesium Nitrate & $\mathrm{Mg}(\mathrm{NO} 3) 2.6 \mathrm{H} 2 \mathrm{O}$ & 0.00 & \\
\hline Manganous Chloride & $\mathrm{MnCl} 2.4 \mathrm{H} 2 \mathrm{O}$ & 0.09 & \\
\hline Neodymium Nitrate & $\mathrm{Nd}(\mathrm{NO} 3) 3.6 \mathrm{H} 2 \mathrm{O}$ & 0.08 & \\
\hline Nickel Nitrate & $\mathrm{Ni}(\mathrm{NO} 3) 2.6 \mathrm{H} 2 \mathrm{O}$ & 1.68 & \\
\hline Potassium Nitrate & KNO3 & 4.11 & \\
\hline Rubidium Nitrate & $\mathrm{RbNO3}$ & 0.01 & \\
\hline Strontium Nitrate & $\operatorname{Sr}(\mathrm{NO} 3) 2$ & 0.005 & \\
\hline Zinc Nitrate & $\mathrm{Zn}(\mathrm{NO} 3) 2.6 \mathrm{H} 2 \mathrm{O}$ & 0.02 & \\
\hline Zirconyl Nitrate & $\mathrm{ZrO}(\mathrm{NO} 3) 2 . \mathrm{H} 2 \mathrm{O}$ & 0.03 & \\
\hline Disodium Ethylenediaminetetraacetate & $\mathrm{Na2C10H14N2O8}$ & 2.92 & \\
\hline $\begin{array}{l}\mathrm{n}-(2- \\
\text { Hydroxyethyl)ethylenediaminetriacetic } \\
\text { acid }\end{array}$ & $\mathrm{C} 10 \mathrm{H} 18 \mathrm{~N} 2 \mathrm{O} 7$ & 0.30 & \\
\hline Sodium Gluconate & $\mathrm{HOCH} 2(\mathrm{CHOH}) 4 \mathrm{C}$ & 1.34 & \\
\hline Citric Acid & $\begin{array}{ll}\mathrm{C} 6 \mathrm{H} 8 \mathrm{O} 7 . \mathrm{H} 2 \mathrm{O} \\
\end{array}$ & 4.22 & \\
\hline Nitrilotriacetic Acid & C6H9NO6 & 0.21 & \\
\hline Iminodiacetic Acid & $\mathrm{C} 4 \mathrm{H} 7 \mathrm{NO} 4$ & 3.71 & \\
\hline Succinic Acid & $\mathrm{C} 4 \mathrm{H} 6 \mathrm{O} 4$ & 0.03 & \\
\hline Glutaric Acid & $\mathrm{C} 5 \mathrm{H} 8 \mathrm{O} 4$ & 0.05 & \\
\hline Adipic Acid & $\mathrm{C} 6 \mathrm{H} 10 \mathrm{OO} 4$ & 0.20 & \\
\hline Azelaic Acid & $\mathrm{C} 9 \mathrm{H} 16 \mathrm{O} 4$ & 0.85 & \\
\hline Suberic Acid & $\mathrm{C} 8 \mathrm{H} 14 \mathrm{O} 4$ & 1.49 & \\
\hline Ammonium Acetate & $\mathrm{NH} 4 \mathrm{CH} 3 \mathrm{COO}$ & 0.51 & \\
\hline Boric acid & $\mathrm{H} 3 \mathrm{BO} 3$ & 0.17 & \\
\hline Sodium Chloride & $\mathrm{NaCl}$ & 6.38 & \\
\hline Sodium Fluoride & $\mathrm{NaF}$ & 3.09 & \\
\hline Sodium Sulfate & $\mathrm{Na} 2 \mathrm{SO} 4$ & 15.22 & \\
\hline Potassium Molybdate & $\mathrm{K} 2 \mathrm{MoO} 4$ & 0.09 & \\
\hline
\end{tabular}


WSRC-TR-2003-00056, REV. 0

SRT-RPP-2002-00231, REV. 0

In separate container mix the following

\begin{tabular}{|l|l|r|l|}
\hline Add & Formula & Mass Needed & Actual Wt, grams \\
\hline Sodium Hydroxide & $\mathrm{NaOH}$ & 79.31 & \\
\hline Aluminum Nitrate & $\mathrm{Al}(\mathrm{NO} 3) 3.9 \mathrm{H} 2 \mathrm{O}$ & 139.03 & \\
\hline Sodium Phosphate & $\mathrm{Na3} \mathrm{PO} 4.12 \mathrm{H} 2 \mathrm{O}$ & 18.01 & \\
\hline Sodium Tungstate & $\mathrm{Na} 2 \mathrm{WO} 4.2 \mathrm{H} 2 \mathrm{O}$ & 0.25 & \\
\hline Sodium Metasilicate & $\mathrm{Na} 2 \mathrm{SiO} 3.9 \mathrm{H} 2 \mathrm{O}$ & 0.08 & \\
\hline Sodium formate & $\mathrm{NaHCOO}$ & 10.36 & \\
\hline Sodium Glycolate & $\mathrm{HOCH} 2 \mathrm{COONa}$ & 11.14 & \\
\hline Sodium Acetate & $\mathrm{NaCH} 3 \mathrm{COO} .3 \mathrm{H} 2$ & 0.55 & \\
\hline Sodium Oxalate & $\mathrm{Na} 2 \mathrm{C} 2 \mathrm{O} 4$ & 0.57 & \\
\hline
\end{tabular}

\begin{tabular}{|l|l|l|}
\hline Add & grams & Actual Wt, grams \\
\hline Water & 200 & \\
\hline
\end{tabular}

Mix thoroughly. Then add this solution to the Vessel

\begin{tabular}{|l|l|r|l|}
\hline Add & Formula & Mass Needed & Actual Wt, grams \\
\hline Sodium Chromate & $\mathrm{Na2CrO} 4$ & 0.64 & \\
\hline Sodium Carbonate & $\mathrm{Na2CO} 3$ & 78.98 & \\
\hline
\end{tabular}

Mix thoroughly.

\begin{tabular}{|l|l|r|l|}
\hline Mix & Formula & Mass Needed & Actual Wt, grams \\
\hline Sodium Nitrate & NaNO3 & 87.85 & \\
\hline Sodium Nitrite & NaNO2 & 80.71 & \\
\hline Water & & 100 & \\
\hline
\end{tabular}

Add and Mix thoroughly.

\begin{tabular}{l|l|l|l|}
\hline Add & Formula & Mass Needed & Actual Wt, grams \\
\hline Water & $\mathrm{H} 2 \mathrm{O}$ & \multicolumn{2}{|c|}{241.54} \\
\hline
\end{tabular}


WSRC-TR-2003-00056, REV. 0

SRT-RPP-2002-00231, REV. 0

\section{APPENDIX A7. PARTICLE SIZE DISTRIBUTION DATA}

\section{Graphical Data - Volume Distributions}

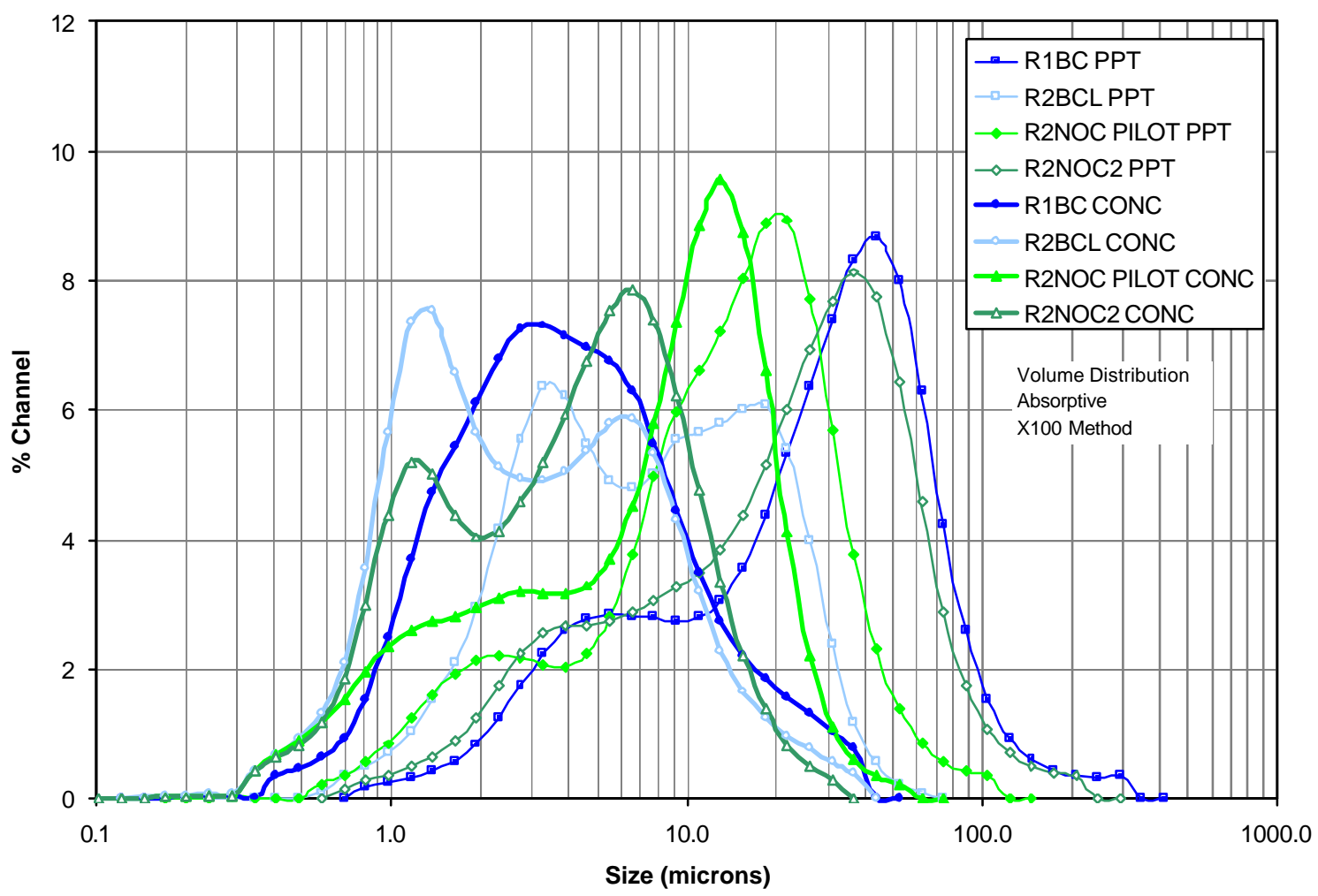

Page 113 of 124 
WSRC-TR-2003-00056, REV. 0

SRT-RPP-2002-00231, REV. 0
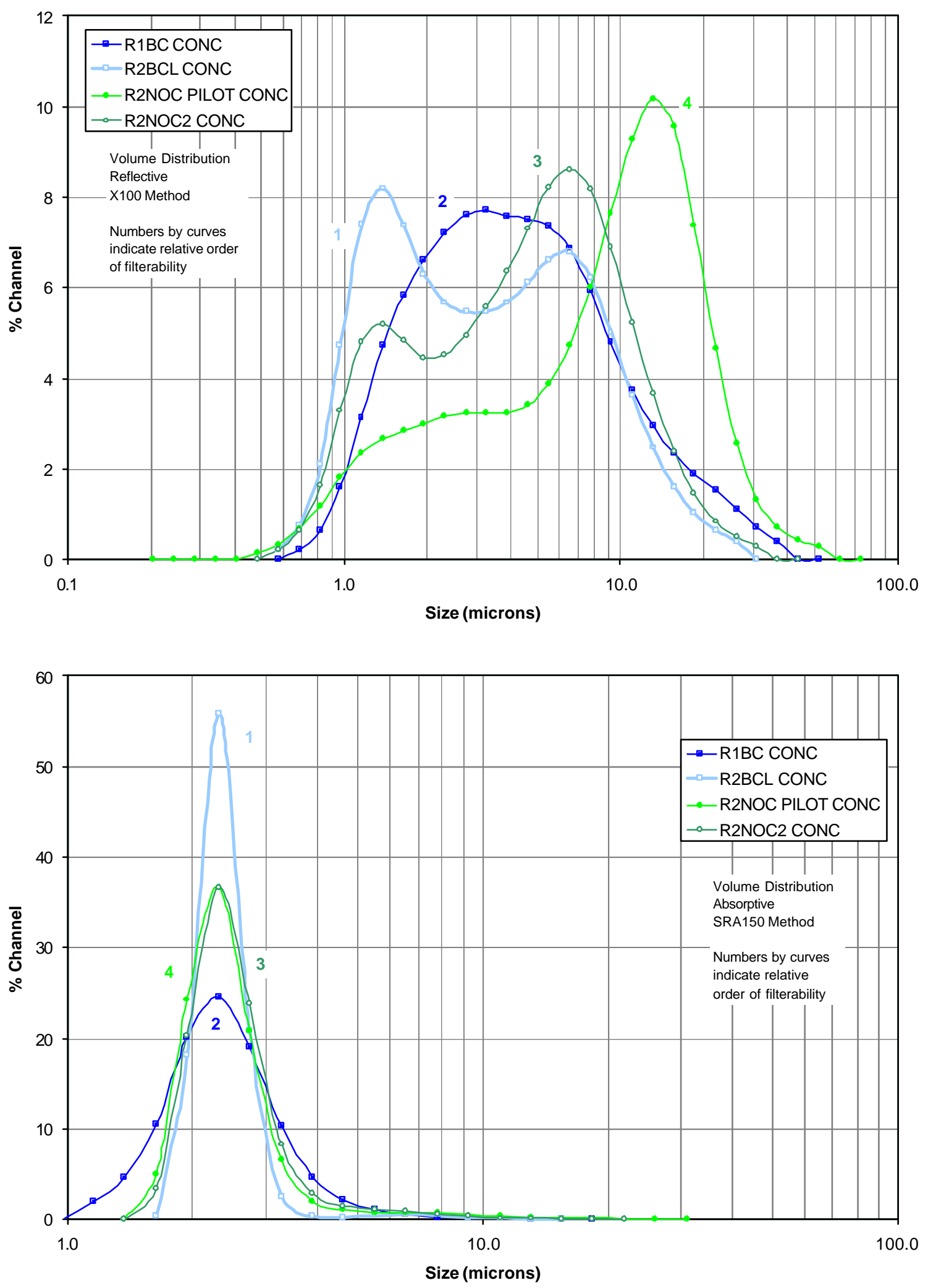

Page 114 of 124 
WSRC-TR-2003-00056, REV. 0

SRT-RPP-2002-00231, REV. 0
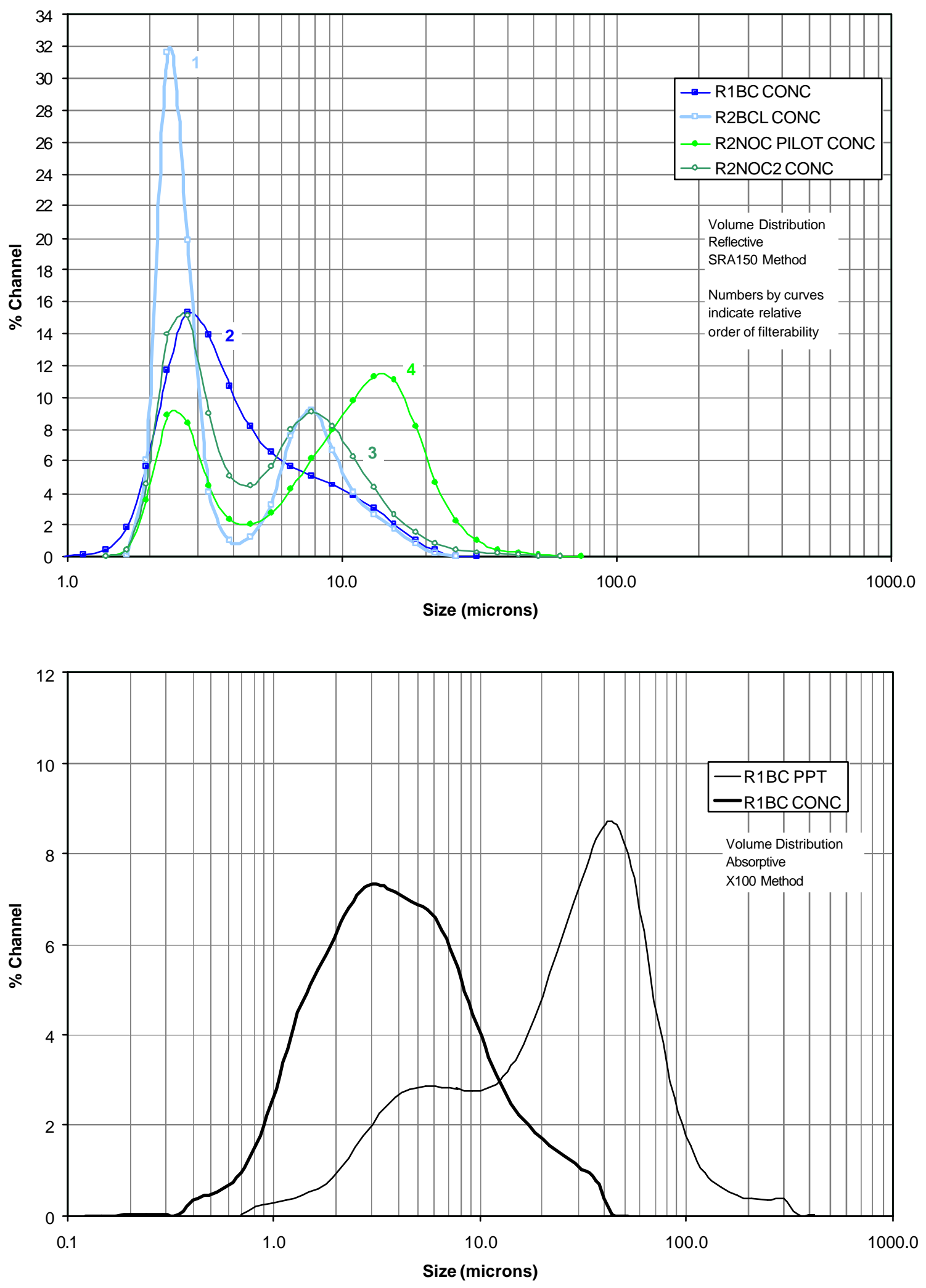

Page 115 of 124 
WSRC-TR-2003-00056, REV. 0

SRT-RPP-2002-00231, REV. 0
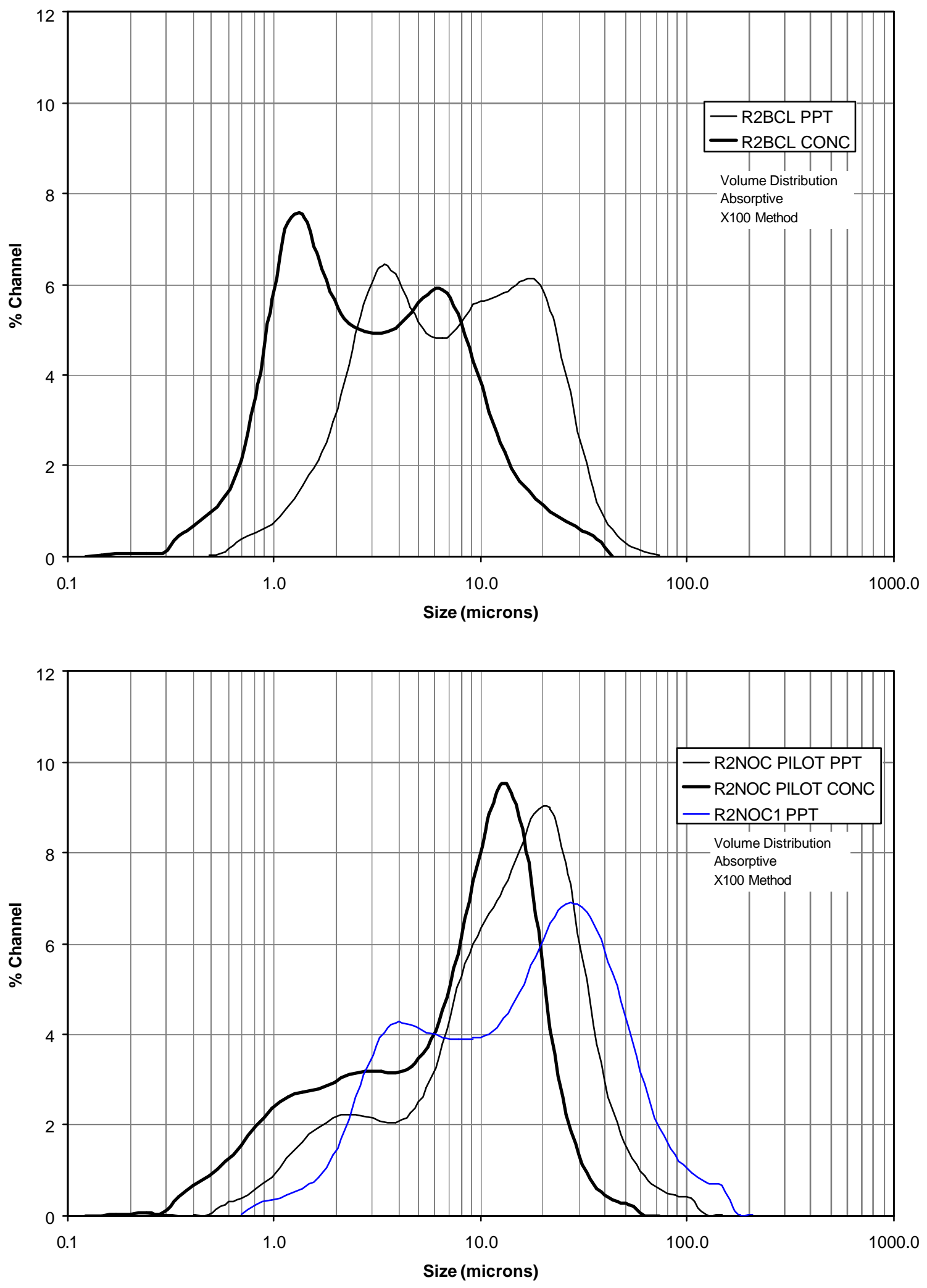

Page 116 of 124 
WSRC-TR-2003-00056, REV. 0

SRT-RPP-2002-00231, REV. 0

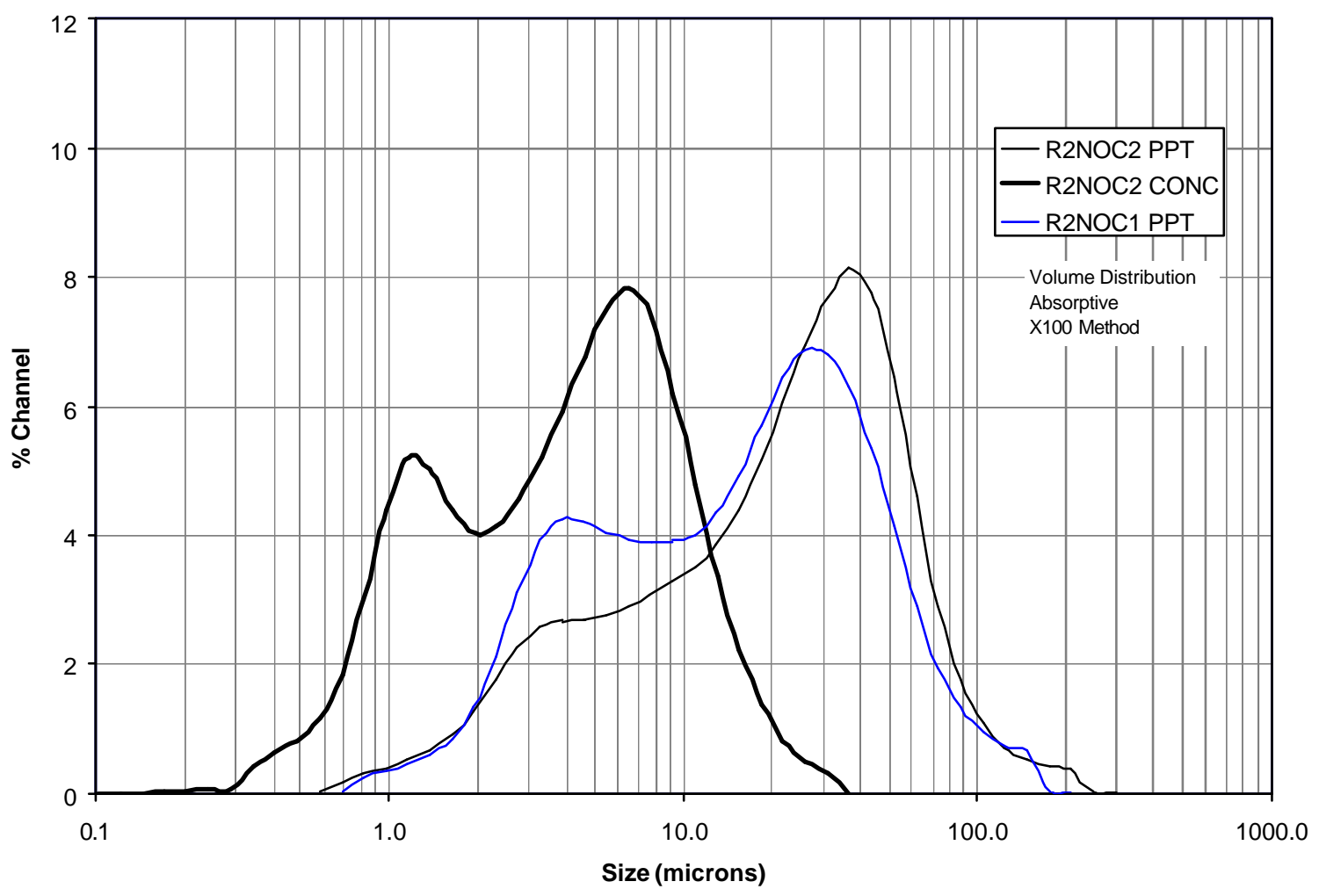

Page 117 of 124 


\section{Number Distributions}
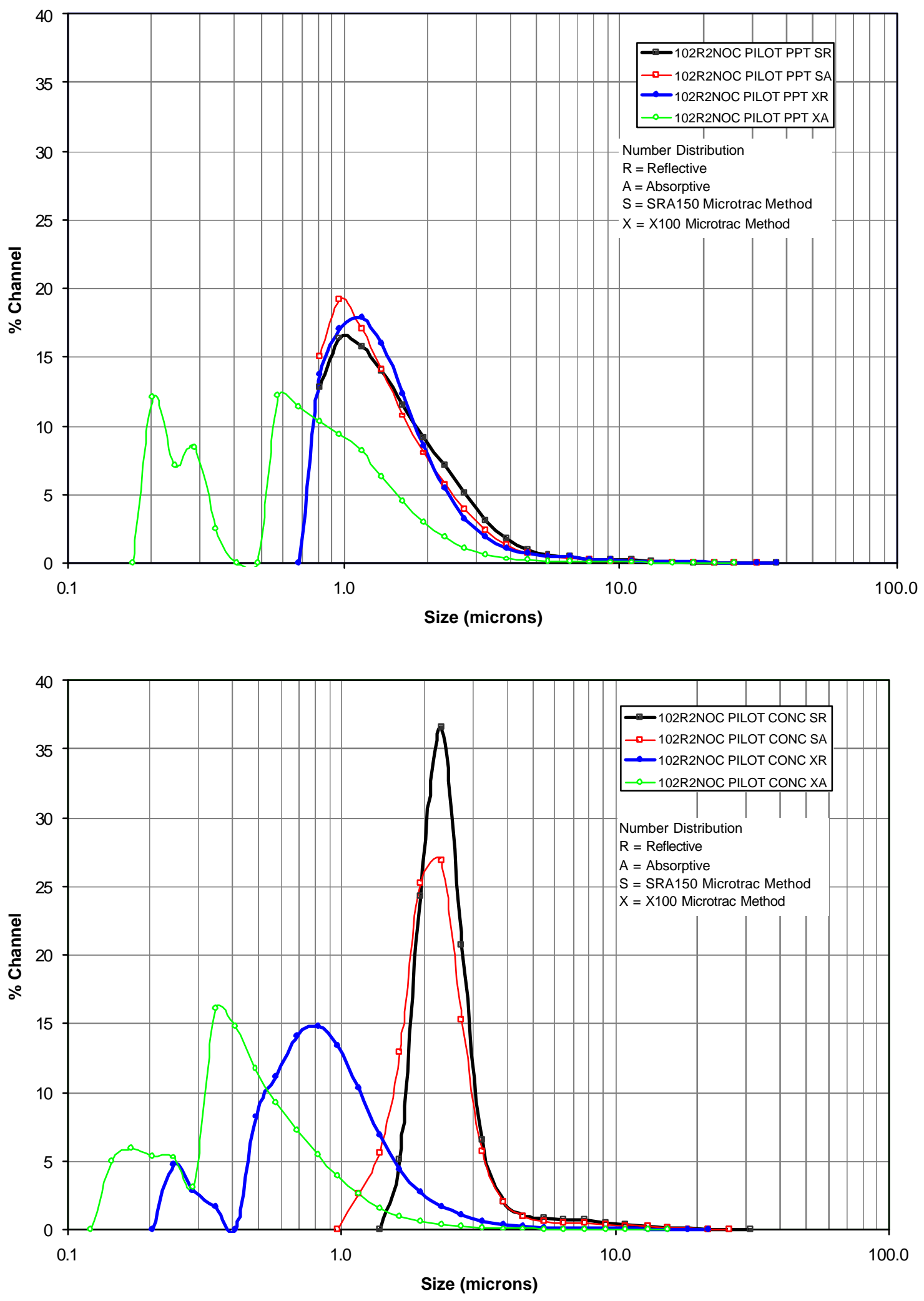

Page 118 of 124 
WSRC-TR-2003-00056, REV. 0

SRT-RPP-2002-00231, REV. 0
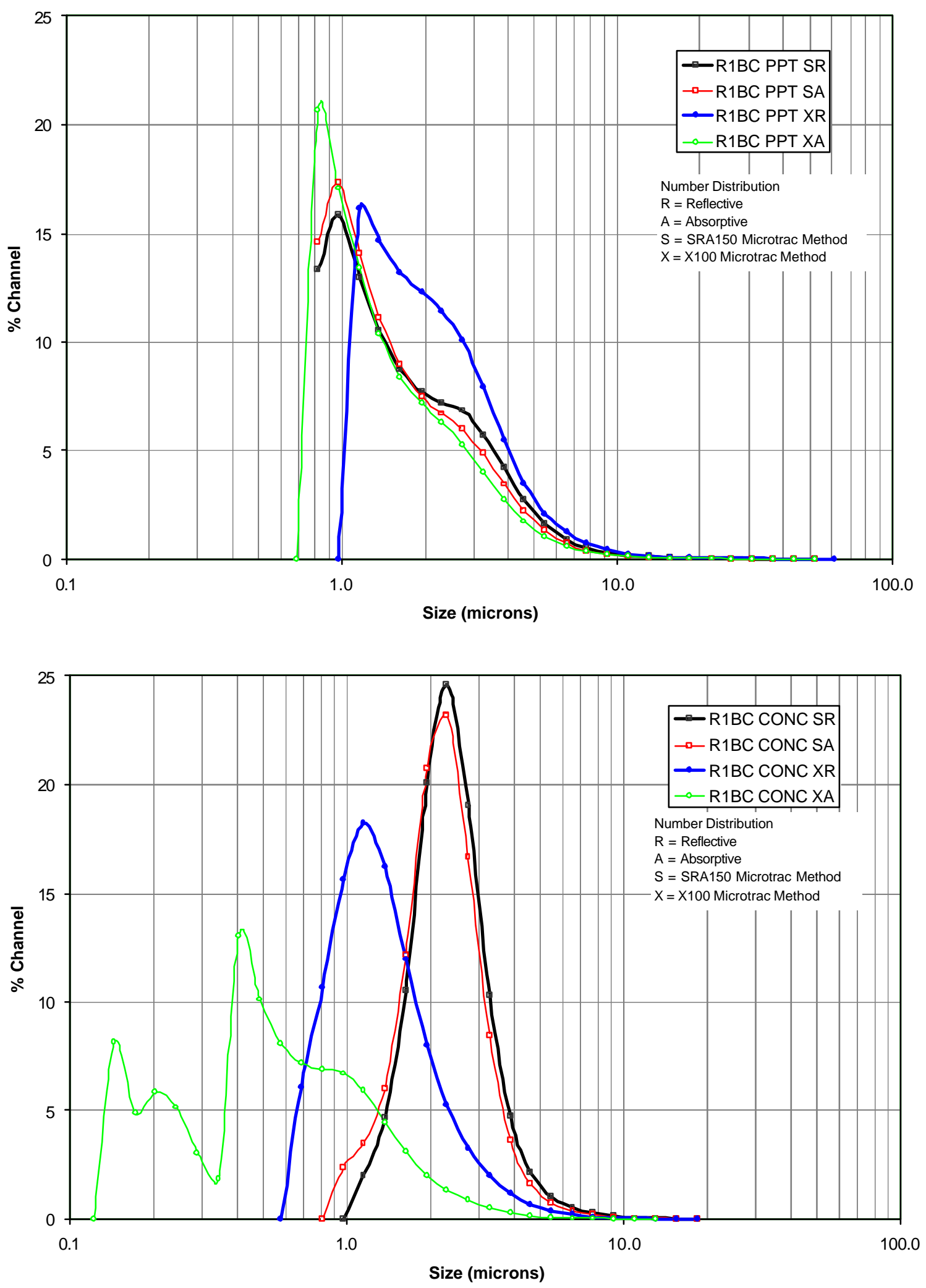

Page 119 of 124 
WSRC-TR-2003-00056, REV. 0

SRT-RPP-2002-00231, REV. 0
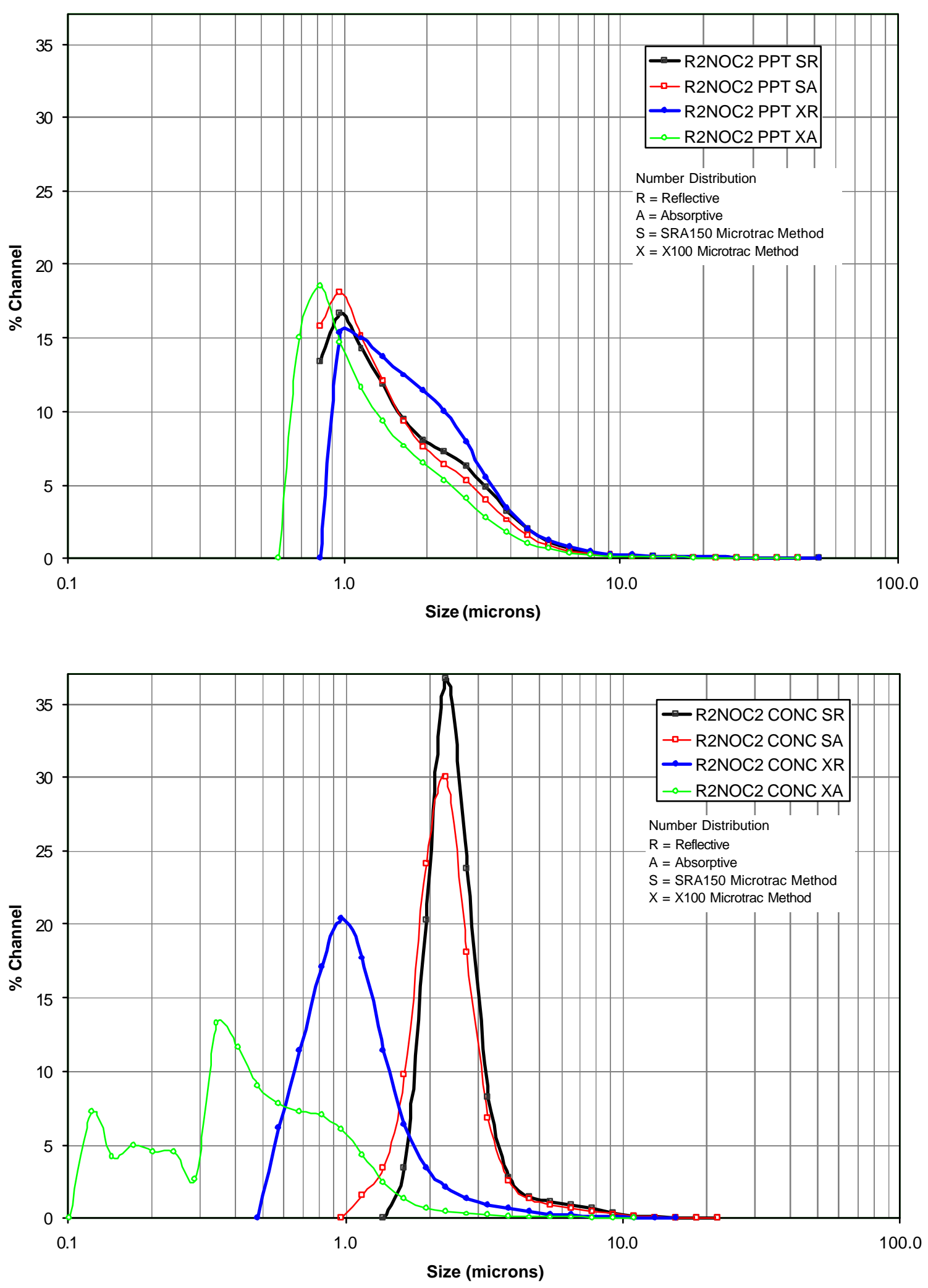

Page 120 of 124 
WSRC-TR-2003-00056, REV. 0

SRT-RPP-2002-00231, REV. 0
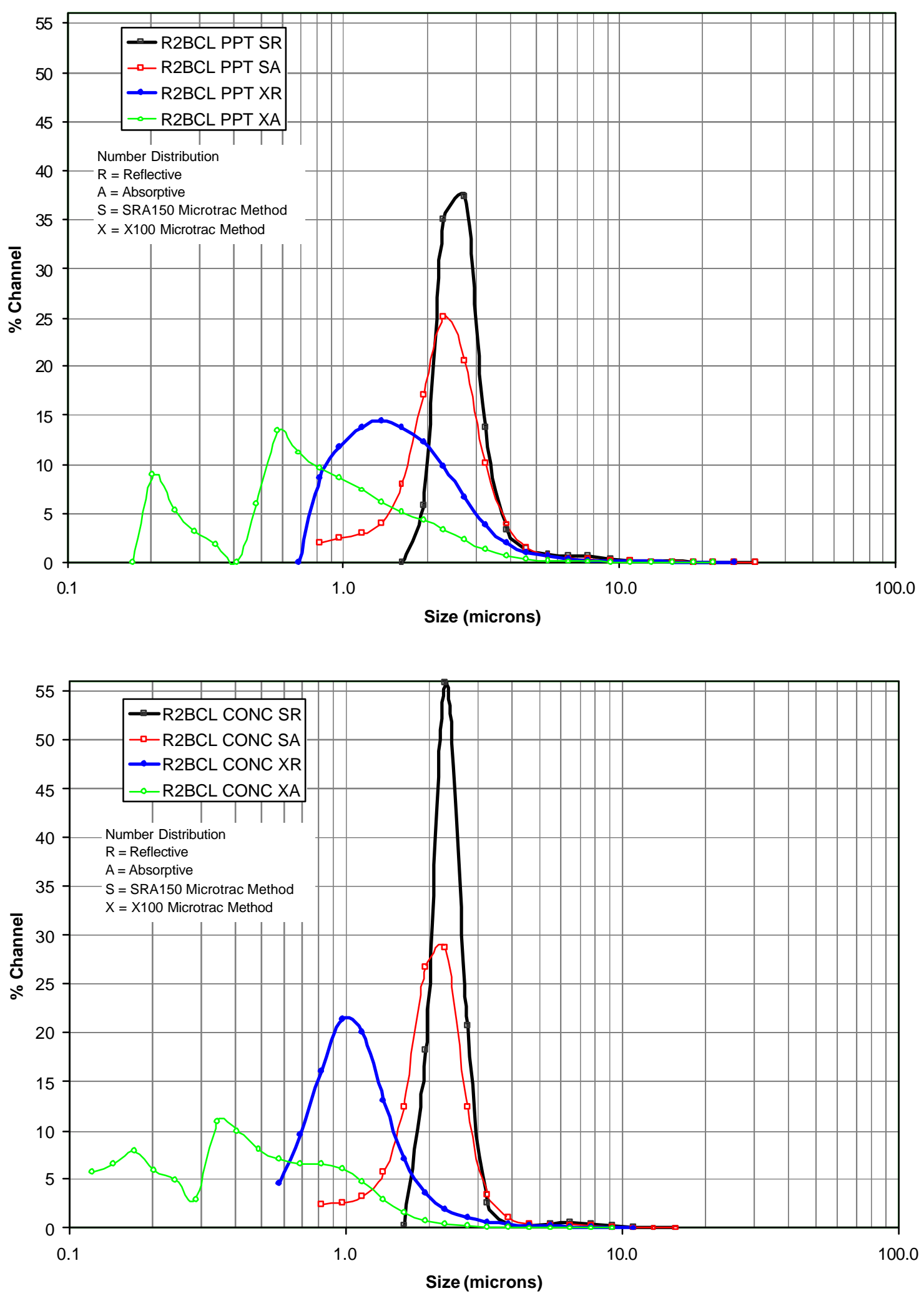

Page 121 of 124 
WSRC-TR-2003-00056, REV. 0

SRT-RPP-2002-00231, REV. 0
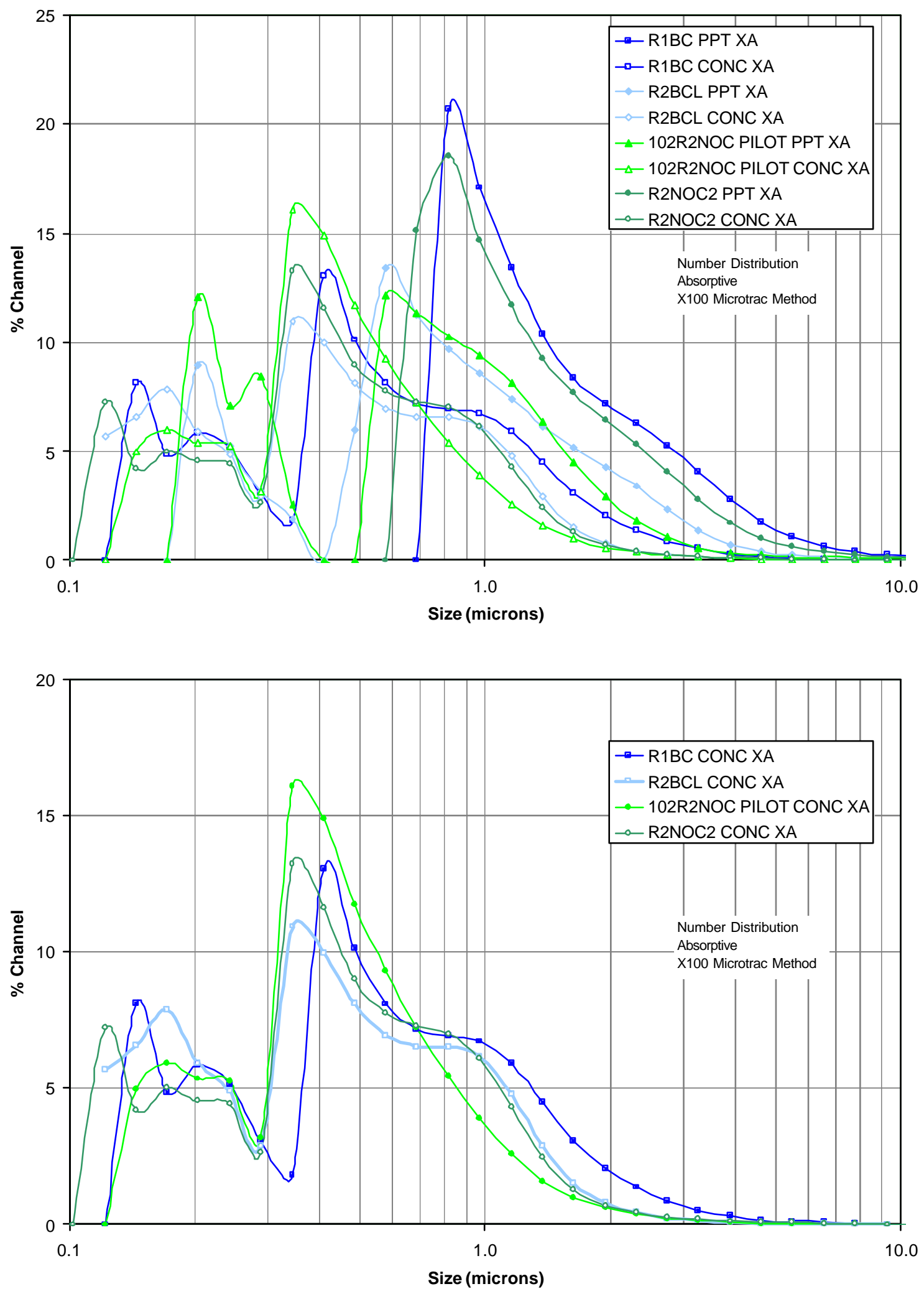

Page 122 of 124 
WSRC-TR-2003-00056, REV. 0

SRT-RPP-2002-00231, REV. 0

\section{APPENDIX A8. EMAIL FROM TOWNSON TO ZAMECNIK}

\author{
"Townson, Paul S." \\ <pstownso@bechtel.com>
}

To: $\quad$ "'jack.zamecnik@srs.gov'" <jack.zamecnik@srs.gov>
cc:

Subject: RE: Questions about Sr/TRU precipitation recipe in AN102 Cold C

04/22/2002 11:05 AM

Jack,

Looks like an old set of numbers slipped through the net! Well spotted! I have an excel spreadsheet which does all the calcs for me and it takes into account all dilutions to end up with the correct concentrations. The output from it is shown below: The first five lines show the input data, the next four the targets, the next four the actual concentrations achieved and the last four the amount of each reagent to add.

DATA
INPUT

SOLVER

TARGETS

ACTUAL ACHIEVED

DATA

OUTPUT
Sample:

Starting $\mathrm{Na}$ : (M)

Starting $\mathrm{OH}$ : (M)

$\mathrm{NaMnO} 4$ strength

Strontium strength

Sodium hydroxide strength

(M)

Target $\mathrm{Na}$ after water addition

(M)

Target final $\mathrm{OH}(\mathrm{M})$

Target final Sr (M)

Target final $\mathrm{MnO} 4(\mathrm{M})$

Final $\mathrm{Na}(\mathrm{M})$

Final $\mathrm{OH}(\mathrm{M})$

Final $\mathrm{Sr}(\mathrm{M})$

Final $\mathrm{MnO} 4(\mathrm{M})$

Water

$\mathrm{NaOH}$

$\mathrm{Sr}(\mathrm{NO} 3) 2$ addn

$\mathrm{NaMnO} 4$ addn
241-AN-102

7

0

1

1

19

6.0

0.9 Can only be changed in the macro itself

0.075

0.05

5.864

0.900

0.075

0.050

0.167

0.067

0.106

0.071
I per litre original sample I per litre original sample

I per litre original sample I per litre original sample 
WSRC-TR-2003-00056, REV. 0

SRT-RPP-2002-00231, REV. 0

-----Original Message-----

From: Jack Zamecnik

Sent: Monday, April 22, 2002 7:37 AM

To: Townson, Paul S.

Cc: Michael Poirier

Subject: Questions about Sr/TRU precipitation recipe in AN102 Cold CUF Test Spec

Paul:

The attached document shows my analysis of the recipe for the Sr/TRU precipitation.

It appears that the water added to bring the Na molarity to $6 \mathrm{M}$ was not accounted for in the subsequent calculations.

Could you please look this over and let me know if my analysis is correct? Either way, please let me know how to proceed.

Thanks,

Jack Zamecnik, Ph. D.

Westinghouse Savannah River Co.

Aiken, SC 29808 